Susana Catarina Neves Meneses

\title{
MULTI-OBJECTIVE DECISION-AID TOOL FOR PAVEMENT MANAGEMENT
}

Thesis submitted to the Faculty of Sciences and Technology of the University of Coimbra in partial fulfillment of the requirements for the degree of Doctor of Philosophy in Civil Engineering, under the scientific advising of Professor Adelino Jorge Lopes Ferreira.

July 2013

U

C $\quad \cdot$

UNIVERSIDADE DE COIMBRA 

For all the smiles and hugs,

Fernando e Laura 



\section{Financial support}

This research work was developed as part of the project MODAT - Multi-Objective Decision-Aid Tool for Highway Asset Management (Grant PTDC/ECM/112775/2009), co-financed by the European Regional Development Fund (ERDF) through the Operational Programme for Competitiveness Factors (COMPETE) and by national funds through the Portuguese Science and Technology Foundation. This research work was also funded by the Portuguese Science and Technology Foundation through grant SFRH/BD/49923/2009. The authors are grateful to all these institutions.

\section{FCT Fundação para a Ciência e a Tecnologia} MINISTÉRIO DA CIÊNCIA, TECNOLOGIA E ENSINO SUPERIOR Portugal

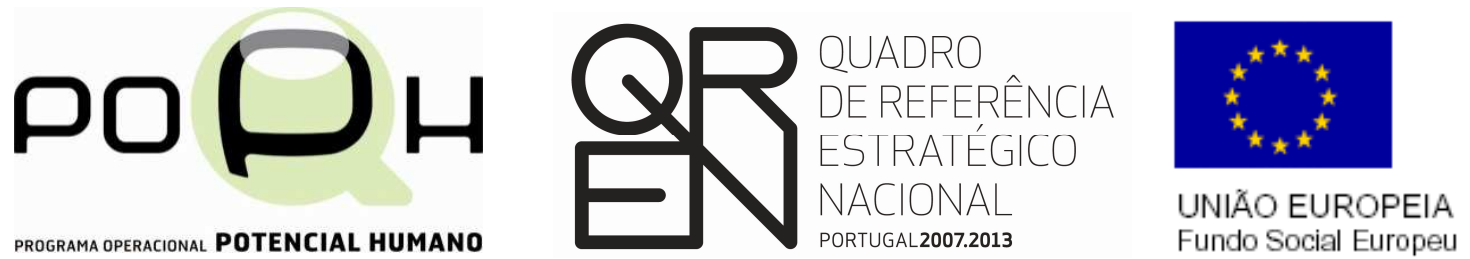





\section{Acknowledgements}

I am grateful to Professor Adelino Jorge Lopes Ferreira for giving me the opportunity to conduct this doctoral thesis. His knowledge and guidance were my strongest ally, and his determination was a great source of motivation and confidence for me at moments that I most needed.

To Fundação para a Ciência e a Tecnologia, and Ministério da Ciência, Tecnologia e Ensino Superior, I express my gratitude for the financial support during three years.

I would like to thank my colleague António Paulino. From the first moment on, your expertise, willingness and dedication professionally were priceless. I thank the patience in teaching me so many things about Matlab. You have added a great value to this work.

I would also like to thank my colleague António Correia. During these years your interest, encouragement and availability were very important to overcome some difficult times.

To my sons Fernando and Laura, I would like to thank for always demanding more and more from me, my attention, my presence and my help. Please, forgive me for anything.

To my husband and family, I thank for always being by my side, and all the patience and support during this time. 



\section{Contents}

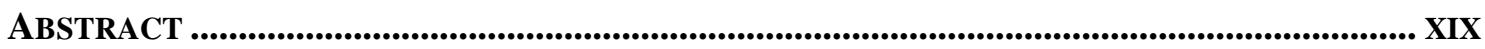

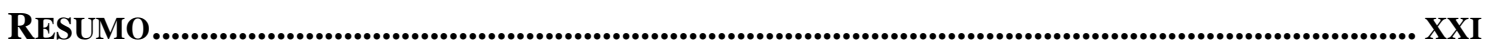

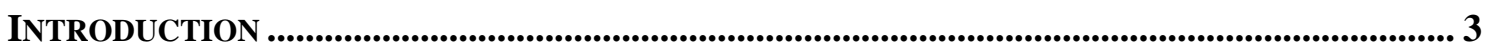

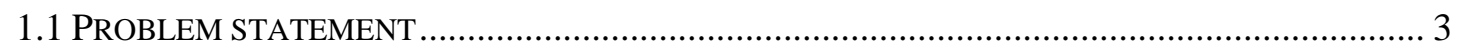

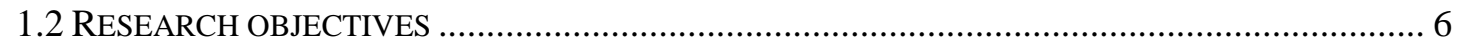

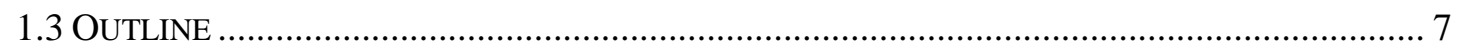

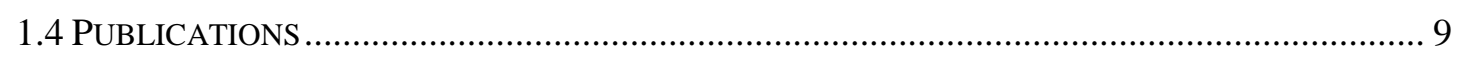

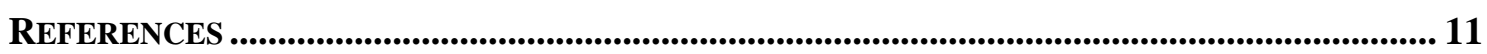

MULTI-OBJECTIVE DECISION-AID TOOL FOR PAVEMENT MANAGEMENT................................. 17

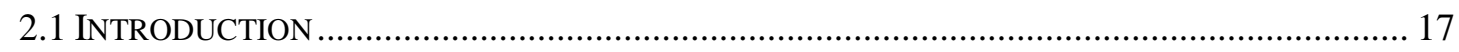

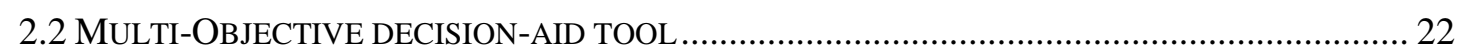

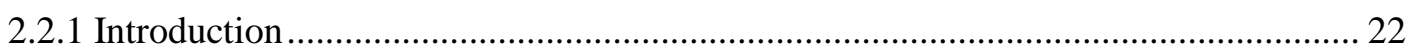

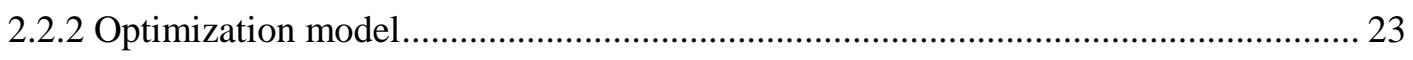

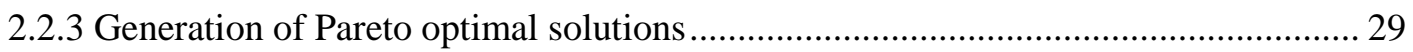

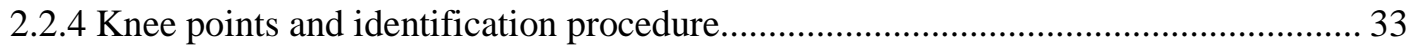

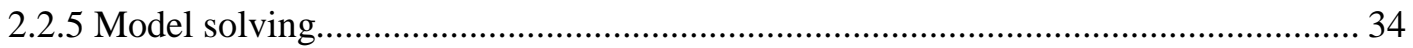

2.2.6 Results of the application of the MODAT .............................................................. 35

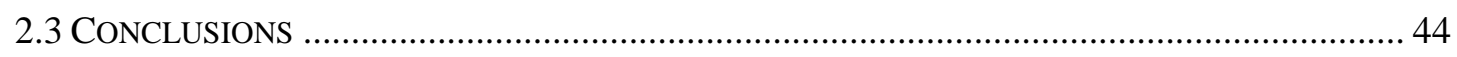

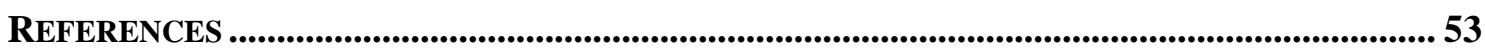


PAVEMENT MAINTENANCE PROGRAMMING CONSIDERING TWO OBJECTIVES: MAINTENANCE COSTS AND USER COSTS .................................................................................................................61 61

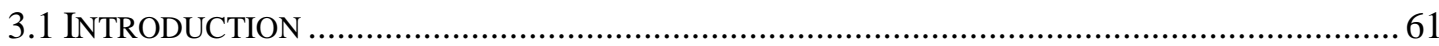

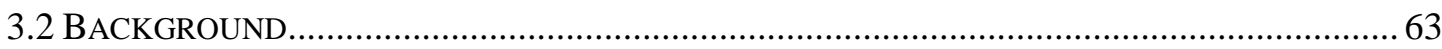

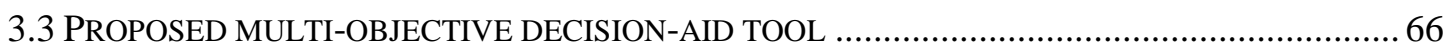

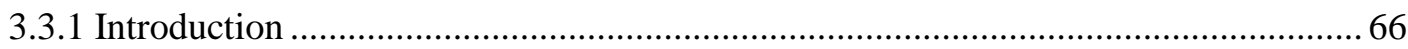

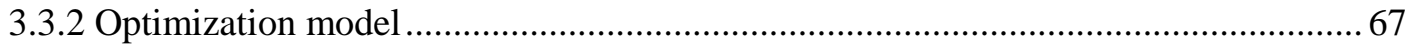

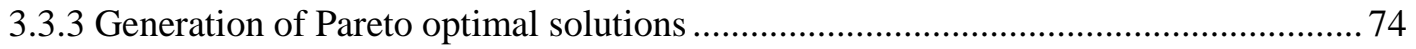

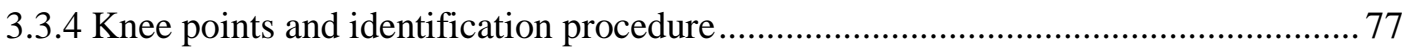

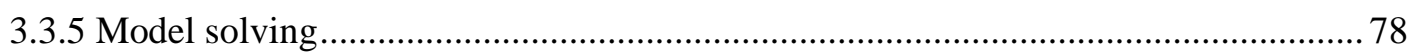

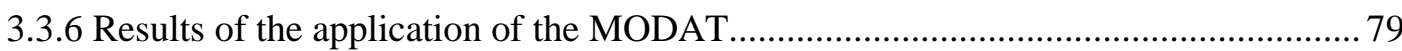

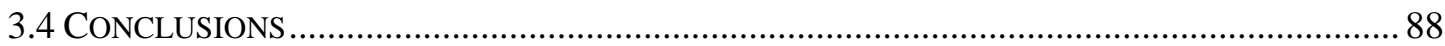

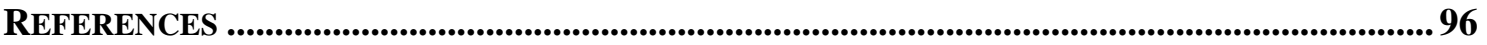

PAVEMENT MAINTENANCE PROGRAMMING CONSIDERING TWO OBJECTIVES: MINIMIZATION

OF MAINTENANCE AND REHABILITATION COSTS AND MAXIMIZATION OF THE RESIDUAL

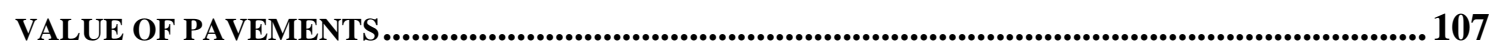

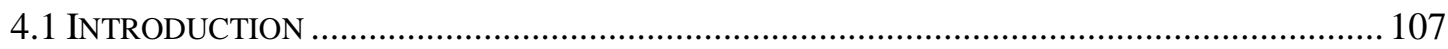

4.2 Multi-OBJective Decision-Aid Tool...................................................................... 110

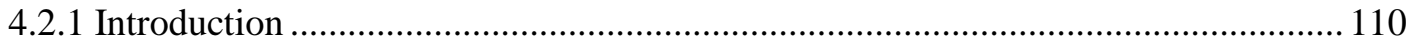

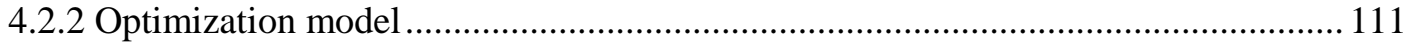

4.2.3 Generation of Pareto optimal solutions ……….................................................... 118

4.2.4 Knee points and identification procedure …….................................................... 121

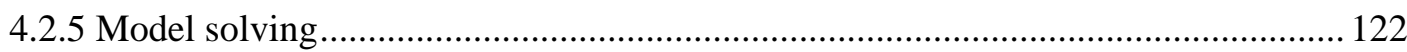

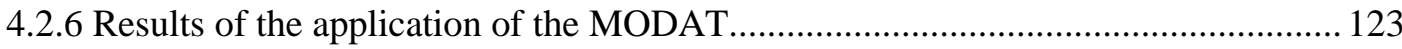


REFERENCES.

PaVement Maintenance PRogramming CONSIDERING THREE OBJECTIVES: MINIMIZATION OF MAINTENANCE AND REHABILITATION COSTS, MINIMIZATION OF USER COSTS AND MAXIMIZATION OF THE RESIDUAL VALUE OF PAVEMENTS

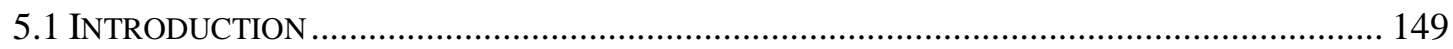

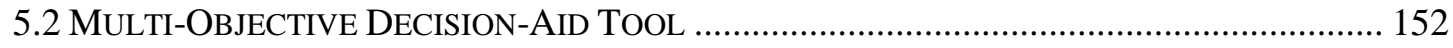

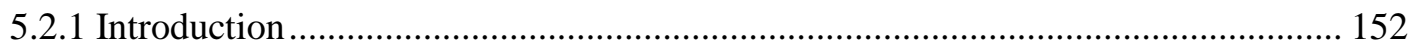

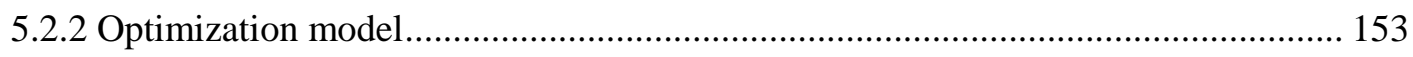

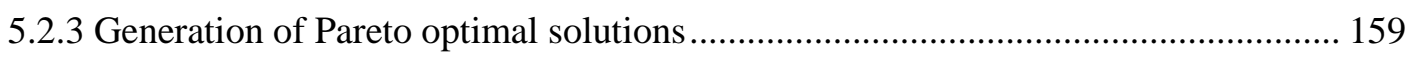

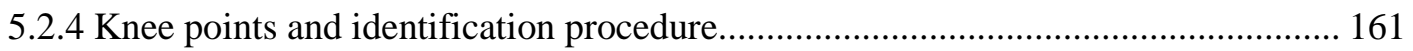

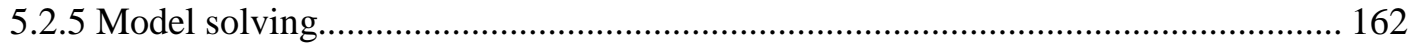

5.2.6 Results of the application of the MODAT …......................................................... 163

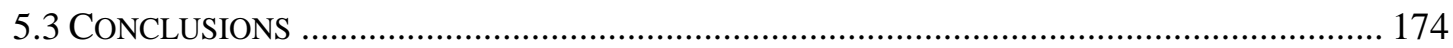

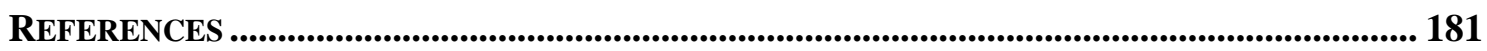

MULTI-OBJECTIVE DECISION-AID TOOL FOR PAVEMENT MANAGEMENT: SENSITIVITY

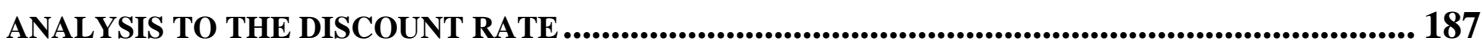

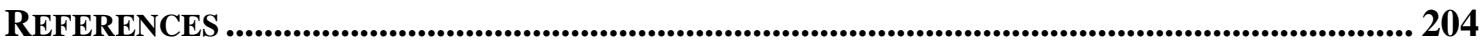

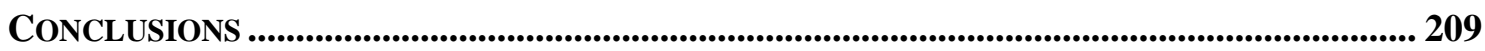





\section{List of Figures}

Figure 2-1 - Structure of the Pavement Management System.

Figure 2-2 - MODAT components

Figure 2-3 - Pavement performance curve as a function of equivalent single-axle load applications

Figure 2-4 - The Pareto frontier and the ideal and nadir solutions.

Figure 2-5 - Quality of pavements of the Oliveira do Hospital's road network 35

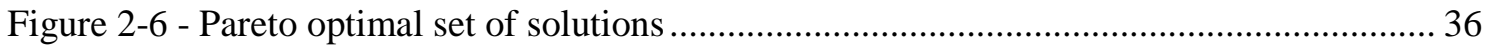

Figure 2-7 - Pareto optimal set of normalised solutions …….................................................... 37

Figure 2-8 - Costs throughout the planning time-span of 20 years ............................................ 39

Figure 2-9 - Normalised costs throughout the planning time-span of 20 years .......................... 39

Figure 2-10 - PSI average value for all the road network pavements ...................................... 40

Figure 2-11 - Evolution of PSI for pavement section 34 of municipal road EM 514 ................ 43

Figure 2-12 - Evolution of PSI for pavement section 22 of municipal road EM 509 ................. 44

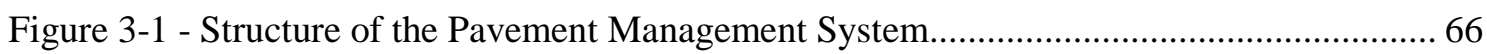

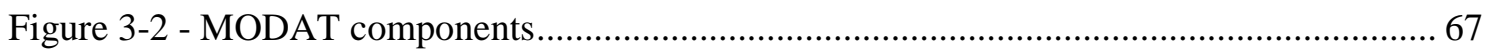

Figure 3-3 - Pavement performance curve as a function of equivalent single-axle load applications 70

Figure 3-4 - The Pareto frontier and the ideal and nadir solutions............................................ 77

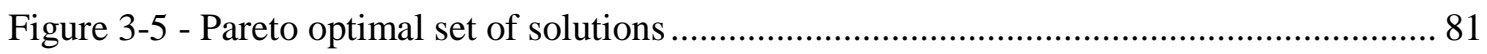

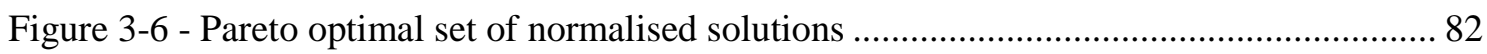

Figure 3-7 - Costs throughout the planning time-span of 20 years .............................................. 83

Figure 3-8 - Normalised costs throughout the planning time-span of 20 years ......................... 83 
Figure 3-9 - PSI average value for all the road network pavements ......................................... 84

Figure 3-10 - Evolution of PSI for pavement section 05001 of a national road........................... 86

Figure 3-11 - Evolution of PSI for pavement section 05004 of a national road........................... 87

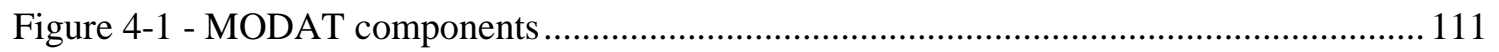

Figure 4-2 - Pavement performance curve as a function of equivalent single-axle load applications

Figure 4-3 - The Pareto frontier and the ideal and nadir solutions......................................... 121

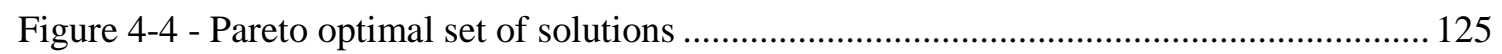

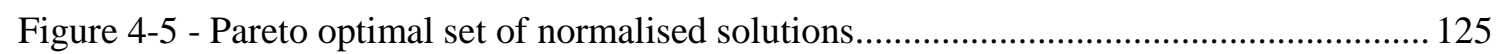

Figure 4-6 - Costs throughout the planning time-span of 20 years .......................................... 128

Figure 4-7 - Normalised costs throughout the planning time-span of 20 years ..................... 128

Figure 4-8 - PSI average value for all the road network pavements ........................................ 129

Figure 4-9 - Evolution of PSI for pavement 05001 of a national road...................................... 132

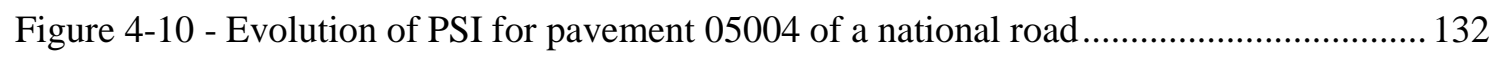

Figure 4-11 - Evolution of PSI for pavement 05003 of a national road................................... 133

Figure 4-12 - Evolution of PSI for pavement 05012 of a national road ................................... 133

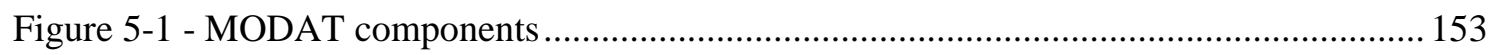

Figure 5-2 - Pavement performance curve as a function of equivalent single-axle load

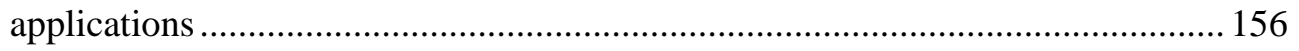

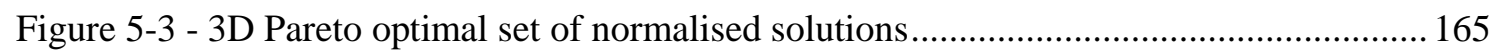

Figure 5-4 - Solutions in a three-objective representation using a scatter-plot matrix............... 166

Figure 5-5 - Costs throughout the planning time-span of 20 years ........................................ 168

Figure 5-6 - Normalised costs throughout the planning time-span of 20 years ........................ 168

Figure 5-7 - PSI average value for all the road network pavements ....................................... 169

Figure 5-8 - Evolution of PSI for pavement 05012 of a national road..................................... 172 
Figure 5-9 - Evolution of PSI for pavement 05001 of a national road.

Figure 5-10 - Evolution of PSI for pavement 05003 of a national road 173

Figure 5-11 - Evolution of PSI for pavement 05004 of a national road.

Figure 6-1 - Evolution of the discount factor throughout planning period of 20 years 192

Figure 6-2 - Pareto optimal set of solutions for all considered rates.

Figure 6-3 - Pareto optimal set of normalised solutions for all considered rates.

Figure 6-4 - M\&R Costs throughout the planning time-span of 20 years for all considered rates

Figure 6-5- User Costs throughout the planning time-span of 20 years for all considered rates

Figure 6-6 - Residual Value throughout the planning time-span of 20 years for all considered rates.

Figure 6-7 - Total Costs throughout the planning time-span of 20 years for all considered rates

Figure 6-8 - Evolution of PSI for pavement section 05012 of a national road 199

Figure 6-9 - Evolution of PSI for pavement section 05004 of a national road 200

Figure 6-10 - Evolution of PSI for pavement section 05001 of a national road 201

Figure 6-11 - Evolution of PSI for pavement section 05003 of a national road 202 



\section{List of Tables}

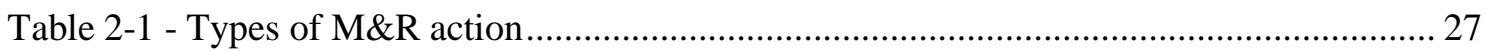

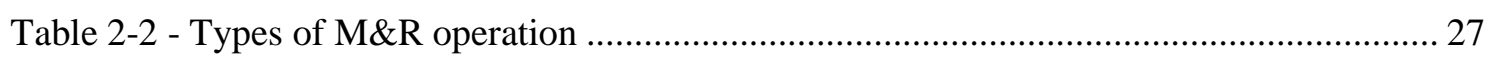

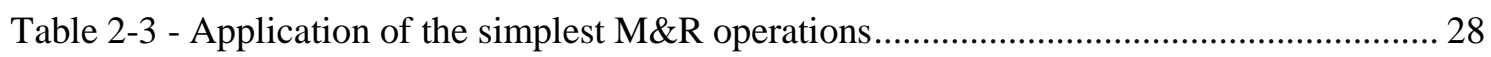

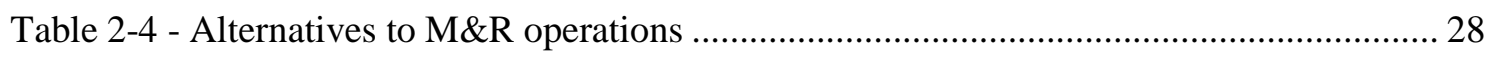

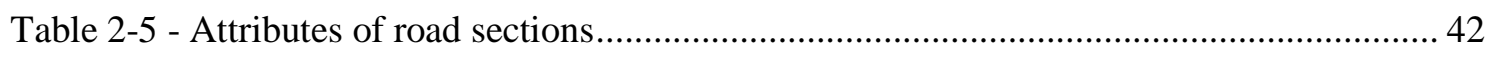

Table 2-6 - M\&R operations to be applied in road sections ........................................................ 43

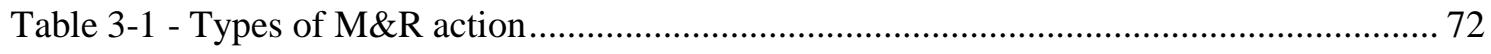

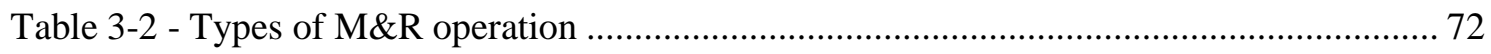

Table 3-3 - Application of the simplest M\&R operations...................................................... 72

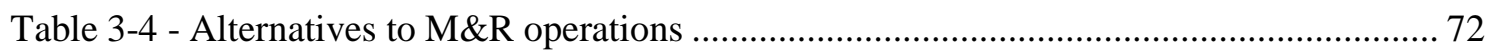

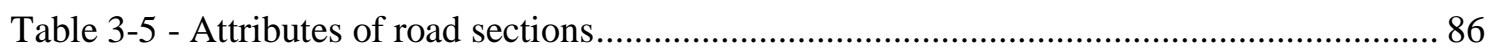

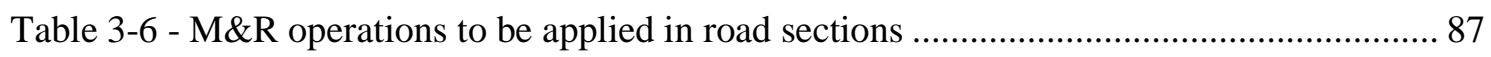

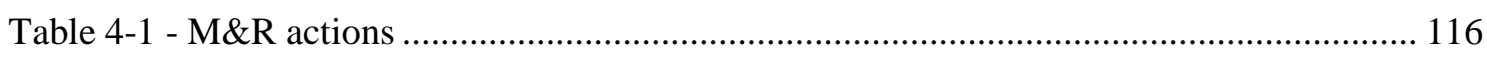

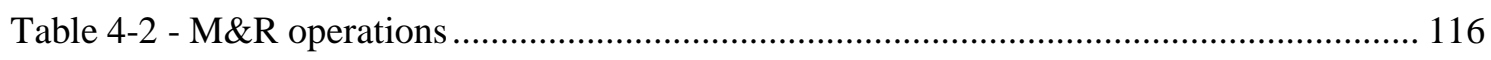

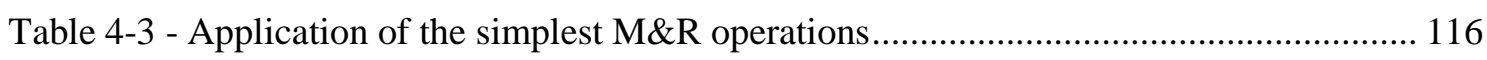

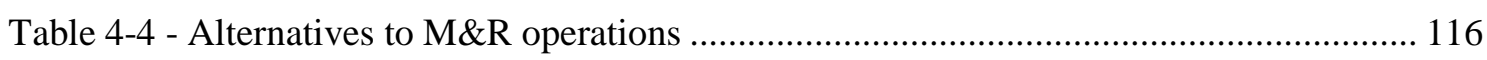

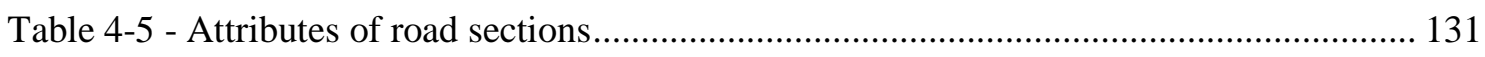

Table 4-6 - M\&R operations to be applied in road sections ............................................... 131

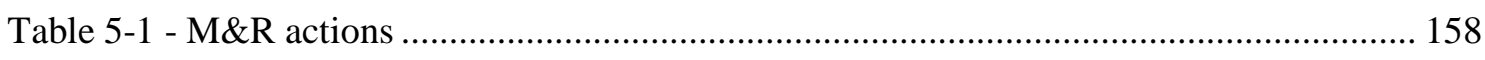

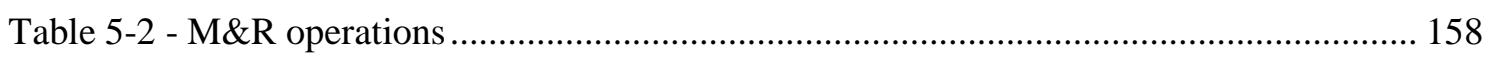

Table 5-3 - Application of the simplest M\&R operations..................................................... 158 


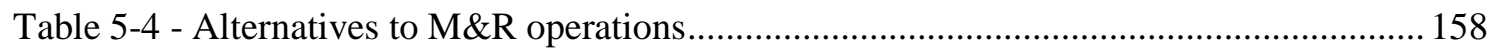

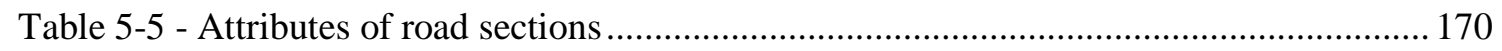

Table 5-6 - M\&R operations to be applied in road sections.................................................... 171

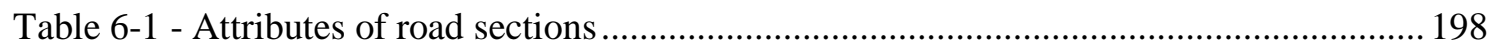

Table 6-2 - M\&R operations to be applied in road section 05012 .......................................... 199

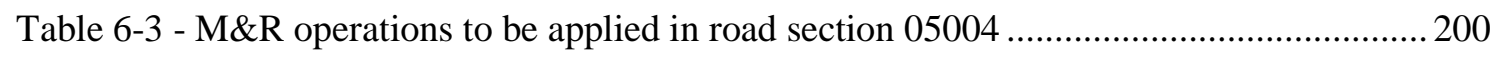

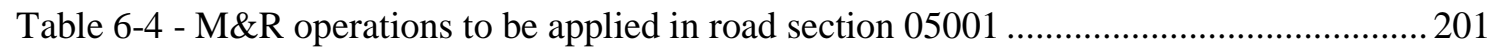

Table 6-5 - M\&R operations to be applied in road section 05003 ........................................... 202 


\section{Abstract}

Nowadays in Portugal, as in many other countries, due to the economic crisis, the trend of budgetary pressures on highway agencies is increasing. At the same time, road users are increasingly demanding in terms of highway quality, comfort and safety. Several highway maintenance and rehabilitation projects have been delayed because of budget constraints. The economic crisis has also stimulated a wider debate about the state of Portugal's road network infrastructure and the consequences of past large-investment in new construction and under-investment in maintenance and rehabilitation. Fortunately, in the last three years, the construction of new highways has almost ceased and the scarce funds available have been used essentially for maintenance and rehabilitation of existing highways and roads. To meet these challenges, highway agencies are looking for more cost-effective methodologies for pavement maintenance programming at network-level. So, in the coming years, highway agencies are open to new Decision-Aid Tools that minimise the costs related to their area of action.

This PhD thesis presents a Multi-Objective Decision-Aid Tool, called MODAT, which can solve the pavement management problem for the case involving major rehabilitation interventions. The MODAT, which has the objective of minimising costs over a selected planning period, allows closing of the gap between project and network management. This is made possible by replacing the traditional microscopic approach, which uses models that include independent variables explaining the pavement deterioration process (i.e. layer thickness, resilient modulus, asphalt characteristics, 
traffic, climate, etc.), with a macroscopic approach that uses models for predicting the future condition of the pavement based on measured condition data (i.e. cracking, ravelling, potholes, patching, rutting, longitudinal roughness, skid resistance, traffic, climate, etc.). The macroscopic approach requires that each road section is homogeneous in terms of quality, pavement structure, traffic and climate. It is assumed that each road section possesses one performance curve with any estimated future performance value representing the overall average pavement condition. The MODAT considers the pavement performance model used in the AASHTO flexible pavement design method but any other preferred model can be used as well. In the implementation of an optimum solution recommended by the MODAT, a field review must be conducted to identify continuous road sections with the same or identical M\&R interventions with the goal of aggregating them into the same road project. It is recommended that whenever actual pavement performance data becomes available, it should replace the predicted PSI values from the AASHTO pavement performance model. Any other appropriate pavement condition indicator can easily be used as an alternative in this methodology. The MODAT constitutes a new useful tool to help the road engineers in their task of maintenance and rehabilitation of pavements. The MODAT was applied to a municipal road network (Oliveira do Hospital) and also to a national road network (main road network of Castelo Branco), both located in Portugal. 


\section{Resumo}

Atualmente, em Portugal, como em muitos outros países, devido à crise económica, está a aumentar a pressão orçamental sobre as administrações rodoviárias. Ao mesmo tempo, os utentes estão cada vez mais exigentes em termos de qualidade da estrada, de conforto e de segurança rodoviária. Vários projetos de conservação e reabilitação de estradas foram adiados devido a restrições orçamentais. A crise económica também tem estimulado um amplo debate sobre o estado das infraestruturas rodoviárias em Portugal e as consequências do grande investimento em novas construções efetuado no passado recente e o reduzido investimento em conservação e reabilitação. Felizmente, nos últimos três anos, a construção de novas estradas quase cessou e os escassos recursos financeiros disponíveis foram utilizados essencialmente para a conservação e reabilitação de estradas e autoestadas em serviço. Para enfrentar esses desafios, as administrações rodoviárias procuram metodologias com melhor relação custo-benefício para a programação da conservação e reabilitação dos pavimentos ao nível da rede. Assim, nos próximos anos, as administrações rodoviárias estão abertos a novas ferramentas de apoio à decisão que minimizem os custos relacionados com a sua área de atuação.

Esta dissertação de doutoramento apresenta um Sistema de Apoio à Decisão Multiobjectivo, designado por MODAT, o qual resolve o problema da gestão de pavimentos em termos de intervenções de conservação periódica. O Sistema MODAT, que tem como objetivo a minimização de custos durante um determinado período de 
planeamento, permite aproximar a gestão de pavimentos a nível da rede da gestão de pavimentos a nível de projeto. Isto tornou-se possível por substituição da abordagem microscópica, a qual considera modelos que incluem variáveis independentes que explicam o processo de degradação dos pavimentos (isto é, a espessura das camadas, o módulo de deformabilidade, as características do betão betuminoso, o tráfego, as condições climáticas, etc.) por uma abordagem macroscópica que considera modelos de previsão do estado futuro dos pavimentos baseados em dados medidos em ensaios não destrutivos (isto é, fendilhamento, desagregação superficial, covas e peladas, reparações, rodeiras, irregularidade longitudinal, aderência, tráfego, condições climáticas, etc.). Esta abordagem macroscópica requer que cada trecho rodoviário seja homogéneo em termos de qualidade, estrutura do pavimento, tráfego e condições climáticas. Assume-se que existe um modelo de previsão do comportamento do pavimento para cada trecho rodoviário que permite estimar o seu desempenho futuro. $\mathrm{O}$ sistema MODAT considera o modelo de previsão do comportamento dos pavimentos utilizado no método de dimensionamento de pavimentos flexíveis da AASHTO. No entanto pode ser utilizado qualquer outro modelo. Na implementação das soluções ótimas de conservação e reabilitação dos pavimentos recomendadas pelo sistema MODAT, deve ser efetuado um estudo para identificar trechos rodoviários contíguos com intervenções idênticas de conservação ou reabilitação com o objetivo de as agregar no mesmo projeto rodoviário. Recomenda-se, que quando existir informação suficiente sobre o desempenho dos pavimentos ao longo de vários anos, esta deverá ser utilizada para substituir a previsão dada pelo modelo da AASHTO. Em alternativa a esta metodologia, pode ser facilmente considerado outro indicador apropriado do estado dos 
pavimentos. O sistema MODAT constitui uma nova ferramenta para ajudar os engenheiros rodoviários nas suas tarefas de conservação e reabilitação dos pavimentos. O sistema MODAT foi aplicado a uma rede rodoviária municipal (rede rodoviária do município de Oliveira do Hospital) e também a uma rede rodoviária nacional (rede rodoviária principal de Castelo Branco), ambas localizadas em Portugal. 



\section{MULTI-OBJECTIVE DECISION-AID TOOL FOR PAVEMENT MANAGEMENT}





\section{Chapter 1}

\section{Introduction}

\subsection{Problem statement}

During the 1980s, and particularly after the first North American Pavement Management Conference, held in Toronto, Canada, in 1985, Pavement Management Systems (PMS) were recognised to be major tools in aiding the road network administrations. An efficient PMS for a road network is one that would maintain all pavement sections at a sufficiently high level of service and structural condition, but would require only a reasonably low budget and use of resources, and does not create any significant adverse impacts on the environment, safe traffic operations, and social and community activities. Unfortunately, many of these are conflicting requirements. For example, more resources and budget are usually needed if the pavements are to be maintained at a higher level of serviceability; and a program with more pavement treatment activities would, in general, cause longer traffic delays, increase environmental pollution and create more disruption of social activities and inconvenience to the community. Therefore, the decision process in programming 
pavement maintenance activities involves multi-objective considerations that should address these competing requirements. Practically, all the pavement maintenance programming tools currently in use are based on single-objective optimization. In these single-objective analyses, those requirements not selected as the objective function are imposed as constraints in the formulation. This can be viewed as interference in the optimization process by artificially setting limits on selected problem parameters. As a result, the solutions obtained from these single-objective analyses are suboptimal in comparison to one derived from multi-objective considerations.

One of the main components of a PMS is the methodology used to select the best maintenance and rehabilitation (M\&R) strategy taking into account the expected evolution of pavement quality. This methodology, realised in a Decision-Aid Tool (DAT), may be based on prioritisation (ranking) models (Hawker and Abell 2000; Kulkarni et al. 2004; Sebaaly et al. 1996; Wong et al. 2003) or optimization models (Abaza 2006; Abaza et al. 2004; Ferreira et al. 2002a; Ferreira et al. 2002b; Ferreira et al. 2009a; Ferreira et al. 2009b; Golabi et al. 1982; Madanat et al. 2006; Nunoo and Mrawira 2004; Picado-Santos et al. 2004).

Using prioritisation models, pavement condition data are combined into an index to represent the present pavement quality. Then, prioritisation is sorted by ranking and categorising all the pavement sections by using a priority-ranking criterion. The commonly used ranking parameters include road class, traffic volume, quality index, etc. The M\&R resources are allocated to road sections based on ranking and priorities assigned to them. 
In optimization models, the goal of the analysis can be the minimization of any combination between agency costs, user costs and residual value of pavements over a selected planning time-span subject to minimum quality level constraints (Abaza 2006; Abaza et al. 2004; Ferreira et al. 2002a; Ferreira et al. 2002b; Ferreira et al. 2009a; Golabi et al. 1982; Madanat et al. 2006; Nunoo and Mrawira 2004; Picado-Santos et al. 2004) or the maximization of the whole network quality or performance subject to annual budget constraints (Abaza 2006; Abaza et al. 2004; Abaza et al. 2001; Ferreira et al. 2009b; Nunoo and Mrawira 2004). In these models, pavement condition data are used as model inputs, pavement performance models are used to predict future quality of pavements and annual budgets and minimum quality levels are constraints that must be assured. The pavement management problem is then formulated as an optimization model with variables representing the various $M \& R$ actions or operations. Basically, the optimal solution defines the amount and type of M\&R work to be applied to each road pavement.

The main weakness of prioritisation models is that they do not assure the selection of the best possible $M \& R$ strategy when considering long planning time-spans (for example 20 years). This can only be achieved if the approach followed for selecting the M\&R strategy is based on optimization techniques. The Arizona Department of Transportation and Woodward-Clyde Consultants, using optimization techniques, won the 1982 Franz Edelman Management Science Achievement Award from the Institute of Management Sciences, now the Institute for Operations Research and the Management Sciences (INFORMS), for developing and implementing the Network Optimization System of the Arizona PMS (Golabi et al. 1982). More recently, the 
Lisbon City Council and the Department of Civil Engineering of the University of Coimbra, also using optimization techniques, won the Parkman Medal awarded by the Institution of Civil Engineers from England for the best chapter published in the year 2004 on the practical aspects of the control or management, including project management of the design and/or construction of a specific scheme, for developing and implementing the Lisbon PMS (Picado-Santos et al. 2004).

Recently, researchers (Flintsch and Chen 2004; Fwa et al. 2000; Kaliszewski 2004; Wu and Flintsch 2009) have concluded that maintenance planning and programming requires optimization analysis involving multi-objective considerations. However, traditionally single-objective optimization techniques have been employed by pavement researchers and practitioners because of the complexity involved in multi-objective analysis. Other researchers concluded that it is possible to develop a Multi-objective Decision-Aid Tool, incorporating into the same optimization model several objectives, for example one for minimization of maintenance costs and another for maximization of the residual value of pavements using the concepts of Pareto optimal solution set and rank-based fitness evaluation (Deb 2008; Fwa et al. 2000; Iniestra and Gutiérrez 2009; Mansouri 2005).

\subsection{Research objectives}

The main objective of this $\mathrm{PhD}$ thesis was the development and implementation of a Multi-objective Decision-Aid Tool (MODAT) incorporating into the same optimization model several objectives (minimization of maintenance and rehabilitation costs, minimization of user costs, maximization of the residual value of pavements, etc.) using 
the concepts of Pareto optimal solution set and rank-based fitness evaluation. There are several optimization methods that can be used to generate the set of Pareto optimal solutions. Hwang and Masud (1979) and later Miettinen (1999) classified them into the following four types: no-preference methods; posterior methods; a priori methods; and interactive methods. Another main objective was to develop a decision-aid tool able to close the gap between project and network management. This is possible using pavement performance models which are also used in pavement design. An example of this king of models is the pavement performance model used in the AASHTO flexible pavement design method (AASHTO 1993). This new approach allows Pavement Management Systems to become interactive decision-aid tools, capable of providing road administrations with answers to "what-if" questions in short periods of time. Another main objective was the development and implementation of a heuristic method, based on genetic algorithms, able to solve the multi-objective optimization model. Given the particular features of the optimization model, a combinatorial problem with multiple objectives, it is not possible to use an exact algorithm for solving the problem efficiently. The use of a genetic algorithm approach was considered that could overcome the difficulties inherent in the nature of the optimization model. A third main objective was to apply the MODAT to municipal road networks and also national road networks to verify the usefulness of the decision-aid tool.

\subsection{Outline}

The thesis is organized into seven chapters. Besides chapter 1 (introduction) and chapter 7 (conclusions), all the other chapters are based on scientific papers. Each chapter 
between 2 and 6 corresponds to a paper applying the MODAT in different situations. Hence, they all contain an introduction section, sections addressing literature overview, problem statement, model formulation, a case study application, and finally a conclusions section. The reader can therefore read all chapters sequentially or separately with no constraints. The drawback of such independency is the undesirable but inevitable repetition of a few ideas throughout the $\mathrm{PhD}$ thesis.

In spite of the independency between chapters, this thesis forms a consistent $\mathrm{PhD}$ formal document. All chapters address the theme of the pavement management problem, considering the MODAT system, but applied to different road networks and analyzed from different perspectives. In addition, the results presented in each chapter were sequentially used to improve the MODAT development.

Chapter 2 presents the results of the application of MODAT to a municipal road network, the road network of the municipality of Oliveira do Hospital. In this application two objectives were considered: minimisation of agency costs (maintenance and rehabilitation costs); and minimisation of user costs.

Chapter 3 presents the results of the application of MODAT to a national road network, the main road network of Castelo Branco, a district of Portugal. In this application the same two objectives were considered: minimization of maintenance and rehabilitation costs; and minimisation of user costs.

Chapter 4 presents the results of the application of MODAT also to a national road network, the main road network of Castelo Branco, but considering other objectives: 
minimization of maintenance and rehabilitation costs; and maximization of the residual value of pavements.

Chapter 5 presents the results of the application of MODAT also to the main road network of Castelo Branco, but considering three objectives: minimization of maintenance and rehabilitation costs; minimization of user costs; and maximization of the residual value of pavements.

Chapter 6 presents the results of a sensitivity analysis to the discount rate considering the optimization problem presented in chapter 2 . It is fundamental to perform a sensitivity analysis to the major input parameters in order to determine the impact of their variability in the results of each MODAT application.

Finally, the conclusions of this research work are summarized in Chapter 7, along with the discussion of future lines of research.

\subsection{Publications}

As mentioned in the previous section, this thesis is based on five scientific papers. Thus, as a conclusion to this introductory chapter, it is worth listing the publications that resulted (or are expected to result in the near future) from this research work. Some of the chapters have been published, or have been accepted for publication in international ISI journals, while others are currently under review.

("Multi-objective decision-aid tool for pavement management") corresponds to a paper published in the Transport journal from the Institution of Civil Engineers (Meneses et al. 2013). Chapter 3 ("Pavement maintenance programming considering two objectives: 
maintenance costs and user costs") corresponds to a paper published in the International Journal of Pavement Engineering (Meneses and Ferreira 2013). It is noteworthy that this recent paper belongs to the list of the 20 most downloaded $\left(6^{\text {th }}\right.$ place) with 282 downloads. Chapter 4 ("Pavement maintenance programming considering two objectives: maintenance costs and terminal value of pavements") corresponds to a paper submitted for publication in the International Journal of Pavement Engineering. Chapter 5 ("Pavement maintenance programming considering three objectives: minimization of maintenance and rehabilitation costs, minimization of user costs and maximization of the residual value of pavements") corresponds to a paper submitted for publication in the Journal of Transportation Engineering. Finally, Chapter 6 ("Multiobjective decision-aid tool for pavement management: sensitivity analysis to the discount rate") corresponds to a working paper to submit to the International Journal of Pavement Engineering. During this research work, several publications were also presented in international and national conferences. 


\section{References}

Abaza, K. (2006). Iterative linear approach for nonlinear nonhomogenous stochastic pavement management models. Journal of Transportation Engineering, 132(3), 244256.

Abaza, K., Ashur, S., Abu-Eisheh, S. and Rabay'A, A. (2001). Macroscopic optimum system for management of pavement rehabilitation. Journal of Transportation Engineering, 127(6), 493-500.

Abaza, K., Ashur, S., Abu-Eisheh, S. and Al-Khatib, I. (2004). Integrated pavement management system with a markovian prediction model. Journal of Transportation Engineering, 130(1), 24-33.

Deb, K. (2008). Multi-objective optimization using evolutionary algorithms, Wiley, West Sussex, United Kingdom, 1-536.

Ferreira, A., Antunes, A. and Picado-Santos, L. (2002a). Probabilistic segment-linked pavement management optimization model. Journal of Transportation Engineering, 128(6), 568-577.

Ferreira, A., Picado-Santos, L. and Antunes, A. (2002b). A segment-linked optimization model for deterministic pavement management systems. The International Journal of Pavement Engineering, 3(2), 95-105. 
Ferreira, A., Picado-Santos, L., Wu, Z. and Flintsch, G. (2008). Analysis of Pavement Performance Models for use in Pavement Management Systems. Proceedings of the Third European Pavement and Asset Management Conference, CD Ed., chapter 1136.pdf, 1-10, Coimbra, Portugal.

Ferreira, A., Meneses, S. and Vicente, F. (2009a). Pavement management system for Oliveira do Hospital, Portugal. Proceedings of the Institution of Civil EngineersTransport, 162(3), 157-169.

Ferreira, A., Meneses, S. and Vicente, F. (2009b). Alternative decision-aid tool for pavement management. Proceedings of the Institution of Civil Engineers-Transport, 162(1), 3-17.

Ferreira, A., Picado-Santos, L., Wu, Z. and Flintsch, G. (2011). Selection of pavement performance models for use in the Portuguese PMS. International Journal of Pavement Engineering, 12 (1), 87-97.

Flintsch, G. W. and Chen, C. (2004). Soft computing applications in infrastructure management. Journal of Infrastructure Systems, 10 (4), 157-166.

Fwa, T., Chan, W., and Hoque, K. (2000). Multiobjective optimization for pavement maintenance programming. Journal of Transportation Engineering, 126 (5), 367374.

Golabi, K., Kulkarni, R. and Way, G. (1982). A state-wide pavement management system. Interfaces, 12(6), 5-21. 
Hawker, L. and Abell, R. (2000). Selection and prioritisation of maintenance works on major roads in England. Proceedings of the 1st European Pavement Management Systems Conference, Budapest, Hungary, CD Ed., 1-8.

Horta, C., Pereira, F., Lopes, S. and Morgado, J. (2013). The EP's Pavement Management System - balance of a consolidated implementation. Proceedings of the $7^{\text {th }}$ Portuguese Road Conference, Laboratório Nacional de Engenharia Civil, CD Edition, Lisboa, Portugal, chapter 149_Art_T5_7CRP_2013.pdf, 1-10.

Hwang, C. and Masud, A. (1979). Multiple objective decision making - methods and applications: a state-of-the-art survey, Springer-Verlag, Berlin, Germany.

Iniestra, J. and Gutiérrez, J. (2009). Multi-criteria decisions on interdependent infrastructure transportation projects using an evolutionary-based framework. Applied Soft Computing, 9 (2), 512-526.

Kaliszewski, I. (2004). Out of the mist-towards decision-maker-friendly multiple criteria decision making support. European Journal of Operational Research, 158 (2), 293-307.

Kulkarni, R., Miller, D., Ingram, R., Wong, C. and Lorenz, J. (2004). Need-based project prioritisation: alternative to cost-benefit analysis. Journal of Transportation Engineering, 130(2), 150-158.

Madanat, S., Park, S. and Kuhn, K. (2006). Adaptive optimization and systematic probing of infrastructure system maintenance policies under model uncertainly. Journal of Infrastructure Systems, 12(3), 192-198. 
Mansouri, S. (2005). A multi-objective genetic algorithm for mixed-model sequencing on JIT assembly lines. European Journal of Operational Research, 167, 696-716.

Marler, R., and Arora, J. (2004). Survey of multi-objective optimization methods for engineering. Structural and Multidisciplinary Optimization, 26, 369-395.

Meneses, S. and Ferreira, A. (2013). Pavement maintenance programming considering two objectives: maintenance costs and user costs, International Journal of Pavement Engineering, 14 (2), 206-221.

Meneses, S., Ferreira, A. and Collop, A. (2013). Multi-objective decision-aid tool for pavement management, Proceedings of the Institution of Civil Engineers-Transport, $166(2), 79-94$.

Miettinen, K. (1999). Nonlinear multi-objective optimization, Kluwer Academic Publishers, Boston, USA, 1-324.

Nunoo, C. and Mrawira, D. (2004). Shuffled complex evolution algorithms in infrastructure works programming. Journal of Computing in Civil Engineering, 18(3), 257-266.

Picado-Santos, L., Ferreira, A., Antunes, A., Carvalheira, C., Santos, B., Bicho, M. H., Quadrado, I. and Silvestre, S. (2004). The pavement management system for Lisbon. Proceedings of the Institution of Civil Engineers-Municipal Engineer, 157(3), 157165.

Picado-Santos, L., Ferreira, A., Costa Pereira, F. and Conceição Azevedo, M. (2006). The evaluation of maintenance and rehabilitation strategies in the pavement 
management system of the Portuguese road administration. Proceedings of the $4^{\text {th }}$ Portuguese Road Congress, Lisbon, Portugal, 1-10 (in Portuguese).

Picado-Santos, L., and Ferreira, A. (2007). Development and implementation of a new pavement management system. Proceedings of the Fifth International Symposium on Maintenance and Rehabilitation of Pavements and Technological Control, CD Ed., 433-438, Utah, USA.

Picado-Santos, L., and Ferreira, A. (2008). Contributions to the development of the Portuguese road administration's pavement management system. Proceedings of the Third European Pavement and Asset Management Conference, CD Ed., chapter 1138.pdf, 1-10, Coimbra, Portugal.

Sebaaly, P. E., Hand, A., Epps, J. and Bosch C. (1996). Nevada's approach to pavement management. Transportation Research Record 1524, Transportation Research Board, Washington, D.C., 109-117.

Trindade, M. and Horta, C. (2009). Pavement management system of Estradas de Portugal, S.A. Proceedings of the $15^{\text {th }}$ Congreso Ibero-Latinoamericano del Asfalto, CD Ed., 1351-1360, Lisboa, Portugal (in Portuguese).

Wong, W., He, G. and Luk, S. (2003). Development of road management systems in China. Proceedings of the Institution of Civil Engineers-Transport, 156(4), 179-188.

Wu, Z. and Flintsch, G. (2009). Pavement preservation optimization considering multiple objectives and budget variability. Journal of Transportation Engineering, 135 (5), 305-315. 



\section{Chapter 2}

\section{Multi-objective decision-aid tool for pavement management}

\subsection{Introduction}

During the 1980s, and particularly after the first North American Pavement Management Conference, held in Toronto, Canada, in 1985, Pavement Management Systems (PMS) were recognised to be major tools in aiding the road network administrations. An efficient PMS for a road network is one that would maintain all pavement sections at a sufficiently high level of service and structural condition, but would require only a reasonably low budget and use of resources, and does not create any significant adverse impacts on the environment, safe traffic operations, and social and community activities. Unfortunately, many of these are conflicting requirements. For example, more resources and budget are usually needed if the pavements are to be maintained at a higher level of serviceability; and a program with more pavement treatment activities would, in general, cause longer traffic delays, increase 
environmental pollution and create more disruption of social activities and inconvenience to the community. Therefore, the decision process in programming pavement maintenance activities involves multi-objective considerations that should address these competing requirements. Practically, all the pavement maintenance programming tools currently in use are based on single-objective optimization. In these single-objective analyses, those requirements not selected as the objective function are imposed as constraints in the formulation. This can be viewed as interference in the optimization process by artificially setting limits on selected problem parameters. As a result, the solutions obtained from these single-objective analyses are suboptimal in comparison to one derived from multi-objective considerations.

One of the main components of a PMS is the methodology used to select the best maintenance and rehabilitation (M\&R) strategy taking into account the expected evolution of pavement quality. This methodology, realised in a Decision-Aid Tool (DAT), may be based on prioritisation (ranking) models (Hawker and Abell 2000; Kulkarni et al. 2004; Sebaaly et al. 1996; Wong et al. 2003) or optimization models (Abaza 2006; Abaza et al. 2004; Ferreira et al. 2002a; Ferreira et al. 2002b; Ferreira et al. 2009a; Ferreira et al. 2009b; Golabi et al. 1982; Madanat et al. 2006; Nunoo and Mrawira 2004; Picado-Santos et al. 2004).

Using prioritisation models, pavement condition data are combined into an index to represent the present pavement quality. Then, prioritisation is sorted by ranking and categorising all the pavement sections by using a priority-ranking criterion. The commonly used ranking parameters include road class, traffic volume, quality index, 
etc. The M\&R resources are allocated to road sections based on ranking and priorities assigned to them.

In optimization models, the goal of the analysis can be the minimization of any combination between agency costs, user costs and residual value of pavements over a selected planning time-span subject to minimum quality level constraints (Abaza 2006; Abaza et al. 2004; Ferreira et al. 2002a; Ferreira et al. 2002b; Ferreira et al. 2009a; Golabi et al. 1982; Madanat et al. 2006; Nunoo and Mrawira 2004; Picado-Santos et al. 2004) or the maximization of the whole network quality or performance subject to annual budget constraints (Abaza 2006; Abaza et al. 2004; Abaza et al. 2001; Ferreira et al. 2009b; Nunoo and Mrawira 2004). In these models, pavement condition data are used as model inputs, pavement performance models are used to predict future quality of pavements and annual budgets and minimum quality levels are constraints that must be assured. The pavement management problem is then formulated as an optimization model with variables representing the various $M \& R$ actions or operations. Basically, the optimal solution defines the amount and type of M\&R work to be applied to each road pavement.

The main weakness of prioritisation models is that they do not assure the selection of the best possible $M \& R$ strategy when considering long planning time-spans (for example 20 years). This can only be achieved if the approach followed for selecting the M\&R strategy is based on optimization techniques. The Arizona Department of Transportation and Woodward-Clyde Consultants, using optimization techniques, won the 1982 Franz Edelman Management Science Achievement Award from the Institute of Management Sciences, now the Institute for Operations Research and the 
Management Sciences (INFORMS), for developing and implementing the Network Optimization System of the Arizona PMS (Golabi et al. 1982). More recently, the Lisbon City Council and the Department of Civil Engineering of the University of Coimbra, also using optimization techniques, won the Parkman Medal awarded by the Institution of Civil Engineers from England for the best chapter published in the year 2004 on the practical aspects of the control or management, including project management of the design and/or construction of a specific scheme, for developing and implementing the Lisbon PMS (Picado-Santos et al. 2004).

Recently, researchers (Flintsch and Chen 2004; Fwa et al. 2000; Kaliszewski 2004; Wu and Flintsch 2009) have concluded that maintenance planning and programming requires optimization analysis involving multi-objective considerations. However, traditionally single-objective optimization techniques have been employed by pavement researchers and practitioners because of the complexity involved in multi-objective analysis. Other researchers concluded that it is possible to develop a Multi-objective Decision-Aid Tool, incorporating into the same optimization model several objectives, for example one for minimization of maintenance costs and another for maximization of the residual value of pavements using the concepts of Pareto optimal solution set and rank-based fitness evaluation (Deb 2008; Fwa et al. 2000; Iniestra and Gutiérrez 2009; Mansouri 2005).

This chapter presents the development and implementation of a Multi-objective Decision-Aid Tool (MODAT) tested with data of the Oliveira do Hospital's Pavement Management System (OHPMS). The OHPMS includes the following components (Ferreira et al. 2009a): a Road Network Database; a Quality Evaluation Tool; a Costs 
Model; a Pavement Performance Model; and a Decision-Aid Tool (Figure 2.1). Nowadays, the Decision-Aid Tool of the OHPMS uses a deterministic section-linked optimization model with the objective of minimising the total expected discounted costs over the planning time-span while keeping the road pavements within given quality standards. The MODAT uses a multi-objective deterministic section-linked optimization model with three different possible goals: minimization of agency costs (maintenance and rehabilitation costs); minimization of user costs; and maximization of the residual value of pavements (Susana and Ferreira 2010). This new approach allows PMS to become an interactive decision-aid tool, capable of providing road administrations with answers to "what-if" questions in short periods of time. The MODAT uses the deterministic pavement performance model used in the AASHTO flexible pavement design method that allows closing of the gap between project and network management. The information produced by the MODAT is shown in maps using a Geographic Information System (GIS). The GIS, with its spatial analysis capabilities, is considered to be the most appropriate tool to enhance PMS with features such as graphical display of road data (Ferreira and Duarte 2006; Kennedy and Johns 2001; Parida et al. 2005). 


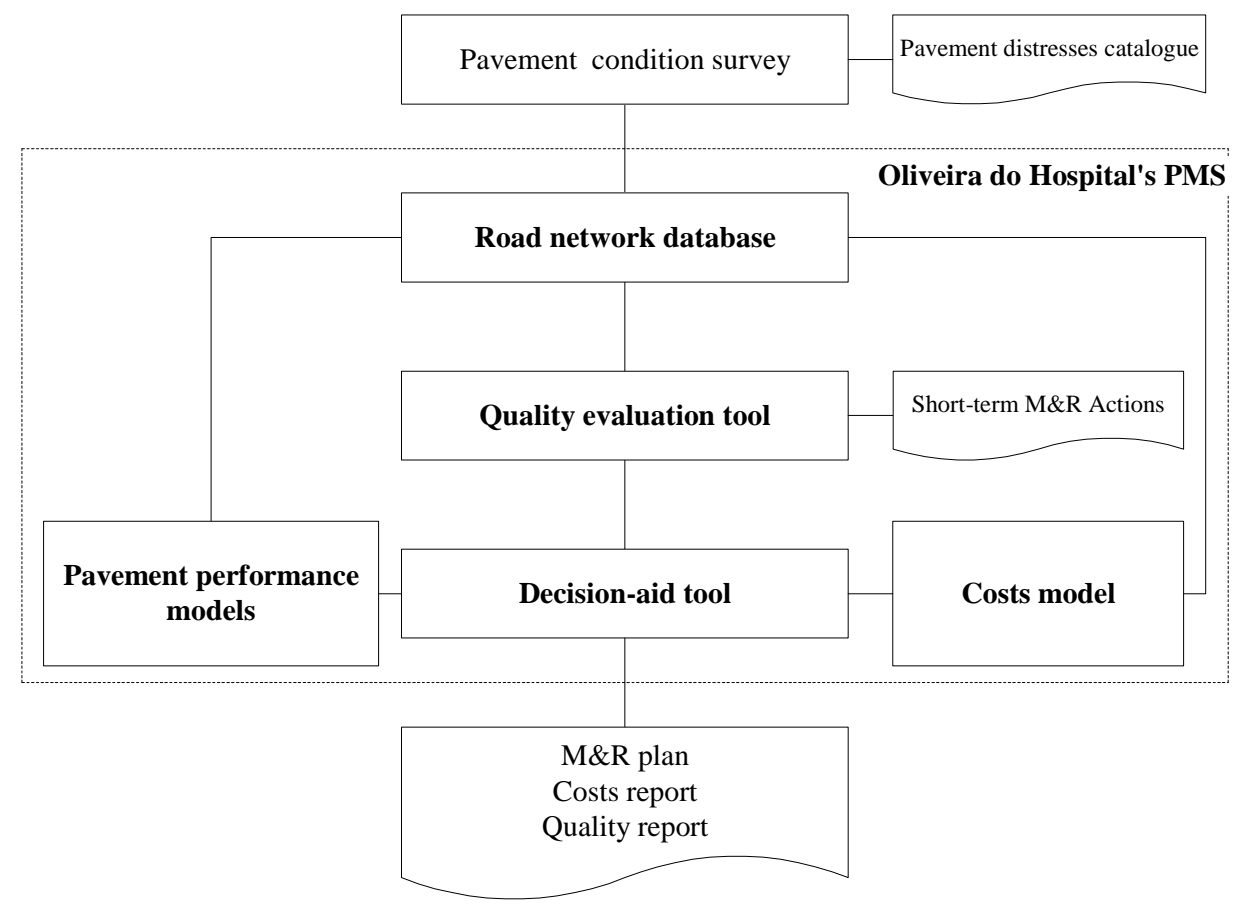

Figure 2-1 - Structure of the Pavement Management System

\subsection{Multi-Objective decision-aid tool}

\subsubsection{Introduction}

The Multi-Objective Decision-Aid Tool (MODAT) is constituted by the components shown in Figure 2.2: the objectives of the analysis; the data and the models about the road pavements; the constraints that the system must guarantee; and the results. Several objectives can be considered in the analysis, including the minimization of agency costs (maintenance and rehabilitation costs), the minimization of user costs, the maximization of the residual value of pavements at the end of the planning time-span, etc. The results of the application of the MODAT to a road network are constituted by the M\&R plan, the costs report, and the structural and functional quality report. The data and the 
models about the road pavements, and the constraints that the system must guarantee are described in the following section.

\begin{tabular}{|c|c|}
\hline Objectives & $\begin{array}{l}\text { Minimisation of agency costs (maintenance and rehabilitation costs) } \\
\text { Minimisation of user costs } \\
\text { Maximisation of the residual value of pavements } \\
\ldots\end{array}$ \\
\hline \\
\hline Data and models & $\begin{array}{c}\text { Number of years of the planning period } \\
\text { Discount rate } \\
\text { Areas and volumes } \\
\text { Structural and functional quality } \\
\text { Performance models } \\
\text { M\&R actions and unit agency costs } \\
\text { User costs model } \\
\text { Residual value model } \\
\text { Minimum quality levels to guarantee } \\
\text { Annual budgets }\end{array}$ \\
\hline \multicolumn{2}{|l|}{$\checkmark$} \\
\hline Constraints & $\begin{array}{l}\text { Verifying the minimum quality levels } \\
\text { Using only the M\&R actions defined by the infrastructure manager } \\
\text { Not exceeding the available budget } \\
\text { Not exceeding the maximum number of M\&R actions during the planning period }\end{array}$ \\
\hline \\
\hline Results & $\begin{array}{l}\text { Maintenance and rehabilitation plan } \\
\text { Costs report } \\
\text { Structural and functional quality report }\end{array}$ \\
\hline
\end{tabular}

Figure 2-2 - MODAT components

\subsubsection{Optimization model}

A detailed description of the model formulation can be seen in Appendix I and details of the deterministic optimization model can be found in Appendix II. Equation (2.1) is one of the objective functions of the optimization model and expresses the minimization of agency costs (maintenance and rehabilitation costs) over the planning time-span. Equation (2.2) is the second objective function and expresses the minimization of user costs over the planning time-span. Equation (2.3) is the third objective function and 
expresses the maximization of the residual value of pavements at the end of the planning time-span. Other objective functions can be included in the optimization model; for example the maximization of the road network performance (Ferreira et al., 2009b).

The constraints represented by Equation (2.4) correspond to the pavement condition functions. They express pavement condition in terms of the PSI in each road section and year as a function of the initial PSI and the M\&R actions previously applied to the road section. The functions shown in Equations (2.13)-(2.16) of Appendix III are used to evaluate the PSI over time. The quality of the road pavements in the present year is evaluated by the PSI, representing the condition of the pavement according to the following parameters: longitudinal roughness, rutting, cracking, surface disintegration and patching. This global quality index, calculated through Equation (2.13), ranges from 0.0 to 5.0 , with 0.0 for a pavement in extremely poor condition and 5.0 for a pavement in very good condition. In practice, through this index, a new pavement rarely exceeds the value 4.5 and a value of 2.0 is generally defined as the minimum quality level (MQL) for municipal roads considering traffic safety and comfort. Equation (2.14) represents the pavement performance model used for flexible pavements. This pavement performance model is the one used in the AASHTO flexible pavement design method (AASHTO 1993; C-SHRP 2002). This design approach applies several factors such as the change in $P S I$ over the design period, the number of $80 \mathrm{kN}$ equivalent single axle load applications, material properties, drainage and environmental conditions, and performance reliability, to obtain a measure of the required structural strength through an index known as the structural number $(S N)$. The $S N$ is then converted to pavement 
layer thicknesses according to layer structural coefficients representing relative strength of the layer materials. The basic design equation used for flexible pavements is Equation (2.14). The $S N$ in each road section and year of the planning period can be calculated by Equation (2.15). The number of $80 \mathrm{kN}$ equivalent single axle load applications are computed using Equation (2.16). The use of a pavement performance model for pavement design into a PMS allows the gap to be closed between project and network management, which is an important objective to be achieved and that has been mentioned by several researchers (Ferreira et al. 2009a).

This pavement performance model was chosen from a range of current models implemented in several PMS because it is widely used and tested. Nevertheless, other pavement performance models can be used instead, as for example the deterioration models developed for local authority roads by Stephenson et al. (2004) or the deterioration models developed for use in the Swedish PMS (Andersson 2007; Ihs and Sjögren 2003; Lang and Dahlgren 2001; Lang and Potucek 2001). Equation (2.14) defines a pavement performance model in terms of PSI as a function of the number of $80 \mathrm{kN}$ equivalent single axle load applications (Figure 2.3) or the number of years of service time. An incremental change in the present serviceability index $\left(\Delta P S I_{t-1, t}\right)$ corresponds to an estimated incremental change in load applications $\left(\left(\Delta \mathrm{W}_{80}\right)_{t-1, t}\right)$ and, at the same time, to an incremental service time interval $\left(\Delta T_{t-1, t}\right)$. The Present Serviceability Index in year $t\left(P S I_{t}\right)$ is defined as the difference between the serviceability index in year $t-1\left(P S I_{t-1}\right)$ and the incremental change in the present serviceability index $\left(\Delta P S I_{t-1, t}\right)$. At the same time, the Present Serviceability Index in year $t\left(P S I_{t}\right)$ is defined as the difference between the initial serviceability index $\left(P S I_{\mathrm{o}}\right)$ 
and the total incremental change in the present serviceability index $\left(\triangle P S I_{0, t}\right)$. The Present Serviceability Index in year $t\left(P S I_{t}\right)$ ranges between its initial value of about 4.5 (value for a new pavement) and the AASHTO lowest allowed PSI value of 1.5 (value for a pavement of a municipal road in the end of its service life).

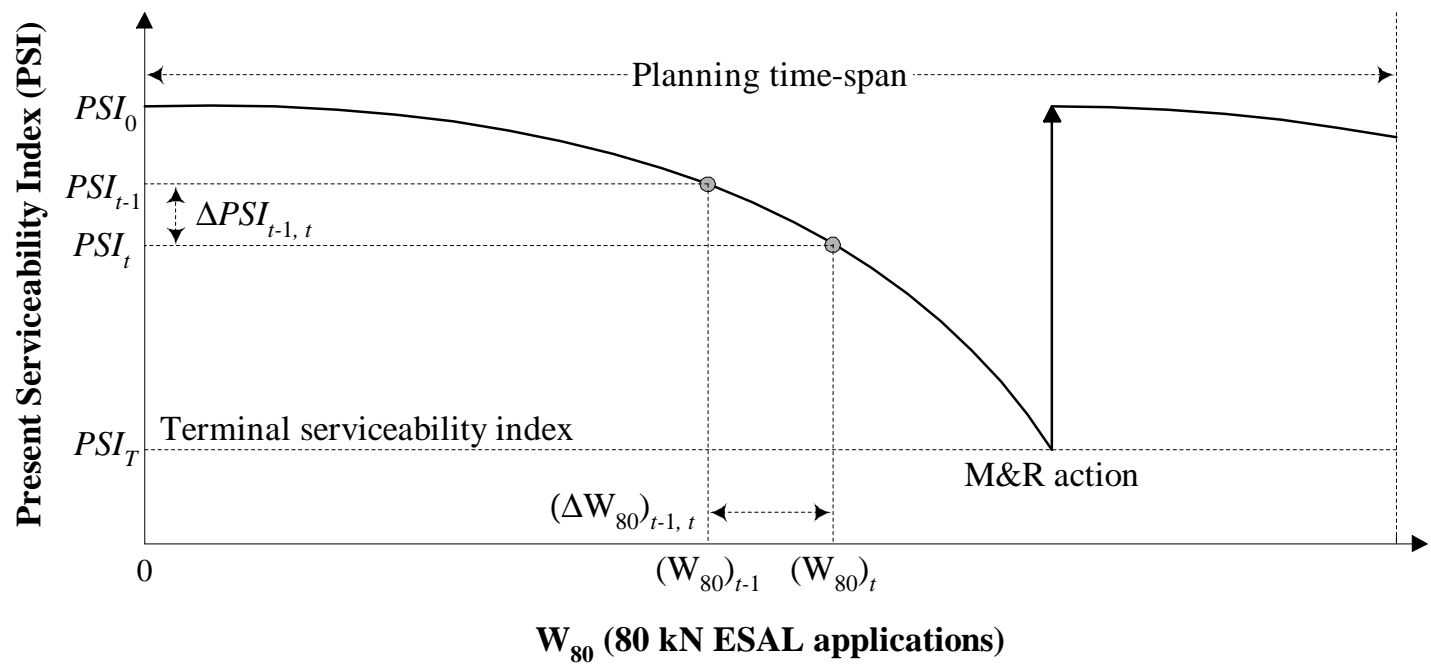

Figure 2-3 - Pavement performance curve as a function of equivalent single-axle load applications

The constraints given by Equation (2.5) are the warning level constraints. They define the MQL considering the PSI index for each pavement of the road network. The warning level adopted in this study was a PSI value of 2.0. A corrective M\&R operation appropriate for the rehabilitation of a pavement must be performed on a road section when the PSI value is lower than 2.0.

The constraints represented by Equation (2.6) represent the feasible operation sets, i.e., the M\&R operations that can be performed on each road section and in each year. These operations depend on the pavement condition characterising the section. In the present study the same five different $M \& R$ operations were considered, corresponding to nine M\&R actions applied individually or in combination with others, as in previous studies 
(Ferreira el al. 2009a; Ferreira et al. 2009b). The types of M\&R actions and operations considered are presented in Tables 2.1 and 2.2. The M\&R action costs considered in this study, calculated using information from M\&R works executed on the Oliveira do Hospital road network, are also presented in Tables 2.1 and 2.2.

Table 2-1 - Types of M\&R action

\begin{tabular}{ccc}
\hline M\&R action & Description & Cost \\
\hline 1 & Do nothing & $€ 0.00 / \mathrm{m} 2$ \\
2 & Tack coat & $€ 0.17 / \mathrm{m} 2$ \\
3 & Longitudinal roughness levelling $(1 \mathrm{~cm})$ & $€ 0.92 / \mathrm{m} 2$ \\
4 & Longitudinal roughness levelling $(2 \mathrm{~cm})$ & $€ 1.84 / \mathrm{m} 2$ \\
5 & Membrane anti-reflection of cracks & $€ 0.70 / \mathrm{m} 2$ \\
6 & Base layer $(10 \mathrm{~cm})$ & $€ 6.50 / \mathrm{m} 2$ \\
7 & Binder layer $(5 \mathrm{~cm})$ & $€ 3.30 / \mathrm{m} 2$ \\
8 & Non-structural wearing layer & $€ 0.70 / \mathrm{m} 2$ \\
9 & wearing layer $(5 \mathrm{~cm})$ & $€ 4.46 / \mathrm{m} 2$ \\
\hline
\end{tabular}

Table 2-2 - Types of M\&R operation

\begin{tabular}{cccc}
\hline M\&R operation & Description & M\&R actions involved & Cost \\
\hline 1 & Do nothing & 1 & $€ 0.00 / \mathrm{m} 2$ \\
2 & Non-structural maintenance & $2+3+2+8$ & $€ 1.96 / \mathrm{m} 2$ \\
3 & Minor rehabilitation & $2+4+2+5+2+9$ & $€ 7.51 / \mathrm{m} 2$ \\
4 & Medium rehabilitation & $2+4+2+5+2+7+2+9$ & $€ 10.98 / \mathrm{m} 2$ \\
5 & Major rehabilitation & $2+4+2+5+2+6+2+9$ & $€ 14.18 / \mathrm{m} 2$ \\
\hline
\end{tabular}

As shown in Table 2.3, the operations to apply to the road sections depend on the warning level. M\&R operation 1 that corresponds to "do nothing" is applied to a road section if the PSI value is above the warning level, i.e., if the PSI value is greater than 2.0. $M \& R$ operation number 5 is the operation that must be applied to the road section when the warning level is reached, i.e., this operation applies to solve pavement 
serviceability problems. This operation has the longest efficiency period which is defined as the time between its application to the pavement and the time when the pavement reaches the warning level for the PSI. M\&R operations 2, 3, 4 and 5 are alternative operations that can be applied instead of operation 1 (see Table 2.4). In this case they constitute preventive $M \& R$ operations. The analysis of Tables 2.3 and 2.4 clearly shows that the application of $M \& R$ operations may be corrective or preventive. An M\&R operation is corrective if it is performed when the warning level is reached, and it is preventive if it is performed before the warning level is reached. When deciding which $M \& R$ operations should be applied in a given year to a given road section with PSI value above the warning level, it is possible to select either the simplest operation (M\&R operation 1) or a preventive operation (M\&R operation 2, 3, 4 or 5). In fact, selecting a preventive operation may be more efficient (less costly) in the medium or long-term.

Table 2-3 - Application of the simplest M\&R operations

\begin{tabular}{cccc}
\hline Warning level & PSI & M\&R operation & M\&R action \\
\hline \multirow{2}{*}{ PSI $=2.0$} & $\geq 2.0$ & 1 & 1 \\
& $<2.0$ & 5 & $2+4+2+5+2+6+2+9$ \\
\hline
\end{tabular}

Table 2-4 - Alternatives to M\&R operations

\begin{tabular}{cccccc}
\hline \multirow{2}{*}{ M\&R operation } & \multicolumn{5}{c}{ Alternative M\&R operations } \\
\cline { 2 - 6 } & 1 & 2 & 3 & 4 & 5 \\
\hline 1 & $v$ & $v$ & $v$ & $v$ & $v$ \\
2 & - & $v$ & $v$ & $v$ & $v$ \\
3 & - & - & $v$ & $v$ & $v$ \\
4 & - & - & - & $v$ & $v$ \\
5 & - & - & - & - & $v$ \\
\hline
\end{tabular}


The constraints given by Equation (2.7) state that only one $M \& R$ operation per road section should be performed in each year. The constraints represented by Equation (2.8) represent the agency cost functions. They express the costs for the road agency involved in the application of a given $M \& R$ operation to a road section in a given year as a function of the pavement condition in that section and year. These costs are obtained by multiplying the unit agency costs for the $M \& R$ actions involved in the $M \& R$ operation by the pavement areas to which the M\&R actions are applied. The constraints defined by Equation (2.9) represent the user cost functions. They express the cost for road users as a function of the pavement condition in that section and year. For calculating the vehicle operation cost, Equation (2.17) in Appendix III was used. The constraints represented by Equation (2.10) represent the pavement residual value functions. They express the value of the pavement of a road section at the end of the planning time-span as a function of pavement condition at that time. For calculating the residual value of pavements Equation (2.18) in Appendix III was used. The constraints given by Equation (2.11) are the annual budget constraints. They specify the maximum amount of money to be spent on $M \& R$ operations during each year. The constraints represented by Equation (2.12) were included in the model to avoid frequent M\&R operations applied to the same road section.

\subsubsection{Generation of Pareto optimal solutions}

Given the mathematical formulation of the optimization model presented in the previous section, the next step consists of the adoption of the appropriate mechanism for generating a representative set of Pareto optimal solutions (Ferreira and Meneses 2010). 
At this point it is evident that, given the particular features of the optimization model (a combinatorial problem with multiple objectives), it is not possible to use an exact algorithm for solving the problem efficiently. In this section, the use of a genetic algorithm approach was considered that could overcome the difficulties inherent in the nature of the optimization model.

There are several optimization methods that can be used to generate the set of Pareto optimal solutions. Hwang and Masud (1979) and later Miettinen (1999) classified them into the following four types: no-preference methods; posterior methods; a priori methods; and interactive methods. The no-preference methods do not assume any information about the importance of different objectives and a heuristic is used to find a single optimal solution. Posterior methods use preference information of each objective and iteratively generate a set of Pareto optimal solutions. Alternatively, a priori methods use more information about the preference of objectives and usually find one preferred Pareto optimal solution. Interactive methods use the preference information progressively during the optimization process.

According to Marler and Arora (2004), no single approach is, in general, superior to the other methods. Rather, the selection of a specific method depends on the users' preferences, the type of information provided, the solution requirements, and the availability of software. This study uses a genetic algorithm approach with the incorporation of the weighting sum method. This method, as the name suggests, combines a set of objectives into a single objective by pre-multiplying each objective with a user-defined weight. This method is the simplest approach and is probably the most widely used (Deb 2008; Wu and Flintsch 2009). Setting relative weights for 
individual objectives becomes a central issue in applying this method. As the weight vector for the multiple objectives often depends highly on the magnitude of each objective function, it is desirable to normalise those objectives to achieve roughly the same scale of magnitude. Equation (2.19) represents the application of the weighting sum method (Deb 2008) to the three objective functions of the optimization model presented in the previous section.

Minimise $\bar{Z}=w_{A C} \cdot \frac{A C_{i}-A C_{\min }}{A C_{\max }-A C_{\min }}+w_{U C} \cdot \frac{U C_{i}-U C_{\min }}{U C_{\max }-U C_{\min }}+w_{R V} \cdot\left(-\frac{R V_{i}-R V_{\min }}{R V_{\max }-R V_{\min }}\right)$

where: $\bar{Z}$ is the normalised value of a solution; $w_{A C}, w_{U C}$, and $w_{R V}$ are the weight values for each objective function; $A C_{i}, U C_{i}$, and $R V_{i}$ are the individual objective function values that depend on the decision variables values; $A C_{\min }, U C_{\min }$, and $R V_{\min }$ are the minimum values obtained for each objective; $A C_{\max }, U C_{\max }$, and $R V_{\max }$ are the maximum values obtained for each objective.

The third objective corresponds to the maximization of the residual value of pavements at the end of the planning time-span. When an objective is required to be maximised, the duality principle (Deb 2008) can be used to transform the original objective of maximization into an objective of minimization by multiplying the objective function by (-1). The range of values for the various objective functions $\left(A C_{\min }, A C_{\max }\right)$, $\left(U C_{\min }, U C_{\max }\right)$, and $\left(R V_{\min }, R V_{\max }\right)$ are obtained by applying the optimization model considering only one objective at each time, i.e., varying the weight values vector $\left(w_{A C}, w_{U C}, w_{R V}\right)$ among the extreme situations of $(1,0,0),(0,1,0)$ and $(0,0,1)$ and 
considering that initially all minimum values are 0 and all maximum values are 1 . Considering only two objectives (Figure 2.4), the minimum values obtained for each objective corresponds to the ideal solution $\left(Z^{*}\right)$. In general, this solution is a nonexistent solution that is used as a reference solution and it is also used as lower boundary to normalise the objective values in a common range. The nadir solution $\left(\mathrm{Z}^{\mathrm{nad}}\right)$, which is used as upper boundary to normalise the objective values in a common range, corresponds to the upper boundary of each objective in the entire Pareto optimal set, and not in the entire search space $\left(\mathrm{Z}^{* *}\right)$.

The Pareto optimal solution set is finally obtained by using the objective function defined by Equation (2.19) considering different combinations of the weight values.

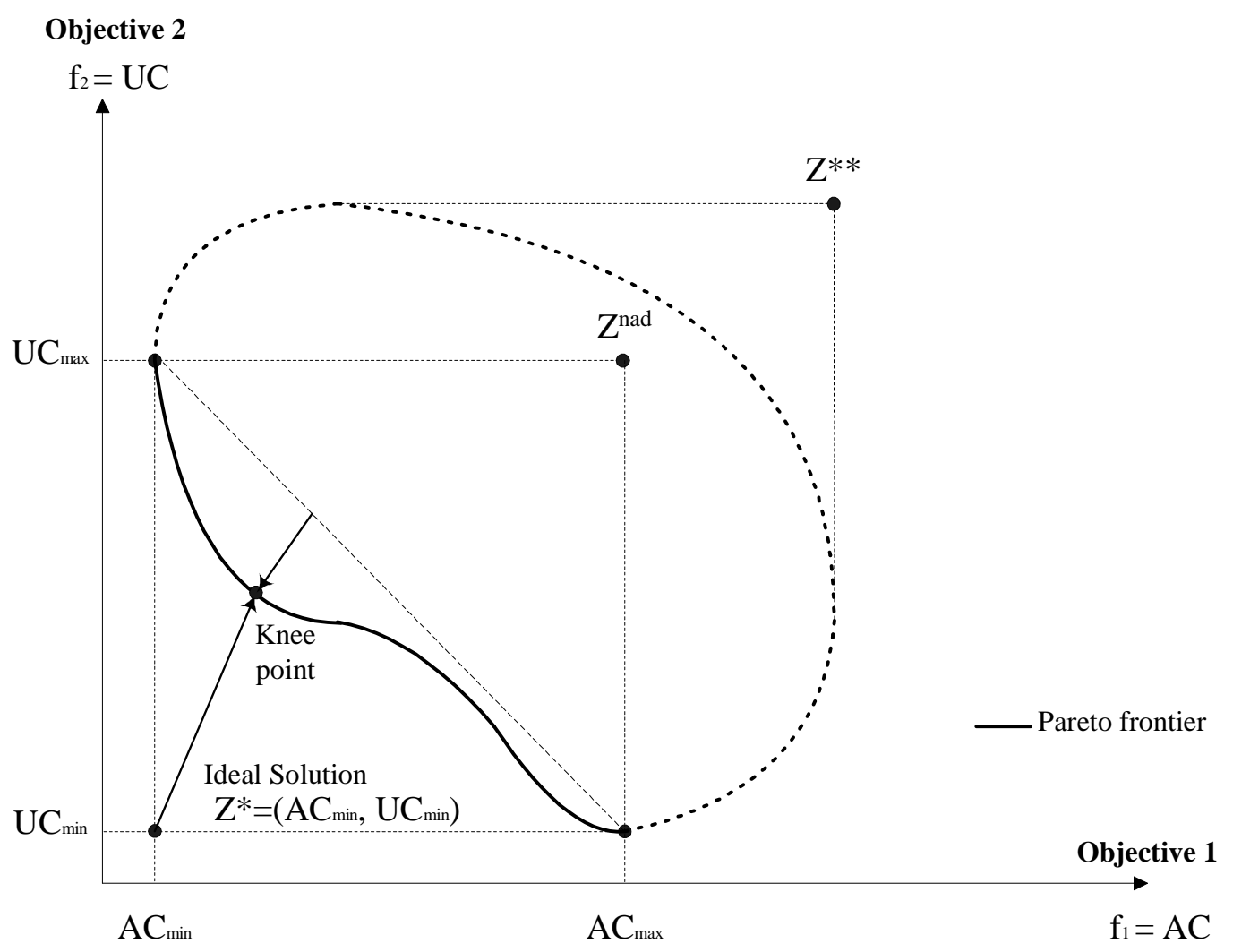

Figure 2-4 - The Pareto frontier and the ideal and nadir solutions 


\subsubsection{Knee points and identification procedure}

In general, when dealing with a multi-objective optimization problem, the decision maker has great difficulties in selecting a particular solution for implementation from the Pareto optimal solution set. Das (1999), to avoid this difficulty, developed the Normal-Boundary Intersection (NBI) method to identify the so called "Knee point" of the Pareto frontier. Considering only two objectives (Figure 2.4), the Knee is a point on the region of the Pareto frontier that results from the projection of a normal vector from the line connecting the end points of the Pareto frontier (the two individual optima). The "knee point" is the farthest away Pareto point from this line in the direction of the normal vector. Knee points represent the most interesting solutions of the Pareto frontier due to their implicit large marginal rates of substitution (Iniestra and Gutiérrez 2009). Wu and Flintsch (2009) considered another method to identify the best solution of the Pareto frontier. As the ideal solution may not be achieved due to the conflicting objectives, the best solution is the solution of the Pareto frontier that has the shortest normalised distance from the ideal solution, computed using Equation (2.20).

$$
D_{i}=\left[\left(\frac{A C_{i}-A C_{\min }}{A C_{\max }-A C_{\min }}-\bar{Z}_{1}^{*}\right)^{2}+\left(\frac{U C_{i}-U C_{\min }}{U C_{\max }-U C_{\min }}-\bar{Z}_{2}^{*}\right)^{2}+\left(\frac{R V_{i}-R V_{\min }}{R V_{\max }-R V_{\min }}-\bar{Z}_{3}^{*}\right)^{2}\right]^{\frac{1}{2}}
$$

where: $D_{i}$ is the normalised distance between each Pareto solution point and the ideal

solution point; $\bar{Z}_{1}^{*}, \bar{Z}_{2}^{*}$, and $\bar{Z}_{3}^{*}$ are the normalised values for each objective of the ideal solution (are equal to 0 or 1 depending on whether it is a minimization or maximization objective). 


\subsubsection{Model solving}

The deterministic optimization model presented in the previous section is extremely complex, being impossible to solve with exact optimization methods (except, for small, highly idealised instances, through complete enumeration) available through commercial packages like XPRESS-MP (FICO 2009) or GAMS-CPLEX (IBM 2009). Indeed, it can only be solved through heuristic methods. Nowadays, a large number of classic and modern heuristic methods are available (Deb, 2008, Gendreau and Potvin 2005, Michalewicz and Fogel 2004) to solve these kind of complex optimization models. The optimization model and its heuristic solver were implemented in a computer program called MODAT. The heuristic method used to solve this optimization model is a genetic-algorithm (GA) that was implemented in Microsoft Visual Studio programming language (David et al. 2006, Randolph and Gardner 2008) adapting and introducing new functionalities to an existing GA program called GENETIPAV-D (Ferreira 2001, Ferreira et al. 2002b) previously developed to solve single-objective deterministic optimization models. Since they were proposed by Holland (1975), genetic algorithms have been successfully used on many occasions to deal with complex engineering optimization problems. The MODAT applied to the Oliveira do Hospital road network was run on a $2.0 \mathrm{GHz}$ personal computer (PC) with 1.0 GB of RAM and $120 \mathrm{~GB}$ of capacity. Each best solution given by the MODAT was obtained in approximately 30 minutes of computing time. 


\subsubsection{Results of the application of the MODAT}

The MODAT was tested with data from the Oliveira do Hospital Pavement Management System (Ferreira et al. 2009a; Ferreira et al. 2009b) to plan the maintenance and rehabilitation of the road network considering two objectives, the minimization of agency costs and the minimization of user costs. The main road network has a total length of $65.8 \mathrm{~km}$, and the corresponding network model has 36 road sections. The secondary roads of the network were not included in this study. The discount rate considered in this study was $2.5 \%$. Figure 2.5 shows the quality of pavements for Oliveira do Hospital's road network using a PSI representation with 9 levels $(0.0 \leq \mathrm{PSI} \leq 0.5 ; 0.5<\mathrm{PSI} \leq 1.0 ; 1.0<\mathrm{PSI} \leq 1.5 ; \ldots$; PSI $>4.0)$. There are several road sections with PSI value below 2.0, which is the quality level that indicates the need for rehabilitation of the pavement.

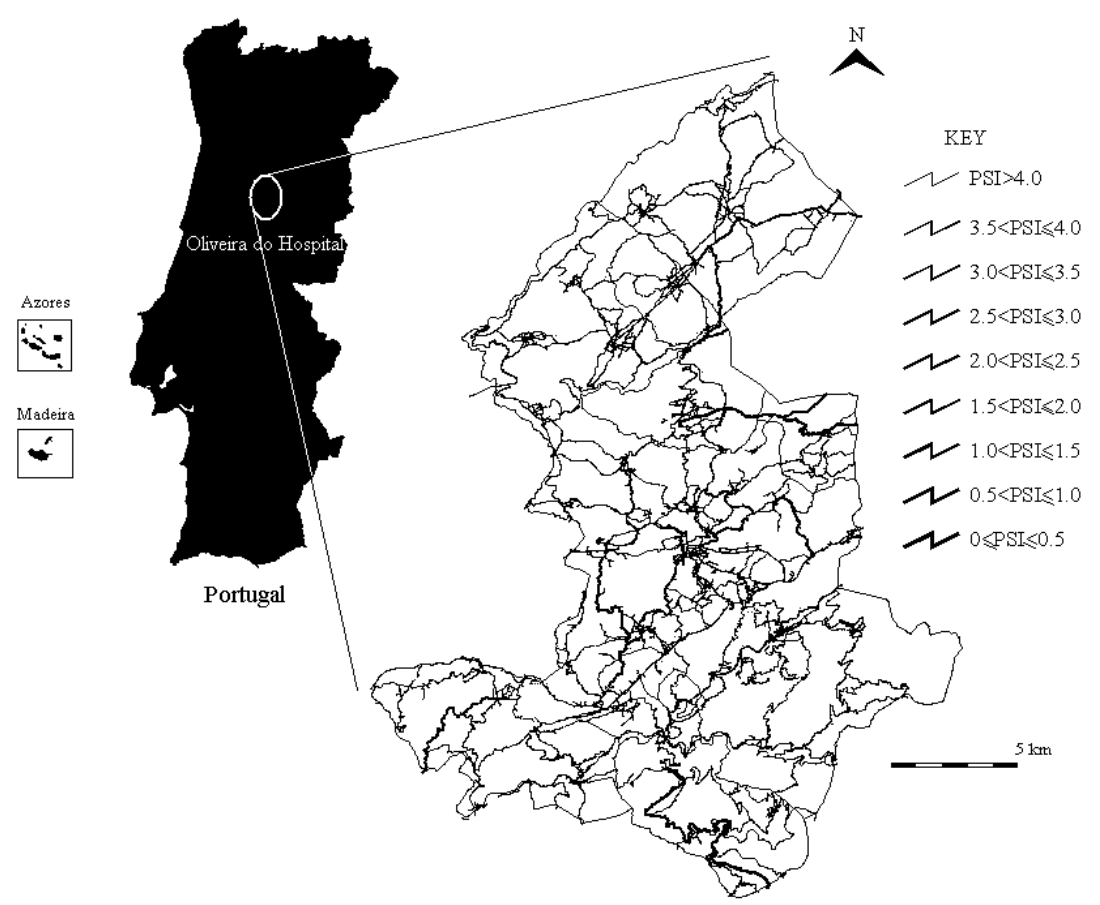

Figure 2-5 - Quality of pavements of the Oliveira do Hospital's road network 
Figure 2.6 represents the Pareto optimal set of solutions in the objective space by varying the weight values while Figure 2.7 represents the optimal set of normalised solutions. The point with black colour represents the "Knee point" and was obtained considering the following weight values: $\left(w_{A C}, w_{U C}, w_{R V}\right)=(0.05,0.95,0.00)$; and it corresponds to the following objective values $(A C, U C, R V)=(€ 2476361.6$, $€ 2386407.3$, €2793815.6). The range of values for the two objective functions are $\left(A C_{\min }, A C_{\max }\right)=(€ 2061528.8, € 13426199.3)$, and $\left(U C_{\min }, U C_{\max }\right)=(€ 2374058.4$, $€ 2840482.9$ ). From Figures 2.6 and 2.7 it can be concluded that, when varying the two weights through a grid of values from 0 to 1 with a fixed increment step, as for example 0.05 , the two objective values were not transformed maintaining the same fixed range.

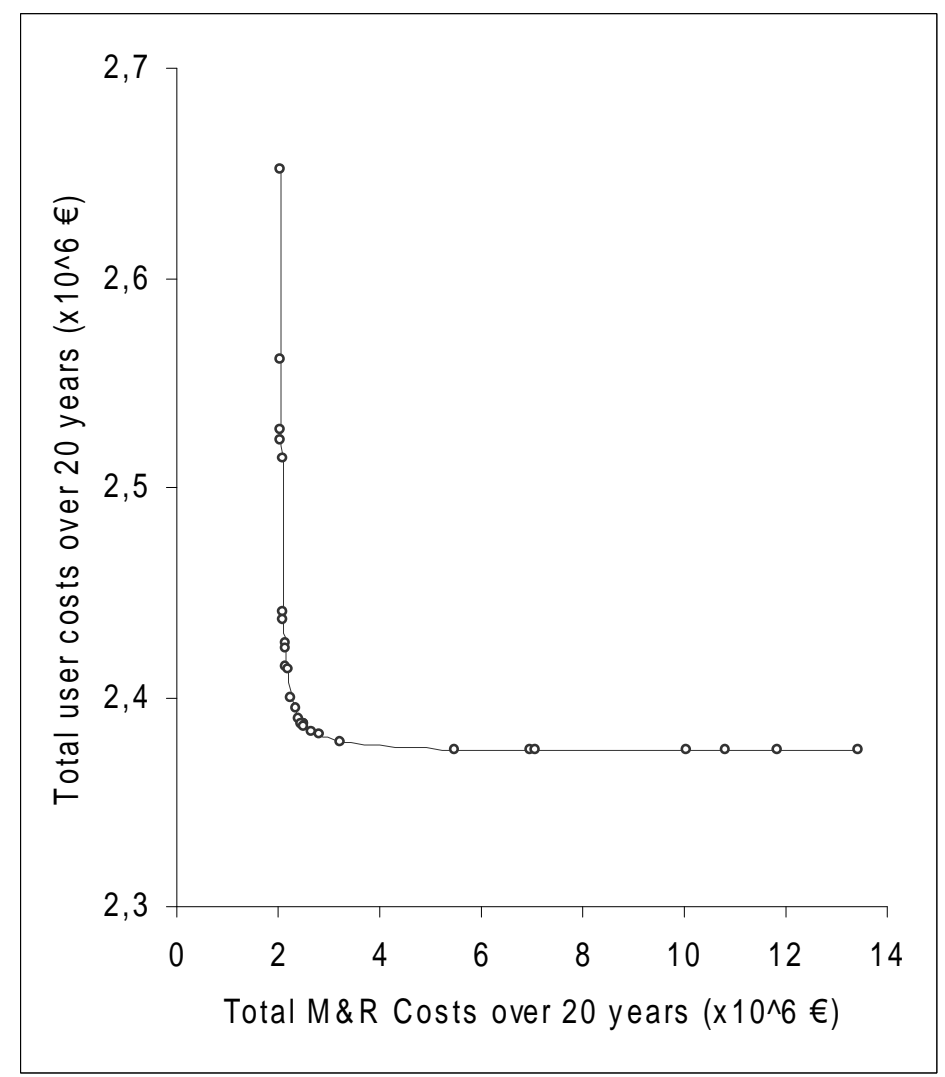

Figure 2-6 - Pareto optimal set of solutions 


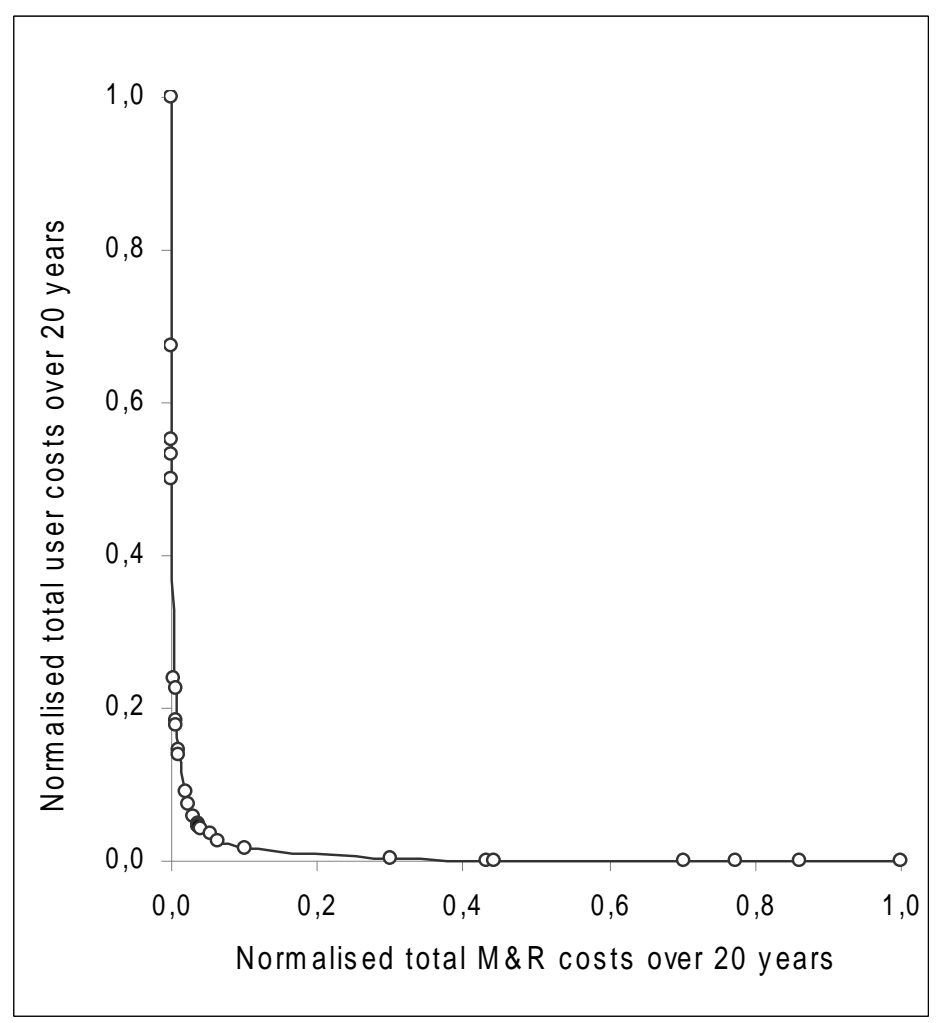

Figure 2-7 - Pareto optimal set of normalised solutions

Therefore, each weight value not only indicates the importance of an objective, but also compensates, to some extent, for differences in objective function magnitudes.

In multi-objective problems there is no perfect method to select one "optimal" solution from the Pareto optimal set of solutions.

The final best-compromise solution is always up to the decision maker. For that purpose, four different $M \& R$ solutions of the Pareto frontier were considered for comparison.

a) Solution I: Multi-objective optimization approach (corrective-preventive) considering the "Knee point" $\left(w_{A C}=0.05, w_{U C}=0.95, w_{R V}=0.00\right)$;

b) Solution II: Multi-objective optimization approach (corrective-preventive) considering the following weights $\left(w_{A C}=1.00, w_{U C}=0.00, w_{R V}=0.00\right)$; 
c) Solution III: Multi-objective optimization approach (corrective-preventive) considering the following weights $\left(w_{A C}=0.00, w_{U C}=1.00, w_{R V}=0.00\right)$;

d) Solution IV: Multi-objective optimization approach (corrective-preventive) considering the following weights $\left(w_{A C}=0.50, w_{U C}=0.50, w_{R V}=0.00\right)$.

The costs and normalised costs during the entire planning time-span for these four Pareto optimal solutions are summarised in Figures 2.8 and 2.9, respectively. Figure 2.9 shows that, as expected, solution I ("Knee point") is the Pareto optimal solution with less normalised value of $\mathrm{M} \& \mathrm{R}$ costs plus user costs. Considering the non-normalised value of $M \& R$ costs plus user costs (Figure 2.8), one can verify that this optimal solution does not have the least value. Figure 2.9 also shows that solution I ("Knee point") is not the Pareto optimal solution with less total normalised costs, computed by adding M\&R normalised costs and user normalised costs and deducting the residual normalised value (in this case the solution with less total normalised costs is solution IV). This happens because this solution I ("Knee point”) was defined considering only two objectives (minimization of agency costs and minimization of user costs).

Figure 2.10 represents the predicted PSI average value over the years of the planning time span for all the road network pavements and for each solution. By analysing this Figure it can be seen that solution III, i.e., the solution of the multi-objective optimization approach (corrective-preventive) considering the weights $\left(w_{A C}=0.00, w_{U C}=1.00, w_{R V}=0.00\right)$, corresponds to the largest average PSI values as expected because this solution corresponds to the minimization of user costs. The differences between the PSI curves are small because the present quality of almost all the pavements is low and because its degradation is slow due to the reduced values of 
the traffic volume in this road network. Solution I ("Knee point") is the second best solution in terms of average PSI values also as expected because corresponds to a high weight value for user costs and a small weight value for agency costs $\left(w_{A C}=0.05, w_{U C}=0.95, w_{R V}=0.00\right)$.

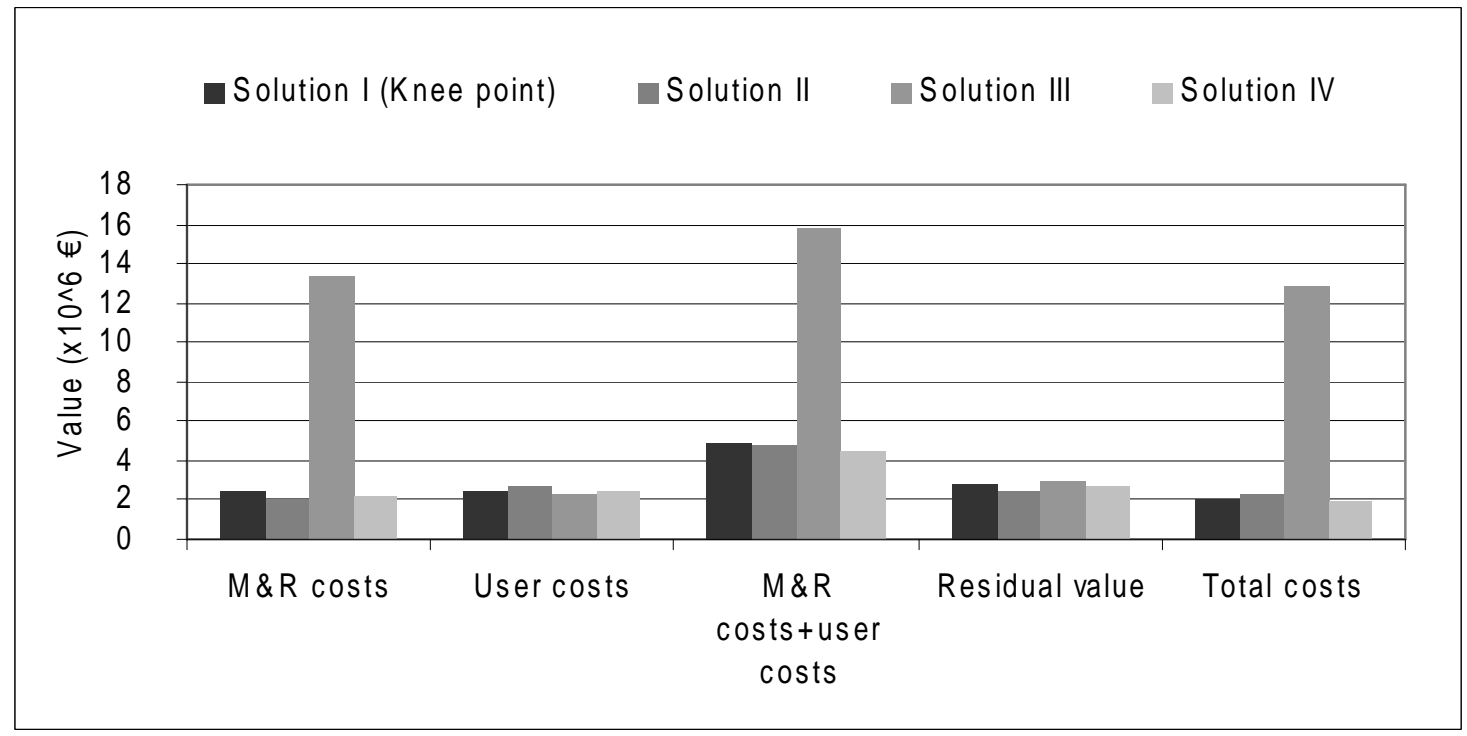

Figure 2-8 - Costs throughout the planning time-span of 20 years

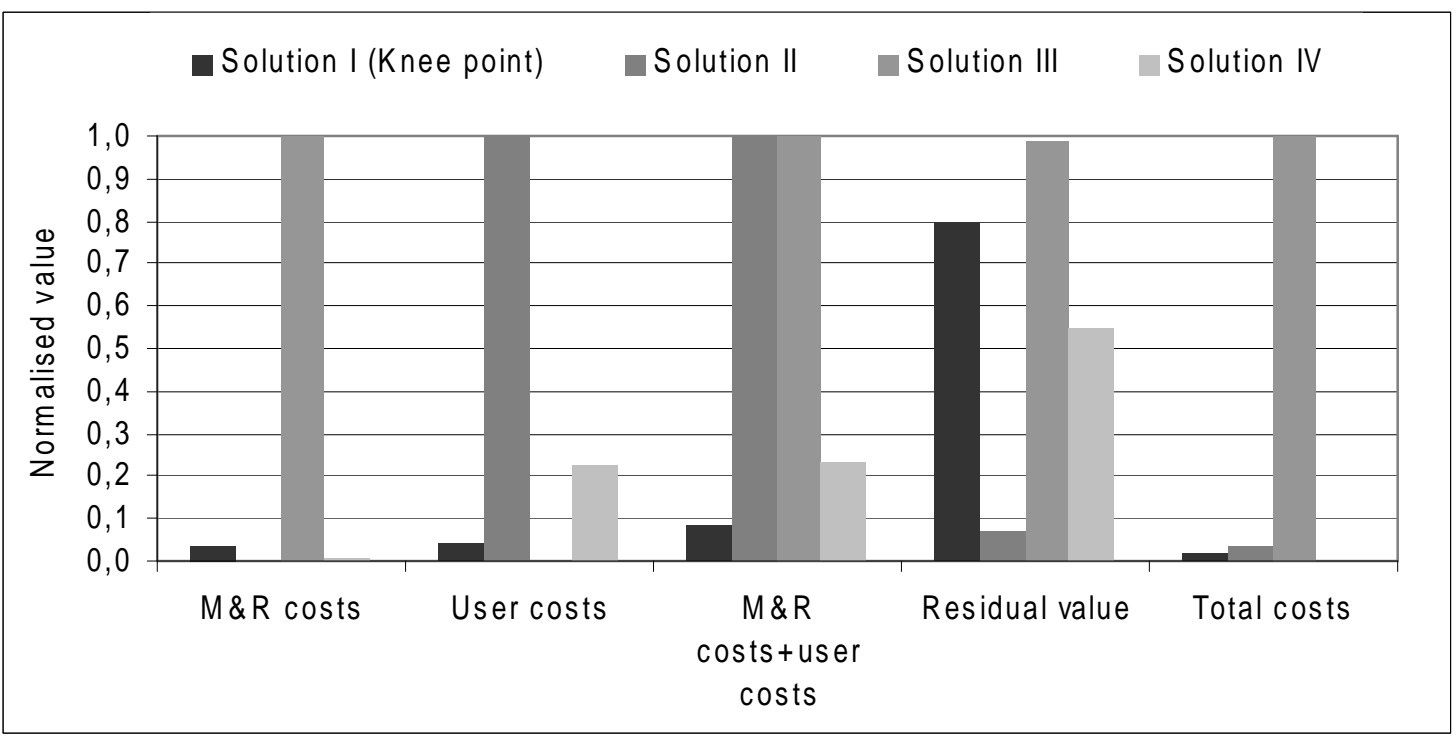

Figure 2-9 - Normalised costs throughout the planning time-span of 20 years 


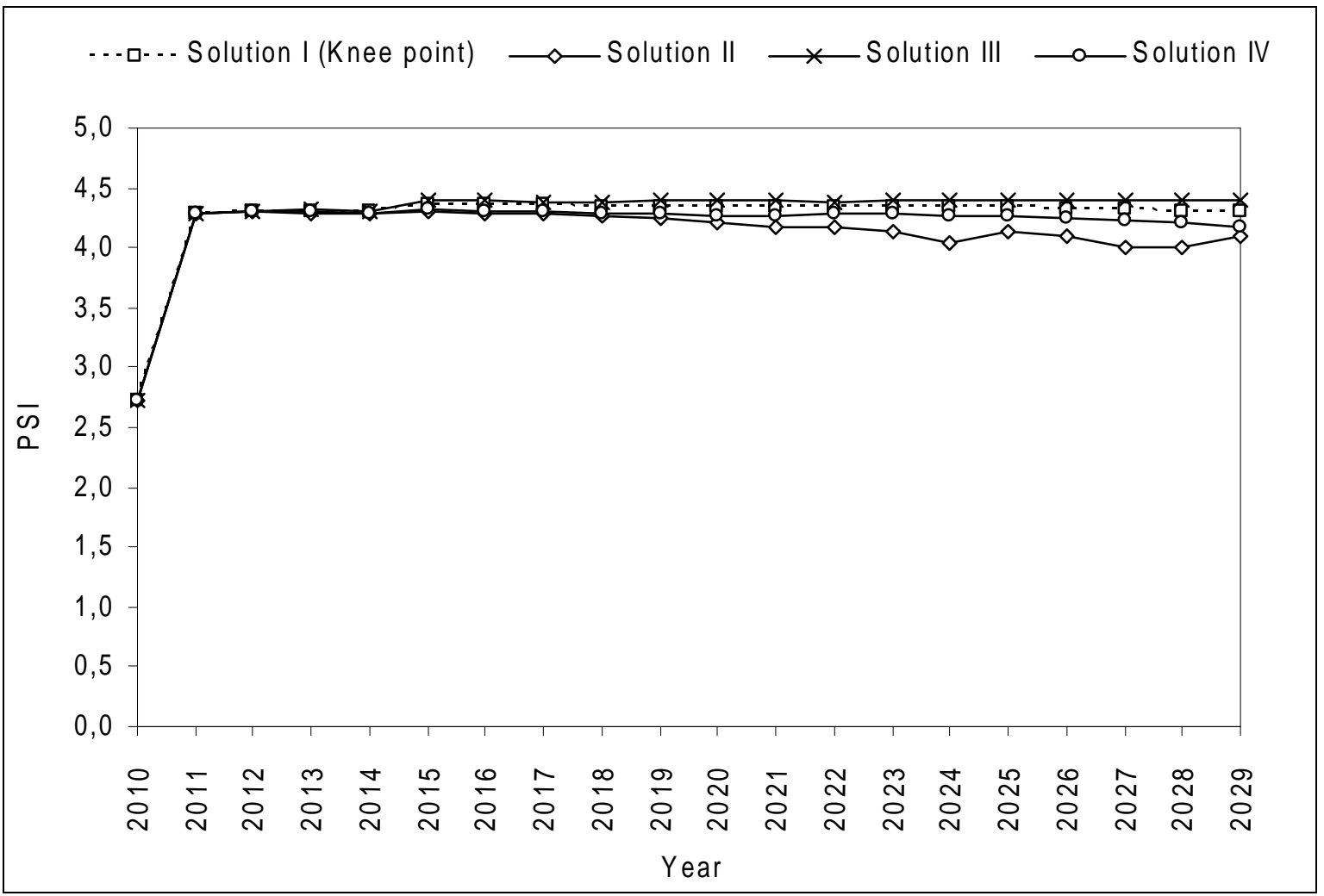

Figure 2-10 - PSI average value for all the road network pavements

In addition to these summarised results, the MODAT provides extensive information about the M\&R strategy to be implemented for each road section. To analyse these road section-linked results, four road sections were chosen with different attributes in the present year. Table 2.5 illustrates the attributes of these four road sections including their present PSI value. In Table 2.6 the M\&R operations to be applied are presented in the four road sections considering the four M\&R solutions of the Pareto frontier. Figure 2.11 represents the predicted evolution of the PSI value over the years for pavement section 34 of municipal road EM 514 as a consequence of the execution of the M\&R plan. For this pavement section, which has a PSI value of 3.67, if solution I of MODAT is adopted, the same M\&R operation 2 (non-structural maintenance) would be applied in years 2012 and 2019. If solution II of MODAT is adopted the two M\&R operations 
would be the same that were allocated considering solution I (M\&R operation 2) but would be applied in different years (2013 and 2027). If solution IV of MODAT is adopted the two M\&R operations would be the same that were allocated considering solutions I and II (M\&R operation 2) but would be applied in different years (2012 and 2024). In terms of $M \& R$ operations it is a solution located between the other two solutions, as expected, taking into account the weights that were considered. If solution III of MODAT is adopted the recommended M\&R operations are very different. The MODAT recommends the application of three M\&R operations 5 (major rehabilitation) in years 2012, 2016, and 2020, and one M\&R operation 4 (medium rehabilitation) in year 2024. In this solution the $M \& R$ operations are more and heavier because this solution corresponds to the minimization of user costs which means that the pavement quality must be always high.

An identical analysis could be made for pavement section 22 of municipal road EM 509 (see Table 2.6 and Figure 2.12), which has a PSI value of 3.50. If solution I of MODAT is adopted the M\&R operation 3 (minor rehabilitation) would be applied in year 2011 and M\&R operation 2 (non-structural maintenance) would be applied in year 2022. If solution II of MODAT is adopted the same M\&R operation 2 (non-structural maintenance) would be applied in years 2011 and 2021. If solution IV of MODAT is adopted the two M\&R operations would be the same that were allocated considering the solution II (M\&R operation 2) but the second $M \& R$ would be applied earlier (in year 2018 instead of year 2021). In terms of M\&R operations it is a solution located between the other two solutions, as expected, taking into account the weights that were considered. If solution III is adopted the recommended M\&R operations are more and 
heavier, as appended for pavement section 34 of municipal road EM 514. In this case the MODAT recommends the application of four $M \& R$ operations 5 (major rehabilitation) in years 2011, 2015, 2019, and 2023.

Table 2-5 - Attributes of road sections

\begin{tabular}{ccccc}
\hline Attributes & \multicolumn{4}{c}{ Sections } \\
\hline Municipal road & EM 508 & EM 506 & EM 509 & EM 514 \\
Section_ID1 & 14 & 4 & 22 & 34 \\
Section_ID2 & 3015050019 & 3015030012 & 3025080001 & 3025140017 \\
Road_class & Local dist. & Local dist. & Local dist. & Local dist. \\
Length (m) & 1200.00 & 2067.00 & 700.00 & 600.00 \\
Width (m) & 5.00 & 5.00 & 5.00 & 5.00 \\
Subgrade_CBR (\%) & 10 & 10 & 10 & 10 \\
Thickness_of_pavement_layers (m) & 0.26 & 0.28 & 0.26 & 0.26 \\
Structural_number & 1.91 & 1.91 & 1.91 & 1.91 \\
Age_of_pavements (years) & 28 & 25 & 3 & 3 \\
Annual_average_daily_traffic & 38 & 260 & 64 & 25 \\
Annual_average_daily_heavy_traffic & 25 & 60 & 15 & 12 \\
Annual_growth_average_tax & 0.03 & 0.03 & 0.03 & 0.03 \\
Truck_factor & 2.00 & 2.00 & 2.00 & 2.00 \\
Cracked_area (\%) & 23.00 & 8.00 & 0.00 & 2.20 \\
Alligator_cracked_area (\%) & 8.00 & 0.00 & 0.00 & 0.00 \\
Potholes_area (\%) & 19.00 & 0.00 & 0.00 & 0.00 \\
Ravelling_area (\%) & 0.00 & 61.00 & 0.00 & 0.00 \\
Patching_area (\%) & 50.00 & 29.00 & 0.00 & 0.00 \\
Average_rut_depth (mm) & 0.00 & 0.00 & 0.00 & 0.00 \\
IRI (mm/km) & 3500 & 3500 & 5500 & 3500 \\
PSI ${ }_{0}$ & 1.88 & 1.90 & 3.50 & 3.67 \\
\hline
\end{tabular}


Table 2-6 - M\&R operations to be applied in road sections

\begin{tabular}{|c|c|c|c|c|c|c|c|c|c|c|c|c|c|c|c|c|c|c|c|c|c|}
\hline \multirow[b]{2}{*}{ Section } & \multirow[b]{2}{*}{$\mathbf{P S I}_{0}$} & \multicolumn{20}{|c|}{ Year } \\
\hline & & 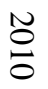 & $\begin{array}{l}\stackrel{ }{\ominus} \\
=\end{array}$ & $\underset{N}{\stackrel{N}{\ominus}}$ & $\underset{\omega}{\stackrel{N}{\varrho}}$ & $\stackrel{N}{\stackrel{N}{\oplus}}$ & $\begin{array}{l}\stackrel{N}{O} \\
\text { ur }\end{array}$ & $\begin{array}{l}\stackrel{N}{\varrho} \\
\sigma\end{array}$ & 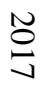 & $\underset{\infty}{\stackrel{N}{\varrho}}$ & $\frac{N}{\varrho}$ & $\begin{array}{l}\text { No } \\
\text { N্}\end{array}$ & 옹 & $\begin{array}{l}\text { N } \\
\text { N }\end{array}$ & $\underset{\text { స్ }}{\text { స్ }}$ & $\begin{array}{l}\text { N } \\
\stackrel{N}{+}\end{array}$ & $\begin{array}{l}\text { No } \\
\text { N } \\
\text { un }\end{array}$ & $\begin{array}{l}\text { N } \\
\text { N }\end{array}$ & $\begin{array}{l}\text { N } \\
\text { N }\end{array}$ & $\begin{array}{l}\text { N } \\
\stackrel{\infty}{\infty}\end{array}$ & $\begin{array}{l}\text { N } \\
\text { N్}\end{array}$ \\
\hline 14 & 1,88 & 5 & 1 & 1 & 1 & 1 & 2 & 1 & 1 & 1 & 1 & 2 & 1 & 1 & 1 & 1 & 2 & 1 & 1 & 1 & 1 \\
\hline 4 & 1,90 & 5 & 1 & 1 & 1 & 1 & 1 & 1 & 1 & 1 & 1 & 1 & 2 & 1 & 1 & 1 & 1 & 1 & 1 & 1 & 1 \\
\hline \multicolumn{22}{|c|}{ Solution II $\left(w_{A C}=1.00, w_{U C}=0.00, w_{R V}=0.00\right)$} \\
\hline 14 & 1,88 & 5 & 1 & 1 & 1 & 1 & 1 & 1 & 1 & 1 & 1 & 1 & 1 & 1 & 1 & 1 & 1 & 1 & 1 & 1 & 1 \\
\hline 4 & 1,90 & 5 & 1 & 1 & 1 & 1 & 1 & 1 & 1 & 1 & 1 & 1 & 1 & 1 & 1 & 1 & 1 & 1 & 1 & 1 & 1 \\
\hline 22 & 3,50 & 1 & 2 & 1 & 1 & 1 & 1 & 1 & 1 & 1 & 1 & 1 & 2 & 1 & 1 & 1 & 1 & 1 & 1 & 1 & 1 \\
\hline 34 & 3,67 & 1 & 1 & 1 & 2 & 1 & 1 & 1 & 1 & 1 & 1 & 1 & 1 & 1 & 1 & 1 & 1 & 1 & 2 & 1 & 1 \\
\hline 22 & 3,50 & 1 & 5 & 1 & 1 & 1 & 5 & 1 & 1 & 1 & 5 & 1 & 1 & 1 & 5 & 1 & 1 & 1 & 1 & 1 & 1 \\
\hline 34 & 3,67 & 1 & 1 & 3 & 1 & 1 & 1 & 5 & 1 & 1 & 1 & 5 & 1 & 1 & 1 & 5 & 1 & 1 & 1 & 1 & 1 \\
\hline \multicolumn{22}{|c|}{ Solution IV $\left(w_{A C}=0.50, w_{U C}=0.50, w_{R V}=0.00\right)$} \\
\hline 14 & 1,88 & 5 & 1 & 1 & 1 & 1 & 1 & 1 & 1 & 1 & 1 & 1 & 1 & 1 & 1 & 1 & 1 & 1 & 1 & 1 & 1 \\
\hline 4 & 1,90 & 5 & 1 & 1 & 1 & 1 & 1 & 1 & 1 & 1 & 1 & 1 & 1 & 1 & 1 & 1 & 1 & 1 & 1 & 1 & 1 \\
\hline 22 & 3,50 & 1 & 2 & 1 & 1 & 1 & 1 & 1 & 1 & 2 & 1 & 1 & 1 & 1 & 1 & 1 & 1 & 1 & 1 & 1 & 1 \\
\hline 34 & 3,67 & 1 & 1 & 2 & 1 & 1 & 1 & 1 & 1 & 1 & 1 & 1 & 1 & 1 & 1 & 2 & 1 & 1 & 1 & 1 & 1 \\
\hline
\end{tabular}

KEY (M\&R actions):

$\mathbf{1}$ - Do nothing; 2 - Non structural maintenance; 3 - Minor rehabilitation; 4 - Medium rehabilitation; 5

- Major rehabilitation

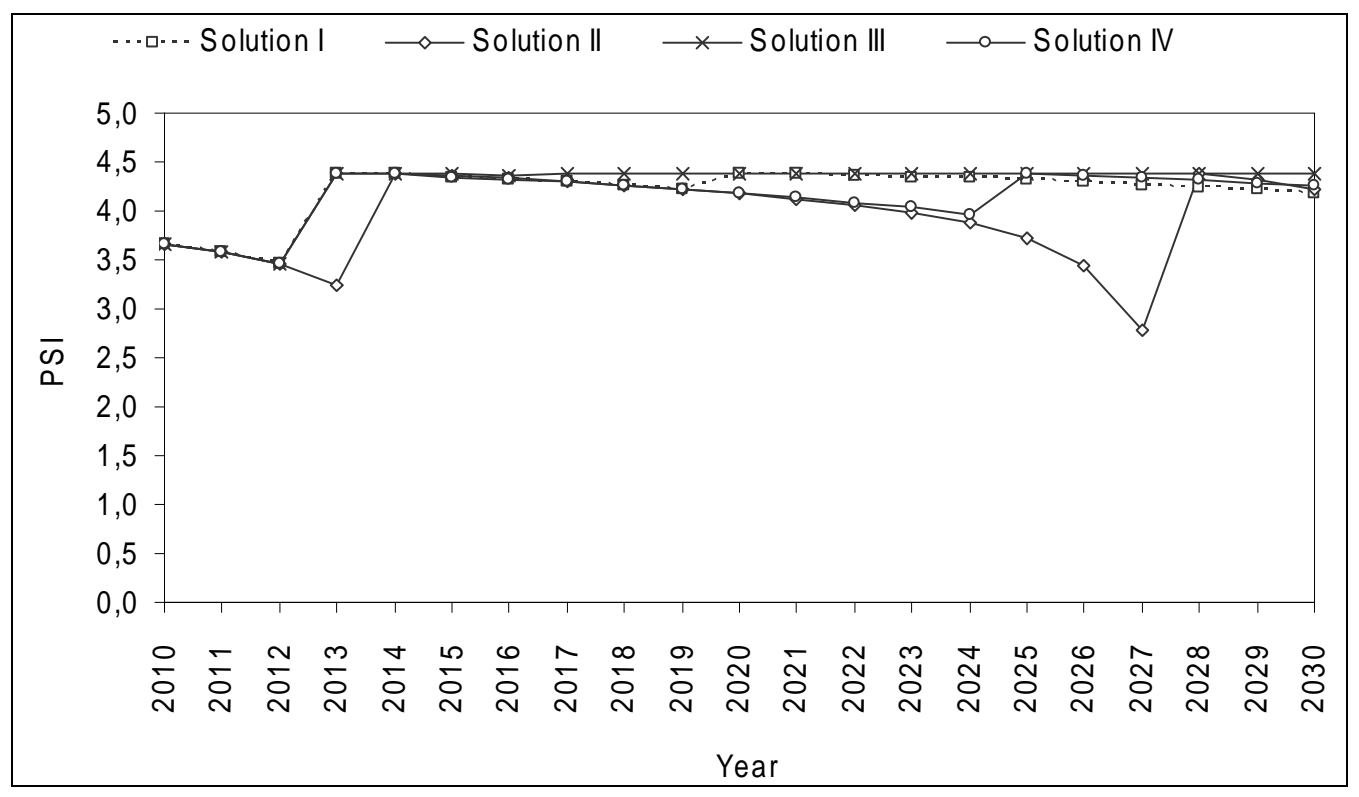

Figure 2-11 - Evolution of PSI for pavement section 34 of municipal road EM 514 


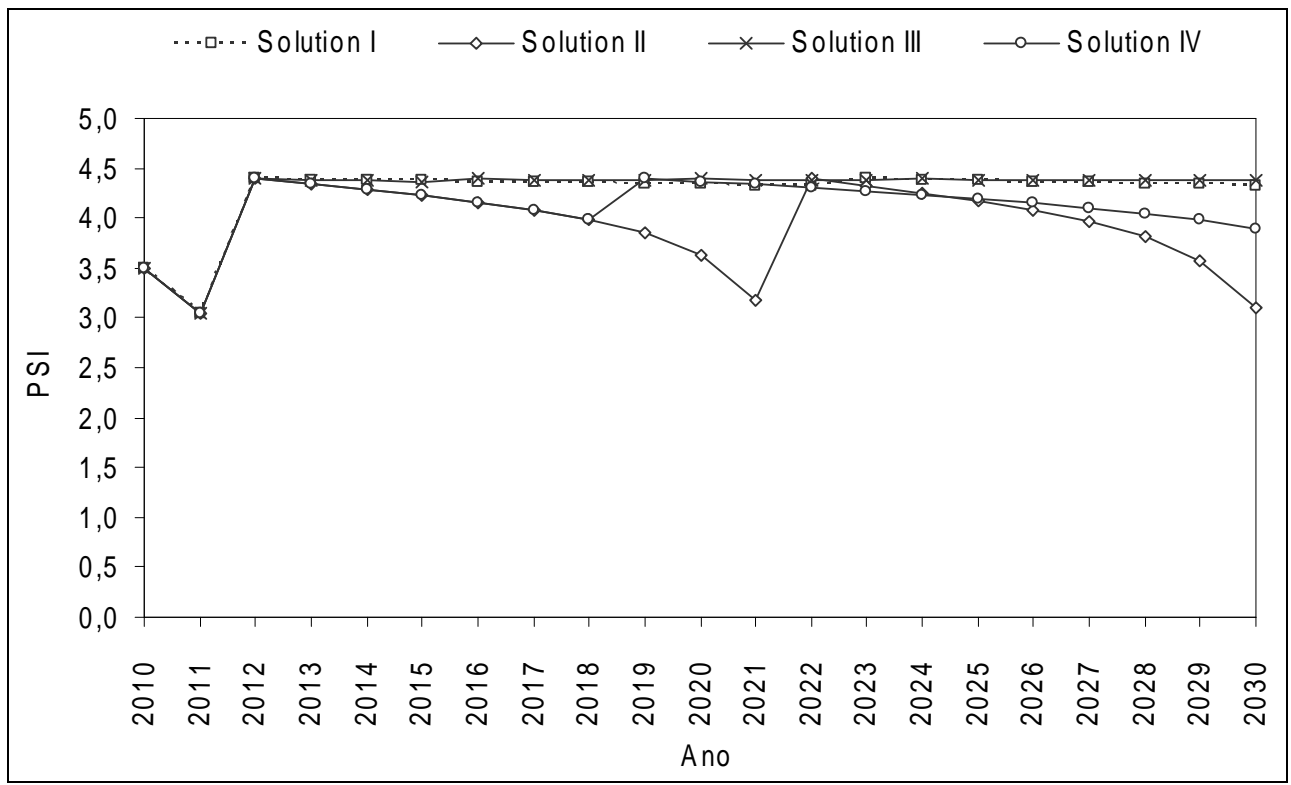

Figure 2-12 - Evolution of PSI for pavement section 22 of municipal road EM 509

\subsection{Conclusions}

In this chapter, we have presented the Multi-Objective Decision-Aid Tool (MODAT) incorporating several objectives into the same optimization model, can solve the pavement management problem for the case involving major rehabilitation interventions. The MODAT, as well as the decision-aid tool currently in use in the Oliveira do Hospital's PMS, which has the objective of minimising costs over a selected planning time-span, allows closing of the gap between project and network management. This is made possible by replacing the traditional microscopic approach, which uses models that include independent variables explaining the pavement deterioration process (i.e. layer thickness, resilient modulus, asphalt characteristics, traffic, climate, etc.), with a macroscopic approach that uses models for predicting the 
future condition of the pavement based on measured condition data (i.e. cracking, ravelling, potholes, patching, rutting, longitudinal roughness, skid resistance, traffic, climate, etc.). The macroscopic approach requires that each road section is homogeneous in terms of quality, pavement structure, traffic and climate. It is assumed that each road section possesses one performance curve with any estimated future performance value representing the overall average pavement condition. The MODAT considers the pavement performance model used in the AASHTO flexible pavement design method but any other preferred model can be used as well. In the implementation of an optimum solution recommended by the MODAT, a field review must be conducted to identify continuous road sections with the same or identical M\&R interventions with the goal of aggregating them into the same road project. It is recommended that whenever actual pavement performance data becomes available, it should replace the predicted PSI values from the AASHTO pavement performance model. Any other appropriate pavement condition indicator can easily be used as an alternative in this methodology. It is further recommended that the MODAT is applied as often as necessary (annually or bi-annually) to obtain revised optimum M\&R plans that would incorporate the impact of any recent changes that might have taken place in the pavement network.

The MODAT constitutes a new useful tool to help the road engineers in their task of maintenance and rehabilitation of pavements. This new approach allows PMS to become interactive decision-aid tools, capable of providing road administrations with answers to "what-if" questions in short periods of time. In the future, because the MODAT is an open system, some modifications could be made to better serve the needs 
of road engineers. In the near future, our research in the pavement management field will follow two main directions. First, the MODAT will be applied to a national road network, with heavier traffic, to see if the results are identical. Second, pavement performance models will be developed using pavement performance data available in some road network databases and will be incorporated into MODAT for future applications to road networks.

\section{APPENDIX 1: NOTATION}

$A C_{r s t}$ is the agency cost for applying operation $r$ to road section $s$ in year $t$;

$B_{t}$ is the budget for year $t$;

$C_{0}$ is the total cracked pavement area in year $0\left(\mathrm{~m}^{2} / 100 \mathrm{~m}^{2}\right)$;

$C_{n}^{e}$ is the structural coefficient of layer $n$;

$C_{n}^{d}$ is the drainage coefficient of layer $n$;

$C_{s, \text { const }}$ is the cost of construction or the cost of the last rehabilitation of pavement section $s$;

$d$ is the discount rate;

$D_{0}$ is the total disintegrated area (with potholes and ravelling) in year $0\left(\mathrm{~m}^{2} / 100 \mathrm{~m}^{2}\right)$;

$H_{n}$ is the thickness of layer $n(\mathrm{~mm})$;

$I R I_{0}$ is the pavement longitudinal roughness in year $0(\mathrm{~mm} / \mathrm{km})$;

$M_{R}$ is the subgrade resilient modulus (pounds per square inch); 
$N_{\max }$ is the maximum number of M\&R operations that may occur in road section $s$ over the planning time-span;

$W_{80}$ is the number of $80 \mathrm{kN}$ equivalent single axle load applications estimated for a selected design period and design lane;

$P a_{0}$ is the pavement patching in year $0\left(\mathrm{~m}^{2} / 100 \mathrm{~m}^{2}\right)$;

$\mathrm{PSI}_{t}$ is the Present Serviceability Index in year $t$;

$P S I_{s, \text { rehab }}$ is the $P S I$ value after the application of a rehabilitation action in pavement section $s$;

$R$ is the number of alternative $\mathrm{M} \& \mathrm{R}$ operations;

$R_{0}$ is the mean rut in year $0(\mathrm{~mm})$;

$R V_{s, T+1}$ is the residual value for the pavement of section $s$;

$S$ is the number of road sections;

$S_{0}$ is the combined standard error of the traffic prediction and performance prediction;

$S N_{t}$ is the structural number of a road pavement in year $t$;

$T$ is the number of years in the planning time-span;

$t c$ is the annual average growth rate of heavy traffic;

$T M D A_{p}$ is the annual average daily heavy traffic in the year of construction or the last rehabilitation, in one direction and per lane;

$U C_{s t}$ is the user cost for road section $s$ in year $t$;

$V O C_{t}$ are the vehicle operation costs in year $t(€ / \mathrm{km} / \mathrm{vehicle})$; 


\section{Chapter 2}

$X_{r s t}$ is equal to one if operation $r$ is applied to section $s$ in year $t$, and is equal to zero otherwise;

$Y_{t}$ is the time since the pavement's construction or its last rehabilitation (years);

$Z_{R}$ is the standard normal deviate;

$P S I_{s t}$ are the pavement condition for section $s$ in year $t$;

$\overline{P S I}$ is the warning level for the pavement condition;

$\alpha$ is the average heavy traffic damage factor or simply truck factor;

$\triangle P S I_{t}$ is the difference between the initial value of the present serviceability index $\left(P S I_{0}\right)$ and the value of the present serviceability index in year $t\left(P S I_{t}\right)$;

$\Psi a$ are the agency cost functions;

$\Psi p$ are the pavement condition functions;

$\Psi r$ are the residual value functions;

$\Psi u$ are the user cost functions;

$\Omega$ are the feasible operations sets. 


\section{APPENDIX 2: DECISION-AID TOOL MODEL}

For explanation of notation, refer to the Appendix 1.

\section{A.2.1 Objective functions}

Minimise agency costs (maintenance and rehabilitation costs)

Minimise $A C=\sum_{r=1}^{R} \sum_{s=1}^{S} \sum_{t=1}^{T} \frac{1}{(1+d)^{t}} \cdot A C_{r s t} \cdot X_{r s t}$

Minimise user costs

Minimise $U C=\sum_{s=1}^{S} \sum_{t=1}^{T} \frac{1}{(1+d)^{t}} \cdot U C_{s t}$

Maximise the residual value of pavements at the end of the planning time-span

Maximise $R V=\sum_{s=1}^{S} \frac{1}{(1+d)^{T+1}} \cdot R V_{s, T+1}$

\section{A.2.2 Constraints}

Pavement condition functions

$\boldsymbol{P S I}_{s t}=\Psi p\left(\boldsymbol{P S I}_{s 0}, X_{1 s 1}, \ldots, X_{1 s t}, \ldots, X_{R s 1}, \ldots, X_{R s t}\right), s=1, \ldots, S ; t=1, \ldots, T$ 
Warning level constraints

$\boldsymbol{P S I}_{s t} \geq \overline{\mathrm{PSI}}_{s}, \quad s=1, \ldots, S ; t=1, \ldots, T$

Feasible operation sets

$X_{r s t} \in \Omega\left(\boldsymbol{P S \boldsymbol { I } _ { s t }}\right), r=1, \ldots, R ; s=1, \ldots, S ; t=1, \ldots, T$

Annual operations constraints

$\sum_{r=1}^{R} X_{r s t}=1, s=1, \ldots, S ; t=1, \ldots, T$

Agency cost functions

$A C_{r s t}=\Psi a\left(\boldsymbol{P S I} \boldsymbol{I}_{s t}, X_{r s t}\right), r=1, \ldots, R ; s=1, \ldots, S ; t=1, \ldots, T$

User cost functions

$U C_{s t}=\Psi u\left(\boldsymbol{P S I _ { s t }}\right), s=1, \ldots, S ; t=1, \ldots, T$

Residual value functions

$R V_{s, T+1}=\Psi r\left(\boldsymbol{P S I _ { s , T + 1 }}\right), s=1, \ldots, S$ 
Annual budget constraints

$\sum_{r=1}^{R} \sum_{s=1}^{S} A C_{r s t} \cdot X_{r s t} \leq B_{t}, t=1, \ldots, T$

Planning time-span operations constraints

$\sum_{r=2}^{R} \sum_{t=1}^{T} X_{r s t} \leq N \max _{s}, \forall s=1, \ldots, S$ 
APPENDIX 3: PAVEMENT CONDITION AND OTHER FUNCTIONS USED IN THE MODEL

\section{A.3.1 Pavement condition functions}

$P S I_{0}=5 \cdot e^{-0.000065 \cdot I R I_{0}}-0.000535 \cdot R_{0}{ }^{2}-0.21 \cdot\left(C_{0}+D_{0}+P a_{0}\right)^{0.5}$

$P S I_{t}=P S I_{0}-(4.2-1.5) \cdot 10^{\left[\left(\log _{10}\left(W_{18}\right)-Z_{R} \cdot S_{0}-9.36 \log _{10}(S N+1)+0.22-2.32 \log _{10}\left(M_{R}\right)+8.07\right) \cdot\left(0.4+\frac{1094}{(S N+1)^{5.19}}\right)\right]}$

$S N_{t}=\sum_{n=1}^{N} H_{n} \times C_{n}^{e} \times C_{n}^{d}$

$W_{80_{t}}=365 \times T M D A_{p} \times \frac{(1+t c)^{Y_{t}}-1}{t c} \times \alpha$

\section{A.3.2 User cost function}

$V O C_{t}=1.20487-0.49116 \times P S I_{t}+0.05458 \times P S I_{t}^{2}$

\section{A.3.3 Residual value of pavements function}

$$
R V_{s, T+1}=C_{s, \text { const }} \cdot \frac{P S I_{s, T+1}-1.5}{P S I_{s, \text { rehab }}-1.5}
$$




\section{References}

AASHTO (1993). Guide for design of pavement structures. American Association of State Highway and Transportation Officials, Washington, D.C., USA, 4th ed., 1-640.

Abaza, K. (2005). Performance-based models for flexible pavement structural overlay design. Journal of Transportation Engineering, 131(2), 149-159.

Abaza, K. (2006). Iterative linear approach for nonlinear nonhomogenous stochastic pavement management models. Journal of Transportation Engineering, 132(3), 244256.

Abaza, K., Ashur, S., Abu-Eisheh, S. and Al-Khatib, I. (2004). Integrated pavement management system with a markovian prediction model. Journal of Transportation Engineering, 130(1), 24-33.

Abaza, K., Ashur, S., Abu-Eisheh, S. and Rabay'A, A. (2001). Macroscopic optimum system for management of pavement rehabilitation. Journal of Transportation Engineering, 127(6), 493-500.

AIPCR (2000). Highway development and management, volume one - overview of HDM-4. World Road Association, Paris, France, I, 1-53.

Andersson, P. (2007). Multi-year maintenance optimization for paved public roads segment based modelling and price-directive decomposition. $\mathrm{PhD}$ Thesis, Linköping University, Linköping, Sweden, 1-214. 
Black, M., Brint, A. and Brailsford, J. (2005). Comparing probabilistic methods for the asset management of distributed items. Journal of Infrastructure Systems, 11(2), 102109.

Campo, J. and Orden, H. (2004). Integration of improvement works into highway management systems. Proceedings of the 2nd European Pavement and Asset Management Conference, Berlin, Germany, CD Ed., 1-10.

C-SHRP (2002). Pavement structural design practices across Canada. C-SHRP Technical Brief No. 23, Canadian Strategic Highway Research Program, Ottawa. Ontario, Canada, 1-10.

Das, I. (1999). On characterizing the "knee" of the Pareto curve based on normal boundary intersection. Structural and Multidisciplinary Optimization, 18, 107-115.

David, J., Loton, T., Gunvaldson, E., Bowen, C., Coad, N. and Jefford, D. (2006). Professional Visual Studio 2005 Team System. Wiley Publishing, Inc., Indiana, USA, $1-660$.

Deb, K. (2008). Multi-objective optimization using evolutionary algorithms, Wiley, West Sussex, United Kingdom, 2008.

Ferreira, A. (2001). Pavement maintenance optimization of road networks. PhD Thesis, Coimbra University, Coimbra, Portugal, 1-383 (in Portuguese).

Ferreira, A. (2005). A life-cycle cost analysis system for transportation asset management systems. Proceedings of the 16th IASTED International Conference on Modelling and Simulation, Cancun, México, CD Ed., chapter 459-093.pdf, 234-239. 
Ferreira, A., Antunes, A. and Picado-Santos, L. (2002a). Probabilistic segment-linked pavement management optimization model. Journal of Transportation Engineering, 128(6), 568-577.

Ferreira, A. and Meneses, S. (2006). A deterministic optimization model proposed to be used in the PMS of a Portuguese municipality. Proceedings of the Fifth International Conference on Engineering Computational Technology, Las Palmas de Gran Canaria, Spain, CD Ed., 1-15.

Ferreira, A. and Duarte, A. (2006). A GIS-based infrastructure management system for municipalities. Proceedings of the Institution of Civil Engineers-Municipal Engineer, 159(2), 113-120.

Ferreira, A. and Meneses, S. (2010). Multi-objective decision-aid tool for pavement maintenance management. Proceedings of the International Workshop on Applied Modelling \& Simulation, Búzios, Brasil, CD Ed., 1-10.

Ferreira, A., Meneses, S. and Vicente, F. (2009a). Pavement management system for Oliveira do Hospital, Portugal. Proceedings of the Institution of Civil EngineersTransport, 162(3), 157-169.

Ferreira, A., Meneses, S. and Vicente, F. (2009b). Alternative decision-aid tool for pavement management. Proceedings of the Institution of Civil Engineers-Transport, 162(1), 3-17.

Ferreira, A., Picado-Santos, L. and Antunes, A. (2002b). A segment-linked optimization model for deterministic pavement management systems. The International Journal of Pavement Engineering, 3(2), 95-105. 
Ferreira, A., Picado-Santos, L., Wu, Z. and Flintsch, G. (2009). Selection of pavement performance models for use in the Portuguese PMS. International Journal of Pavement Engineering, Taylor \& Francis. Submitted for publication.

FICO (2009). Xpress-optimizer - reference manual, release 20.00. Fair Isaac Corporation, Leamington Spa, Warwickshire, UK, 1-470.

Fwa, T., Chan, W., and Hoque, K. (2000). Multiobjective optimization for pavement maintenance programming. Journal of Transportation Engineering, 126(5), 367-374.

Gendreau, M. and Potvin, J. (2005). Metaheuristics in combinatorial optimization. Annals of Operations Research, 140(1), 189-213.

Golabi, K., Kulkarni, R. and Way, G. (1982). A state-wide pavement management system. Interfaces, 12(6), 5-21.

Hawker, L. and Abell, R. (2000). Selection and prioritisation of maintenance works on major roads in England. Proceedings of the 1st European Pavement Management Systems Conference, Budapest, Hungary, CD Ed., 1-8.

Holland, J. (1975). Adaptation in natural and artificial systems. University of Michigan Press, Ann Arbor, MI, USA.

Hwang, C. and Masud, A. (1979). Multiple objective decision making - methods and applications: a state-of-the-art survey, Springer-Verlag, Berlin, Germany.

IBM (2009). IBM ILOG CPLEX 12.1 - reference manual. IBM Corporation, Armonk, New York, USA, 1-884.

Ihs, A. and Sjögren, L. (2003). An overview of HDM-4 and the Swedish pavement management system. VTI - Infrastructure Maintenance, Linköping, Sweden, 1-31. 
Iniestra, J. and Gutiérrez, J. (2009). Multi-criteria decisions on interdependent infrastructure transportation projects using an evolutionary-based framework. Applied Soft Computing, 9(2), 512-526.

Kaliszewski, I. (2004). Out of the mist-towards decision-maker-friendly multiple criteria decision making support. European Journal of Operational Research, 158(2), 293-307.

Kennedy, C. and Johns, A. (2001). Partnering in the provision of a highway management system. Proceedings of the Institution of Civil Engineers-Municipal Engineer, 145(3), 227-233.

Kulkarni, R., Miller, D., Ingram, R., Wong, C. and Lorenz, J. (2004). Need-based project prioritisation: alternative to cost-benefit analysis. Journal of Transportation Engineering, 130(2), 150-158.

Lang, J. and Dahlgren, J. (2001). Prediction model in the Swedish PMS. Proceedings of the Fifth International Conference on Managing Pavements, CD Ed., Seattle, Washington, USA, chapter 100.pdf, 1-10.

Lang, J. and Potucek, J. (2001). Pavement management systems in Sweden. Proceedings of the Fifth International Conference on Managing Pavements, CD Ed., Seattle, Washington, USA, chapter 097.pdf, 1-12.

Madanat, S., Park, S. and Kuhn, K. (2006). Adaptive optimization and systematic probing of infrastructure system maintenance policies under model uncertainly. Journal of Infrastructure Systems, 12(3), 192-198. 
Marler, R., and Arora, J. (2004). Survey of multi-objective optimization methods for engineering. Structural and Multidisciplinary Optimization, 26, 369-395.

Mansouri, S. (2005). A multi-objective genetic algorithm for mixed-model sequencing on JIT assembly lines. European Journal of Operational Research, 167, 696-716.

Mbwana, J. and Turnquist, M. (1996). Optimization modelling for enhanced networklevel pavement management system. Transportation Research Record 1524, Transportation Research Board, 76-85.

Meneses, S. and Ferreira, A. (2005). Implementation of a pavement management system for Oliveira do Hospital's road network. Proceedings of the Fourth International Symposium on Maintenance and Rehabilitation of Pavements and Technological Control, Belfast, Ireland, CD Ed., chapter 118.pdf, 1-9.

Meneses, S. and Ferreira, A. (2010). Multi-objective decision-aid tool for pavement management systems. Proceedings of the $12^{\text {th }}$ World Conference on Transport Research, Lisbon, Portugal, CD Ed., 1-11.

Michalewicz, Z. and Fogel, D. (2004). How to solve it: modern heuristics. SpringerVerlag, Berlin, Germany.

Miettinen, K. (1999). Nonlinear multi-objective optimization, Kluwer Academic Publishers, Boston, USA, 1-324.

Nunoo, C. and Mrawira, D. (2004). Shuffled complex evolution algorithms in infrastructure works programming. Journal of Computing in Civil Engineering, 18(3), 257-266. 
Parida, M., Aggarwal, S. and Jain, S. (2005). Enhancing pavement management systems using GIS. Proceedings of the Institution of Civil Engineers-Transport, 158(2), 107113.

Picado-Santos, L., Ferreira, A., Antunes, A., Carvalheira, C., Santos, B., Bicho, M. H., Quadrado, I. and Silvestre, S. (2004). The pavement management system for Lisbon. Proceedings of the Institution of Civil Engineers-Municipal Engineer, 157(3), 157165.

Picado-Santos, L., Ferreira, A., Costa Pereira, F. and Conceição Azevedo, M. (2006). The evaluation of maintenance and rehabilitation strategies in the pavement management system of the Portuguese road administration. Proceedings of the $4^{\text {th }}$ Portuguese Road Congress, Lisbon, Portugal, 1-10 (in Portuguese).

Randolph, N. and Gardner, D. (2008). Professional Visual Studio 2008. Wiley Publishing, Inc., Indiana, USA, 1-946.

Sebaaly, P. E., Hand, A., Epps, J. and Bosch C. (1996). Nevada's approach to pavement management. Transportation Research Record 1524, Transportation Research Board, Washington, D.C., 109-117.

Sinhal, R., Abell, R. and Ramdas, V. (2001). Use of whole life costs in network level assessments of road maintenance budgets. Proceedings of the Fifth International Conference on Managing Pavements, Seattle, USA, CD Ed., 1-14.

Stephenson, M., Epps, R. and Kennedy, C. (2004). Development of deterioration models for local authority roads. Proceedings of the Institution of Civil EngineersMunicipal Engineer 157(3), 167-172. 
Wang, K. and Zaniewski, J. (1996). 20/30 hindsight: the new pavement optimization in the Arizona state highway network. Interfaces, 26(3), 77-89.

Wong, W., He, G. and Luk, S. (2003). Development of road management systems in China. Proceedings of the Institution of Civil Engineers-Transport, 156(4), 179-188.

Wu, Z., Flintsch, G. (2009). Pavement preservation optimization considering multiple objectives and budget variability. Journal of Transportation Engineering, 135(5), 305-315.

Wu, Z., Flintsch, G., Ferreira, A. and Picado-Santos, L. (2009). Multi-criteria optimization applications in highway asset management. Journal of Transportation Engineering. Submitted for publication. 


\section{Chapter 3}

\section{Pavement maintenance}

programming considering two objectives: maintenance costs and

\section{user costs}

\subsection{Introduction}

An efficient PMS for a road network is one that would maintain the pavement sections at a sufficiently level of service and structural condition, allowing low user costs, but would require only a reasonably low budget and use of resources, and does not create any significant adverse impacts on the environment, safe traffic operations, and social and community activities (Fwa et al. 2000). Unfortunately, many of these are conflicting requirements and therefore, the decision process in programming maintenance and rehabilitation (M\&R) interventions involves multi-objective considerations (Wu and Flintsch 2009). For example, a road network administration 
may wish to find $M \& R$ interventions that minimise agency costs while at the same time minimise user costs. Nevertheless, any M\&R strategy that minimises user costs would require that pavements be maintained at a high level of service, which consequently will increase agency costs considerably.

Almost all the pavement maintenance programming tools currently in use are based on single-objective optimization. In these single-objective analyses, those requirements not selected as the objective function are imposed as constraints in the model formulation. This can be viewed as interference in the optimization process by artificially setting limits on selected problem parameters. As a result, the solutions obtained from these single-objective analyses are suboptimal compared with ones derived from multiobjective considerations (Fwa et al. 2000). In addition, only few applications have made use of multi-objective optimization techniques. Fwa et al. (2000) developed an optimization model with three objectives: the maximization of the work production; the minimization of the total maintenance cost; and the maximization of overall network pavement condition. The model was applied to four highway classes, each one with three need-urgency levels (high, medium, low), considering four M\&R interventions and a planning time-span of 45 working days. Wang et al. (2003) developed a different optimization model with two objectives: the maximization of the total M\&R effectiveness; and the minimization of the total M\&R disturbance cost. The model was applied to a small network of 10 road sections considering a planning time-span of five years. Wu and Flintsch (2009) developed another optimization model with two objectives: the maximization of the network level of service; and the minimization of the total M\&R cost. The model was applied to four pavement state quality types 
(excellent, good, fair and poor) considering four M\&R interventions and a planning time-span of 10 years. None of these multi-objective optimization models considers the minimization of user costs and a pavement performance model also used for pavement design which allows closing the gap between project and network management.

This chapter presents the development and implementation of a Multi-objective Decision-Aid Tool (MODAT) which considers two different objectives, the minimization of agency costs (maintenance and rehabilitation costs) and the minimization of user costs. The MODAT is tested with data from the PMS used by the main Portuguese concessionaire (Estradas de Portugal, S.A.), the institution that acted until 2007 as the Portuguese Road Administration (Picado-Santos et al. 2006, PicadoSantos and Ferreira 2007, Picado-Santos and Ferreira 2008, Ferreira et al. 2008, Trindade and Horta 2009, Ferreira et al. 2011).

\subsection{Background}

One of the main components of a PMS is the methodology used to select the best M\&R strategy taking into account the expected evolution of pavement quality. This methodology, realised in a Decision-Aid Tool (DAT), may be based on prioritisation (ranking) models (Sebaaly et al. 1996, Hawker and Abell 2000, Wong et al. 2003, Kulkarni et al. 2004) or optimization models (Golabi et al. 1982, Mbwana and Turnquist 1996, Wang and Zaniewski 1996, Ferreira et al. 2002a, Ferreira et al. 2002b, Abaza et al. 2004, Nunoo and Mrawira 2004, Picado-Santos et al. 2004, Abaza 2006, Madanat et al. 2006, Durango-Cohen and Tadepalli 2006, Gabriel et al. 2006, Abaza 
2007, Yoo and Garcia-Diaz 2008, Ferreira et al. 2009a, Ferreira et al. 2009b, Li and Sinha 2009, Li 2009, Jorge and Ferreira 2012).

In optimization models, the goal of the analysis can be the minimization of any combination between costs (agency costs, user costs, etc.) over a selected planning time-span subject to minimum quality level constraints (Golabi et al. 1982, Ferreira et al. 2002a, Ferreira et al. 2002b, Picado-Santos et al. 2004, Abaza et al. 2004, Abaza 2006, Madanat et al. 2006, Abaza 2007, Madanat et al. 2006, Durango-Cohen and Tadepalli 2006, Ferreira et al. 2009a, Jorge and Ferreira 2012), the maximization of the whole network quality or performance subject to annual budget constraints (Abaza et al. 2001, Nunoo and Mrawira 2004, Abaza 2006, Abaza 2007, Yoo and Garcia-Diaz 2008, Ferreira et al. 2009b, Li and Sinha 2009, Li 2009), or considering both at the same time (Fwa et al. 2000, Wang et al. 2003, Wu and Flintsch 2009). In these models, pavement condition data are used as model inputs, pavement performance models are used to predict future quality of pavements and annual budgets and minimum quality levels are constraints that must be assured. The pavement management problem is then formulated as an optimization model with variables representing the various $M \& R$ actions or operations. Basically, the optimal solution defines the amount and type of M\&R work to be applied to each road pavement.

The main weakness of prioritisation models is that they do not assure the selection of the best possible $M \& R$ strategy when considering long planning time-spans (for example 20 years). This can only be achieved if the approach followed for selecting the M\&R strategy is based on optimization techniques. The Arizona Department of Transportation and Woodward-Clyde Consultants, using optimization techniques, won 
the 1982 Franz Edelman Management Science Achievement Award from the Institute of Management Sciences, now the Institute for Operations Research and the Management Sciences (INFORMS), for developing and implementing the Network Optimization System of the Arizona PMS (Golabi et al. 1982). More recently, the Lisbon City Council and the Department of Civil Engineering of the University of Coimbra, also using optimization techniques, won the Parkman Medal awarded by the Institution of Civil Engineers from England for the best chapter published in the year 2004 on the practical aspects of the control or management, including project management of the design and/or construction of a specific scheme, for developing and implementing the Lisbon PMS (Picado-Santos et al. 2004).

Recently, researchers (Fwa et al. 2000, Kaliszewski 2004, Flintsch and Chen 2004, Wu and Flintsch 2009) have concluded that maintenance planning and programming requires optimization analysis involving multi-objective considerations. However, traditionally single-objective optimization techniques have been employed by pavement researchers and practitioners because of the complexity involved in multi-objective analysis. Other researchers (Fwa et al. 2000, Mansouri 2005, Deb 2008, Iniestra and Gutiérrez 2009) concluded that it is possible to develop a Multi-objective Decision-Aid Tool, incorporating into the same optimization model several objectives, for example one for minimization of maintenance costs and another for minimization of user costs using the concepts of Pareto optimal solution set and rank-based fitness evaluation (Pareto 1906, Goldberg 1989). 


\subsection{Proposed multi-objective decision-aid tool}

\subsubsection{Introduction}

The Multi-Objective Decision-Aid Tool (MODAT), an alternative Decision-Aid Tool to the one that forms part of the Estradas de Portugal's PMS (Figure 3.1), is constituted by the components shown in Figure 3.2: the objectives of the analysis; the data and the models about the road pavements; the constraints that the system must guarantee; and the results. Several objectives can be considered in the analysis, including the minimization of agency costs (maintenance and rehabilitation costs), the minimization of user costs, etc. The results of the application of the MODAT to a road network are constituted by the M\&R plan, the costs report, and the structural and functional quality report. The data and the models about the road pavements, and the constraints that the system must guarantee are described in the following section.

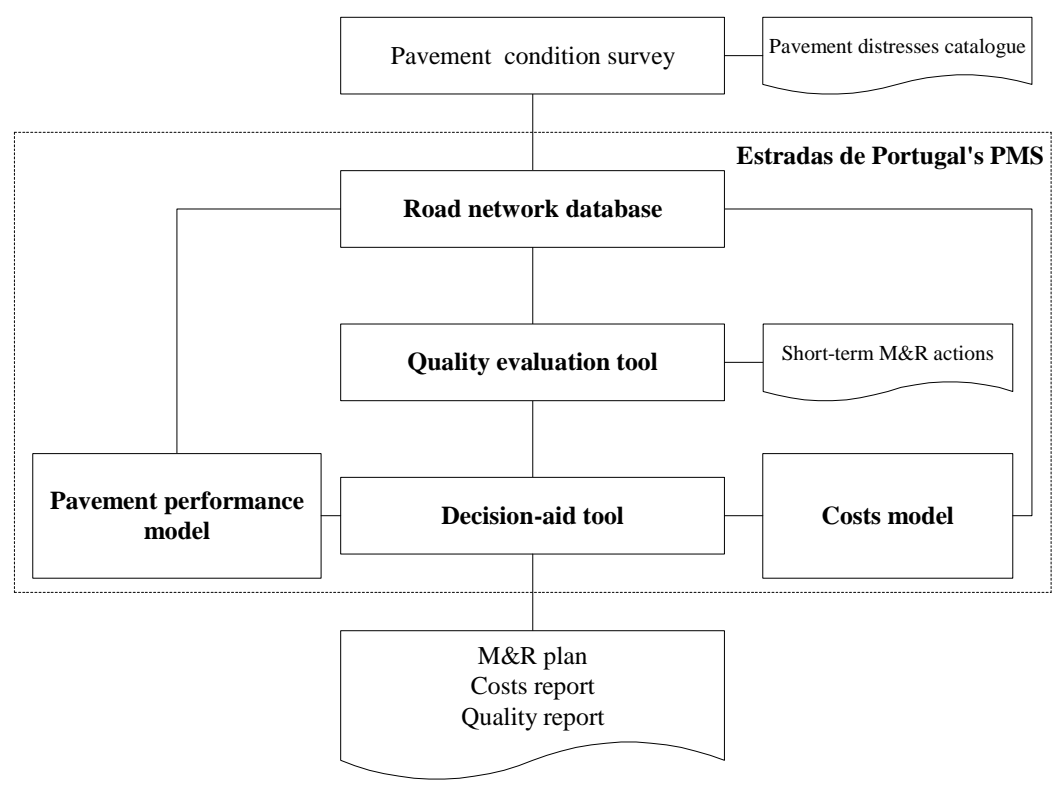

Figure 3-1 - Structure of the Pavement Management System 


\begin{tabular}{|l|c|}
\hline \multicolumn{2}{|c|}{ Minimisation of agency costs (maintenance and rehabilitation costs) } \\
Minimisation of user costs
\end{tabular}

Figure 3-2 - MODAT components

\subsubsection{Optimization model}

The notation used in the model formulation can be seen in Appendix I and details of the deterministic optimization model can be found in Appendix II. Equation (3.1) is one of the objective functions of the optimization model and expresses the minimization of agency costs (maintenance and rehabilitation costs) over the planning time-span. Equation (3.2) is the second objective function and expresses the minimization of user costs over the planning time-span.

The constraints represented by Equation (3.3) correspond to the pavement condition functions. They express pavement condition in terms of the PSI in each road section and 
year as a function of the initial PSI and the M\&R actions previously applied to the road section. The functions shown in Equations (3.12)-(3.15) of Appendix III are used to evaluate the PSI over time. The quality of the road pavements in the present year is evaluated by the PSI, representing the condition of the pavement according to the following parameters: longitudinal roughness, rutting, cracking, surface disintegration and patching. This global quality index, calculated through Equation (3.12), ranges from 0.0 to 5.0 , with 0.0 for a pavement in extremely poor condition and 5.0 for a pavement in very good condition. In practice, through this index, a new pavement rarely exceeds the value 4.5 and a value of 2.0 is generally defined as the minimum quality level (MQL) for national roads considering traffic safety and comfort. Equation (3.13) represents the pavement performance model used for flexible pavements. This pavement performance model is the one used in the AASHTO flexible pavement design method (AASHTO 1993, C-SHRP 2002). This design approach applies several factors such as the change in PSI over the design period, the number of $80 \mathrm{kN}$ equivalent single axle load applications, material properties, drainage and environmental conditions, and performance reliability, to obtain a measure of the required structural strength through an index known as the structural number $(S N)$. The $S N$ is then converted to pavement layer thicknesses according to layer structural coefficients representing relative strength of the layer materials. The $S N$ in each road section and year of the planning period can be calculated by Equation (3.14). The number of $80 \mathrm{kN}$ equivalent single axle load applications is computed using Equation (3.15). The use of a pavement performance model for pavement design into a PMS allows the gap to be closed between project and 
network management, which is an important objective to be achieved and that has been mentioned by several researchers (Ferreira et al. 2009a, Haas 2012).

This pavement performance model was chosen from a range of current models implemented in several PMS because it is widely used and tested. Nevertheless, other pavement performance models can be used instead, as for example the pavement performance models of HDM-4 (AIPCR, 2000), the deterioration models developed for local authority roads by Stephenson et al. (2004), or the deterioration models developed for use in the Swedish PMS (Lang and Dahlgren 2001, Lang and Potucek 2001, Ihs and Sjögren 2003, Andersson 2007). Equation (3.13) defines a pavement performance model in terms of $P S I$ as a function of the number of $80 \mathrm{kN}$ equivalent single axle load applications (Figure 3.3) or the number of years of service time. An incremental change in the present serviceability index $\left(\triangle P S I_{t-1, t}\right)$ corresponds to an estimated incremental change in load applications $\left(\left(\Delta \mathrm{W}_{80}\right)_{t-1, t}\right)$ and, at the same time, to an incremental service time interval $\left(\Delta T_{t-1, t}\right)$. The Present Serviceability Index in year $t\left(P S I_{t}\right)$ is defined as the difference between the serviceability index in year $t-1\left(P S I_{t-1}\right)$ and the incremental change in the present serviceability index $\left(\Delta P S I_{t-1, t}\right)$. At the same time, the Present Serviceability Index in year $t\left(P S I_{t}\right)$ is defined as the difference between the initial serviceability index $\left(P S I_{0}\right)$ and the total incremental change in the present serviceability index $\left(\Delta P S I_{0, t}\right)$. The Present Serviceability Index in year $t\left(P S I_{t}\right)$ ranges between its initial value of about 4.5 (value for a new pavement) and the AASHTO lowest allowed PSI value of 1.5 (value for a pavement of a national road in the end of its service life). 


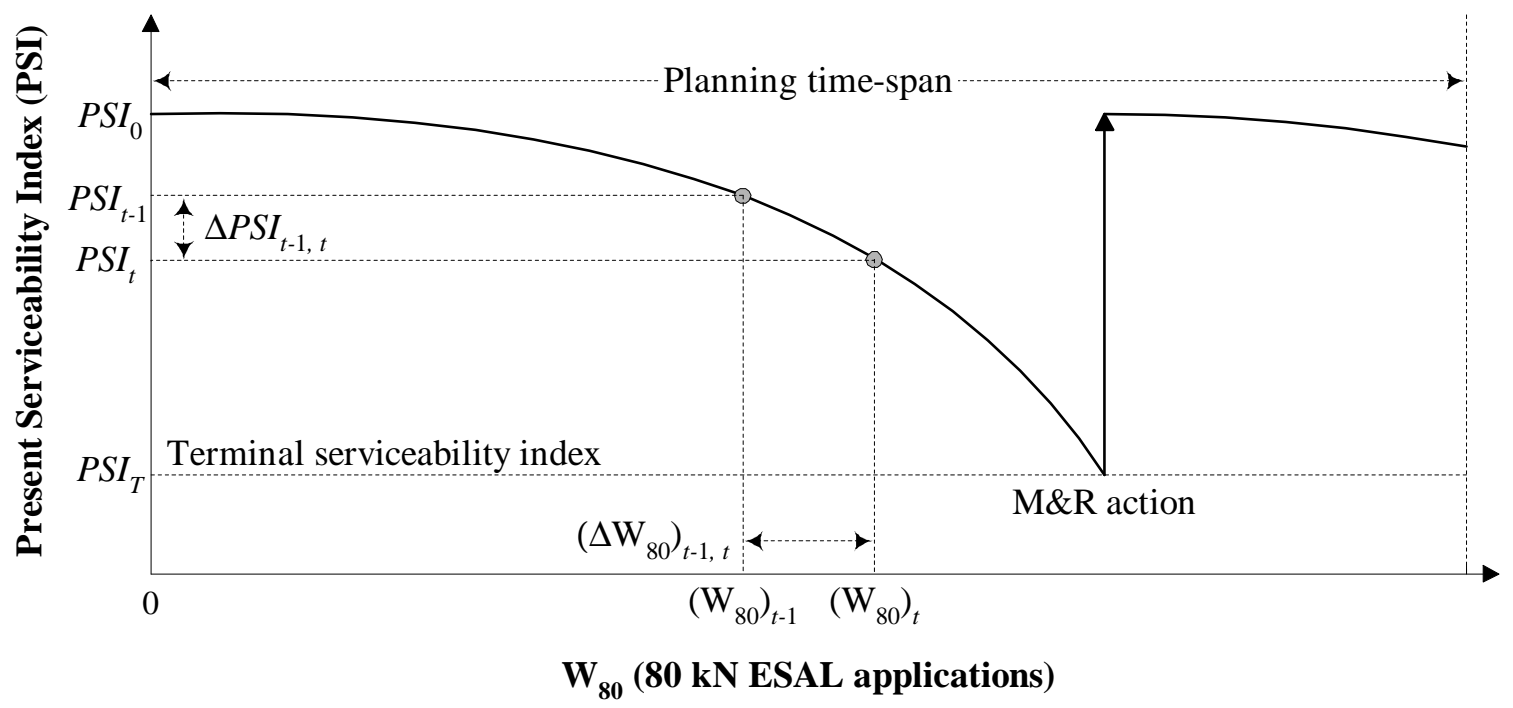

Figure 3-3 - Pavement performance curve as a function of equivalent single-axle load applications

The constraints given by Equation (3.4) are the warning level constraints. They define the MQL considering the PSI index for each pavement of the road network. The warning level adopted in this study was a PSI value of 2.0. A corrective M\&R operation appropriate for the rehabilitation of a pavement must be performed on a road section when the PSI value is lower than 2.0.

The constraints represented by Equation (3.5) represent the feasible operation sets, i.e., the M\&R operations that can be performed on each road section and in each year. These operations depend on the pavement condition characterising the section. In the present study the same five different $M \& R$ operations were considered, corresponding to nine $\mathrm{M} \& \mathrm{R}$ actions applied individually or in combination with others, as in previous studies (Picado-Santos and Ferreira 2008, Ferreira et al. 2008). The types of M\&R actions and operations considered are presented in Tables 3.1 and 3.2. The $M \& R$ action costs 
considered in this study, calculated using information from $M \& R$ works executed on the Castelo Branco road network, are also presented in Tables 3.1 and 3.2.

As shown in Table 3.3, the operations to apply to the road sections depend on the warning level. M\&R operation 1 that corresponds to "do nothing" is applied to a road section if the PSI value is above the warning level, i.e., if the PSI value is greater than 2.0. $M \& R$ operation 5 is the operation that must be applied to the road section when the warning level is reached, i.e., this operation applies to solve pavement serviceability problems. This operation has the longest efficiency period which is defined as the time between its application to the pavement and the time when the pavement reaches the warning level for the PSI. M\&R operations 2, 3, 4 and 5 are alternative operations that can be applied instead of operation 1 (see Table 3.4). In this case they constitute preventive M\&R operations. The analysis of Tables 3.3 and 3.4 clearly shows that the application of $M \& R$ operations may be corrective or preventive. An $M \& R$ operation is corrective if it is performed when the warning level is reached, and it is preventive if it is performed before the warning level is reached. When deciding which $M \& R$ operations should be applied in a given year to a given road section with PSI value above the warning level, it is possible to select either the simplest operation (M\&R operation 1) or a preventive operation (M\&R operation 2, 3, 4 or 5). In fact, selecting a preventive operation may be more efficient (less costly) in the medium or long-term. 
Table 3-1 - Types of M\&R action

\begin{tabular}{ccc}
\hline M\&R action & Description & Cost \\
\hline 1 & Do nothing & $€ 0.00 / \mathrm{m}^{2}$ \\
2 & Tack coat & $€ 0.41 / \mathrm{m}^{2}$ \\
3 & Longitudinal roughness levelling $(1 \mathrm{~cm})$ & $€ 1.23 / \mathrm{m}^{2}$ \\
4 & Longitudinal roughness levelling $(2 \mathrm{~cm})$ & $€ 2.45 / \mathrm{m}^{2}$ \\
5 & Membrane anti-reflection of cracks & $€ 1.88 / \mathrm{m}^{2}$ \\
6 & Base layer $(10 \mathrm{~cm})$ & $€ 8.63 / \mathrm{m}^{2}$ \\
7 & Binder layer $(5 \mathrm{~cm})$ & $€ 6.13 / \mathrm{m}^{2}$ \\
8 & Non-structural wearing layer & $€ 3.13 / \mathrm{m}^{2}$ \\
9 & wearing layer $(5 \mathrm{~cm})$ & $€ 6.69 / \mathrm{m}^{2}$ \\
\hline
\end{tabular}

Table 3-2 - Types of M\&R operation

\begin{tabular}{cccc}
\hline M\&R operation & Description & M\&R actions involved & Cost \\
\hline 1 & Do nothing & 1 & $€ 0.00 / \mathrm{m}^{2}$ \\
2 & Non-structural maintenance & $2+3+2+8$ & $€ 5.18 / \mathrm{m}^{2}$ \\
3 & Minor rehabilitation & $2+4+2+5+2+9$ & $€ 15.31 / \mathrm{m}^{2}$ \\
4 & Medium rehabilitation & $2+4+2+5+2+7+2+9$ & $€ 18.79 / \mathrm{m}^{2}$ \\
5 & Major rehabilitation & $2+4+2+5+2+6+2+9$ & $€ 21.29 / \mathrm{m}^{2}$ \\
\hline
\end{tabular}

Table 3-3 - Application of the simplest M\&R operations

\begin{tabular}{cccc}
\hline Warning level & PSI & M\&R operation & M\&R action \\
\hline \multirow{2}{*}{ PSI $=2.0$} & $\geq 2.0$ & 1 & 1 \\
& $<2.0$ & 5 & $2+4+2+5+2+6+2+9$ \\
\hline
\end{tabular}

Table 3-4 - Alternatives to M\&R operations

\begin{tabular}{cccccc}
\hline \multirow{2}{*}{ M\&R operation } & \multicolumn{5}{c}{ Alternative M\&R operations } \\
\cline { 2 - 6 } & 1 & 2 & 3 & 4 & 5 \\
\hline 1 & $v$ & $v$ & $v$ & $v$ & $v$ \\
2 & - & $v$ & $v$ & $v$ & $v$ \\
3 & - & - & $v$ & $v$ & $v$ \\
4 & - & - & - & $v$ & $v$ \\
5 & - & - & - & - & $v$
\end{tabular}

The constraints given by Equation (3.6) state that only one M\&R operation per road section should be performed in each year. The constraints represented by Equation (3.7) 
represent the agency cost functions. They express the costs for the road agency involved in the application of a given $M \& R$ operation to a road section in a given year as a function of the pavement condition in that section and year. These costs are obtained by multiplying the unit agency costs for the $M \& R$ actions involved in the $M \& R$ operation by the pavement areas to which the $M \& R$ actions are applied. The constraints defined by Equation (3.8) represent the user cost functions. They express the cost for road users as a function of the pavement condition in that section and year. For calculating the vehicle operation cost, Equation (3.16) in Appendix III was used.

This Equation is currently in use in the Estradas de Portugal's PMS (Picado-Santos and Ferreira 2008, Ferreira et al. 2008, Ferreira et al. 2011). So far, the main Portuguese concessionaire (Estradas de Portugal, S.A.) considers only this component of the user costs. The totality of the user costs involves the following components: vehicle operation costs; motorised travel time costs; non-motorised travel time costs; accident costs; and environmental costs. The vehicle operation costs, although being the most important component for road users, involve only the following components: fuel consumption; tyre consumption; parts consumption; oil and lubricants consumption; labour hours; depreciation; interest; and overheads.

The constraints represented by Equation (3.9) represent the pavement residual value functions. They express the value of the pavement of a road section at the end of the planning time-span as a function of pavement condition at that time. For calculating the residual value of pavements Equation (3.17) in Appendix III was used. This equation was defined based on the AASHTO guide for design of pavement structures (AASHTO, 
1993) considering a terminal value of 1.5. The constraints given by Equation (3.10) are the annual budget constraints. They specify the maximum amount of money to be spent on $\mathrm{M} \& \mathrm{R}$ operations during each year. The constraints represented by Equation (3.11) were included in the model to avoid frequent $M \& R$ operations applied to the same road section.

\subsubsection{Generation of Pareto optimal solutions}

Given the mathematical formulation of the optimization model presented in the previous section, the next step consists of the adoption of the appropriate mechanism for generating a representative set of Pareto optimal solutions (Meneses and Ferreira 2010). At this point it is evident that, given the particular features of the optimization model (a combinatorial problem with multiple objectives), it is not possible to use an exact algorithm for solving the problem efficiently. In this section, the use of a genetic algorithm approach was considered that could overcome the difficulties inherent in the nature of the optimization model.

There are several optimization methods that can be used to generate the set of Pareto optimal solutions. Hwang and Masud (1979) and later Miettinen (1999) classified them into the following four types: no-preference methods; posterior methods; a priori methods; and interactive methods. The no-preference methods do not assume any information about the importance of different objectives and a heuristic is used to find a single optimal solution. Posterior methods use preference information of each objective and iteratively generate a set of Pareto optimal solutions. Alternatively, a priori methods use more information about the preference of objectives and usually find one preferred 
Pareto optimal solution. Interactive methods use the preference information progressively during the optimization process.

According to Marler and Arora (2004), no single approach is, in general, superior to the other methods. Rather, the selection of a specific method depends on the users' preferences, the type of information provided, the solution requirements, and the availability of software. This study uses a genetic algorithm approach with the incorporation of the weighting sum method. This method, as the name suggests, combines a set of objectives into a single objective by pre-multiplying each objective with a user-defined weight. This method is the simplest approach and is probably the most widely used (Deb 2008, Wu and Flintsch 2009). Setting relative weights for individual objectives becomes a central issue in applying this method. As the weight vector for the multiple objectives often depends highly on the magnitude of each objective function, it is desirable to normalise those objectives to achieve roughly the same scale of magnitude. Equation (3.18) represents the application of the weighting sum method (Deb 2008) to the two objective functions of the optimization model presented in the previous section.

$\operatorname{Min} \bar{Z}=w_{A C} \cdot \frac{A C_{i}-A C_{\min }}{A C_{\max }-A C_{\min }}+w_{U C} \cdot \frac{U C_{i}-U C_{\min }}{U C_{\max }-U C_{\min }}$

where: $\bar{Z}$ is the normalised value of a solution; $w_{A C}$ and $w_{U C}$ are the weight values for each objective function; $A C_{i}$ and $U C_{i}$ are the individual objective function values that depend on the decision variables values; $A C_{\min }$ and $U C_{\min }$ are the minimum values 
obtained for each objective; $A C_{\max }$ and $U C_{\max }$ are the maximum values obtained for each objective.

The range of values for the various objective functions $\left(A C_{\min }, A C_{\max }\right)$ and $\left(U C_{\min }, U C_{\max }\right)$ are obtained by applying the optimization model considering only one objective at each time, i.e., varying the weight values vector $\left(w_{A C}, w_{U C}\right)$ among the extreme situations of $(1,0)$ and $(0,1)$ considering that initially all minimum values are 0 and all maximum values are 1. Considering these two objectives (Figure 3.4), the minimum values obtained for each objective corresponds to the ideal solution $\left(Z^{*}\right)$. In general, this solution is a non-existent solution that is used as a reference solution and it is also used as lower boundary to normalise the objective values in a common range. The nadir solution $\left(\mathrm{Z}^{\mathrm{nad}}\right)$, which is used as upper boundary to normalise the objective values in a common range, corresponds to the upper boundary of each objective in the entire Pareto optimal set, and not in the entire search space $\left(Z^{* *}\right)$. The Pareto optimal solution set is finally obtained by using the objective function defined by Equation (3.18) considering different combinations of the weight values. 


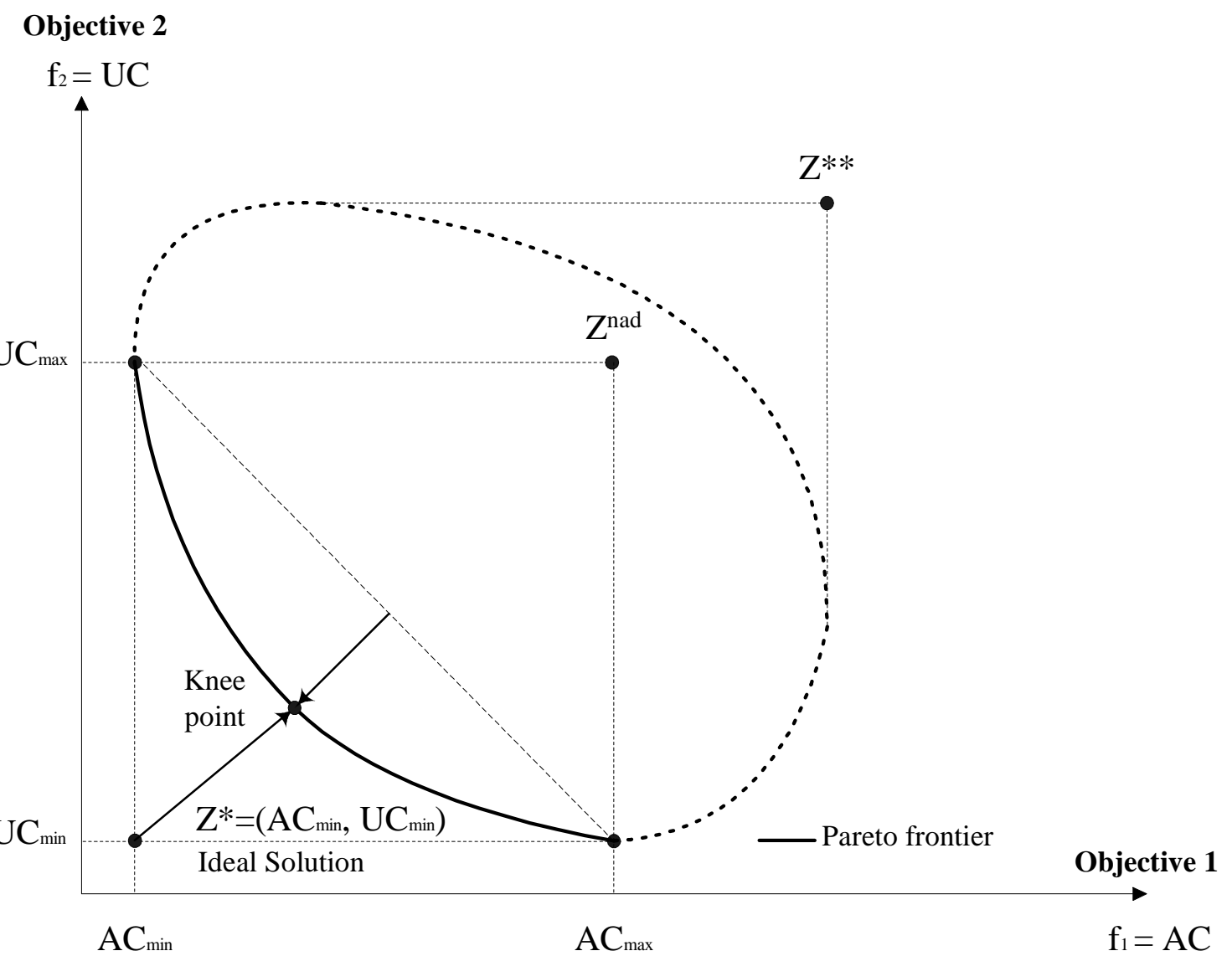

Figure 3-4 - The Pareto frontier and the ideal and nadir solutions

\subsubsection{Knee points and identification procedure}

In general, when dealing with a multi-objective optimization problem, the decision maker has great difficulties in selecting a particular solution for implementation from the Pareto optimal solution set. Das (1999), to avoid this difficulty, developed the Normal-Boundary Intersection (NBI) method to identify the so called "Knee point" of the Pareto frontier. Considering only two objectives (Figure 3.4), the Knee is a point on the region of the Pareto frontier that results from the projection of a normal vector from 
the line connecting the end points of the Pareto frontier (the two individual optima). The "knee point" is the farthest away Pareto point from this line in the direction of the normal vector. Knee points represent the most interesting solutions of the Pareto frontier due to their implicit large marginal rates of substitution (Iniestra and Gutiérrez 2009). Wu and Flintsch (2009) considered the Euclidian distance to identify the best solution of the Pareto frontier. As the ideal solution may not be achieved due to the conflicting objectives, the best solution is the solution of the Pareto frontier that has the shortest normalised distance from the ideal solution, computed using Equation (3.19). This method to identify the so called "Knee point" of the Pareto frontier is based on TOPSIS method (Lofti et al. 2007, Deb 2008, Yuan et al. 2010, Mostafavi and Karamouz 2010).

$D_{i}=\left[\left(\frac{A C_{i}-A C_{\min }}{A C_{\max }-A C_{\min }}-\bar{Z}_{1}^{*}\right)^{2}+\left(\frac{U C_{i}-U C_{\min }}{U C_{\max }-U C_{\min }}-\bar{Z}_{2}^{*}\right)^{2}\right]^{\frac{1}{2}}$

where: $D_{i}$ is the normalised distance between each Pareto solution point and the ideal

solution point; $\bar{Z}_{1}^{*}$ and $\bar{Z}_{2}^{*}$ are the normalised values for each objective of the ideal solution (are equal to 0 or 1 depending on whether it is a minimization or maximization objective).

\subsubsection{Model solving}

The deterministic mixed integer optimization model presented in the previous section is extremely complex, being impossible to solve with exact optimization methods (except, 
for small, highly idealised instances, through complete enumeration) available through commercial packages like XPRESS-MP (FICO 2009) or GAMS-CPLEX (IBM 2009). Even for a small problem (seven road sections, 20 years of planning period, and five M\&R operations) the number of alternatives $M \& R$ plans to be evaluated is huge $\left(5^{(7 \times 20)}\right.$ $\left.=7.2 \times 10^{97}\right)$. Indeed, it can only be solved through heuristic methods. Nowadays, a large number of classic and modern heuristic methods are available (Michalewicz and Fogel 2004, Gendreau and Potvin 2005, Deb 2008) to solve this kind of complex optimization models. The optimization model and its heuristic solver were implemented in a computer program called MODAT. The heuristic method used to solve this optimization model is a genetic-algorithm (GA) that was implemented in Microsoft Visual Studio programming language (David et al. 2006, Randolph and Gardner 2008) adapting and introducing new functionalities to an existing GA program called GENETIPAV-D (Ferreira 2001, Ferreira et al. 2002b) previously developed to solve single-objective deterministic optimization models. Since they were proposed by Holland (1975), genetic algorithms have been successfully used on many occasions to deal with complex engineering optimization problems. The MODAT applied to the Castelo Branco road network was run on a $2.2 \mathrm{GHz}$ personal computer (PC) with 2.0 GB of RAM and 200 GB of capacity. Each best solution given by the MODAT was obtained in approximately 30 minutes of computing time.

\subsubsection{Results of the application of the MODAT}

The MODAT was tested with data from the Estradas de Portugal's PMS (Picado-Santos and Ferreira 2008, Trindade e Horta 2009, Ferreira et al. 2011) to plan the maintenance 
and rehabilitation of the road network considering two objectives, the minimization of agency costs and the minimization of user costs. The Estradas de Portugal road network has a total length of $14500.0 \mathrm{~km}$. The MODAT was applied only to the road network of one of the eighteen districts of Portugal, the district of Castelo Branco. This road network has a total length of $589.9 \mathrm{~km}$ and the corresponding network model has 32 road sections. The discount rate considered in this study was $2.5 \%$.

Figure 3.5 represents the Pareto optimal set of solutions in the objective space by varying the weight values while Figure 3.6 represents the optimal set of normalised solutions. The point with white colour represents the "Knee point" and was obtained considering the following weight values: $\left(w_{A C}, w_{U C}\right)=(0.04,0.96)$; and it corresponds to the following objective values $(A C, U C)=\left(€ 62.8 \times 10^{6}, € 1508.8 \times 10^{6}\right)$. The range of values for the two objective functions are $\left(A C_{\min }, A C_{\text {max }}\right)=\left(€ 44.2 \times 10^{6}, € 206.0 \times 10^{6}\right)$, and $\left(U C_{\min }, U C_{\max }\right)=\left(€ 1424.2 \times 10^{6}, € 2529.3 \times 10^{6}\right)$. From Figures 3.5 and 3.6 it can be concluded that, when varying the two weights through a grid of values from 0 to 1 with a fixed increment step, as for example 0.05, the two objective values were not transformed maintaining the same fixed range.

In multi-objective problems there is no perfect method to select one "optimal" solution from the Pareto optimal set of solutions. The final best-compromise solution is always up to the decision maker. For that purpose, four different M\&R solutions of the Pareto frontier were considered for comparison.

a) Solution I: Multi-objective optimization approach (corrective-preventive) considering the "Knee point" $\left(w_{A C}=0.04, w_{U C}=0.96\right)$; 
b) Solution II: Multi-objective optimization approach (corrective-preventive) considering the following weights $\left(w_{A C}=1.00, w_{U C}=0.00\right)$;

c) Solution III: Multi-objective optimization approach (corrective-preventive) considering the following weights $\left(w_{A C}=0.00, w_{U C}=1.00\right)$;

d) Solution IV: Multi-objective optimization approach (corrective-preventive) considering the following weights $\left(w_{A C}=0.50, w_{U C}=0.50\right)$.

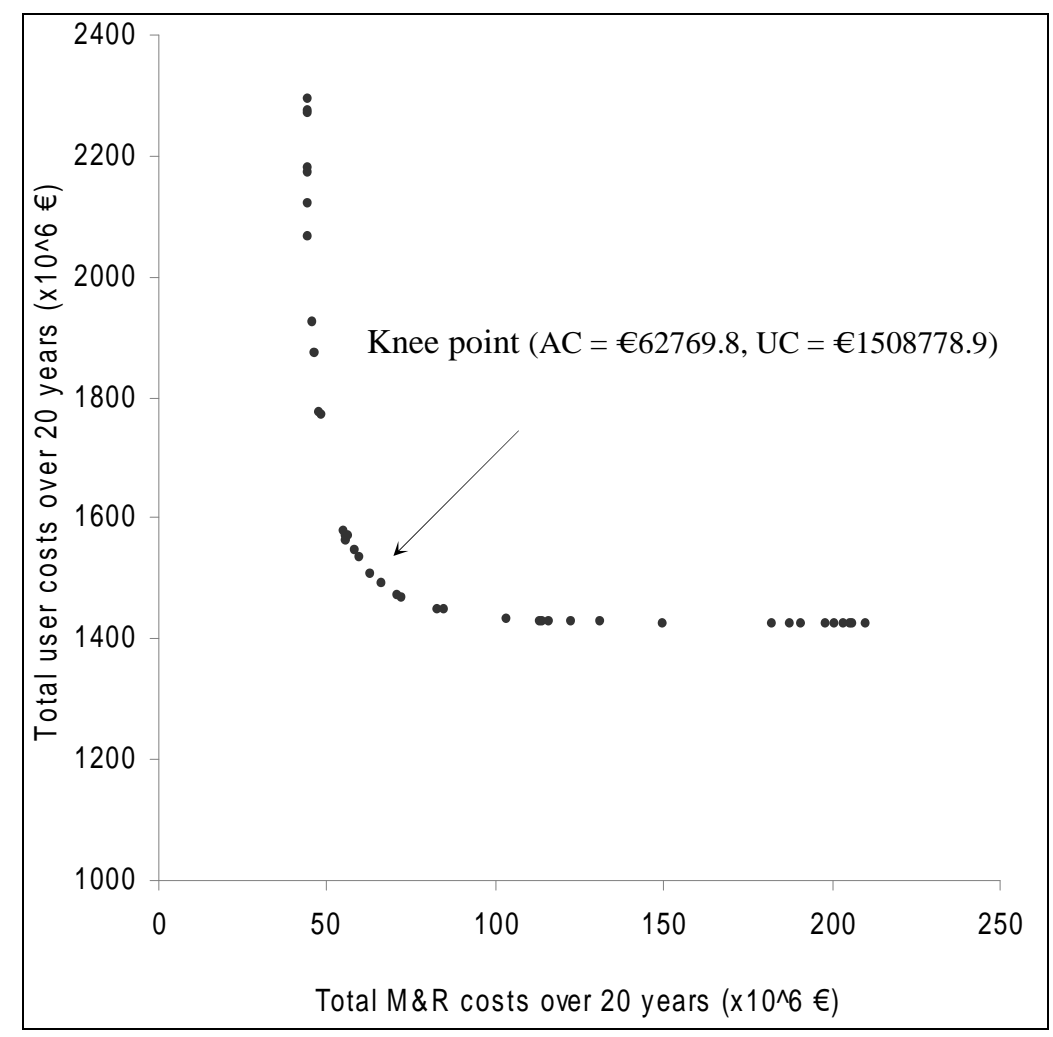

Figure 3-5 - Pareto optimal set of solutions 


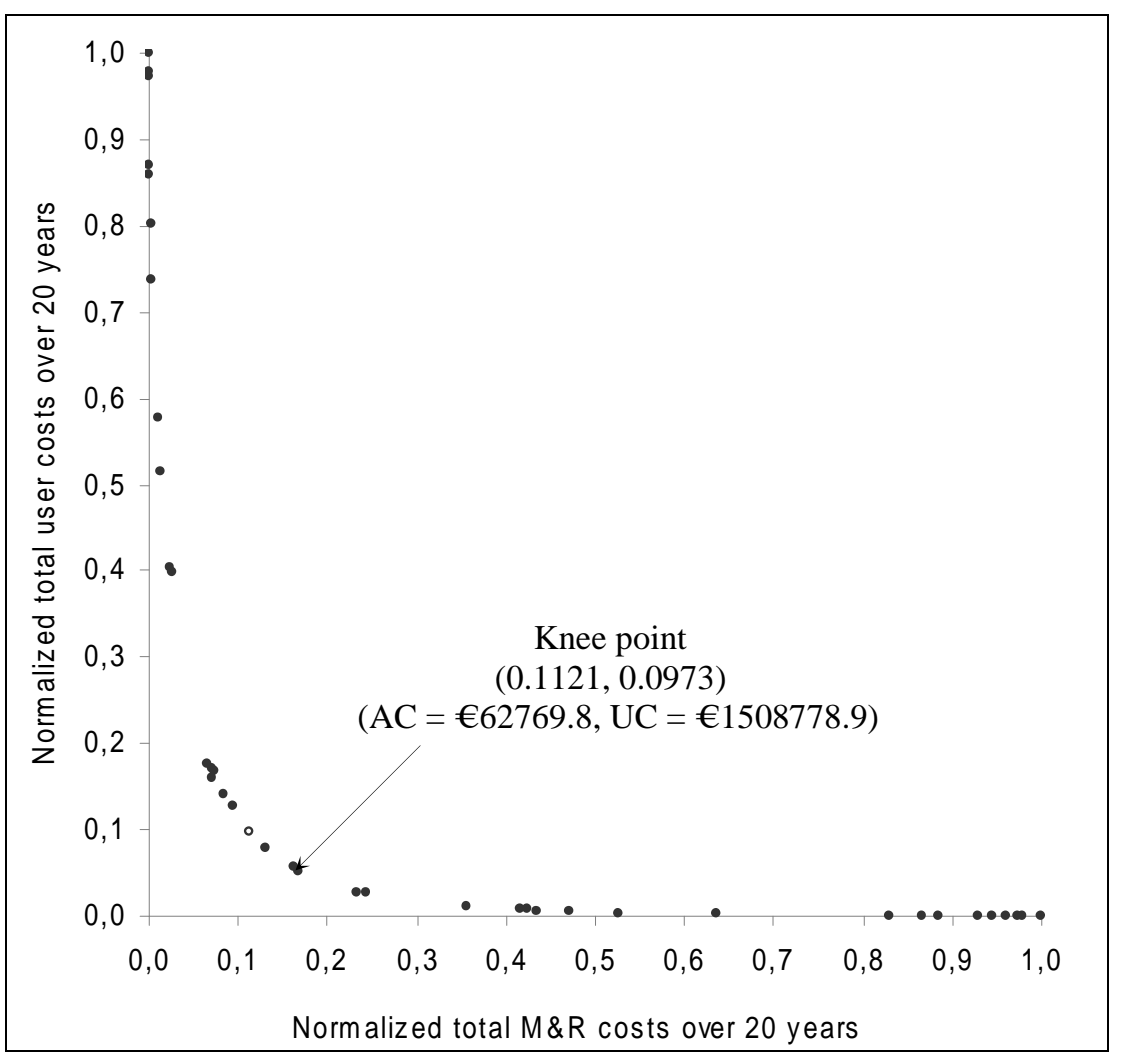

Figure 3-6 - Pareto optimal set of normalised solutions

The costs and normalised costs during the entire planning time-span for these four Pareto optimal solutions are summarised in Figures 3.7 and 3.8, respectively. Figure 3.8 shows that, as expected, solution I ("Knee point") is the Pareto optimal solution with less normalised value of $\mathrm{M} \& \mathrm{R}$ costs plus user costs. Considering the non-normalised value of $M \& R$ costs plus user costs (Figure 3.7), one can verify that this optimal solution continues to have the least value. Figure 3.8 also shows that solution I ("Knee point") is the Pareto optimal solution with less total normalised costs, computed by adding M\&R normalised costs and user normalised costs and deducting the residual normalised value. 


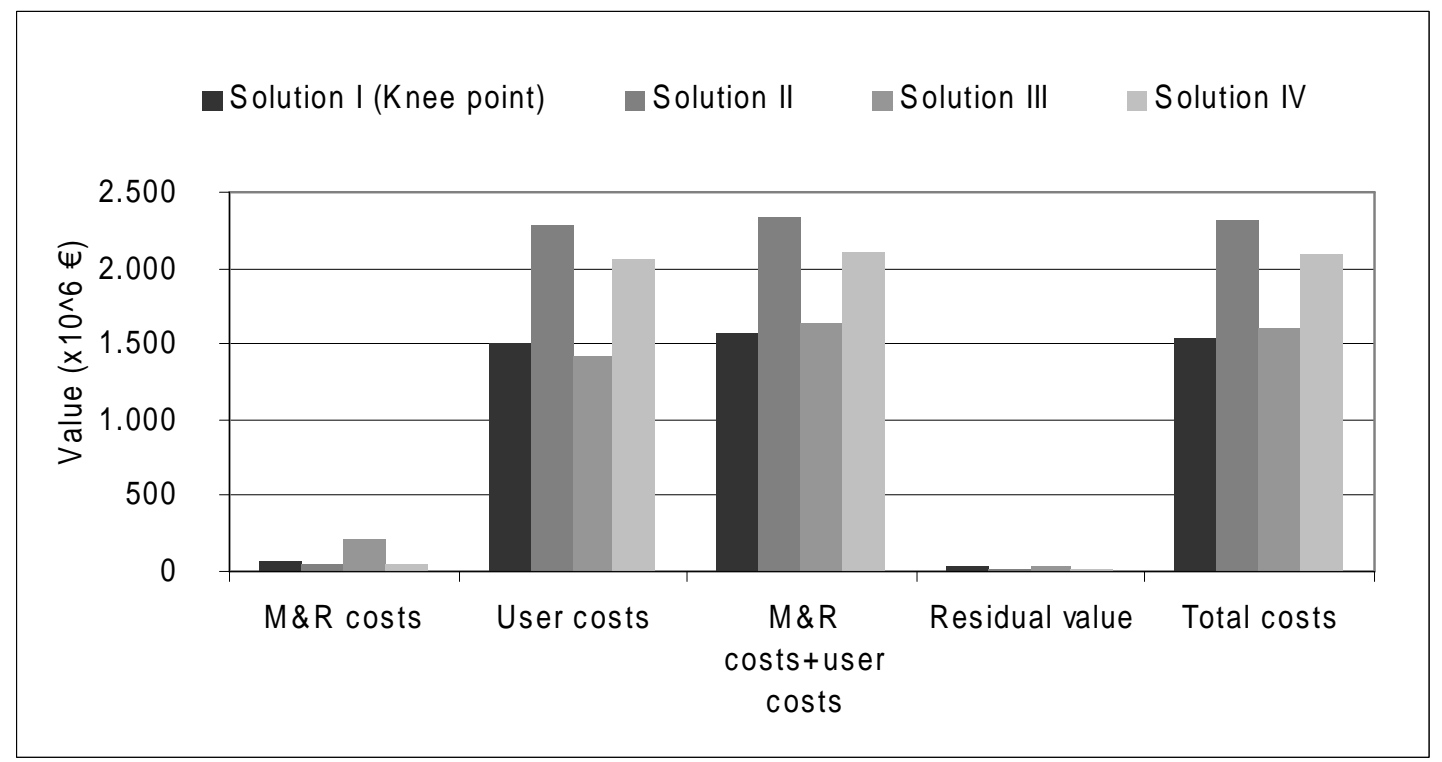

Figure 3-7 - Costs throughout the planning time-span of 20 years

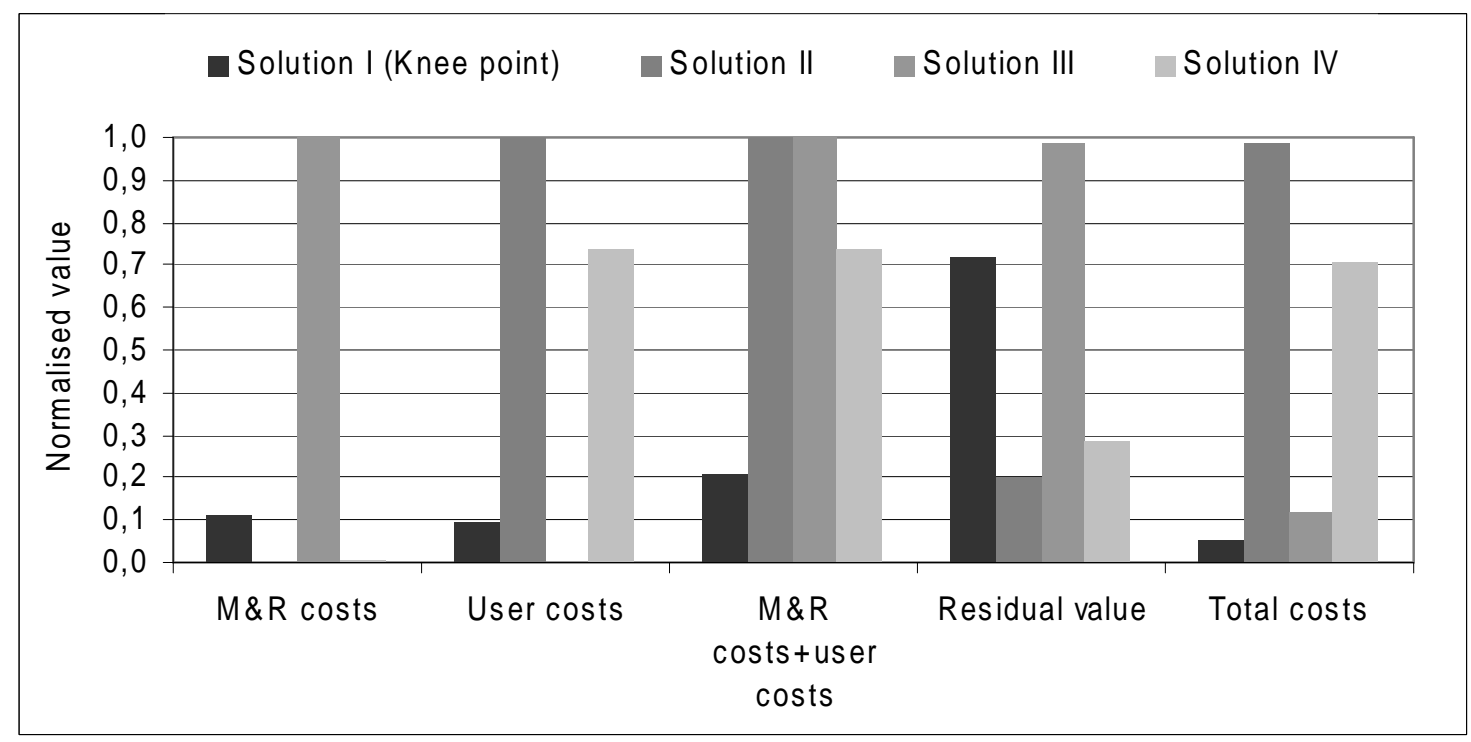

Figure 3-8 - Normalised costs throughout the planning time-span of 20 years

Figure 3.9 represents the predicted PSI average value over the years of the planning time span for all the road network pavements and for each solution. By analysing this Figure it can be seen that solution III, i.e., the solution of the multi-objective 
optimization approach (corrective-preventive) considering the weights $\left(w_{A C}=0.00, w_{U C}=1.00\right)$, corresponds to the largest average PSI values as expected because this solution corresponds to the minimization of user costs. Solution I ("Knee point") is the second best solution in terms of average PSI values also as expected because corresponds to a high weight value for user costs and a small weight value for agency costs $\left(w_{A C}=0.04, w_{U C}=0.96\right)$.

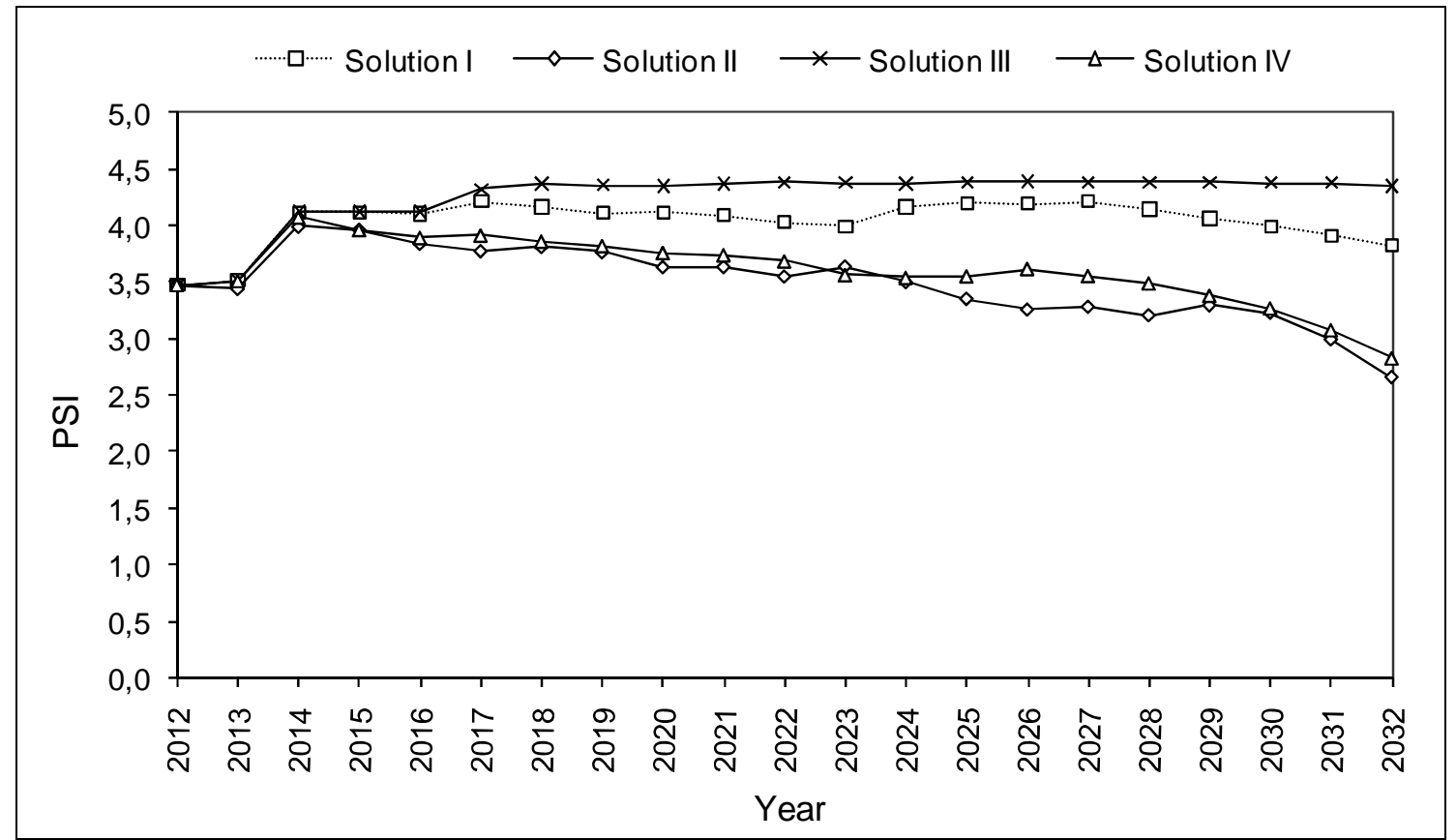

Figure 3-9 - PSI average value for all the road network pavements

In addition to these summarised results, the MODAT provides extensive information about the M\&R strategy to be implemented for each road section. To analyse these road section-linked results, four road sections were chosen with different attributes in the present year. Table 3.5 illustrates the attributes of these four road sections including their present PSI value. Table 3.6 presents the M\&R operations to be applied in the four 
road sections considering the four M\&R solutions of the Pareto frontier. Figure 3.10 represents the predicted evolution of the PSI value over the years for pavement section 05001 of a national road as a consequence of the execution of the M\&R plan. For this pavement section, which is in good quality condition (with a PSI value of 3.81), if solution I of MODAT is adopted, the same M\&R operation 2 (non-structural maintenance) would be applied in years 2016 and 2024. If solution II or solution IV of MODAT is adopted no M\&R operation will be needed in all the planning time-span. If solution III of MODAT is adopted the recommended M\&R operations are very different. The MODAT recommends the application of four M\&R operation 5 (major rehabilitation) in years 2016, 2020, 2024 and 2028, with a constant interval of four years. In this solution the M\&R operations are more and heavier because this solution corresponds to the minimization of user costs which means that the pavement quality must be always high.

An identical analysis could be made for any other pavement section. For example, for pavement section 05004 of another national road (see Table 3.6 and Figure 3.11), which has a PSI value of 2.75 , if solution I of MODAT is adopted the M\&R operation 4 (medium rehabilitation) would be applied in year 2012 and M\&R operation 2 (nonstructural maintenance) would be applied in years 2019 and 2026. If solution II or solution IV of MODAT is adopted only one M\&R operation is recommended, which is M\&R operation 3 (minor rehabilitation) applied in year 2012. Again, if solution III is adopted the recommended M\&R operations are more and heavier as appended for pavement section 05001. In this case the MODAT recommends the application of four M\&R operations 5 (major rehabilitation) in years 2012, 2016, 2020, and 2024. 
Table 3-5 - Attributes of road sections

\begin{tabular}{ccccc}
\hline Attributes & \multicolumn{3}{c}{ Road section } \\
\hline Section_ID & 05012 & 05004 & 05001 & 05003 \\
Road_class & EN & IC & IP & IC \\
Pavement_type & Flexible & Flexible & Flexible & Flexible \\
District & Castelo Branco & Castelo Branco & Castelo Branco & Castelo Branco \\
Length (m) & 21,455 & 19,439 & 1931 & 14,635 \\
Width (m) & 5.9 & 8.8 & 9.4 & 8.6 \\
Sub-grade_CBR (\%) & 5 & 10 & 6 & 4 \\
Structural_number & 2.47 & 3.51 & 5.20 & 4.80 \\
Age_of_pavements (years) & 16 & 14 & 8 & 3 \\
Annual_average_daily_traffic & 744 & 6,212 & 4316 & 5,828 \\
Annual_average_daily_heavy_traffic & 100 & 1000 & 300 & 1000 \\
Annual_growth_average_tax & 3.0 & 4.0 & 3.0 & 4.0 \\
Truck_factor & 2.0 & 4.0 & 3.0 & 4.0 \\
PSI & 1.79 & 2.75 & 3.81 & 3.90 \\
\hline
\end{tabular}

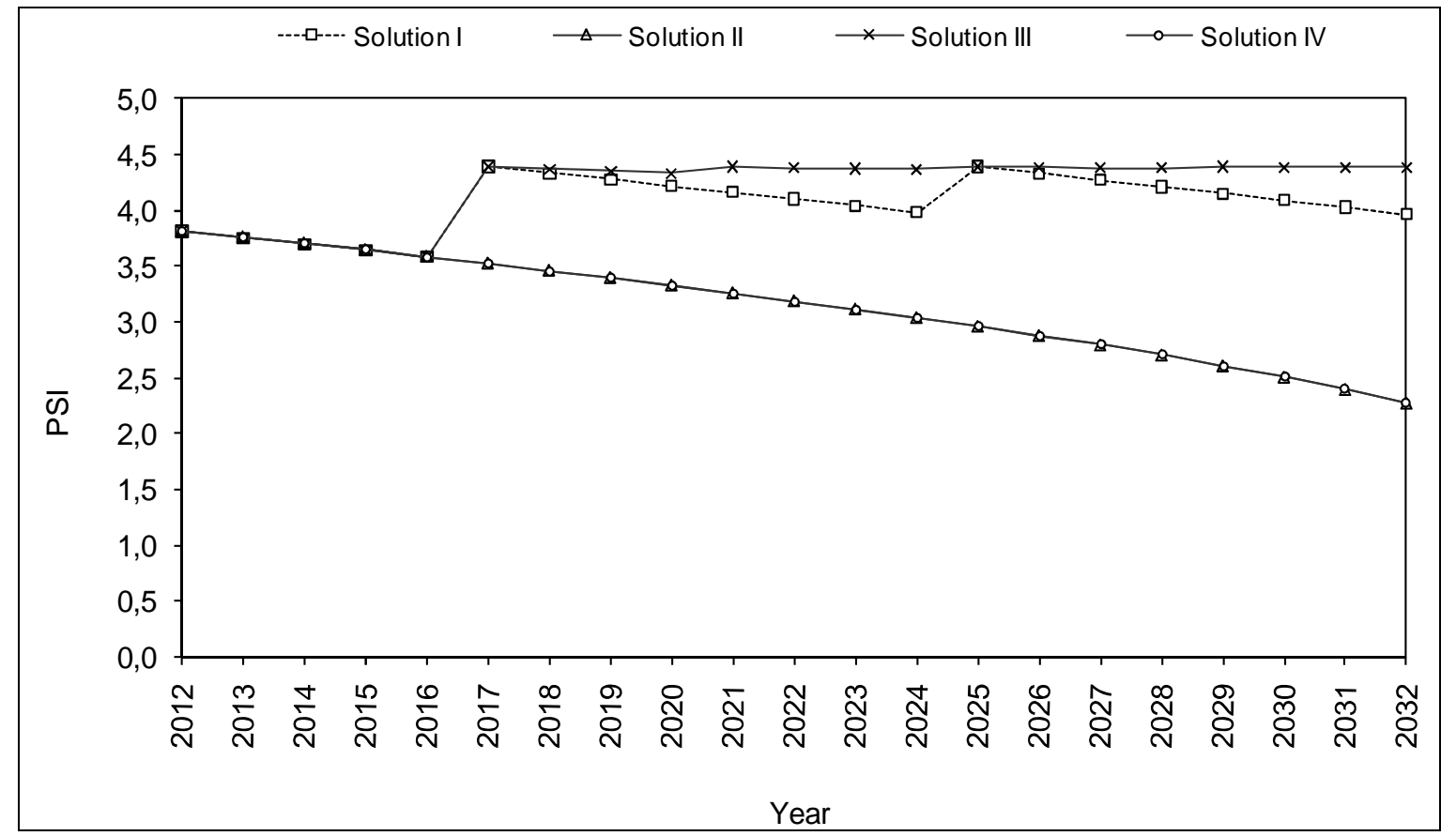

Figure 3-10 - Evolution of PSI for pavement section 05001 of a national road 
Table 3-6 - M\&R operations to be applied in road sections

\begin{tabular}{|c|c|c|c|c|c|c|c|c|c|c|c|c|c|c|c|c|c|c|c|c|c|}
\hline \multirow[b]{2}{*}{ Section } & \multirow[b]{2}{*}{ PSI $_{0}$} & \multicolumn{20}{|c|}{ Year } \\
\hline & & 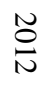 & $\underset{\omega}{\stackrel{N}{\sigma}}$ & $\underset{\perp}{\stackrel{N}{\circ}}$ & $\underset{\sim}{\stackrel{n}{c}}$ & $\frac{N}{\circ}$ & $\stackrel{N}{\circ}$ & $\underset{\infty}{\stackrel{N}{\infty}}$ & $\frac{N}{0}$ & $\begin{array}{l}\text { N } \\
\text { N }\end{array}$ & 芯 & 芯 & 芯 & $\underset{N}{\stackrel{N}{+}}$ & 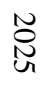 & $\begin{array}{l}\text { N } \\
\text { N }\end{array}$ & 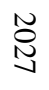 & 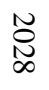 & $\begin{array}{l}\tilde{N} \\
\text { N్ర }\end{array}$ & $\stackrel{N}{\mathscr{O}}$ & 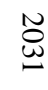 \\
\hline \multicolumn{22}{|c|}{ Solution I - Knee point ( $\left.w_{A C}=0.04, w_{U C}=0.96\right)$} \\
\hline 05012 & 1.79 & 5 & 1 & 1 & 1 & 1 & 1 & 1 & 1 & 1 & 1 & 1 & 1 & 1 & 1 & 1 & 1 & 1 & 1 & 1 & 1 \\
\hline 05004 & 2.75 & 4 & 1 & 1 & 1 & 1 & 1 & 1 & 2 & 1 & 1 & 1 & 1 & 1 & 1 & 2 & 1 & 1 & 1 & 1 & 1 \\
\hline 05001 & 3.81 & 1 & 1 & 1 & 1 & 2 & 1 & 1 & 1 & 1 & 1 & 1 & 1 & 2 & 1 & 1 & 1 & 1 & 1 & 1 & 1 \\
\hline 05003 & 3.90 & 1 & 1 & 3 & 1 & 1 & 1 & 1 & 1 & 2 & 1 & 1 & 1 & 1 & 2 & 1 & 1 & 1 & 2 & 1 & 1 \\
\hline \multicolumn{22}{|c|}{ Solution II $\left(w_{A C}=1.00, w_{U C}=0.00\right)$} \\
\hline 05012 & 1.79 & 5 & 1 & 1 & 1 & 1 & 1 & 1 & 1 & 1 & 1 & 1 & 1 & 1 & 1 & 1 & 1 & 1 & 1 & 1 & 1 \\
\hline 05004 & 2.75 & 3 & 1 & 1 & 1 & 1 & 1 & 1 & 1 & 1 & 1 & 1 & 1 & 1 & 1 & 1 & 1 & 1 & 1 & 1 & 1 \\
\hline 05001 & 3.81 & 1 & 1 & 1 & 1 & 1 & 1 & 1 & 1 & 1 & 1 & 1 & 1 & 1 & 1 & 1 & 1 & 1 & 1 & 1 & 1 \\
\hline 05003 & 3.90 & 1 & 1 & 1 & 1 & 1 & 2 & 1 & 1 & 1 & 1 & 3 & 1 & 1 & 1 & 1 & 1 & 1 & 1 & 1 & 1 \\
\hline \multicolumn{22}{|c|}{ Solution III $\left(w_{A C}=0.00, w_{U C}=1.00\right)$} \\
\hline 05012 & 1.79 & 5 & 1 & 1 & 1 & 5 & 1 & 1 & 1 & 5 & 1 & 1 & 1 & 5 & 1 & 1 & 1 & 1 & 1 & 1 & 1 \\
\hline 05004 & 2.75 & 5 & 1 & 1 & 1 & 5 & 1 & 1 & 1 & 5 & 1 & 1 & 1 & 5 & 1 & 1 & 1 & 1 & 1 & 1 & 1 \\
\hline 05001 & 3.81 & 1 & 1 & 1 & 1 & 5 & 1 & 1 & 1 & 5 & 1 & 1 & 1 & 5 & 1 & 1 & 1 & 5 & 1 & 1 & 1 \\
\hline 05003 & 3.90 & 1 & 1 & 5 & 1 & 1 & 1 & 5 & 1 & 1 & 1 & 5 & 1 & 1 & 1 & 5 & 1 & 1 & 1 & 1 & 1 \\
\hline \multicolumn{22}{|c|}{ Solution IV $\left(w_{A C}=0.50, w_{U C}=0.50\right)$} \\
\hline 05012 & 1.79 & 5 & 1 & 1 & 1 & 1 & 1 & 1 & 1 & 1 & 1 & 1 & 1 & 1 & 1 & 1 & 1 & 1 & 1 & 1 & 1 \\
\hline 05004 & 2.75 & 3 & 1 & 1 & 1 & 1 & 1 & 1 & 1 & 1 & 1 & 1 & 1 & 1 & 1 & 1 & 1 & 1 & 1 & 1 & 1 \\
\hline 05001 & 3.81 & 1 & 1 & 1 & 1 & 1 & 1 & 1 & 1 & 1 & 1 & 1 & 1 & 1 & 1 & 1 & 1 & 1 & 1 & 1 & 1 \\
\hline 05003 & 3.90 & 1 & 1 & 1 & 3 & 1 & 1 & 1 & 1 & 1 & 1 & 1 & 1 & 1 & 2 & 1 & 1 & 1 & 1 & 1 & 1 \\
\hline
\end{tabular}

KEY (M\&R actions):

$\mathbf{1}$ - Do nothing; 2 - Non structural maintenance; 3 - Minor rehabilitation; 4 - Medium rehabilitation; 5 - Major rehabilitation

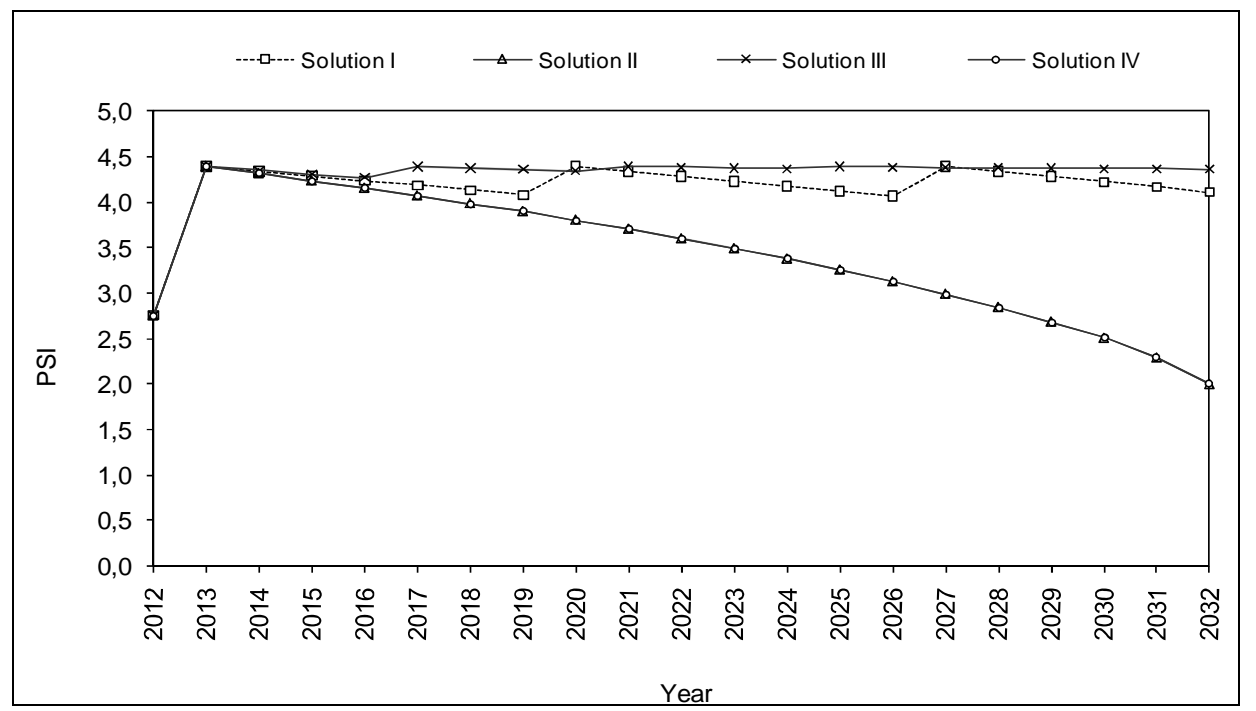

Figure 3-11 - Evolution of PSI for pavement section 05004 of a national road 


\subsection{Conclusions}

The Multi-objective Decision-Aid Tool (MODAT) presented in this chapter, incorporating several objectives into the same optimization model, can solve the pavement management problem for the case involving major rehabilitation interventions. The MODAT, as well as the decision-aid tool currently in use in the Estradas de Portugal's PMS, which has the objective of minimising costs over a selected planning time-span, allows closing the gap between project and network management. This is made possible by using a macroscopic approach that uses models for predicting the future condition of the pavement based on measured condition data (i.e. cracking, ravelling, potholes, patching, rutting, longitudinal roughness, skid resistance, traffic, climate, etc.). This macroscopic approach requires that each road section is homogeneous in terms of quality, pavement structure, traffic and climate. It is assumed that each road section possesses one performance curve with any estimated future performance value representing the overall average pavement condition. The MODAT considers the pavement performance model used in the AASHTO flexible pavement design method but any other preferred model can be used as well.

The MODAT constitutes a new useful tool to help the road engineers in their task of maintenance and rehabilitation of pavements. In the MODAT application, the Knee point, that represents the most interesting solution of the Pareto frontier, corresponds to an agency costs weight value of $4 \%$ and an user costs weight value of $96 \%$, demonstrating that user costs, which are generally much greater than agency costs, dominate the decision process. While the case study of this chapter focuses on a national road network, the approach proposed is applicable to any transportation 
infrastructure network, e.g., municipal road network, bridge network, where the decision-making process often involves multiple objective considerations. Because the MODAT is an open system, some modifications could be made to better serve the needs of road engineers. In the near future, our research in the pavement management field will follow two main directions. First, the MODAT will be applied considering also other objectives, beyond the two existent ones, as for example the maximization of the residual value of pavements or the maximization of the road network performance. Second, pavement performance models will be developed using pavement performance data available in some road network databases and will be incorporated into MODAT for future applications to road networks. 


\section{APPENDIX 1: NOTATION}

$A C_{r s t}$ is the agency cost for applying operation $r$ to road section $s$ in year $t$;

$B_{t}$ is the budget for year $t$;

$C_{0}$ is the total cracked pavement area in year $0\left(\mathrm{~m}^{2} / 100 \mathrm{~m}^{2}\right)$;

$C_{n}^{e}$ is the structural coefficient of layer $n$;

$C_{n}^{d}$ is the drainage coefficient of layer $n$;

$C_{s, \text { const }}$ is the cost of construction or the cost of the last rehabilitation of pavement section $s$;

$d$ is the discount rate;

$D_{0}$ is the total disintegrated area (with potholes and raveling) in year $0\left(\mathrm{~m}^{2} / 100 \mathrm{~m}^{2}\right)$;

$H_{n}$ is the thickness of layer $n(\mathrm{~mm})$;

$I R I_{0}$ is the pavement longitudinal roughness in year $0(\mathrm{~mm} / \mathrm{km})$;

$M_{R}$ is the sub-grade resilient modulus (pounds per square inch);

$N_{\max _{s}}$ is the maximum number of M\&R operations that may occur in road section $s$ over the planning time-span;

$W_{80}$ is the number of $80 \mathrm{kN}$ equivalent single axle load applications estimated for a selected design period and design lane;

$P a_{0}$ is the pavement patching in year $0\left(\mathrm{~m}^{2} / 100 \mathrm{~m}^{2}\right)$;

$\mathrm{PSI}_{t}$ is the Present Serviceability Index in year $t$;

$P S I_{s, \text { rehab }}$ is the PSI value after the application of a rehabilitation action in pavement section $s$;

$R$ is the number of alternative M\&R operations; 
$R_{0}$ is the mean rut in year $0(\mathrm{~mm})$;

$R V_{s, T+1}$ is the residual value for the pavement of section $s$;

$S$ is the number of road sections;

$S_{0}$ is the combined standard error of the traffic prediction and performance prediction;

$S N_{t}$ is the structural number of a road pavement in year $t$

$T$ is the number of years in the planning time-span;

$t c$ is the annual average growth rate of heavy traffic;

$T M D A_{p}$ is the annual average daily heavy traffic in the year of construction or the last rehabilitation, in one direction and per lane;

$U C_{s t}$ is the user cost for road section $s$ in year $t$;

$V O C_{t}$ are the vehicle operation costs in year $t(€ / \mathrm{km} / \mathrm{vehicle})$;

$X_{r s t}$ is equal to one if operation $r$ is applied to section $s$ in year $t$, and is equal to zero otherwise;

$Y_{t}$ is the time since the pavement's construction or its last rehabilitation (years);

$Z_{R}$ is the standard normal deviate;

$P S I_{s t}$ are the pavement condition for section $s$ in year $t$;

$\overline{P S I}$ is the warning level for the pavement condition;

$\alpha$ is the average heavy traffic damage factor or simply truck factor;

$\triangle P S I_{t}$ is the difference between the initial value of the present serviceability index $\left(P S I_{0}\right)$ and the value of the present serviceability index in year $t\left(P S I_{t}\right)$;

$\Psi a$ are the agency cost functions;

$\Psi p$ are the pavement condition functions;

$\Psi r$ are the residual value functions; 
$\Psi u$ are the user cost functions;

$\Omega$ are the feasible operations sets.

\section{APPENDIX 2: DECISION-AID TOOL MODEL}

For explanation of notation, refer to the Appendix 1.

\section{A.2.1 Objective functions}

Minimise agency costs (maintenance and rehabilitation costs)

$\operatorname{Min} A C=\sum_{r=1}^{R} \sum_{s=1}^{S} \sum_{t=1}^{T} \frac{1}{(1+d)^{t}} \cdot A C_{r s t} \cdot X_{r s t}$

Minimise user costs

$\operatorname{Min} U C=\sum_{s=1}^{S} \sum_{t=1}^{T} \frac{1}{(1+d)^{t}} \cdot U C_{s t}$

\section{A.2.2 Constraints}

Pavement condition functions

$\boldsymbol{P S \boldsymbol { I } _ { s t }}=\Psi p\left(\boldsymbol{P S I _ { s 0 }}, X_{1 s 1}, \ldots, X_{1 s t}, \ldots, X_{R s 1}, \ldots, X_{R s t}\right), s=1, \ldots, S ; t=1, \ldots, T$

Warning level constraints

$\boldsymbol{P S I}_{s t} \geq \overline{P S I}_{s}, s=1, \ldots, S ; t=1, \ldots, T$ 
Feasible operation sets

$X_{r s t} \in \Omega\left(\boldsymbol{P S I}_{s t}\right), r=1, \ldots, R ; s=1, \ldots, S ; t=1, \ldots, T$

Annual operations constraints

$\sum_{r=1}^{R} X_{r s t}=1, s=1, \ldots, S ; t=1, \ldots, T$

Agency cost functions

$A C_{r s t}=\Psi a\left(P S I_{s t}, X_{r s t}\right), r=1, \ldots, R ; s=1, \ldots, S ; t=1, \ldots, T$

User cost functions

$U C_{s t}=\Psi u\left(\boldsymbol{P S I} \boldsymbol{I}_{s t}\right), s=1, \ldots, S ; t=1, \ldots, T$

Residual value functions

$R V_{s, T+1}=\Psi r\left(\boldsymbol{P S I} \boldsymbol{s}_{s, T+1}\right), s=1, \ldots, S$

Annual budget constraints

$\sum_{r=1}^{R} \sum_{s=1}^{S} A C_{r s t} \cdot X_{r s t} \leq B_{t}, t=1, \ldots, T$ 
Chapter 3

Planning time-span operations constraints

$\sum_{r=2}^{R} \sum_{t=1}^{T} X_{r s t} \leq N \max _{s}, \forall s=1, \ldots, S$ 


\section{THE MODEL}

\section{A.3.1 Pavement condition functions}

$$
\begin{aligned}
& P S I_{0}=5 \times e^{-0.0002598 \times I R I_{0}}-0.002139 \times R_{0}{ }^{2}-0.03 \times\left(C_{0}+D_{0}+P a_{0}\right)^{0.5} \\
& P S I_{t}=P S I_{0}-(4.2-1.5) \times 10^{\left[\left(\log _{10}\left(W_{18}\right)-Z_{R} \times S_{0}-9.36 \times \log _{10}(S N+1)+0.2-2.32 \times \log _{10}\left(M_{R}\right)+8.07\right) \times\left(0.4+\frac{1094}{(S N+1)^{5.19}}\right)\right]} \\
& S N_{t}=\sum_{n=1}^{N} H_{n} \times C_{n}^{e} \times C_{n}^{d} \\
& W_{80_{t}}=365 \times T M D A_{p} \times \frac{(1+t c)^{Y_{t}}-1}{t c} \times \alpha
\end{aligned}
$$

\section{A.3.2 User cost function}

$$
V O C_{t}=1.20487-0.49116 \times P S I_{t}+0.05458 \times P S I_{t}^{2}
$$

\section{A.3.3 Residual value of pavements function}

$$
R V_{s, T+1}=C_{s, \text { const }} \cdot \frac{P S I_{s, T+1}-1.5}{P S I_{s, \text { rehab }}-1.5}
$$




\section{References}

AASHTO (1993). Guide for design of pavement structures. American Association of State Highway and Transportation Officials, Washington, D.C., USA, 4th ed., 1-640.

Abaza, K. (2005). Performance-based models for flexible pavement structural overlay design. Journal of Transportation Engineering, 131 (2), 149-159.

Abaza, K. (2006). Iterative linear approach for nonlinear nonhomogenous stochastic pavement management models. Journal of Transportation Engineering, 132 (3), 244-256.

Abaza, K. (2007). Expected performance of pavement repair works in a global network optimization. Journal of Infrastructure Systems, 13 (2), 124-134.

Abaza, K., Ashur, S., Abu-Eisheh, S. and Al-Khatib, I. (2004). Integrated pavement management system with a markovian prediction model. Journal of Transportation Engineering, 130 (1), 24-33.

Abaza, K., Ashur, S., Abu-Eisheh, S. and Rabay'A, A. (2001). Macroscopic optimum system for management of pavement rehabilitation. Journal of Transportation Engineering, 127 (6), 493-500.

AIPCR (2000). Highway development and management, volume one - overview of HDM-4. World Road Association, Paris, France, I, 1-53. 
Andersson, P. (2007). Multi-year maintenance optimization for paved public roads segment based modelling and price-directive decomposition. $\mathrm{PhD}$ Thesis, Linköping University, Linköping, Sweden, 1-214.

C-SHRP (2002). Pavement structural design practices across Canada. C-SHRP Technical Brief No. 23, Canadian Strategic Highway Research Program, Ottawa. Ontario, Canada, 1-10.

Das, I. (1999). On characterizing the "knee" of the Pareto curve based on normal boundary intersection. Structural and Multidisciplinary Optimization, 18 (2), 107115.

David, J., Loton, T., Gunvaldson, E., Bowen, C., Coad, N. and Jefford, D. (2006). Professional Visual Studio 2005 Team System. Wiley Publishing, Inc., Indiana, USA, $1-660$.

Deb, K. (2008). Multi-objective optimization using evolutionary algorithms, Wiley, West Sussex, United Kingdom, 1-536.

Durango-Cohen, P. and Tadepalli, N. (2006). Using advanced inspection technologies to support investments in maintenance and repair of transportation infrastructure facilities. Journal of Transportation Engineering, 132 (1), 60-68.

Ferreira, A. (2001). Pavement maintenance optimization of road networks. PhD Thesis, Coimbra University, Coimbra, Portugal, 1-383 (in Portuguese).

Ferreira, A., Antunes, A. and Picado-Santos, L. (2002a). Probabilistic segment-linked pavement management optimization model. Journal of Transportation Engineering, 128 (6), 568-577. 
Ferreira, A. and Meneses, S. (2006). A deterministic optimization model proposed to be used in the PMS of a Portuguese municipality. Proceedings of the Fifth International Conference on Engineering Computational Technology, Las Palmas de Gran Canaria, Spain, CD Ed., 1-15.

Ferreira, A., Meneses, S. and Vicente, F. (2009a). Pavement management system for Oliveira do Hospital, Portugal. Proceedings of the Institution of Civil EngineersTransport, 162 (3), 157-169.

Ferreira, A., Meneses, S. and Vicente, F. (2009b). Alternative decision-aid tool for pavement management. Proceedings of the Institution of Civil Engineers-Transport, $162(1), 3-17$.

Ferreira, A., Picado-Santos, L. and Antunes, A. (2002b). A segment-linked optimization model for deterministic pavement management systems. The International Journal of Pavement Engineering, 3 (2), 95-105.

Ferreira, A., Picado-Santos, L., Wu, Z. and Flintsch, G. (2008). Analysis of Pavement Performance Models for use in Pavement Management Systems. Proceedings of the Third European Pavement and Asset Management Conference, CD Ed., chapter 1136.pdf, 1-10, Coimbra, Portugal.

Ferreira, A., Picado-Santos, L., Wu, Z. and Flintsch, G. (2011). Selection of pavement performance models for use in the Portuguese PMS. International Journal of Pavement Engineering, 12 (1), 87-97.

FICO (2009). Xpress-optimizer - reference manual, release 20.00. Fair Isaac Corporation, Leamington Spa, Warwickshire, UK, 1-470. 
Flintsch, G. W. and Chen, C. (2004). Soft computing applications in infrastructure management. Journal of Infrastructure Systems, 10 (4), 157-166.

Fwa, T., Chan, W., and Hoque, K. (2000). Multiobjective optimization for pavement maintenance programming. Journal of Transportation Engineering, 126 (5), 367374.

Gabriel, S., Ordóñez, J. and Faria, J. (2006). Contingency planning in project selection using multiobjective optimization and chance constraints. Journal of Infrastructure Systems, 12 (2), 112-120.

Gendreau, M. and Potvin, J. (2005). Metaheuristics in combinatorial optimization. Annals of Operations Research, 140 (1), 189-213.

Golabi, K., Kulkarni, R. and Way, G. (1982). A state-wide pavement management system. Interfaces, 12 (6), 5-21.

Goldberg, D. (1989). Genetic algorithms in search, optimization and machine learning, Addison-Wesley, Reading, Mass.

Haas, R. (2012). Reinventing the (pavement management) wheel. Distinguished Lecture, Fifth International Conference on Managing Pavements (available for download at http://www.asphalt.org/Pubs/PubsO.html).

Hawker, L. and Abell, R. (2000). Selection and prioritisation of maintenance works on major roads in England. Proceedings of the 1st European Pavement Management Systems Conference, Budapest, Hungary, CD Ed., 1-8. 
Holland, J. (1975). Adaptation in natural and artificial systems. University of Michigan Press, Ann Arbor, MI, USA, 1-206.

Hwang, C. and Masud, A. (1979). Multiple objective decision making - methods and applications: a state-of-the-art survey, Springer-Verlag, Berlin, Germany.

IBM (2009). IBM ILOG CPLEX 12.1 - reference manual. IBM Corporation, Armonk, New York, USA, 1-884.

Ihs, A. and Sjögren, L. (2003). An overview of HDM-4 and the Swedish pavement management system. VTI - Infrastructure Maintenance, Linköping, Sweden, 1-31.

Iniestra, J. and Gutiérrez, J. (2009). Multi-criteria decisions on interdependent infrastructure transportation projects using an evolutionary-based framework. Applied Soft Computing, 9 (2), 512-526.

Jorge, D. and Ferreira, A. (2012). Road network pavement maintenance optimization using the HDM-4 pavement performance prediction models. International Journal of Pavement Engineering, 13 (1), 39-51.

Kaliszewski, I. (2004). Out of the mist-towards decision-maker-friendly multiple criteria decision making support. European Journal of Operational Research, 158 (2), 293-307.

Kennedy, C. and Johns, A. (2001). Partnering in the provision of a highway management system. Proceedings of the Institution of Civil Engineers-Municipal Engineer, 145 (3), 227-233. 
Kulkarni, R., Miller, D., Ingram, R., Wong, C. and Lorenz, J. (2004). Need-based project prioritization: alternative to cost-benefit analysis. Journal of Transportation Engineering, 130 (2), 150-158.

Lang, J. and Dahlgren, J. (2001). Prediction model in the Swedish PMS. Proceedings of the Fifth International Conference on Managing Pavements, CD Ed., Seattle, Washington, USA, chapter 100.pdf, 1-10.

Lang, J. and Potucek, J. (2001). Pavement management systems in Sweden. Proceedings of the Fifth International Conference on Managing Pavements, CD Ed., Seattle, Washington, USA, chapter 097.pdf, 1-12.

Li, Z. (2009). Stochastic optimization model and $\mathrm{O}\left(\mathrm{N}^{2}\right)$ solution algorithm for highway investment decision making under budget uncertainty. Journal of Transportation Engineering, 135 (6), 371-379.

Li, Z. and Sinha, K. (2009). Application of Shackle's model and system optimization for highway investment decision making under uncertainty. Journal of Transportation Engineering, 135 (3), 12-139.

Lotfi, F., Allahviranloo, T., Jondabeh, M. and Kiani, N. (2007). A new method for complex decision making based on TOPSIS for complex decision making problems with fuzzy data. Applied Mathematical Sciences, 1 (60), 2981 - 2987.

Madanat, S., Park, S. and Kuhn, K. (2006). Adaptive optimization and systematic probing of infrastructure system maintenance policies under model uncertainly. Journal of Infrastructure Systems, 12 (3), 192-198. 
Marler, R., and Arora, J. (2004). Survey of multi-objective optimization methods for engineering. Structural and Multidisciplinary Optimization, 26, 369-395.

Mansouri, S. (2005). A multi-objective genetic algorithm for mixed-model sequencing on JIT assembly lines. European Journal of Operational Research, 167, 696-716.

Mbwana, J. and Turnquist, M. (1996). Optimization modeling for enhanced networklevel pavement management system. Transportation Research Record 1524, Transportation Research Board, 76-85.

Meneses, S. and Ferreira, A. (2010). Multi-objective decision-aid tool for pavement management systems. Proceedings of the $12^{\text {th }}$ World Conference on Transport Research, Lisbon, Portugal, CD Ed., 1-11.

Michalewicz, Z. and Fogel, D. (2004). How to solve it: modern heuristics. SpringerVerlag, Berlin, Germany, 1-554.

Miettinen, K. (1999). Nonlinear multi-objective optimization, Kluwer Academic Publishers, Boston, USA, 1-324.

Mostafavi, A. and Karamouz, M. (2010). Selecting appropriate project delivery system: fuzzy approach with risk analysis. Journal of Construction Engineering and Management, 136 (8), 923-930.

Nunoo, C. and Mrawira, D. (2004). Shuffled complex evolution algorithms in infrastructure works programming. Journal of Computing in Civil Engineering, 18 (3), 257-266.

Picado-Santos, L., Ferreira, A., Antunes, A., Carvalheira, C., Santos, B., Bicho, M. H., Quadrado, I. and Silvestre, S. (2004). The pavement management system for Lisbon. 
Proceedings of the Institution of Civil Engineers-Municipal Engineer, 157 (3), 157165.

Pareto, V. (1906). Manuale di economica politica, societa editrice libraria, Milan A. S. Schwier, translator, Manual of political economy, A. S. Schwier and A. N. Page, eds., A.M. Kelley, New York.

Picado-Santos, L., and Ferreira, A. (2008). Contributions to the development of the Portuguese road administration's pavement management system. Proceedings of the Third European Pavement and Asset Management Conference, CD Ed., chapter 1138.pdf, 1-10, Coimbra, Portugal.

Picado-Santos, L., and Ferreira, A. (2007). Development and implementation of a new pavement management system. Proceedings of the Fifth International Symposium on Maintenance and Rehabilitation of Pavements and Technological Control, CD Ed., 433-438, Utah, USA.

Picado-Santos, L., Ferreira, A., Costa Pereira, F. and Conceição Azevedo, M. (2006). The evaluation of maintenance and rehabilitation strategies in the pavement management system of the Portuguese road administration. Proceedings of the $4^{\text {th }}$ Portuguese Road Congress, Lisbon, Portugal, 1-10 (in Portuguese).

Randolph, N. and Gardner, D. (2008). Professional Visual Studio 2008. Wiley Publishing, Inc., Indiana, USA, 1-946.

Sebaaly, P. E., Hand, A., Epps, J. and Bosch C. (1996). Nevada's approach to pavement management. Transportation Research Record 1524, Transportation Research Board, Washington, D.C., 109-117. 
Stephenson, M., Epps, R. and Kennedy, C. (2004). Development of deterioration models for local authority roads. Proceedings of the Institution of Civil EngineersMunicipal Engineer 157 (3), 167-172.

Trindade, M. and Horta, C. (2009). Pavement management system of Estradas de Portugal, S.A. Proceedings of the $15^{\text {th }}$ Congreso Ibero-Latinoamericano del Asfalto, CD Ed., 1351-1360, Lisboa, Portugal (in Portuguese).

Yuan, J., Skibniewski, M., Li, Q. and Zheng, L. (2010). Performance objectives selection model in public-private partnership projects based on the perspective of stakeholders. Journal of Management in Engineering, 26 (2), 89-104.

Wang, F., Zhang, Z., and Machemehl, R. (2003). Decision making problem for managing pavement maintenance and rehabilitation projects. Proceedings of the 82nd Transportation Research Board Annual Meeting (CD-ROM), TRB, Washington, D.C.

Wang, K. and Zaniewski, J. (1996). 20/30 hindsight: the new pavement optimization in the Arizona state highway network. Interfaces, 26 (3), 77-89.

Wong, W., He, G. and Luk, S. (2003). Development of road management systems in China. Proceedings of the Institution of Civil Engineers-Transport, 156 (4), 179-188.

Wu, Z. and Flintsch, G. (2009). Pavement preservation optimization considering multiple objectives and budget variability. Journal of Transportation Engineering, 135 (5), 305-315. 
Yoo, J. and Garcia-Diaz, A. (2008). Cost-effective selection and multi-period scheduling of pavement maintenance and rehabilitation strategies. Engineering Optimization, 40 (3), 205-222. 



\section{Chapter 4}

\section{Pavement maintenance}

programming considering two objectives: minimization of maintenance and rehabilitation costs and maximization of the residual value of pavements

\subsection{Introduction}

Nowadays in Portugal, as in many other countries, due to the economic crisis, the trend of budgetary pressures on highway agencies is increasing. At the same time, road users are increasingly demanding in terms of highway quality, comfort and safety. Several highway maintenance and rehabilitation projects have been delayed because of budget constraints. The economic crisis has also stimulated a wider debate about the state of Portugal's road network infrastructure and the consequences of past large-investment in 
new construction and under-investment in maintenance and rehabilitation. Fortunately, in the last three years, the construction of new highways has almost ceased and the scarce funds available have been used essentially for maintenance and rehabilitation of existing highways and roads.

To meet these challenges, highway agencies are looking for more cost-effective methodologies for pavement maintenance programming at network-level. For example, in a plenary session at the 2013 Portuguese Road Conference (CRP 2013), the president of Estradas de Portugal said that it is possible and necessary to reduce maintenance and rehabilitation costs using new methodologies and also new technologies. So, in the coming years, highway agencies are open to new Decision-Aid Tools (DAT) that minimise the costs related to their area of action.

Almost all the pavement maintenance programming tools currently in use are based on single-objective optimization. In these single-objective analyses, those requirements not selected as the objective function are imposed as constraints in the model formulation. This can be viewed as interference in the optimization process by artificially setting limits on selected problem parameters. As a result, the solutions obtained from these single-objective analyses are sub-optimal compared with ones derived from multiobjective considerations (Fwa et al. 2000). In addition, only few applications have made use of multi-objective optimization techniques. Fwa et al. (2000) developed an optimization model with three objectives: the maximization of the work production; the minimization of the total maintenance cost; and the maximization of overall network pavement condition. The model was applied to four highway classes, each one with three need-urgency levels (high, medium, low), considering four $M \& R$ interventions 
and a planning time-span of 45 working days. Wang et al. (2003) developed a different optimization model with two objectives: the maximization of the total $M \& R$ effectiveness; and the minimization of the total M\&R disturbance cost. The model was applied to a small network of 10 road sections considering a planning time-span of five years. Wu and Flintsch (2009) developed another optimization model with two objectives: the maximization of the network level of service; and the minimization of the total M\&R cost. The model was applied to four pavement state quality types (excellent, good, fair and poor) considering four M\&R interventions and a planning time-span of 10 years. Meneses et al. (2013) developed an optimization model with two objectives: the minimization of maintenance and rehabilitation costs; and the minimization of user costs. The model was applied to a municipal road network with 36 pavement sections considering five $M \& R$ interventions and a planning time-span of 20 years. Meneses and Ferreira (2013) applied the same optimization model to a national road network with 32 pavement sections considering five $M \& R$ interventions and a planning time-span of 20 years.

None of these multi-objective optimization models considers the maximization of the residual value of pavements at the end of the planning period which is very important for highway agencies. More residual value of pavements is directly related with more residual life of pavements which means lower maintenance and rehabilitations costs in the next planning period.

This chapter presents the development and implementation of a Multi-objective Decision-Aid Tool (MODAT) which considers two different objectives, the minimization of maintenance and rehabilitation costs and the maximization of the 
residual value of pavements at the end of the planning period. The MODAT is tested with data from the PMS used by the main Portuguese concessionaire (Estradas de Portugal, S.A.), the institution that acted until 2007 as the Portuguese Road Administration (Picado-Santos et al. 2006, Picado-Santos and Ferreira 2007, PicadoSantos and Ferreira 2008, Ferreira et al. 2008, Trindade and Horta 2009, Ferreira et al. 2011, Horta et al., 2013).

\subsection{Multi-Objective Decision-Aid Tool}

\subsubsection{Introduction}

The Multi-Objective Decision-Aid Tool (MODAT) consists of the components shown in Figure 4.1: the objectives of the analysis; the data and the models of the road pavements; the constraints that the system must guarantee; and the results. Several objectives can be considered in the analysis, including the minimization of maintenance and rehabilitation costs, the maximization of the residual value of pavements at the end of the planning period, etc. The results of the application of the MODAT to a road network are constituted by the $M \& R$ plan, the costs report, and the structural and functional quality report. The data and the models about the road pavements, and the constraints that the system must guarantee are described in the following section. 


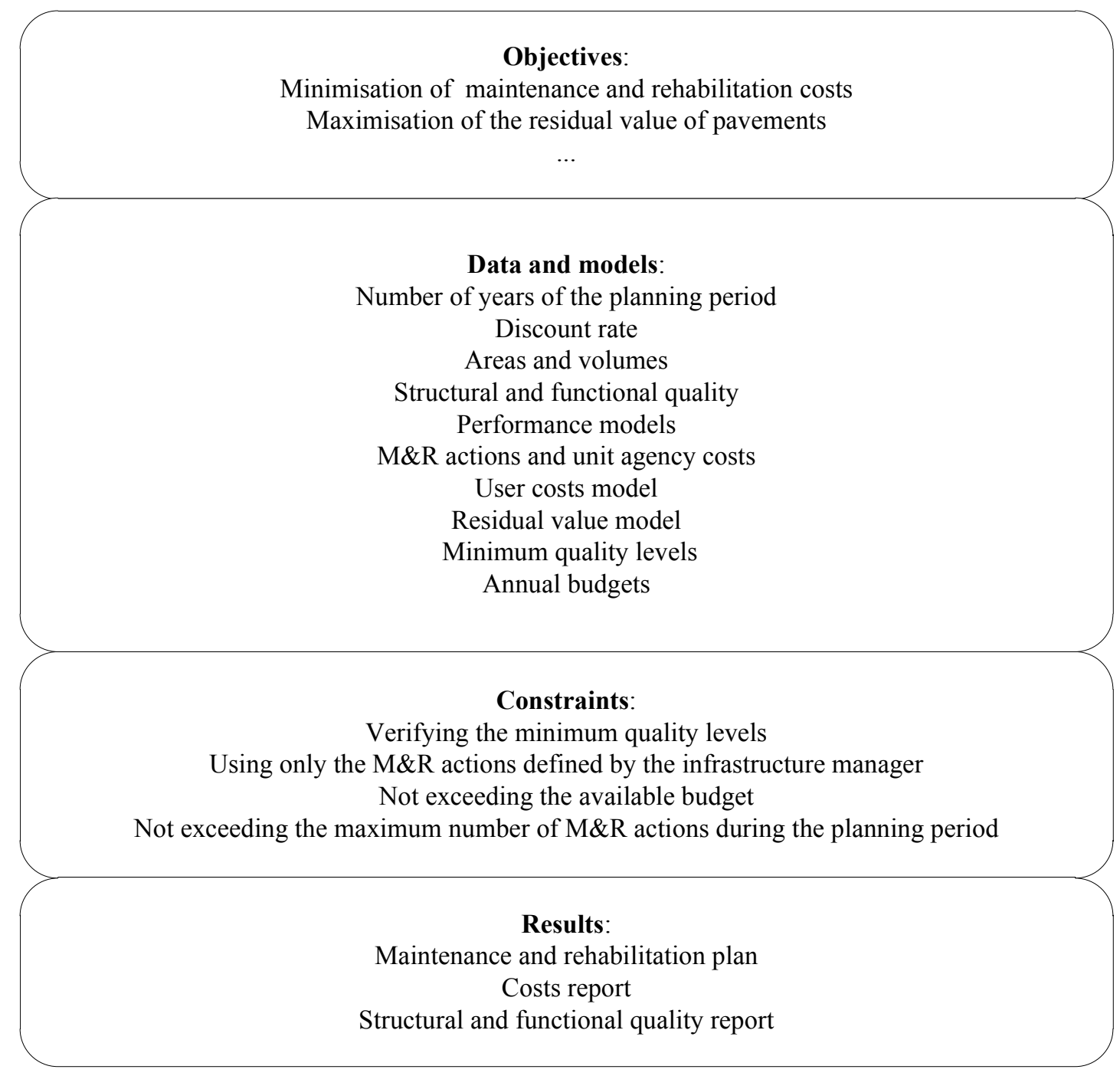

Figure 4-1 - MODAT components

\subsubsection{Optimization model}

The notation used in the model formulation can be seen in Appendix I and details of the deterministic optimization model can be found in Appendix II. Equation (4.1) is one of the objective functions of the optimization model and expresses the minimization of maintenance and rehabilitation costs over the planning time-span. Equation (4.2) is the second objective function and expresses the maximization of the residual value of pavements at the end of the planning period. 
The constraints represented by Equation (4.3) correspond to the pavement condition functions. They express pavement condition in terms of the PSI in each road section and year as a function of the initial PSI and the M\&R actions previously applied to a road section. The functions shown in Equations (4.12)-(4.15) of Appendix III are used to evaluate the PSI over time. The quality of the road pavements in the present year is evaluated by the PSI, representing the condition of the pavement according to the following parameters: longitudinal roughness, rutting, cracking, surface disintegration and patching. This global quality index, calculated through Equation (4.12), ranges from 0.0 to 5.0 , with 0.0 for a pavement in extremely poor condition and 5.0 for a pavement in very good condition. In practice, with this index a new pavement rarely exceeds the value 4.5 and a value of 2.0 is generally defined as the minimum quality level (MQL) for national roads considering traffic safety and comfort. Equation (4.13) represents the pavement performance model used for flexible pavements. This pavement performance model is the one used in the AASHTO flexible pavement design method (AASHTO 1993, C-SHRP 2002). This design approach applies several factors such as the change in $P S I$ over the design period, the number of $80 \mathrm{kN}$ equivalent single axle load applications, material properties, drainage and environmental conditions, and performance reliability, to obtain a measure of the required structural strength through an index known as the structural number $(S N)$. The $S N$ is then converted to pavement layer thicknesses according to layer structural coefficients representing relative strength of the layer materials. The $S N$ in each road section and year of the planning period can be calculated by Equation (4.14). The number of $80 \mathrm{kN}$ equivalent single axle load applications is computed using Equation (4.15). The use of a pavement performance 
model for pavement design into a PMS allows the gap to be closed between project and network management, which is an important objective to be achieved and one that has been mentioned by several researchers (Ferreira et al. 2009, Haas 2012). This pavement performance model was chosen from a range of current models implemented in several PMS because it is widely used and tested. Nevertheless, other pavement performance models can be used instead, such as, for example, the pavement performance models of HDM-4 (AIPCR, 2000), the deterioration models developed for local authority roads by Stephenson et al. (2004), or the deterioration models developed for use in the Swedish PMS (Lang and Dahlgren 2001, Lang and Potucek 2001, Ihs and Sjögren 2003, Andersson 2007). Equation (4.13) defines a pavement performance model in terms of PSI as a function of the number of $80 \mathrm{kN}$ equivalent single axle load applications (Figure 4.2) or the number of years of service time. An incremental change in the present serviceability index $\left(\Delta P S I_{t-1, t}\right)$ corresponds to an estimated incremental change in load applications $\left(\left(\Delta \mathrm{W}_{80}\right)_{t-1, t}\right)$ and, at the same time, to an incremental service time interval $\left(\Delta T_{t-1, t}\right)$. The Present Serviceability Index in year $t\left(P S I_{t}\right)$ is defined as the difference between the serviceability index in year $t-1\left(P S I_{t-1}\right)$ and the incremental change in the present serviceability index $\left(\Delta P S I_{t-1, t}\right)$. At the same time, the Present Serviceability Index in year $t\left(P S I_{t}\right)$ is defined as the difference between the initial serviceability index $\left(P S I_{\mathrm{o}}\right)$ and the total incremental change in the present serviceability index $\left(\triangle P S I_{0, t}\right)$. The Present Serviceability Index in year $t\left(P S I_{t}\right)$ ranges between its initial value of about 4.5 (value for a new pavement) and the AASHTO lowest allowed PSI value of 1.5 (value for a pavement of a national road at the end of its service life). 


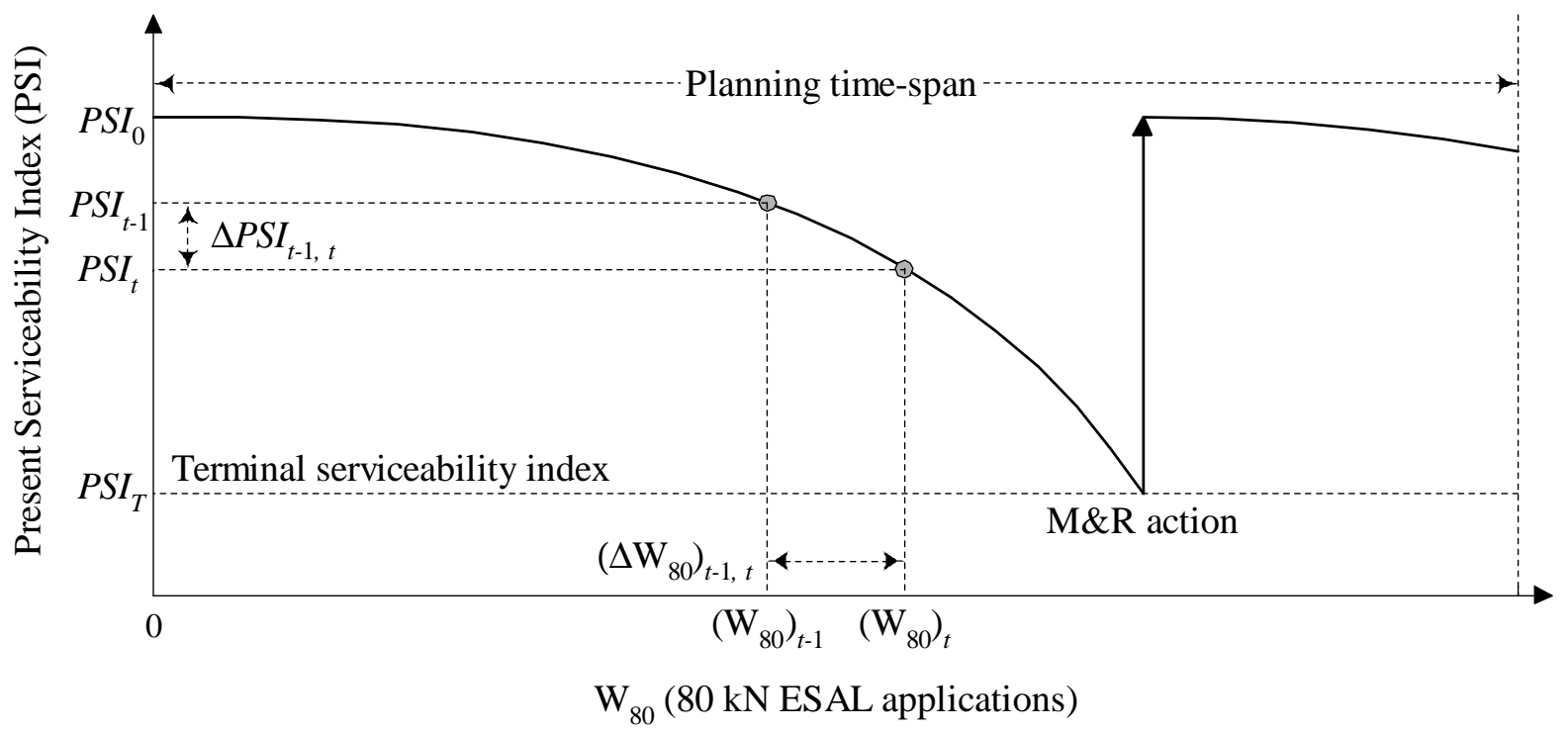

Figure 4-2 - Pavement performance curve as a function of equivalent single-axle load applications

The constraints given by Equation (4.4) are the warning level constraints. They define the MQL considering the PSI index for each pavement of the road network. The warning level adopted in this study was a PSI value of 2.0. A corrective M\&R operation appropriate for the rehabilitation of a pavement must be performed on a road section when the PSI value is lower than 2.0.

The constraints represented by Equation (4.5) represent the feasible operation sets, i.e., the $M \& R$ operations that can be performed on each road section each year. These operations depend on the pavement condition characterising the section. In the present study the same five different $M \& R$ operations were considered, corresponding to nine M\&R actions applied individually or in combination with others, as in previous studies (Picado-Santos and Ferreira 2008, Ferreira et al. 2008). The types of M\&R actions and operations considered are presented in Tables 4.1 and 4.2. The $M \& R$ action costs 
considered in this study, calculated using information from M\&R works executed on the Castelo Branco road network, are also presented in Tables 4.1 and 4.2.

As shown in Table 4.3, the operations to apply to road sections depend on the warning level. M\&R operation 1 which corresponds to "do nothing" is applied to a road section if the PSI value is above the warning level, i.e., if the PSI value is greater than 2.0. M\&R operation 5 is the operation that must be applied to a road section when the warning level is reached, i.e., this operation is applied to solve pavement serviceability problems. This operation has the longest efficiency period which is defined as the time between its application to the pavement and the time when the pavement reaches the warning level for the PSI. M\&R operations 2, 3, 4 and 5 are alternative operations that can be applied instead of operation 1 (see Table 4.4). In this case they constitute preventive M\&R operations. The analysis of Tables 4.3 and 4.4 clearly shows that the application of $M \& R$ operations may be corrective or preventive. An $M \& R$ operation is corrective if it is performed when the warning level is reached, and it is preventive if it is performed before the warning level is reached. When deciding which $M \& R$ operations should be applied in a given year to a given road section with $P S I$ value above the warning level, it is possible to select either the simplest operation (M\&R operation 1) or a preventive operation (M\&R operation 2, 3, 4 or 5). In fact, selecting a preventive operation may be more efficient (less costly) in the medium or long-term. 
Table 4-1 - M\&R actions

\begin{tabular}{clc}
\hline M\&R action & \multicolumn{1}{c}{ Description } & Cost \\
\hline 1 & Do nothing & $€ 0.00 / \mathrm{m}^{2}$ \\
2 & Tack coat & $€ 0.41 / \mathrm{m}^{2}$ \\
3 & Longitudinal roughness levelling $(1 \mathrm{~cm})$ & $€ 1.23 / \mathrm{m}^{2}$ \\
4 & Longitudinal roughness levelling $(2 \mathrm{~cm})$ & $€ 2.45 / \mathrm{m}^{2}$ \\
5 & Membrane anti-reflection of cracks & $€ 1.88 / \mathrm{m}^{2}$ \\
6 & Base layer $(10 \mathrm{~cm})$ & $€ 8.63 / \mathrm{m}^{2}$ \\
7 & Binder layer $(5 \mathrm{~cm})$ & $€ 6.13 / \mathrm{m}^{2}$ \\
8 & Non-structural wearing layer & $€ 3.13 / \mathrm{m}^{2}$ \\
9 & wearing layer $(5 \mathrm{~cm})$ & $€ 6.69 / \mathrm{m}^{2}$ \\
\hline
\end{tabular}

Table 4-2 - M\&R operations

\begin{tabular}{clcc}
\hline M\&R operation & \multicolumn{1}{c}{ Description } & M\&R actions involved & Cost \\
\hline 1 & Do nothing & 1 & $€ 0.00 / \mathrm{m}^{2}$ \\
2 & Non-structural maintenance & $2+3+2+8$ & $€ 5.18 / \mathrm{m}^{2}$ \\
3 & Minor rehabilitation & $2+4+2+5+2+9$ & $€ 15.31 / \mathrm{m}^{2}$ \\
4 & Medium rehabilitation & $2+4+2+5+2+7+2+9$ & $€ 18.79 / \mathrm{m}^{2}$ \\
5 & Major rehabilitation & $2+4+2+5+2+6+2+9$ & $€ 21.29 / \mathrm{m}^{2}$ \\
\hline
\end{tabular}

Table 4-3 - Application of the simplest M\&R operations

\begin{tabular}{cccc}
\hline Warning level & $P S I$ & M\&R operation & M\&R action \\
\hline \multirow{2}{*}{$P S I=2.0$} & $\geq 2.0$ & 1 & 1 \\
& $<2.0$ & 5 & $2+4+2+5+2+6+2+9$ \\
\hline
\end{tabular}

Table 4-4 - Alternatives to M\&R operations

\begin{tabular}{cccccc}
\hline \multirow{2}{*}{ M\&R operation } & \multicolumn{5}{c}{ Alternative M\&R operations } \\
\cline { 2 - 6 } & 1 & 2 & 3 & 4 & 5 \\
\hline 1 & $v$ & $v$ & $v$ & $v$ & $v$ \\
2 & - & $v$ & $v$ & $v$ & $v$ \\
3 & - & - & $v$ & $v$ & $v$ \\
4 & - & - & - & $v$ & $v$ \\
5 & - & - & - & - & $v$ \\
\hline
\end{tabular}


The constraints given by Equation (4.6) state that only one M\&R operation per road section should be performed in each year. The constraints represented by Equation (4.7) represent the agency cost functions. They express the costs for the road agency involved in the application of a given $M \& R$ operation to a road section in a given year as a function of the pavement condition in that section and year. These costs are obtained by multiplying the unit agency costs for the $M \& R$ actions involved in the $M \& R$ operation by the pavement areas to which the $M \& R$ actions are applied. The constraints defined by Equation (4.8) represent the user cost functions. They express the cost for road users as a function of the pavement condition in that section and year. To calculate the vehicle operation cost, Equation (4.16) of Appendix III was used. This Equation is currently in use in the Estradas de Portugal's PMS (Picado-Santos and Ferreira 2008, Ferreira et al. 2008, Ferreira et al. 2011). The constraints represented by Equation (4.9) represent the pavement residual value functions. They express the value of the pavement of a road section at the end of the planning time-span as a function of pavement condition at that time. To calculate the residual value of pavements Equation (4.17) of Appendix III was used. This equation was defined based on the AASHTO guide for design of pavement structures (AASHTO, 1993) considering a terminal value of 1.5. The constraints given by Equation (4.10) are the annual budget constraints. They specify the maximum amount of money to be spent on M\&R operations during each year. The constraints represented by Equation (4.11) were included in the model to avoid frequent $M \& R$ operations applied to the same road section. 


\subsubsection{Generation of Pareto optimal solutions}

Multi-objective optimization decouples the optimization and decision-making process by first analysing all feasible candidate solutions and subsequently presents the tradeoffs between them to a decision maker. This allows the decision maker to articulate individual preferences between alternative solutions and to select an optimal solution. Such an approach has been widely applied to solve engineering problems where costquality trade-offs need to be made between multiple conflicting and possibly immeasurable criteria, e.g. having different units. Because of the contradiction and possible immeasurability of the objective functions, a single solution that would be optimal for all the objectives simultaneously does not exist in general. Instead, multiple solutions exist, and therefore a criterion to define optimality in the multi-objective context is required (Hoffmann et al. 2006).

After defining the mathematical formulation of the optimization model, the next step consists of the adoption of the appropriate mechanism for generating a representative set of Pareto optimal solutions (Meneses and Ferreira 2013). At this point it is evident that, given the particular features of the optimization model (a combinatorial problem with multiple objectives), it is not possible to use an exact algorithm for solving the problem efficiently. In this section, we used a genetic algorithm approach that could overcome the difficulties inherent to the nature of the optimization model.

There are several optimization methods that can be used to generate the set of Pareto optimal solutions. Hwang and Masud (1979) and later Miettinen (1999) classified them into the following four types: no-preference methods; posterior methods; a priori methods; and interactive methods. The no-preference methods do not assume any 
information about the importance of different objectives and a heuristic is used to find a single optimal solution. Posterior methods use preference information of each objective and iteratively generate a set of Pareto optimal solutions. Alternatively, a priori methods use more information about the preference of objectives and usually find one preferred Pareto optimal solution. Interactive methods use the preference information progressively during the optimization process.

According to Marler and Arora (2004), no single approach is, in general, superior to the other methods. Rather, the selection of a specific method depends on the users' preferences, the type of information provided, the solution requirements, and the availability of software. This study uses a genetic algorithm approach with the incorporation of the weighting sum method. This method, as the name suggests, combines a set of objectives into a single objective by pre-multiplying each objective with a user-defined weight. This method is the simplest approach and is probably the most widely used (Deb 2008, Wu and Flintsch 2009). Setting relative weights for individual objectives becomes a central issue in applying this method. As the weight vector for the multiple objectives often depends highly on the magnitude of each objective function, it is desirable to normalise those objectives to achieve roughly the same scale of magnitude. Equation (4.18) represents the application of the weighting sum method (Deb 2008) to the two objective functions of the optimization model presented in the previous section.

Minimise $\bar{Z}=w_{A C} \cdot \frac{A C_{i}-A C_{\min }}{A C_{\max }-A C_{\min }}+(-1) \cdot w_{R V} \cdot \frac{R V_{i}-R V_{\min }}{R V_{\max }-R V_{\min }}$ 
where: $\bar{Z}$ is the normalised value of a solution; $w_{A C}$ and $w_{R V}$ are the weight values for each objective function; $A C_{i}$ and $R V_{i}$ are the individual objective function values that depend on the decision variables values; $A C_{\min }$ and $R V_{\min }$ are the minimum values obtained for each objective; $A C_{\max }$ and $R V_{\max }$ are the maximum values obtained for each objective.

The second objective function corresponds to the maximization of the residual value of pavements at the end of the planning period. When an objective is required to be maximised, the duality principle (Deb 2008) can be used to transform the original objective of maximization into an objective of minimization by multiplying the objective function by (-1). The range of values for the various objective functions $\left(A C_{\min }, A C_{\max }\right)$ and $\left(R V_{\min }, R V_{\max }\right)$ are obtained by applying the optimization model considering only one objective at each time, i.e. varying the weight values vector $\left(w_{A C}\right.$, $\left.w_{R V}\right)$ between the extreme situations of $(1,0)$ and $(0,1)$ and considering that, initially, all minimum values are 0 and all maximum values are 1 . Considering these two objectives (Figure 4.3), the ideal solution $\left(Z^{*}\right)$ corresponds to the minimum value of agency costs and the maximum value of the residual value of pavements. In general, this solution is a non-existent solution that is used as a reference solution. The nadir solution $\left(\mathrm{Z}^{\mathrm{nad}}\right)$, which is used as the upper boundary to normalise the objective values in a common range, corresponds to the upper boundary of each objective in the entire Pareto optimal set and not in the entire search space $\left(\mathrm{Z}^{* *}\right)$. The Pareto optimal solution 
set is finally obtained by using the objective function defined by Equation (4.18), considering different combinations of the weight values.

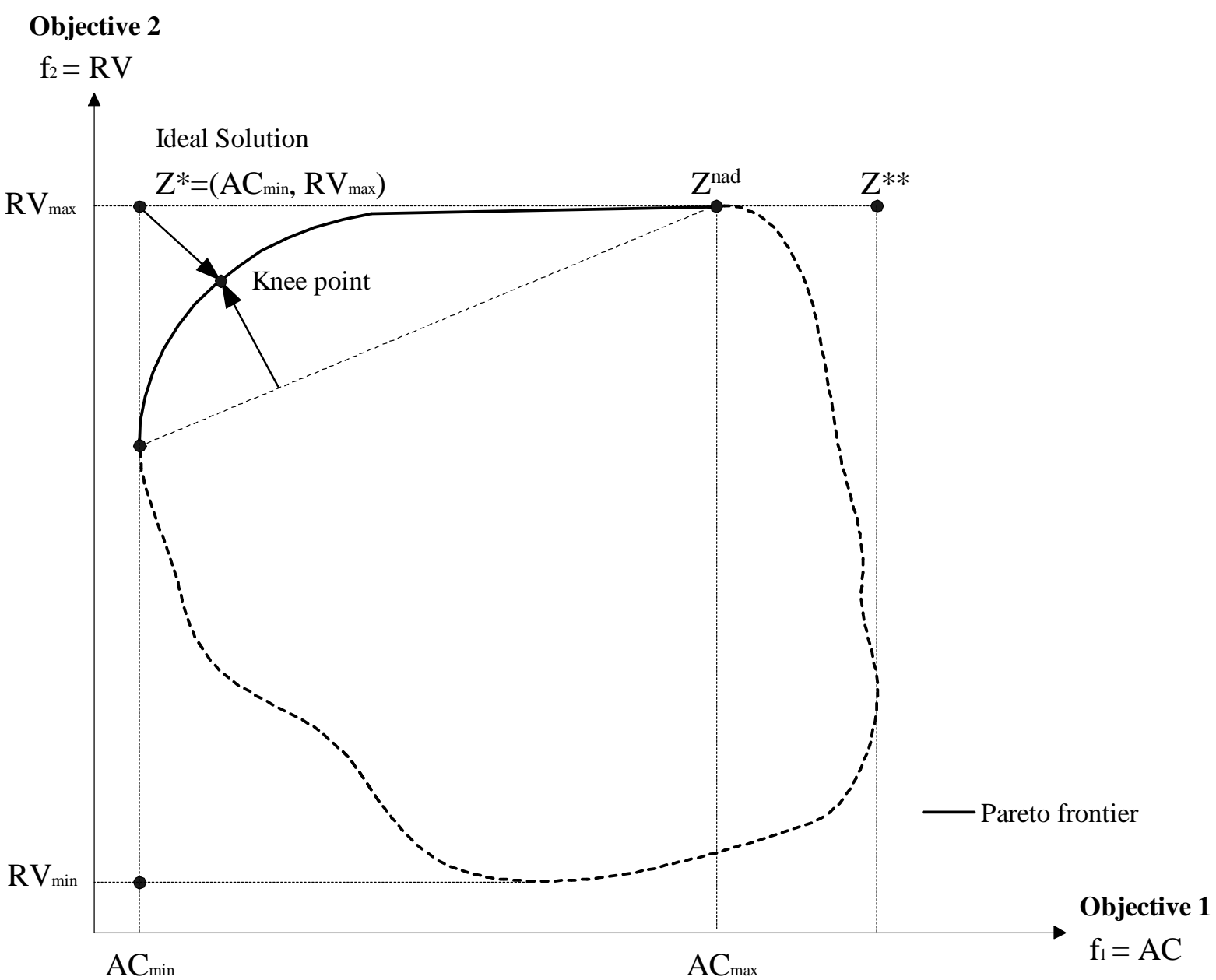

Figure 4-3 - The Pareto frontier and the ideal and nadir solutions

\subsubsection{Knee points and identification procedure}

When dealing with a multi-objective optimization problem, the decision maker has great difficulties in selecting a particular solution for implementation from the Pareto optimal solution set. Das (1999), to avoid this difficulty, developed the NormalBoundary Intersection (NBI) method to identify the so called "Knee point" of the Pareto frontier. Knee points represent the most interesting solutions of the Pareto frontier due 
to their implicit large marginal rates of substitution (Iniestra and Gutiérrez 2009). Considering only two objectives (Figure 4.3), the Knee is a point on the region of the Pareto frontier that results from the projection of a normal vector from the line connecting the end points of the Pareto frontier (the two individual optima). The "knee point" is the farthest Pareto point away from this line in the direction of the normal vector. Wu and Flintsch (2009) considered another method to identify the best solution of the Pareto frontier. As the ideal solution may not be achieved due to conflicting objectives, the best solution is the solution of the Pareto frontier that has the shortest normalised distance from the ideal solution, computed using Equation (4.19). This method to identify the so called "Knee point" of the Pareto frontier is based on TOPSIS method (Lofti et al. 2007, Deb 2008, Yuan et al. 2010, Mostafavi and Karamouz 2010). $D_{i}=\left[\left(\frac{A C_{i}-A C_{\min }}{A C_{\max }-A C_{\min }}-\bar{Z}_{1}^{*}\right)^{2}+\left(\frac{R V_{i}-R V_{\min }}{R V_{\max }-R V_{\min }}-\bar{Z}_{2}^{*}\right)^{2}\right]^{\frac{1}{2}}$

where: $D_{i}$ is the normalised distance between each Pareto solution point and the ideal solution point; $\bar{Z}_{1}^{*}$ and $\bar{Z}_{2}^{*}$ are the normalised values for each objective of the ideal solution (are equal to 0 or 1 depending on whether it is a minimization or maximization objective).

\subsubsection{Model solving}

The multi-objective optimization model presented in the previous section is extremely complex, being impossible to solve with exact optimization methods available through 
commercial packages like XPRESS-MP (FICO 2009) or GAMS-CPLEX (IBM 2009). It is only possible to solve with exact optimization methods for small, highly idealised problems, through complete enumeration. In fact, it can only be solved through heuristic methods. Nowadays, a large number of classic and modern heuristic methods are available (Deb 2008, Gendreau and Potvin 2005, Michalewicz and Fogel 2004) to solve this kind of complex optimization models. The optimization model and its heuristic solver were implemented in a computer program called MODAT. The heuristic method used to solve this optimization model is a genetic-algorithm (GA) that was implemented in Microsoft Visual Studio programming language (David et al. 2006, Randolph and Gardner 2008) adapting and introducing new functionalities to an existing GA program called GENETIPAV-D (Ferreira 2001, Ferreira et al. 2002) previously developed to solve single-objective deterministic optimization models. Since they were proposed by Holland (1975), genetic algorithms have been successfully used on many occasions to deal with complex engineering optimization problems. The MODAT applied to the Castelo Branco road network was run on a $2.2 \mathrm{GHz}$ personal computer (PC) with 2.0 GB RAM and 200 GB capacity. Each best solution given by the MODAT was obtained in approximately 30 minutes of computing time.

\subsubsection{Results of the application of the MODAT}

The MODAT was tested with data from the Estradas de Portugal's PMS (Picado-Santos and Ferreira 2008, Trindade and Horta 2009, Ferreira et al. 2011) to plan the maintenance and rehabilitation of the road network considering two objectives: the minimization of agency costs and the maximization of residual value of pavements. The 
Estradas de Portugal road network has a total length of $14,500 \mathrm{~km}$. The MODAT was applied only to the road network of the district of Castelo Branco, one of the 18 districts of Portugal. This road network has a total length of $589.9 \mathrm{Km}$ and the corresponding network model has 32 road sections. The discount rate considered in this study was $2.5 \%$.

Figure 4.4 represents the Pareto optimal set of solutions in the objective space by varying the weight values while Figure 4.5 represents the optimal set of normalised solutions. The "Knee point" was obtained considering the following weight values: $\left(w_{A C}, w_{R V}\right)=(0.81,0.19)$; and it corresponds to the following objective values $(A C$, $R V)=\left(€ 52.3 \times 10^{6}, € 38,4 \times 10^{6}\right)$. The range of values for the two objective functions is $\left(A C_{\text {min }}, \quad A C_{\text {max }}\right)=\left(€ 44.2 \times 10^{6}, € 206.0 \times 10^{6}\right)$ and $\left(R V_{\min }, R V_{\text {max }}\right)=\left(€ 10.9 \times 10^{6}\right.$, $€ 39.2 \times 10^{6}$ ). From Figures 4.4 and 4.5 , it can be concluded that, when varying the two weights through a grid of values from 0 to 1 with a fixed increment step, for example 0.05 , the two objective values were not transformed maintaining the same fixed range. Therefore, each weight value not only indicates the importance of an objective but also compensates, to some extent, for differences in objective function magnitudes. 


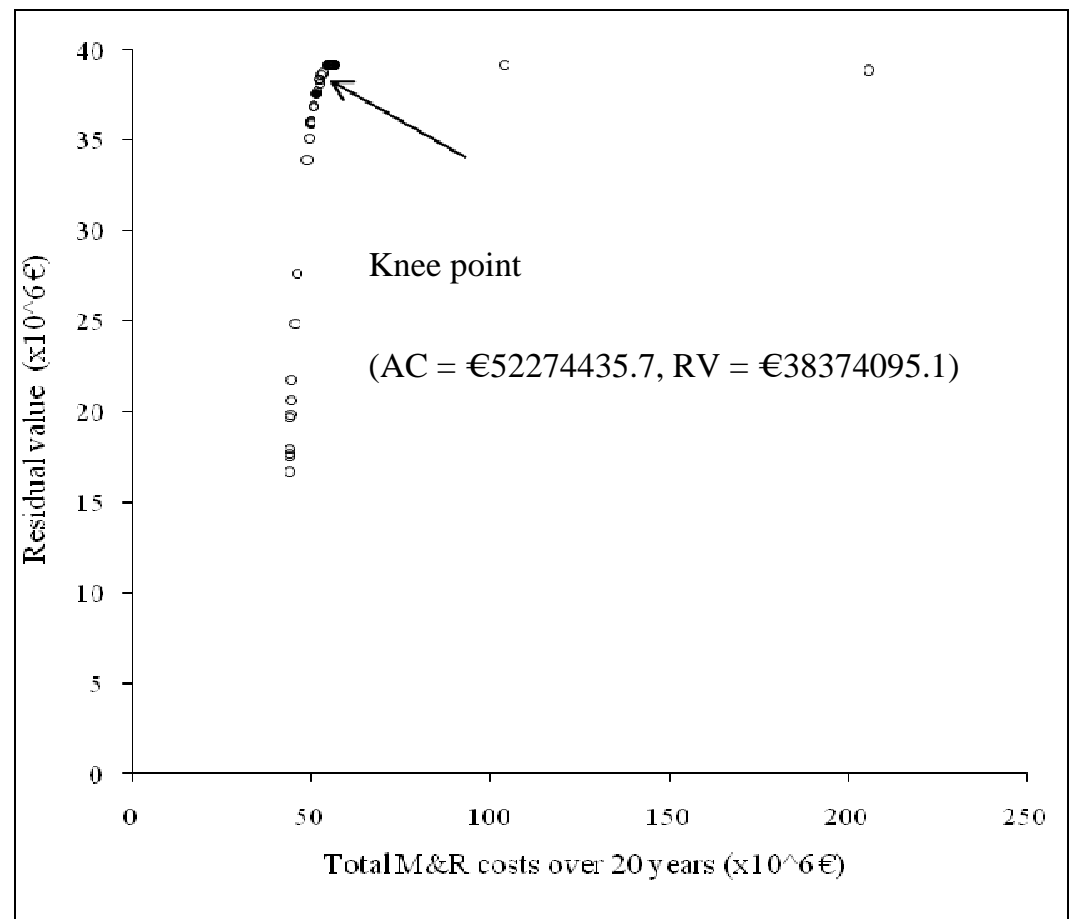

Figure 4-4 - Pareto optimal set of solutions

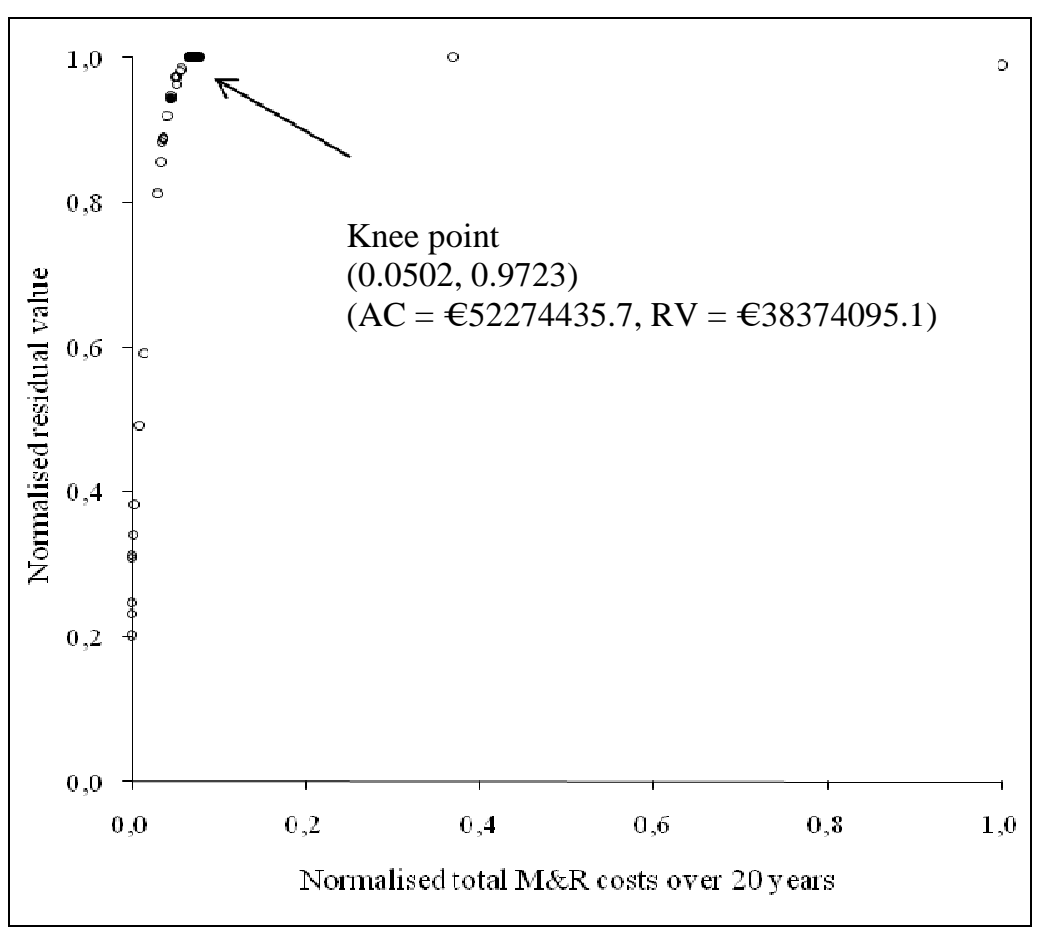

Figure 4-5 - Pareto optimal set of normalised solutions 
In multi-objective problems there is no perfect method to select one "optimal" solution from the Pareto optimal set of solutions. The final best-compromise solution is always up to the decision maker. For that purpose, four different M\&R solutions of the Pareto frontier were considered for comparison.

a) Solution I: Multi-objective optimization approach (corrective-preventive) considering the "Knee point" $\left(w_{A C}=0.81, w_{R V}=0.19\right)$;

b) Solution II: Multi-objective optimization approach (corrective-preventive) considering the following weights $\left(w_{A C}=1.00, w_{R V}=0.00\right)$;

c) Solution III: Multi-objective optimization approach (corrective-preventive) considering the following weights $\left(w_{A C}=0.00, w_{R V}=1.00\right)$;

d) Solution IV: Multi-objective optimization approach (corrective-preventive) considering the following weights $\left(w_{A C}=0.50, w_{R V}=0.50\right)$.

The costs and normalised costs during the entire planning time-span for these four Pareto optimal solutions are summarised in Figures 4.6 and 4.7, respectively. Figure 4.7 shows that, as expected, solution I ('Knee point') is the Pareto optimal solution with least normalised value of $M \& R$ costs minus residual value $(-0.83)$, which was the objective considered in the optimization model. Considering the non-normalised value of $M \& R$ costs minus residual value (Figure 4.6), it can be seen that this optimal solution continues to have the lowest value $\left(€ 13.9 \times 10^{6}\right)$. Figure 4.6 also shows that solution III, i.e. the solution of the multi-objective optimization approach (corrective-preventive) considering the weights $\left(w_{A C}=0.00, w_{R V}=1.00\right)$, is the Pareto optimal solution with the 
lowest total costs, computed by adding $M \& R$ costs and user costs and deducting the residual value. Figure 4.7 also shows that solution III is the Pareto optimal solution with the lowest total normalised costs. This happens because solution III was defined considering only the objective of minimization of the residual value of pavements, which gives high PSI values, at least at the end of the analysis period, which, as a consequence, originates lower user costs.

Figure 4.8 presents the predicted PSI average value over the years of the planning timespan for all the road network pavements and for each solution. By analysing this Figure it can be seen that solution III, i.e. the solution of the multi-objective optimization approach (corrective-preventive) considering the weights $\left(w_{A C}=0.00, w_{R V}=1.00\right)$, corresponds to the highest average PSI values, as expected, because this solution corresponds to the maximization of the residual value of pavements. Solution IV, i.e. the solution of the multi-objective optimization approach (corrective-preventive) considering the weights $\left(w_{A C}=0.50, w_{R V}=0.50\right)$, is the second best solution in terms of average PSI values, also as expected, because this solution corresponds to the second largest weight value for the residual value of pavements of the four solutions $\left(w_{R V}=\right.$ 0.50). This conclusion can be confirmed by analysing the user cost values presented in Figure 4.6 because they are directly proportional to the PSI values during all the planning time-span. 


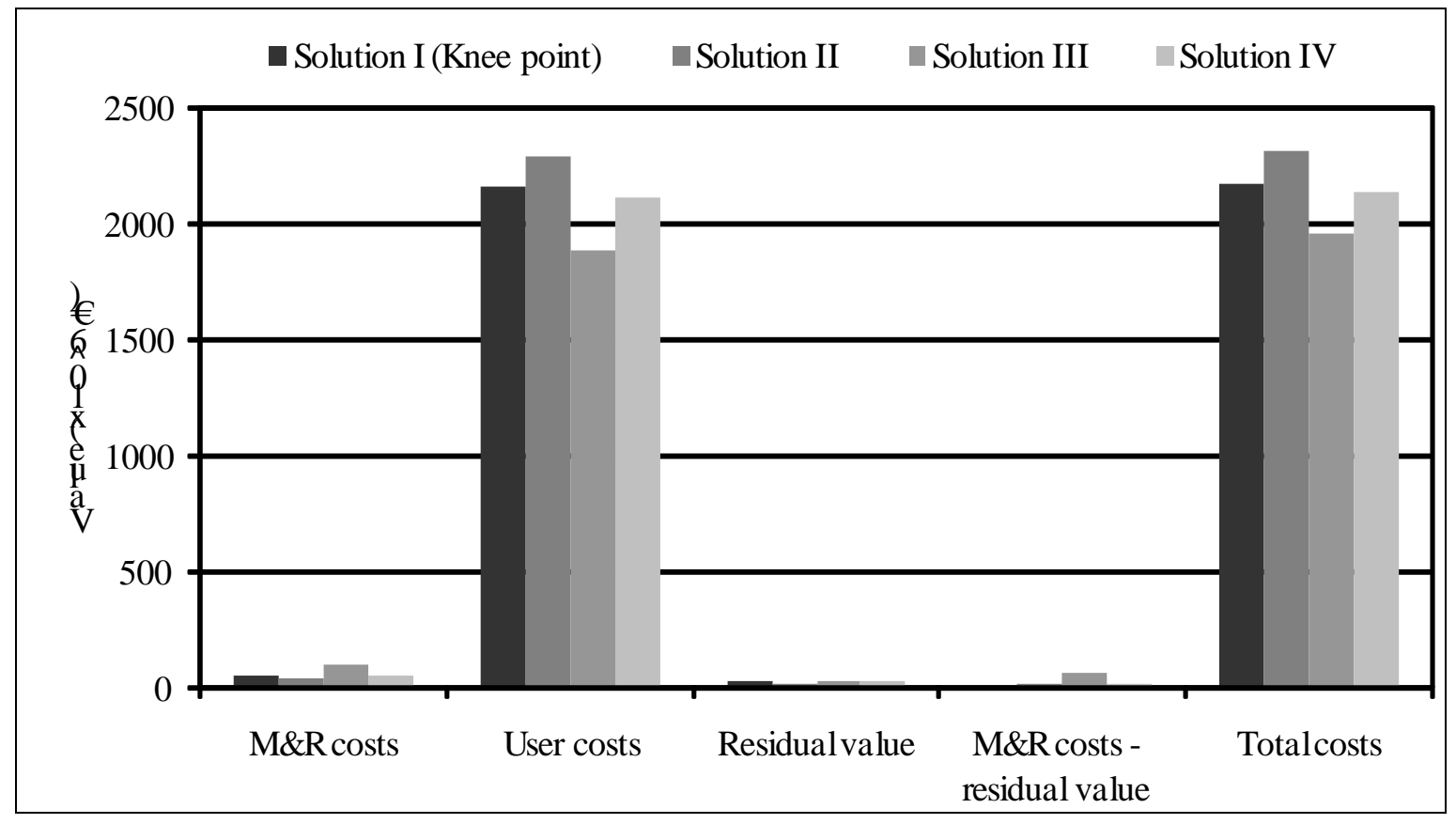

Figure 4-6 - Costs throughout the planning time-span of 20 years

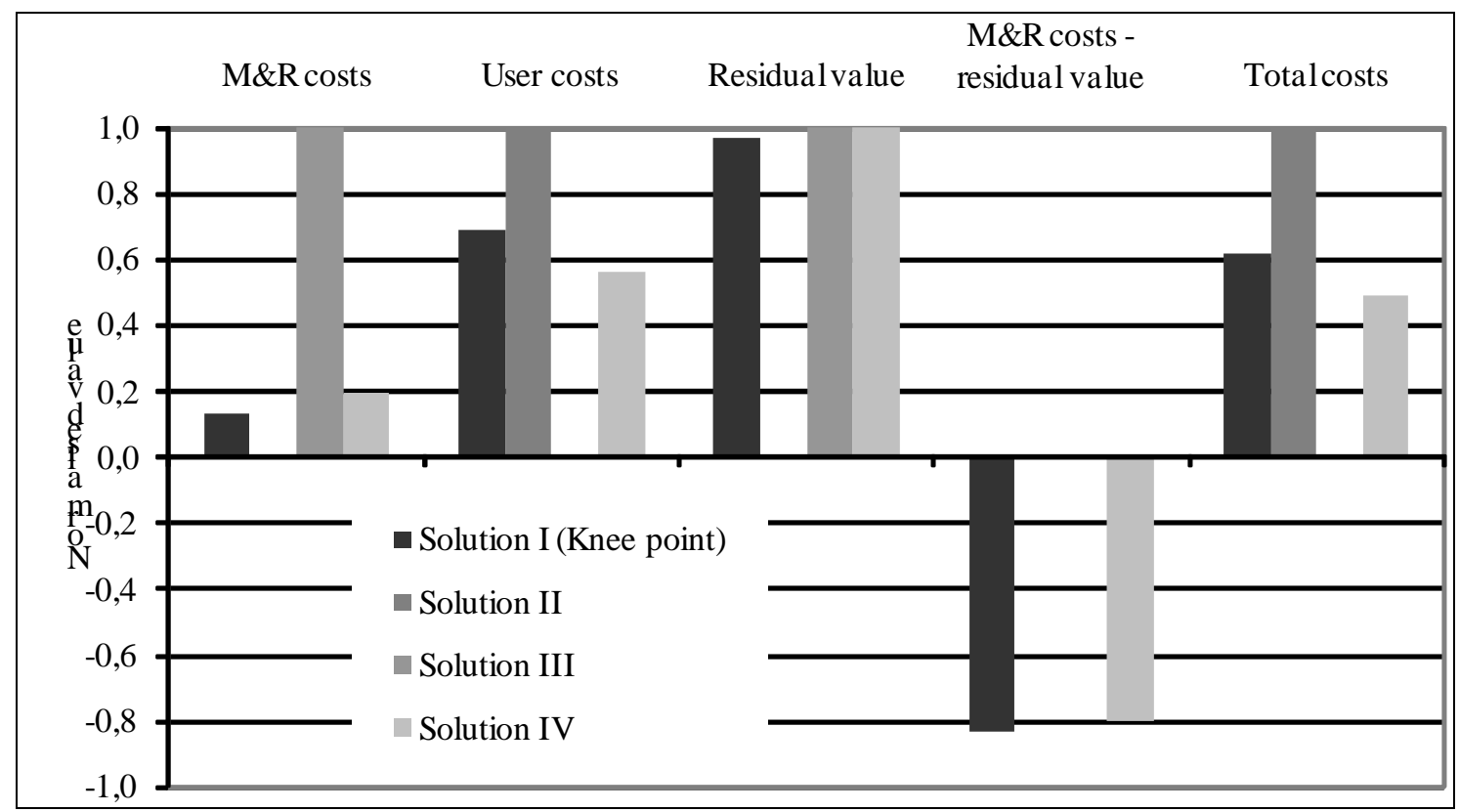

Figure 4-7 - Normalised costs throughout the planning time-span of 20 years 


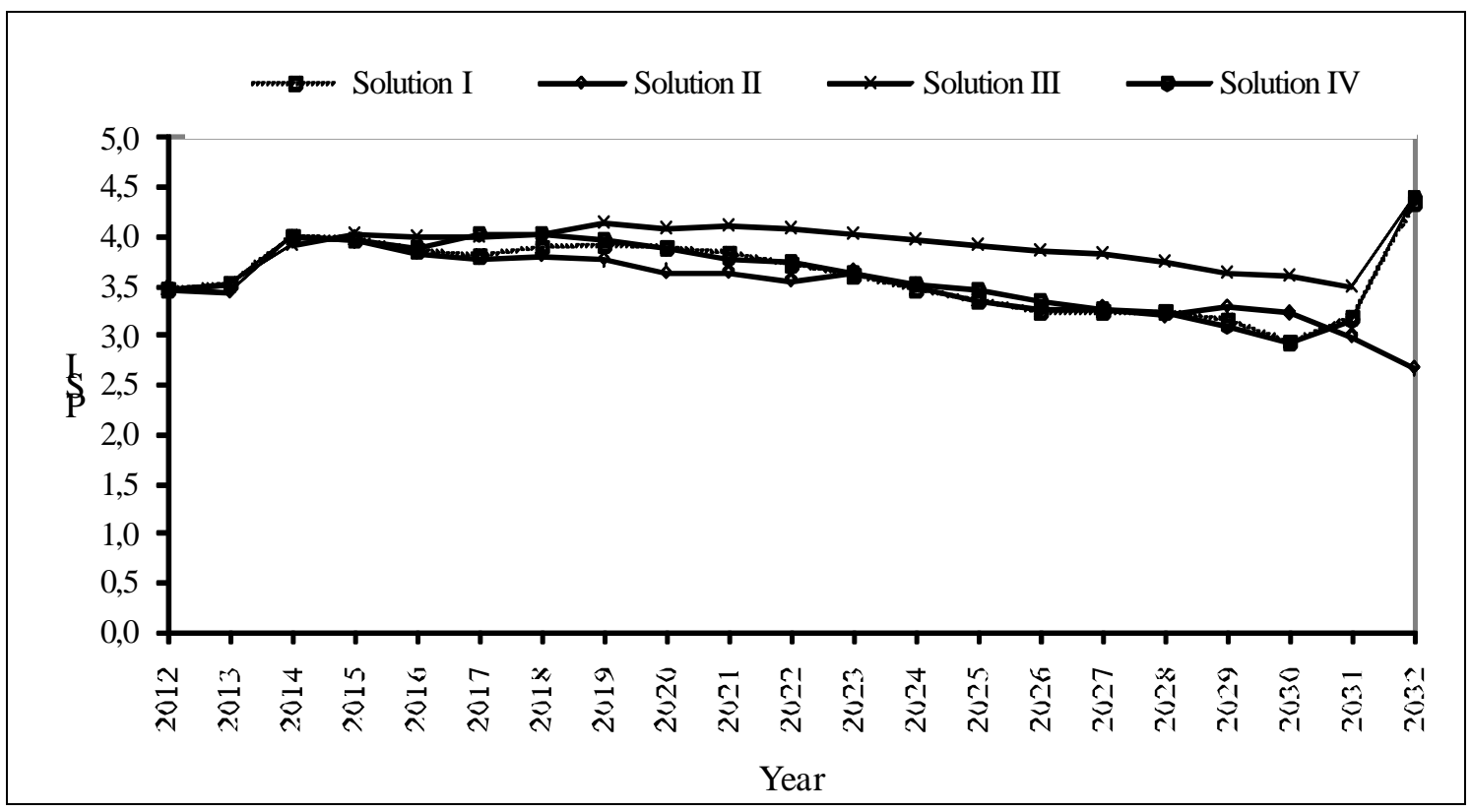

Figure 4-8 - PSI average value for all the road network pavements

In addition to these summarised results, the MODAT provides extensive information about the M\&R strategy to be implemented for each road section. To analyse these road section-linked results, four road sections were chosen with different attributes in the present year. Table 4.5 presents the attributes of these four road sections including their present PSI value. Table 4.6 presents the M\&R operations to be applied in the four road sections, considering the four M\&R solutions of the Pareto frontier. Figure 4.9 shows the predicted evolution of the PSI value over the years for pavement section 05001 of a national road as a consequence of the execution of the $M \& R$ plan. For this pavement section, which is in good condition (PSI value of 3.81), if solution I or solution IV of MODAT is adopted, only one M\&R operation 2 (non-structural maintenance) will be applied to the pavement section and it will be in the last year of the planning time-span (2031). If solution II of MODAT is adopted no M\&R operation will be needed during 
all the planning time-span. If solution III of MODAT is adopted the recommended M\&R operations are very different. The MODAT recommends one M\&R operation 4 (Medium rehabilitation) in year 2018 and the application of two M\&R operation 3 (minor rehabilitation) in years 2022 and 2031. The recommended M\&R operations are heavier in this solution because it corresponds to the maximization of residual value of pavements which means that the pavement quality must be always high.

A similar analysis could be made for any other pavement section. For example, for pavement section 05004 of another national road (see Table 4.6 and Figure 4.10), which is in intermediate condition (PSI value of 2.75), if solution I or solution IV of MODAT is adopted, $\mathrm{M} \& \mathrm{R}$ operation 3 (minor rehabilitation) will be applied in the first year of the planning time-span (2012) and the M\&R operation 2 (non-structural maintenance) will be applied in year 2031. If solution II of MODAT is adopted, only one M\&R operation 3 (minor rehabilitation) will be applied to the pavement section and it will be in the first year of the planning time-span (2012). If solution III of MODAT is adopted, the recommended M\&R operations are again very different. The MODAT recommends one $M \& R$ operation 5 (major rehabilitation) in year 2012, two M\&R operation 3 (minor rehabilitation) in years 2016 and 2031, and one M\&R operation 4 (medium rehabilitation) in year 2021. An identical analysis could be made for any other pavement section. Figures 4.11 and 4.12 present the predicted evolution of the PSI value over the years for pavement section 05003 and pavement section 05012, respectively. 
Table 4-5 - Attributes of road sections

\begin{tabular}{ccccc}
\hline Attributes & \multicolumn{2}{c}{ Road section } \\
\hline Section_ID & 05012 & 05004 & 05001 & 05003 \\
Road_class & EN & IC & IP & IC \\
Pavement_type & Flexible & Flexible & Flexible & Flexible \\
District & Castelo Branco & Castelo Branco & Castelo Branco & Castelo Branco \\
Length (m) & 21,455 & 19,439 & 1931 & 14,635 \\
Width (m) & 5.9 & 8.8 & 9.4 & 8.6 \\
Sub-grade_CBR (\%) & 5 & 10 & 6 & 4 \\
Structural_number & 2.47 & 3.51 & 5.20 & 4.80 \\
Age_of_pavements (years) & 16 & 14 & 8 & 3 \\
Annual_average_daily_traffic & 744 & 6,212 & 4316 & 5,828 \\
Annual_average_daily_heavy_traffic & 100 & 1000 & 300 & 1000 \\
Annual_growth_average_tax & 3.0 & 4.0 & 3.0 & 4.0 \\
Truck_factor & 2.0 & 4.0 & 3.0 & 4.0 \\
PSI & 1.79 & 2.75 & 3.81 & 3.90 \\
\hline
\end{tabular}

Table 4-6 - M\&R operations to be applied in road sections

\begin{tabular}{|c|c|c|c|c|c|c|c|c|c|c|c|c|c|c|c|c|c|c|c|c|c|}
\hline \multirow[b]{2}{*}{ Section } & \multirow[b]{2}{*}{$\mathrm{PSI}_{0}$} & \multicolumn{20}{|c|}{ Year } \\
\hline & & $\frac{N}{\stackrel{N}{N}}$ & $\underset{\omega}{\stackrel{\sim}{\sigma}}$ & $\frac{N}{\stackrel{D}{\perp}}$ & $\begin{array}{l}\stackrel{N}{\varrho} \\
\stackrel{u}{u}\end{array}$ & $\frac{N}{\circ}$ & $\stackrel{N}{\stackrel{\Xi}{\sigma}}$ & 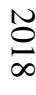 & $\frac{\sqrt{0}}{\sigma}$ & $\begin{array}{l}\text { No } \\
\text { N }\end{array}$ & $\begin{array}{l}\stackrel{N}{N} \\
\stackrel{N}{ }\end{array}$ & $\begin{array}{l}N \\
\text { N } \\
\text { N }\end{array}$ & $\begin{array}{l}\text { N } \\
\text { N }\end{array}$ & $\begin{array}{l}N \\
\stackrel{N}{N} \\
+\end{array}$ & $\begin{array}{l}\text { N } \\
\text { N } \\
\text { un }\end{array}$ & $\begin{array}{l}\text { No } \\
\text { న్ }\end{array}$ & $\begin{array}{l}\text { ON } \\
\text { N }\end{array}$ & $\begin{array}{l}\text { N్} \\
\text { N }\end{array}$ & $\begin{array}{l}\text { N్} \\
\text { N్ర }\end{array}$ & $\underset{\text { ల్ర }}{\stackrel{్}{0}}$ & $\underset{\omega}{\stackrel{\omega}{ٍ ٍ ~}}$ \\
\hline \multicolumn{22}{|c|}{ Solution I - Knee point $\left(w_{A C}=0.81, w_{R V}=0.19\right)$} \\
\hline 05012 & 1.79 & 5 & 1 & 1 & 1 & 1 & 1 & 1 & 1 & 1 & 1 & 1 & 1 & 1 & 1 & 1 & 1 & 1 & 1 & 1 & 2 \\
\hline 05004 & 2.75 & 3 & 1 & 1 & 1 & 1 & 1 & 1 & 1 & 1 & 1 & 1 & 1 & 1 & 1 & 1 & 1 & 1 & 1 & 1 & 2 \\
\hline 05001 & 3.81 & 1 & 1 & 1 & 1 & 1 & 1 & 1 & 1 & 1 & 1 & 1 & 1 & 1 & 1 & 1 & 1 & 1 & 1 & 1 & 2 \\
\hline 05003 & 3.90 & 1 & 1 & 1 & 1 & 1 & 3 & 1 & 1 & 1 & 1 & 1 & 1 & 1 & 1 & 2 & 1 & 1 & 1 & 1 & 2 \\
\hline \multicolumn{22}{|c|}{ Solution II $\left(w_{A C}=1.00, w_{R V}=0.00\right)$} \\
\hline 05012 & 1.79 & 5 & 1 & 1 & 1 & 1 & 1 & 1 & 1 & 1 & 1 & 1 & 1 & 1 & 1 & 1 & 1 & 1 & 1 & 1 & 1 \\
\hline 05004 & 2.75 & 3 & 1 & 1 & 1 & 1 & 1 & 1 & 1 & 1 & 1 & 1 & 1 & 1 & 1 & 1 & 1 & 1 & 1 & 1 & 1 \\
\hline 05001 & 3.81 & 1 & 1 & 1 & 1 & 1 & 1 & 1 & 1 & 1 & 1 & 1 & 1 & 1 & 1 & 1 & 1 & 1 & 1 & 1 & 1 \\
\hline 05003 & 3.90 & 1 & 1 & 1 & 1 & 1 & 2 & 1 & 1 & 1 & 1 & 3 & 1 & 1 & 1 & 1 & 1 & 1 & 1 & 1 & 1 \\
\hline \multicolumn{22}{|c|}{ Solution III $\left(w_{A C}=0.00, w_{R V}=1.00\right)$} \\
\hline 05012 & 1.79 & 5 & 1 & 1 & 1 & 3 & 1 & 1 & 1 & 1 & 1 & 1 & 1 & 1 & 1 & 1 & 1 & 1 & 1 & 1 & 2 \\
\hline 05004 & 2.75 & 5 & 1 & 1 & 1 & 3 & 1 & 1 & 1 & 1 & 4 & 1 & 1 & 1 & 1 & 1 & 1 & 1 & 1 & 1 & 3 \\
\hline 05001 & 3.81 & 1 & 1 & 1 & 1 & 1 & 1 & 4 & 1 & 1 & 1 & 3 & 1 & 1 & 1 & 1 & 1 & 1 & 1 & 1 & 3 \\
\hline 05003 & 3.90 & 1 & 1 & 1 & 1 & 1 & 1 & 5 & 1 & 1 & 1 & 1 & 1 & 1 & 5 & 1 & 1 & 1 & 1 & 1 & 3 \\
\hline \multicolumn{22}{|c|}{ Solution IV $\left(w_{A C}=0.50, w_{R V}=0.50\right)$} \\
\hline 05012 & 1.79 & 5 & 1 & 1 & 1 & 1 & 1 & 1 & 1 & 1 & 1 & 1 & 1 & 1 & 1 & 1 & 1 & 1 & 1 & 1 & 2 \\
\hline 05004 & 2.75 & 3 & 1 & 1 & 1 & 1 & 1 & 1 & 1 & 1 & 1 & 1 & 1 & 1 & 1 & 1 & 1 & 1 & 1 & 1 & 2 \\
\hline 05001 & 3.81 & 1 & 1 & 1 & 1 & 1 & 1 & 1 & 1 & 1 & 1 & 1 & 1 & 1 & 1 & 1 & 1 & 1 & 1 & 1 & 2 \\
\hline 05003 & 3.90 & 1 & 1 & 1 & 1 & 2 & 1 & 1 & 1 & 1 & 3 & 1 & 1 & 1 & 1 & 1 & 1 & 1 & 1 & 1 & 2 \\
\hline
\end{tabular}

KEY (M\&R actions):

$\mathbf{1}$ - Do nothing; 2 - Non structural maintenance; 3 - Minor rehabilitation; 4 - Medium rehabilitation; 5

- Major rehabilitation 


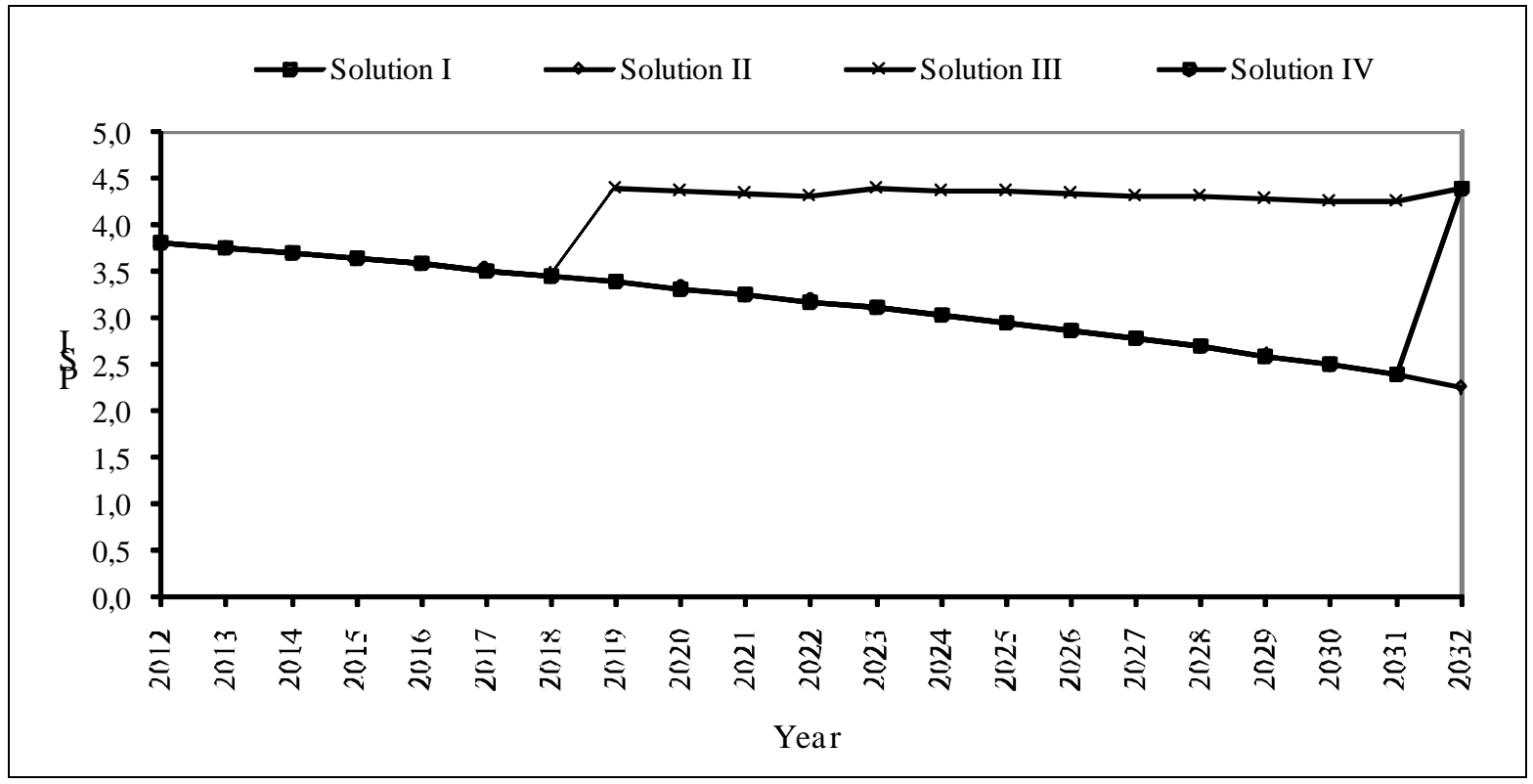

Figure 4-9 - Evolution of PSI for pavement 05001 of a national road

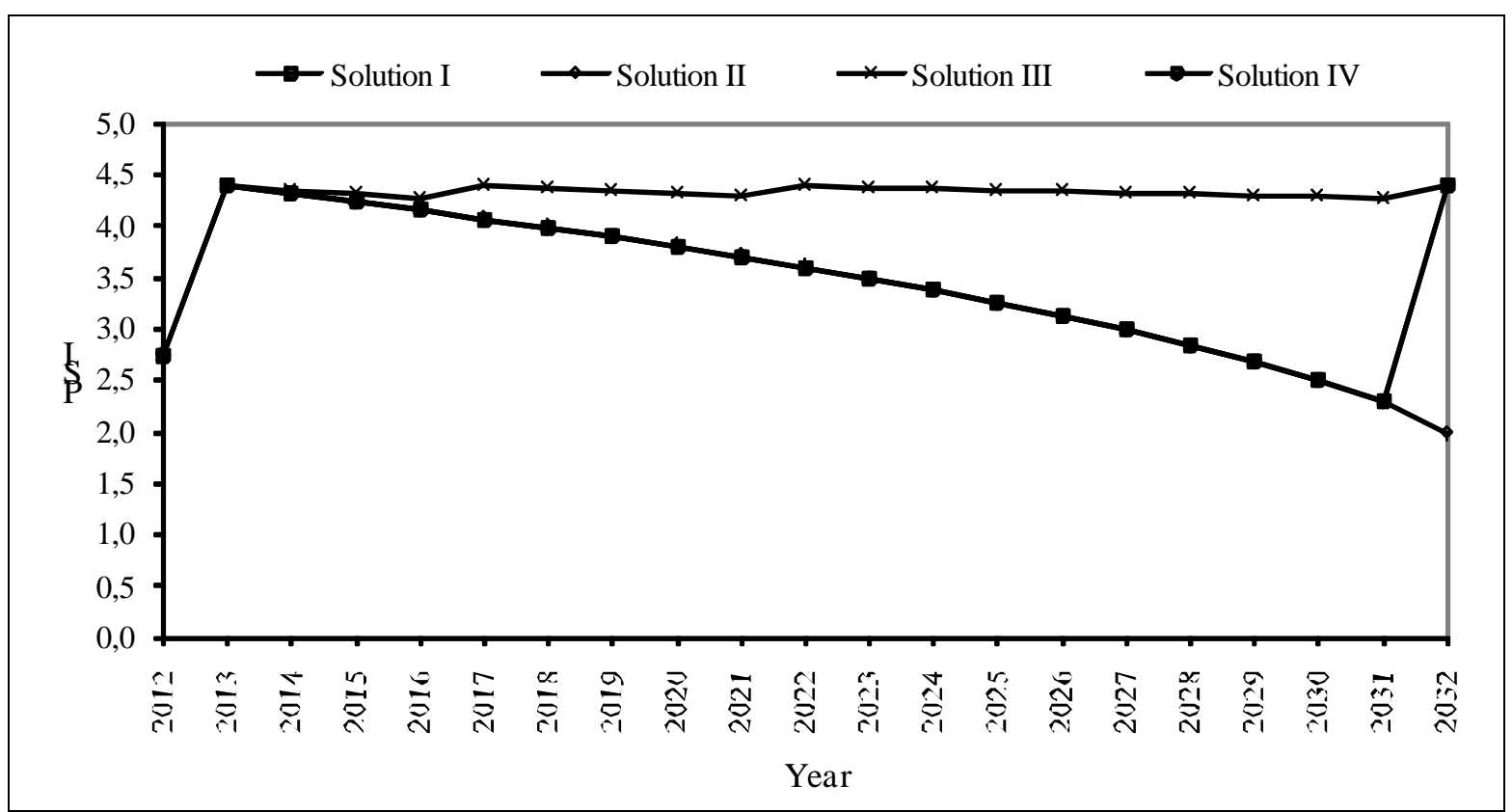

Figure 4-10 - Evolution of PSI for pavement 05004 of a national road 


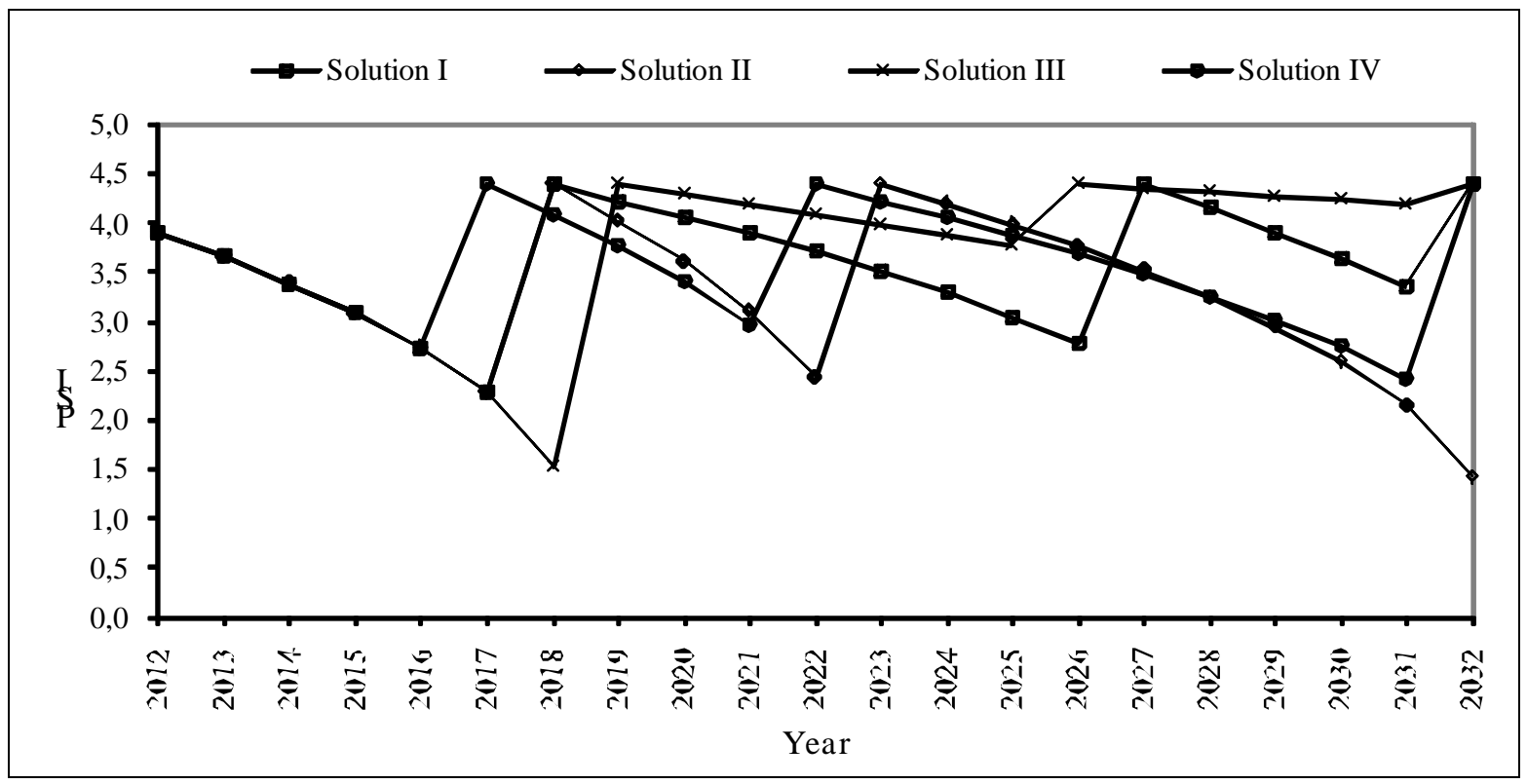

Figure 4-11 - Evolution of PSI for pavement 05003 of a national road

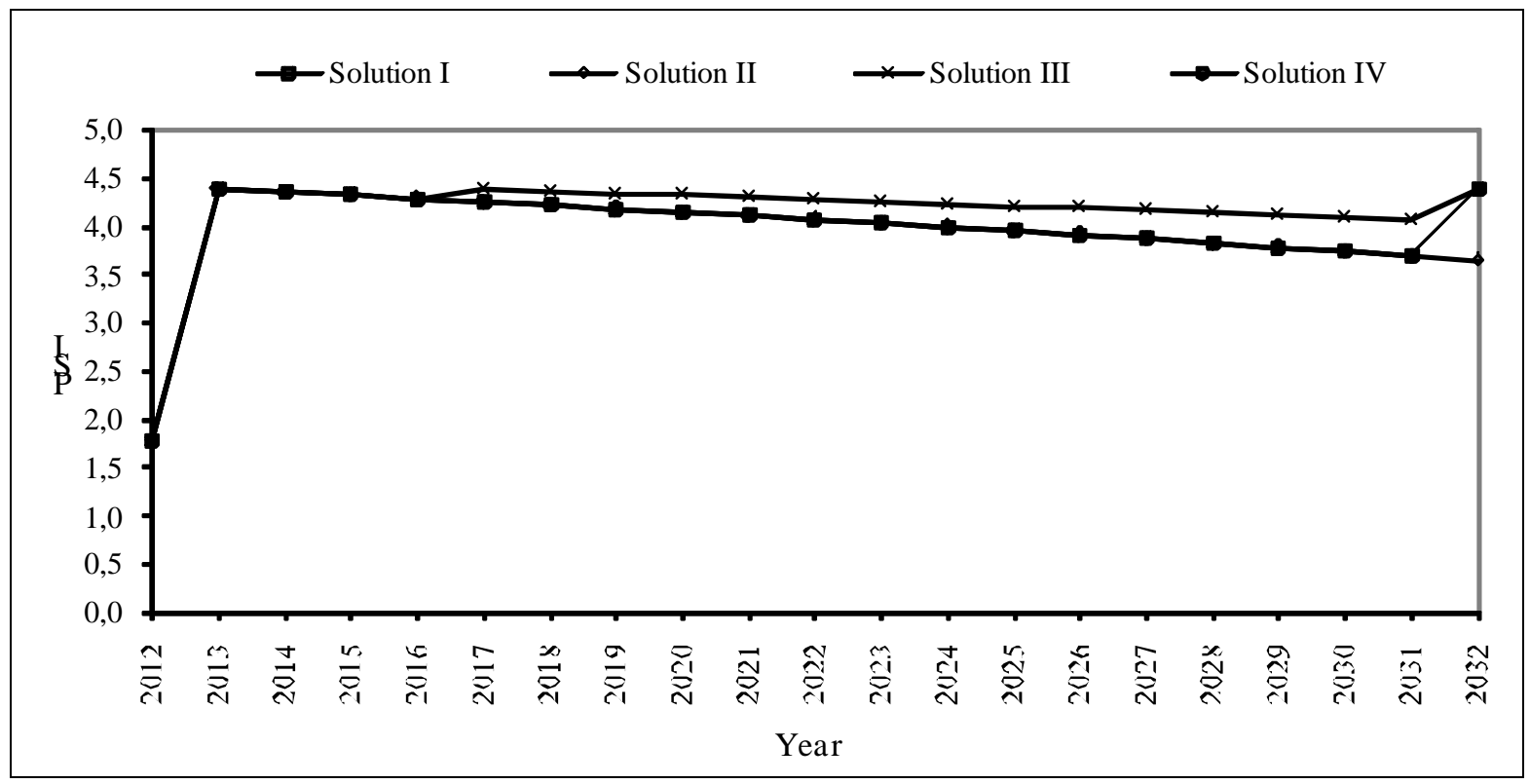

Figure 4-12 - Evolution of PSI for pavement 05012 of a national road 


\subsection{Conclusions}

The Multi-Objective Decision-Aid Tool (MODAT) presented in this chapter allows closing the gap between project and network management and can solve the pavement management problem for cases involving major rehabilitation interventions. This is made feasible by replacing the traditional microscopic approach, which uses models that include independent variables explaining the pavement deterioration process (i.e. layer thickness, resilient modulus, asphalt characteristics, traffic, climate, etc.), with a macroscopic approach that uses models for predicting the future condition of the pavement based on measured condition data (i.e. cracking, ravelling, potholes, patching, rutting, longitudinal roughness, skid resistance, traffic, climate, etc.). The macroscopic approach requires that each road section is homogeneous in terms of quality, pavement structure, pavement foundation, traffic and climate. It is assumed that each road section possesses one performance curve with any estimated future performance value representing the overall average pavement condition. The MODAT considers the pavement performance model used in the AASHTO flexible pavement design method but any other preferred model can be used as well. In the implementation of an optimum solution recommended by the MODAT, a field review must be conducted to identify continuous road sections with the same or identical M\&R interventions with the goal of aggregating them into the same road project. It is recommended that whenever actual pavement performance data becomes available, it should replace the predicted PSI values from the AASHTO pavement performance model. Any other appropriate pavement condition indicator can easily be used as an alternative in this methodology. It 
is further recommended that the MODAT is applied as often as necessary (annually or bi-annually) to obtain revised optimum $M \& R$ plans that would incorporate the impact of any recent changes that might have taken place in the pavement network.

The MODAT constitutes a useful new tool to help road engineers in their task of M\&R of pavements. In this MODAT application, the Knee point, which represents the most interesting solution of the Pareto frontier, corresponds to an agency costs weight value of $81 \%$ and an weight value of $19 \%$ for the residual value of pavements, demonstrating that agency costs, because they are generally much greater than the residual value of pavements, dominates the decision process. While the case study of this chapter focuses on a national road network, the approach proposed is applicable to any transportation infrastructure network, e.g. municipal road network, bridge network, where the decision-making process often involves multiple objective considerations. Because the MODAT is an open system, some modifications could be made to better serve the needs of road engineers. In the near future, our research in the pavement management field will follow three main directions. First, the MODAT will be applied considering three objectives, one more objective beyond the two existent objectives, for example, considering the minimization of user costs or the maximization of the road network performance. Second, a sensitivity analysis will be made of some input parameters considered in the application of the MODAT system, such as the discount rate. Third, pavement performance models will be developed using pavement performance data available in some road network databases and will be incorporated into MODAT for future applications to road networks. 


\section{APPENDIX 1: NOTATION}

$A C_{r s t}$ is the agency cost for applying operation $r$ to road section $s$ in year $t$;

$B_{t}$ is the budget for year $t$;

$C_{0}$ is the total cracked pavement area in year $0\left(\mathrm{~m}^{2} / 100 \mathrm{~m}^{2}\right)$;

$C_{n}^{e}$ is the structural coefficient of layer $n$;

$C_{n}^{d}$ is the drainage coefficient of layer $n$;

$C_{s, c o n s t}$ is the cost of construction or the cost of the last rehabilitation of pavement section $s$;

$d$ is the discount rate;

$D_{0}$ is the total disintegrated area (with potholes and ravelling) in year $0\left(\mathrm{~m}^{2} / 100 \mathrm{~m}^{2}\right)$;

$H_{n}$ is the thickness of layer $n(\mathrm{~mm})$;

$I R I_{0}$ is the pavement longitudinal roughness in year $0(\mathrm{~mm} / \mathrm{km})$;

$M_{R}$ is the subgrade resilient modulus (pounds per square inch);

$N_{\max _{s}}$ is the maximum number of M\&R operations that may occur in road section $s$ over the planning time-span;

$W_{80}$ is the number of $80 \mathrm{kN}$ equivalent single axle load applications estimated for a selected design period and design lane;

$P a_{0}$ is the pavement patching in year $0\left(\mathrm{~m}^{2} / 100 \mathrm{~m}^{2}\right)$;

$P S I_{t}$ is the Present Serviceability Index in year $t$; 
$P S I_{s, \text { rehab }}$ is the $P S I$ value after the application of a rehabilitation action in pavement section $s$;

$R$ is the number of alternative $\mathrm{M} \& \mathrm{R}$ operations;

$R_{0}$ is the mean rut in year $0(\mathrm{~mm})$;

$R V_{s, T+1}$ is the residual value for the pavement of section $s$;

$S$ is the number of road sections;

$S_{0}$ is the combined standard error of the traffic prediction and performance prediction;

$S N_{t}$ is the structural number of a road pavement in year $t$;

$T$ is the number of years in the planning time-span;

$t c$ is the annual average growth rate of heavy traffic;

$T M D A_{p}$ is the annual average daily heavy traffic in the year of construction or the last rehabilitation, in one direction and per lane;

$U C_{s t}$ is the user cost for road section $s$ in year $t$;

$V O C_{t}$ are the vehicle operation costs in year $t(€ / \mathrm{km} / \mathrm{vehicle})$;

$X_{r s t}$ is equal to one if operation $r$ is applied to section $s$ in year $t$, and is equal to zero otherwise;

$Y_{t}$ is the time since the pavement's construction or its last rehabilitation (years);

$Z_{R}$ is the standard normal deviate;

$P S I_{s t}$ are the pavement condition for section $s$ in year $t$; 
$\overline{P S I}$ is the warning level for the pavement condition;

$\alpha$ is the average heavy traffic damage factor or simply truck factor;

$\triangle P S I_{t}$ is the difference between the initial value of the present serviceability index $\left(P S I_{0}\right)$ and the value of the present serviceability index in year $t\left(P S I_{t}\right)$;

$\Psi a$ are the agency cost functions;

$\Psi p$ are the pavement condition functions;

$\Psi r$ are the residual value functions;

$\Psi u$ are the user cost functions;

$\Omega$ are the feasible operations sets.

\section{APPENDIX 2: DECISION-AID TOOL MODEL}

For explanation of notation, refer to the Appendix 1.

\section{A.2.1 Objective functions}

Minimise agency costs (maintenance and rehabilitation costs)

Minimise $A C=\sum_{r=1}^{R} \sum_{s=1}^{S} \sum_{t=1}^{T} \frac{1}{(1+d)^{t}} \cdot A C_{r s t} \cdot X_{r s t}$

Maximise the residual value of pavements at the end of the planning time-span

Maximise $R V=\sum_{s=1}^{S} \frac{1}{(1+d)^{T+1}} \cdot R V_{s, T+1}$ 


\section{A.2.2 Constraints}

Pavement condition functions

$\boldsymbol{P S I}_{s t}=\Psi p\left(\boldsymbol{P S I}_{s 0}, X_{1 s 1}, \ldots, X_{1 s t}, \ldots, X_{R s 1}, \ldots, X_{R s t}\right), s=1, \ldots, S ; t=1, \ldots, T$

Warning level constraints

$\boldsymbol{P S I}_{s t} \geq \overline{P S I}_{s}, s=1, \ldots, S ; t=1, \ldots, T$

Feasible operation sets

$X_{r s t} \in \Omega\left(P S I_{s t}\right), r=1, \ldots, R ; s=1, \ldots, S ; t=1, \ldots, T$

Annual operations constraints

$\sum_{r=1}^{R} X_{r s t}=1, s=1, \ldots, S ; t=1, \ldots, T$

Agency cost functions

$A C_{r s t}=\Psi a\left(P S I_{s t}, X_{r s t}\right), r=1, \ldots, R ; s=1, \ldots, S ; t=1, \ldots, T$ 


\section{User cost functions}

$U C_{s t}=\Psi u\left(\boldsymbol{P S I _ { s t }}\right), s=1, \ldots, S ; t=1, \ldots, T$

Residual value functions

$$
R V_{s, T+1}=\Psi r\left(\boldsymbol{P S I} \boldsymbol{I}_{s, T+1}\right), s=1, \ldots, S
$$

Annual budget constraints

$\sum_{r=1}^{R} \sum_{s=1}^{S} A C_{r s t} \cdot X_{r s t} \leq B_{t}, t=1, \ldots, T$

Planning time-span operations constraints

$\sum_{r=2}^{R} \sum_{t=1}^{T} X_{r s t} \leq N \max _{s}, \forall s=1, \ldots, S$ 


\section{APPENDIX 3: PAVEMENT CONDITION AND OTHER FUNCTIONS USED IN}

THE MODEL

\section{A.3.1 Pavement condition functions}

$P S I_{0}=5 \cdot e^{-0.000065 \cdot I R I_{0}}-0.000535 \cdot R_{0}{ }^{2}-0.21 \cdot\left(C_{0}+D_{0}+P a_{0}\right)^{0.5}$

$P S I_{t}=P S I_{0}-(4.2-1.5) \cdot 10^{\left[\left(\log _{10}\left(W_{80}\right)-Z_{R} \cdot S_{0}-9.36 \log _{10}(S N+1)+0.22 .32 \log _{10}\left(M_{R}\right)+8.07\right) \cdot\left(0.44 \frac{1094}{\left.(S N+1)^{5.19}\right)}\right)\right]}$

$S N_{t}=\sum_{n=1}^{N} H_{n} \times C_{n}^{e} \times C_{n}^{d}$

$W_{80_{t}}=365 \times T M D A_{p} \times \frac{(1+t c)^{Y_{t}}-1}{t c} \times \alpha$

\section{A.3.2 User cost function}

VOC $_{t}=1.20487-0.49116 \times P S I_{t}+0.05458 \times P S I_{t}^{2}$

\section{A.3.3 Residual value of pavements function}

$$
R V_{s, T+1}=C_{s, \text { const }} \cdot \frac{P S I_{s, T+1}-1.5}{P S I_{s, \text { rehab }}-1.5}
$$




\section{References}

AASHTO (1993). Guide for design of pavement structures. American Association of State Highway and Transportation Officials, Washington, D.C., USA, 4th ed., 1-640.

AIPCR (2000). Highway development and management, volume one - overview of HDM-4. World Road Association, Paris, France, I, 1-53.

Andersson, P. (2007). Multi-year maintenance optimization for paved public roads segment based modelling and price-directive decomposition. $\mathrm{PhD}$ Thesis, Linköping University, Linköping, Sweden, 1-214.

C-SHRP (2002). Pavement structural design practices across Canada. C-SHRP Technical Brief No. 23, Canadian Strategic Highway Research Program, Ottawa. Ontario, Canada, 1-10.

CRP (2013). Proceedings of the $7^{\text {th }}$ Portuguese Road Conference, Laboratório Nacional de Engenharia Civil, CD Ed., Lisboa, Portugal.

Das, I. (1999). On characterizing the "knee" of the Pareto curve based on normal boundary intersection. Structural and Multidisciplinary Optimization, 18, 107-115.

David, J., Loton, T., Gunvaldson, E., Bowen, C., Coad, N. and Jefford, D. (2006). Professional Visual Studio 2005 Team System. Wiley Publishing, Inc., Indiana, USA, $1-660$.

Deb, K. (2008). Multi-objective optimization using evolutionary algorithms, Wiley, West Sussex: John Wiley \& Sons, United Kingdom. 1-515. 
Ferreira, A. (2001). Pavement maintenance optimization of road networks. PhD Thesis, Coimbra University, Coimbra, Portugal, 1-383 (in Portuguese).

Ferreira, A., Picado-Santos, L. and Antunes, A. (2002). A segment-linked optimization model for deterministic pavement management systems. The International Journal of Pavement Engineering, 3 (2), 95-105.

Ferreira, A., Meneses, S. and Vicente, F. (2009). Pavement management system for Oliveira do Hospital, Portugal. Proceedings of the Institution of Civil EngineersTransport, 162 (3), 157-169.

Ferreira, A., Picado-Santos, L., Wu, Z. and Flintsch, G. (2011). Selection of pavement performance models for use in the Portuguese PMS. International Journal of Pavement Engineering, 12 (1), 87-97.

FICO (2009). Xpress-optimizer - reference manual, release 20.00. Fair Isaac Corporation, Leamington Spa, Warwickshire, UK, 1-470.

Fwa, T., Chan, W., and Hoque, K. (2000). Multiobjective optimization for pavement maintenance programming. Journal of Transportation Engineering, 126 (5), 367374.

Gendreau, M. and Potvin, J. (2005). Metaheuristics in combinatorial optimization. Annals of Operations Research, 140 (1), 189-213.

Haas, R. (2012). Reinventing the (pavement management) wheel. Distinguished Lecture, Fifth International Conference on Managing Pavements (available for download at http://www.asphalt.org/Pubs/PubsO.html). 
Hoffmann, A., Siem, A., Hertog, D., Kaanders, J. and Huizenga, H. (2006). Derivativefree generation and interpolation of convex Pareto optimal IMRT plans. Physics in Medicine and Biology, 51 (24), 6349-6369.

Holland, J. (1975). Adaptation in natural and artificial systems. University of Michigan Press, Ann Arbor, MI, USA.

Horta, C., Pereira, F., Lopes, S. and Morgado, J. (2013). The EP's Pavement Management System - balance of a consolidated implementation. Proceedings of the $7^{\text {th }}$ Portuguese Road Conference, Laboratório Nacional de Engenharia Civil, CD Edition, Lisboa, Portugal, chapter 149_Art_T5_7CRP_2013.pdf, 1-10.

Hwang, C. and Masud, A. (1979). Multiple objective decision making - methods and applications: a state-of-the-art survey, Springer-Verlag, Berlin, Germany.

IBM (2009). IBM ILOG CPLEX 12.1 - reference manual. IBM Corporation, Armonk, New York, USA, 1-884.

Ihs, A. and Sjögren, L. (2003). An overview of HDM-4 and the Swedish pavement management system. VTI - Infrastructure Maintenance, Linköping, Sweden, 1-31.

Iniestra, J. and Gutiérrez, J. (2009). Multi-criteria decisions on interdependent infrastructure transportation projects using an evolutionary-based framework. Applied Soft Computing, 9 (2), 512-526.

Lang, J. and Dahlgren, J. (2001). Prediction model in the Swedish PMS. Proceedings of the Fifth International Conference on Managing Pavements, CD Ed., Seattle, Washington, USA, chapter 100.pdf, 1-10. 
Lang, J. and Potucek, J. (2001). Pavement management systems in Sweden. Proceedings of the Fifth International Conference on Managing Pavements, CD Ed., Seattle, Washington, USA, chapter 097.pdf, 1-12.

Lotfi, F., Allahviranloo, T., Jondabeh, M. and Kiani, N. (2007). A new method for complex decision making based on TOPSIS for complex decision making problems with fuzzy data. Applied Mathematical Sciences, 1 (60), 2981 - 2987.

Marler, R., and Arora, J. (2004). Survey of multi-objective optimization methods for engineering. Structural and Multidisciplinary Optimization, 26, 369-395.

Meneses, S. and Ferreira, A. (2013). Pavement maintenance programming considering two objectives: maintenance costs and user costs, International Journal of Pavement Engineering, 14 (2), 206-221.

Meneses, S., Ferreira, A. and Collop, A. (2013). Multi-objective decision-aid tool for pavement management, Proceedings of the Institution of Civil Engineers-Transport, $166(2), 79-94$.

Michalewicz, Z. and Fogel, D. (2004). How to solve it: modern heuristics. SpringerVerlag, Berlin, Germany.

Miettinen, K. (1999). Nonlinear multi-objective optimization, Kluwer Academic Publishers, Boston, USA, 1-324.

Mostafavi, A. and Karamouz, M. (2010). Selecting appropriate project delivery system: fuzzy approach with risk analysis. Journal of Construction Engineering and Management, 136 (8), 923-930. 
Picado-Santos, L., Ferreira, A., Costa Pereira, F. and Conceição Azevedo, M. (2006). The evaluation of maintenance and rehabilitation strategies in the pavement management system of the Portuguese road administration. Proceedings of the $4^{\text {th }}$ Portuguese Road Congress, Lisbon, Portugal, 1-10 (in Portuguese).

Picado-Santos, L., and Ferreira, A. (2007). Development and implementation of a new pavement management system. Proceedings of the Fifth International Symposium on Maintenance and Rehabilitation of Pavements and Technological Control, CD Ed., 433-438, Utah, USA.

Picado-Santos, L., and Ferreira, A. (2008). Contributions to the development of the Portuguese road administration's pavement management system. Proceedings of the Third European Pavement and Asset Management Conference, CD Ed., chapter 1138.pdf, 1-10, Coimbra, Portugal.

Randolph, N. and Gardner, D. (2008). Professional Visual Studio 2008. Wiley Publishing, Inc., Indiana, USA, 1-946.

Stephenson, M., Epps, R. and Kennedy, C. (2004). Development of deterioration models for local authority roads. Proceedings of the Institution of Civil EngineersMunicipal Engineer 157 (3), 167-172.

Trindade, M. and Horta, C. (2009). Pavement management system of Estradas de Portugal, S.A. Proceedings of the $15^{\text {th }}$ Congreso Ibero-Latinoamericano del Asfalto, CD Ed., 1351-1360, Lisboa, Portugal (in Portuguese).

Wang, F., Zhang, Z., and Machemehl, R. (2003). Decision making problem for managing pavement maintenance and rehabilitation projects. Transportation Research Record, 1853, 21-28, Washington DC, USA. 
Wu, Z., Flintsch, G. (2009). Pavement preservation optimization considering multiple objectives and budget variability. Journal of Transportation Engineering, 135 (5), 305-315.

Yuan, J., Skibniewski, M., Li, Q. and Zheng, L. (2010). Performance objectives selection model in public-private partnership projects based on the perspective of stakeholders. Journal of Management in Engineering, 26 (2), 89-104. 



\section{Chapter 5}

\section{Pavement maintenance}

programming considering three objectives: minimization of maintenance and rehabilitation costs, minimization of user costs and maximization of the residual value of pavements

\subsection{Introduction}

Due to the economic crisis in almost every country all over the world, the trend of budgetary pressures on highway agencies is increasing continuously. At the same time, road users are increasingly demanding in terms of highway quality, comfort and safety. Several highway maintenance and rehabilitation projects have been delayed because of 
budget constraints. On the other hand, the economic crisis has also stimulated a wider debate about the state of each country's road network infrastructure and the consequences of past large-investment in new construction and under-investment in maintenance and rehabilitation. To meet these challenges, highway agencies are looking more than ever before for cost-effective methodologies for pavement maintenance programming at network-level.

Almost all the pavement maintenance programming tools currently in use are based on single-objective optimization. In these single-objective analyses, those requirements not selected as the objective function are imposed as constraints in the model formulation. This can be viewed as interference in the optimization process by artificially setting limits on selected problem parameters. As a result, the solutions obtained from these single-objective analyses are sub-optimal compared with ones derived from multiobjective considerations (Fwa et al. 2000,Wu et al. 2012). In the literature related to pavement maintenance management, only few applications have made use of multiobjective optimization techniques. Fwa et al. (2000) developed an optimization model with three objectives: the maximization of the work production; the minimization of the total maintenance cost; and the maximization of overall network pavement condition. The model was applied to four highway classes, each one with three need-urgency levels (high, medium, low), considering four $M \& R$ interventions and a planning timespan of 45 working days. Wang et al. (2003) developed a different optimization model with two objectives: the maximization of the total M\&R effectiveness; and the minimization of the total $M \& R$ disturbance cost. The model was applied to a small network of 10 road sections considering a planning time-span of five years. $\mathrm{Wu}$ and 
Flintsch (2009) developed another optimization model with two objectives: the maximization of the network level of service; and the minimization of the total M\&R cost. The model was applied to four pavement state quality types (excellent, good, fair and poor) considering four $M \& R$ interventions and a planning time-span of 10 years. Meneses et al. (2013) developed an optimization model with two objectives: the minimization of maintenance and rehabilitation costs; and the minimization of user costs. The model was applied to a municipal road network with 36 pavement sections considering five $M \& R$ interventions and a planning time-span of 20 years. Meneses and Ferreira (2013) applied the same optimization model to a national road network with 32 pavement sections considering five $M \& R$ interventions and a planning time-span of 20 years.

None of these multi-objective optimization models considers the maximization of the residual value of pavements at the end of the planning period which is very important for highway agencies. Greater residual value of pavements is directly related to a greater residual life of pavements which means lower maintenance and rehabilitations costs in the next planning period.

This chapter presents the development and implementation of a Multi-objective Decision-Aid Tool (MODAT) which considers three different objectives, the minimization of maintenance and rehabilitation costs, the minimization of user costs and the maximization of the residual value of pavements at the end of the planning period. The MODAT is tested with data from the PMS used by the main Portuguese concessionaire (Estradas de Portugal, S.A.), the institution that acted until 2007 as the Portuguese Road Administration (Picado-Santos et al. 2006, Picado-Santos and Ferreira 
2007, Picado-Santos and Ferreira 2008, Ferreira et al. 2008, Trindade and Horta 2009, Ferreira et al. 2011, Horta et al., 2013).

\subsection{Multi-Objective Decision-Aid Tool}

\subsubsection{Introduction}

The Multi-Objective Decision-Aid Tool (MODAT) consists of the components shown in Figure 5.1: the objectives of the analysis; the data and the models about the road pavements; the constraints that the system must guarantee; and the results. Several objectives can be considered in the analysis, including the minimization of maintenance and rehabilitation costs, the minimization of user costs, the maximization of the residual value of pavements at the end of the planning time-span, etc. The results of the application of the MODAT to a road network consist of the M\&R plan, the costs report, and the structural and functional quality report. The data and the models about the road pavements, and the constraints that the system must guarantee are described in the following section. 


Objectives:
Minimisation of maintenance and rehabilitation costs
Minimisation of user costs
Maximisation of the residual value of pavements
Data and models:
Number of years of the planning period
Discount rate
Areas and volumes
Structural and functional quality
Performance models
M\&R actions and unit agency costs
User costs model
Residual value model
Minimum quality levels
Annual budgets
Constraints:
Using only the M\&R actions defined by the infrastructure manager
Not exceeding the available budget
Nerifying the minimum the planning period
Not exceeding the maximum number of M\&R actions during the
Costs report
Maintenance and rehabilitation plan
Cond functional quality report

Figure 5-1 - MODAT components

\subsubsection{Optimization model}

The notation used in the model formulation can be seen in Appendix I and details of the deterministic optimization model can be found in Appendix II. Equation (5.1) is the first objective function of the optimization model and expresses the minimization of maintenance and rehabilitation costs over the planning time-span. Equation (5.2) is the second objective function and expresses the minimization of user costs. Equation (5.3) is the third objective function and expresses the maximization of the residual value of pavements at the end of the planning time-span. The constraints represented by Equation (5.4) correspond to the pavement condition functions. They express pavement 
condition in terms of the PSI in each road section and year as a function of the initial PSI and the M\&R actions previously applied to a road section. The functions shown in Equations (5.13)-(5.16) of Appendix III are used to evaluate the PSI over time. The quality of the road pavements in the present year is evaluated by the PSI, representing the condition of the pavement according to the following parameters: longitudinal roughness, rutting, cracking, surface disintegration and patching. This global quality index, calculated through Equation (5.13), ranges from 0.0 to 5.0, with 0.0 for a pavement in extremely poor condition and 5.0 for a pavement in very good condition. In practice, with this index a new pavement rarely exceeds the value 4.5 and a value of 2.0 is generally defined as the minimum quality level (MQL) for national roads considering traffic safety and comfort. Equation (5.14) represents the pavement performance model used for flexible pavements. This pavement performance model is the one used in the AASHTO flexible pavement design method (AASHTO 1993, C-SHRP 2002). This design approach applies several factors such as the change in PSI over the design period, the number of $80 \mathrm{kN}$ equivalent single axle load applications, material properties, drainage and environmental conditions, and performance reliability, to obtain a measure of the required structural strength through an index known as the structural number $(S N)$. The $S N$ is then converted to pavement layer thicknesses according to layer structural coefficients representing relative strength of the layer materials. The $S N$ in each road section and year of the planning period can be calculated by Equation (5.15). The number of $80 \mathrm{kN}$ equivalent single axle load applications is computed using Equation (5.16). The use of a pavement performance model for pavement design into a PMS allows the gap to be closed between project and network 
management, which is an important objective to be achieved and one that has been mentioned by several researchers (Ferreira et al. 2009, Haas 2012). This pavement performance model was chosen from a range of current models implemented in several PMS because it is widely used and tested. Nevertheless, other pavement performance models can be used instead, such as, for example, the pavement performance models of HDM-4 (AIPCR, 2000), the deterioration models developed for local authority roads by Stephenson et al. (2004), or the deterioration models developed for use in the Swedish PMS (Lang and Dahlgren 2001, Lang and Potucek 2001, Ihs and Sjögren 2003, Andersson 2007). Equation (5.14) defines a pavement performance model in terms of PSI as a function of the number of $80 \mathrm{kN}$ equivalent single axle load applications (Figure 5.2) or the number of years of service time. An incremental change in the present serviceability index $\left(\Delta P S I_{t-1, t}\right)$ corresponds to an estimated incremental change in load applications $\left(\left(\Delta \mathrm{W}_{80}\right)_{t-1, t}\right)$ and, at the same time, to an incremental service time interval $\left(\Delta T_{t-1, t}\right)$. The Present Serviceability Index in year $t\left(P S I_{t}\right)$ is defined as the difference between the serviceability index in year $t-1\left(P S I_{t-1}\right)$ and the incremental change in the present serviceability index $\left(\triangle P S I_{t-1, t}\right)$. At the same time, the Present Serviceability Index in year $t\left(P S I_{t}\right)$ is defined as the difference between the initial serviceability index $\left(P S I_{\mathrm{o}}\right)$ and the total incremental change in the present serviceability index $\left(\triangle P S I_{0, t}\right)$. The Present Serviceability Index in year $t\left(P S I_{t}\right)$ ranges between its initial value of about 4.5 (value for a new pavement) and the AASHTO lowest allowed PSI value of 1.5 (value for a pavement of a national road at the end of its service life). 


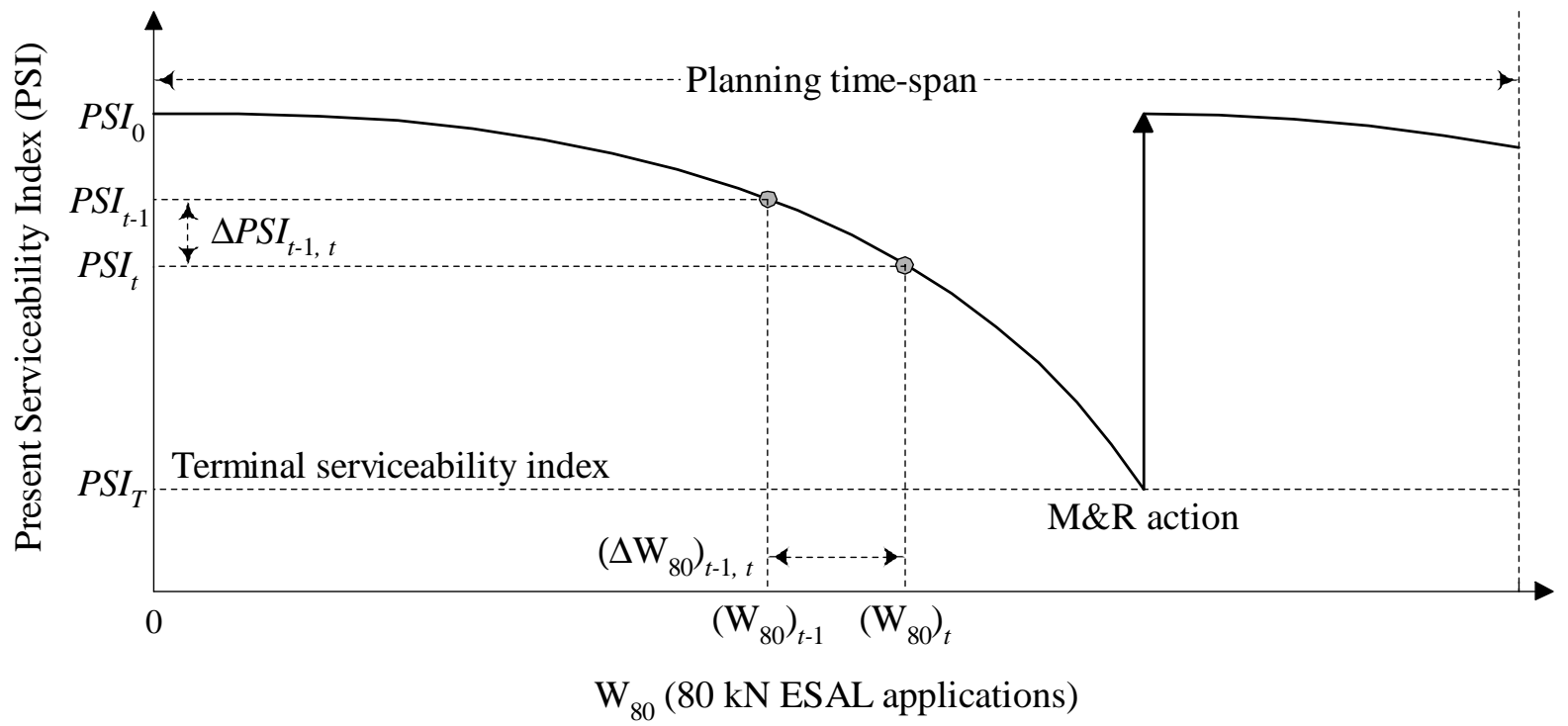

Figure 5-2 - Pavement performance curve as a function of equivalent single-axle load applications The constraints given by Equation (5.5) are the warning level constraints. They define the MQL considering the PSI index for each pavement of the road network. The warning level adopted in this study was a PSI value of 2.0. A corrective M\&R operation appropriate for the rehabilitation of a pavement must be performed on a road section when the PSI value is lower than 2.0.

The constraints represented by Equation (5.6) represent the feasible operation sets, i.e., the M\&R operations that can be performed on each road section each year. These operations depend on the pavement condition characterizing the section. In the present study the same five different $M \& R$ operations were considered, corresponding to nine M\&R actions applied individually or in combination with others, as in previous studies (Picado-Santos and Ferreira 2008, Santos and Ferreira 2012, Ferreira and Santos 2012, Santos and Ferreira 2013). The types of M\&R actions and operations considered are presented in Tables 5.1 and 5.2. The M\&R action costs considered in this study, 
Pavement maintenance programming considering three objectives: minimization of maintenance and rehabilitation costs, minimization of user costs and maximization of the residual value of pavements

calculated using information from $M \& R$ works executed on the Castelo Branco road network, are also presented in Tables 5.1 and 5.2.

As shown in Table 5.3, the operations to apply to road sections depend on the warning level. M\&R operation 1 which corresponds to "do nothing" is applied to a road section if the PSI value is above the warning level, i.e., if the PSI value is greater than 2.0. M\&R operation 5 is the operation that must be applied to a road section when the warning level is reached, i.e., this operation is applied to solve pavement serviceability problems. This operation has the longest efficiency period which is defined as the time between its application to the pavement and the time when the pavement reaches the warning level for the PSI. M\&R operations 2, 3, 4 and 5 are alternative operations that can be applied instead of operation 1 (see Table 5.4). In this case they are considered preventive M\&R operations. The analysis of Tables 5.3 and 5.4 clearly shows that the application of $M \& R$ operations may be either corrective or preventive. An $M \& R$ operation is corrective if it is performed when the warning level is reached, and it is preventive if it is performed before the warning level is reached. When deciding which M\&R operations should be applied in a given year to a given road section with PSI value above the warning level, it is possible to select either the simplest operation (M\&R operation 1) or a preventive operation (M\&R operation 2, 3, 4 or 5 ). In fact, selecting a preventive operation may be more efficient (less costly) in the medium or long-term.

The constraints given by Equation (5.7) state that only one M\&R operation per road section should be performed in each year. 
Table 5-1 - M\&R actions

\begin{tabular}{ccc}
\hline M\&R action & Description & Cost \\
\hline 1 & Do nothing & $€ 0.00 / \mathrm{m}^{2}$ \\
2 & Tack coat & $€ 0.41 / \mathrm{m}^{2}$ \\
3 & Longitudinal roughness leveling $(1 \mathrm{~cm})$ & $€ 1.23 / \mathrm{m}^{2}$ \\
4 & Longitudinal roughness leveling $(2 \mathrm{~cm})$ & $€ 2.45 / \mathrm{m}^{2}$ \\
5 & Membrane anti-reflection of cracks & $€ 1.88 / \mathrm{m}^{2}$ \\
6 & Base layer $(10 \mathrm{~cm})$ & $€ 8.63 / \mathrm{m}^{2}$ \\
7 & Binder layer $(5 \mathrm{~cm})$ & $€ 6.13 / \mathrm{m}^{2}$ \\
8 & Non-structural wearing layer & $€ 3.13 / \mathrm{m}^{2}$ \\
9 & wearing layer $(5 \mathrm{~cm})$ & $€ 6.69 / \mathrm{m}^{2}$ \\
\hline
\end{tabular}

Table 5-2 - M\&R operations

\begin{tabular}{cccc}
\hline M\&R operation & Description & M\&R actions involved & Cost \\
\hline 1 & Do nothing & 1 & $€ 0.00 / \mathrm{m}^{2}$ \\
2 & Non-structural maintenance & $2+3+2+8$ & $€ 5.18 / \mathrm{m}^{2}$ \\
3 & Minor rehabilitation & $2+4+2+5+2+9$ & $€ 15.31 / \mathrm{m}^{2}$ \\
4 & Medium rehabilitation & $2+4+2+5+2+7+2+9$ & $€ 18.79 / \mathrm{m}^{2}$ \\
5 & Major rehabilitation & $2+4+2+5+2+6+2+9$ & $€ 21.29 / \mathrm{m}^{2}$ \\
\hline
\end{tabular}

Table 5-3 - Application of the simplest M\&R operations

\begin{tabular}{cccc}
\hline Warning level & $P S I$ & M\&R operation & M\&R action \\
\hline \multirow{2}{*}{$P S I=2.0$} & $\geq 2.0$ & 1 & 1 \\
& $<2.0$ & 5 & $2+4+2+5+2+6+2+9$ \\
\hline
\end{tabular}

Table 5-4 - Alternatives to M\&R operations

\begin{tabular}{cccccc}
\hline \multirow{2}{*}{ M\&R operation } & \multicolumn{5}{c}{ Alternative M\&R operations } \\
\cline { 2 - 6 } & 1 & 2 & 3 & 4 & 5 \\
\hline 1 & $v$ & $v$ & $v$ & $v$ & $v$ \\
2 & - & $v$ & $v$ & $v$ & $v$ \\
3 & - & - & $v$ & $v$ & $v$ \\
4 & - & - & - & $v$ & $v$ \\
5 & - & - & - & - & $v$ \\
\hline
\end{tabular}


The constraints represented by Equation (5.8) represent the agency cost functions. They express the costs for the road agency involved in the application of a given $M \& R$ operation to a road section in a given year as a function of the pavement condition in that section and year. These costs are obtained by multiplying the unit agency costs for the $M \& R$ actions involved in the $M \& R$ operation by the pavement areas to which the M\&R actions are applied. The constraints defined by Equation (5.9) represent the user cost functions. They express the cost for road users as a function of the pavement condition in that section and year. To calculate the vehicle operation cost, Equation (5.17) of Appendix III was used. This Equation is currently in use in the Estradas de Portugal's PMS (Picado-Santos and Ferreira 2008). The constraints represented by Equation (5.10) represent the pavement residual value functions. They express the value of the pavement of a road section at the end of the planning time-span as a function of pavement condition at that time. To calculate the residual value of pavements Equation (5.18) of Appendix III was used. This equation was defined based on the AASHTO guide for design of pavement structures (AASHTO, 1993) considering a terminal value of 1.5. The constraints given by Equation (5.11) are the annual budget constraints. They specify the maximum amount of money to be spent on $M \& R$ operations during each year. The constraints represented by Equation (5.12) were included in the model to avoid frequent M\&R operations from being applied to the same road section.

\subsubsection{Generation of Pareto optimal solutions}

Hwang and Masud (1979) and later Miettinen (1999) classified the different optimization methods that can be used to generate the set of Pareto optimal solutions, 
also called non-dominated solutions, into the following four types: no-preference methods; posterior methods; a priori methods; and interactive methods.

According to Marler and Arora (2004), no single approach is, in general, superior to the other methods. Rather, the selection of a specific method depends on the users' preferences, the type of information provided, the solution requirements, and the availability of software. This study uses a genetic algorithm approach with the incorporation of the weighting sum method. This method, as the name suggests, combines a set of objectives into a single objective by pre-multiplying each objective with a user-defined weight. As the weight vector for the multiple objectives often depends highly on the magnitude of each objective function, it is desirable to normalize those objectives to achieve roughly the same scale of magnitude. Equation (5.1) represents the application of the weighting sum method (Deb 2008) to the three objective functions of the optimization model presented in the previous section.

Minimise $\bar{Z}=w_{A C} \cdot \frac{A C_{i}-A C_{\min }}{A C_{\max }-A C_{\min }}+w_{U C} \cdot \frac{U C_{i}-U C_{\min }}{U C_{\max }-U C_{\min }}+w_{R V} \cdot\left(-\frac{R V_{i}-R V_{\min }}{R V_{\max }-R V_{\min }}\right)$

where: $\bar{Z}$ is the normalized value of a solution; $w_{A C}, w_{U C}$, and $w_{R V}$ are the weight values for each objective function; $A C_{i}, U C_{i}$, and $R V_{i}$ are the individual objective function values that depend on the decision variables values; $A C_{\min }, U C_{\min }$, and $R V_{\min }$ are the minimum values obtained for each objective; $A C_{\max }, U C_{\max }$, and $R V_{\max }$ are the maximum values obtained for each objective. The third objective function corresponds to the maximization of the residual value of pavements at the end of the planning period. When an objective needs to be maximized, the duality principle (Deb 2008) can be used to transform the original objective of maximization into an objective of 
minimization by multiplying the objective function by $(-1)$. The range of values for the various objective functions $\left(A C_{\min }, A C_{\max }\right),\left(U C_{\min }, U C_{\max }\right)$, and $\left(R V_{\min }, R V_{\max }\right)$ are obtained by applying the optimization model considering only one objective at each time, i.e. varying the weight values vector $\left(w_{A C}, w_{U C}, w_{R V}\right)$ among the extreme situations of $(1,0,0),(0,1,0)$ and $(0,0,1)$ and considering that, initially, all minimum values are 0 and all maximum values are 1 . The Pareto optimal solution set is finally obtained by using the objective function defined by Equation (5.1) considering different combinations of the weight values.

\subsubsection{Knee points and identification procedure}

To avoid the difficulties in selecting a particular solution for implementation from the Pareto optimal solution set, Das (1999) developed the Normal-Boundary Intersection (NBI) method to identify the so called "Knee point" of the Pareto frontier. The "Knee point" is the Pareto point farthest away from this line in the direction of the normal vector. "Knee points" represent the most interesting solutions of the Pareto frontier due to their implicit large marginal rates of substitution (Iniestra and Gutiérrez, 2009). Wu and Flintsch (2009) considered another method to identify the best solution of the Pareto frontier. As the ideal solution (Meneses and Ferreira 2013) may not be achieved due to the conflicting objectives, the best solution is the solution of the Pareto frontier that has the shortest normalized distance from the ideal solution, computed using Equation (5.2). 
$D_{i}=\left[\left(\frac{A C_{i}-A C_{\min }}{A C_{\max }-A C_{\min }}-\bar{Z}_{1}^{*}\right)^{2}+\left(\frac{U C_{i}-U C_{\min }}{U C_{\max }-U C_{\min }}-\bar{Z}_{2}^{*}\right)^{2}+\left(\frac{R V_{i}-R V_{\min }}{R V_{\max }-R V_{\min }}-\bar{Z}_{3}^{*}\right)^{2}\right]^{\frac{1}{2}}$

where: $D_{i}$ is the normalized distance between each Pareto solution point and the ideal

solution point; $\bar{Z}_{1}^{*}, \bar{Z}_{2}^{*}$, and $\bar{Z}_{3}^{*}$ are the normalized values for each objective of the ideal solution (equal to 0 or 1 depending on whether it is a minimization or maximization objective).

\subsubsection{Model solving}

Nowadays, a large number of classic and modern heuristic methods are available to solve this kind of complex optimization models (Deb 2008, Gendreau and Potvin 2005, Michalewicz and Fogel 2004). The heuristic method used to solve this optimization model is a genetic-algorithm (GA) called MODAT that was implemented in Microsoft Visual Studio programming language (David et al. 2006, Randolph and Gardner 2008) adapting and introducing new functionalities to an existing GA program called GENETIPAV-D (Ferreira 2001, Ferreira et al. 2002) previously developed to solve single-objective deterministic optimization models. Since they were proposed by Holland (1975), GAs have been successfully used on many occasions to deal with complex engineering optimization problems. The MODAT applied to the Castelo Branco road network was run on a $2.2 \mathrm{GHz}$ personal computer (PC) with $2.0 \mathrm{~GB}$ of RAM and 200 GB capacity. Each best solution given by the MODAT was obtained in approximately 30 minutes of computing time. 


\subsubsection{Results of the application of the MODAT}

The MODAT was tested with data from the Estradas de Portugal's Pavement Management System (Picado-Santos and Ferreira 2008, Trindade and Horta 2009, Ferreira et al. 2011, Horta et al. 2013) to plan the maintenance and rehabilitation of the road network considering three objectives: the minimization of agency costs; the minimization of user costs; and the maximization of residual value of pavements. The MODAT was applied to the road network of the district of Castelo Branco, one of the 18 districts of Portugal. This road network has a total length of $589.9 \mathrm{Km}$ and the corresponding network model has 32 road sections. The discount rate considered in this study was $2.5 \%$.

The solutions of the optimization problem were shown in a 3D representation using MATLAB (MathWorks 2013). MATLAB is a programming environment for algorithm development, data analysis, visualization, and numerical computation which can be used in a wide range of applications. MATLAB supports the entire data analysis process, from acquiring data from external devices and databases, through preprocessing, visualization, and numerical analysis, to producing excellent quality outputs.

Figure 5.3 presents the three-dimensional (3D) Pareto optimal set of normalized solutions in the objective space by varying the weight values. The "Knee point" was obtained considering the following weight values: $\left(w_{A C}, w_{U C}, w_{R V}\right)=(0.04,0.95$, $0.01)$; and it corresponds to the following objective values $(A C, U C, R V)=$ (€69228291.7, €1497083878.6, €37118050.1). The range of values for the three 
objective functions is $\left(A C_{\min }, A C_{\text {max }}\right)=\left(€ 44.2 \times 10^{6}, € 206.0 \times 10^{6}\right),\left(U C_{\min }, U C_{\text {max }}\right)=$ $\left(€ 1424.2 \times 10^{6}, € 2529.3 \times 10^{6}\right)$ and $\left(R V_{\min }, R V_{\max }\right)=\left(€ 10.9 \times 10^{6}, € 39.2 \times 10^{6}\right)$.

Figure 5.4 shows the solutions in a three-objective representation using a scatter-plot matrix. In an optimization problem with three or more objective functions, like this one, the scatter-plot matrix method is appropriate to present the solutions to a decisionmaker (Cleveland 1994). In this case study, with three objective functions, there are a total of 6 plots. The diagonal sub-plots mark the axis for the corresponding off-diagonal sub-plots. For example, a sub-plot in position $(1,3)$ of the scatter-plot matrix has its horizontal axis marked RV and the vertical axis marked AC. If the decision-maker is not comfortable in viewing a plot with $\mathrm{AC}$ in the vertical axis, the sub-plot in position $(3,1)$ shows the same sub-plot with AC marked in the horizontal axis. Thus, a sub-plot in position $(i, j)$ of the scatter-plot matrix is identical to the sub-plot in the $(j, i)$ position, except that the sub-plot is mirrored.

The final best-compromise solution from the Pareto optimal set of solutions in multiobjective problems is always up to the decision maker. For that purpose, five different M\&R solutions of the Pareto frontier were considered for comparison.

a) Solution I: Multi-objective optimization approach (corrective-preventive) considering the "Knee point" $\left(w_{A C}=0.04, w_{U C}=0.95, w_{R V}=0.01\right)$;

b) Solution II: Multi-objective optimization approach (corrective-preventive) considering the following weights $\left(w_{A C}=1.00, w_{U C}=0.00, w_{R V}=0.00\right)$;

c) Solution III: Multi-objective optimization approach (corrective-preventive) considering the following weights $\left(w_{A C}=0.00, w_{U C}=1.00, w_{R V}=0.00\right)$; 
Pavement maintenance programming considering three objectives: minimization of maintenance and rehabilitation costs, minimization of user costs and maximization of the residual value of pavements

d) Solution IV: Multi-objective optimization approach (corrective-preventive) considering the following weights $\left(w_{A C}=0.00, w_{U C}=0.00, w_{R V}=1.00\right)$;

Solution V: Multi-objective optimization approach (corrective-preventive) considering the following weights $\left(w_{A C}=1 / 3, w_{U C}=1 / 3, w_{R V}=1 / 3\right)$.

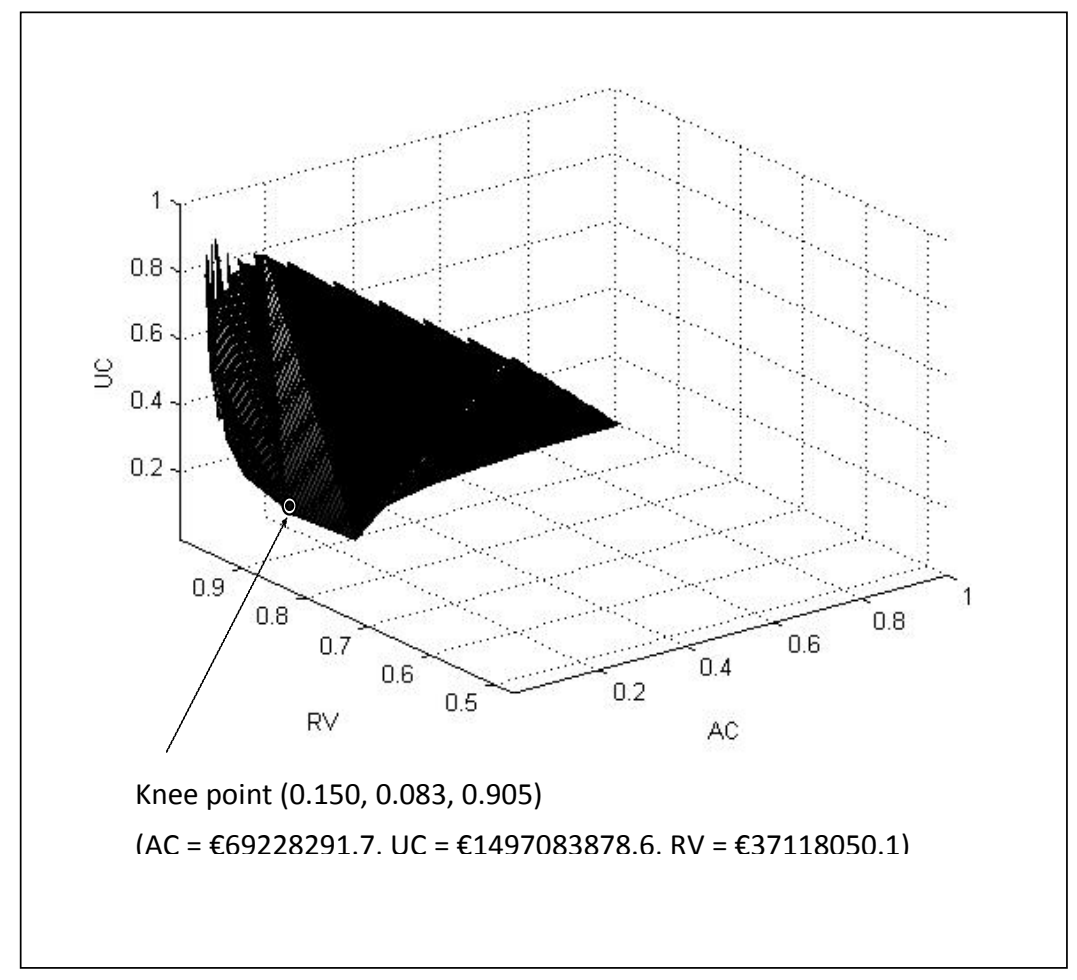

Figure 5-3 - 3D Pareto optimal set of normalised solutions 


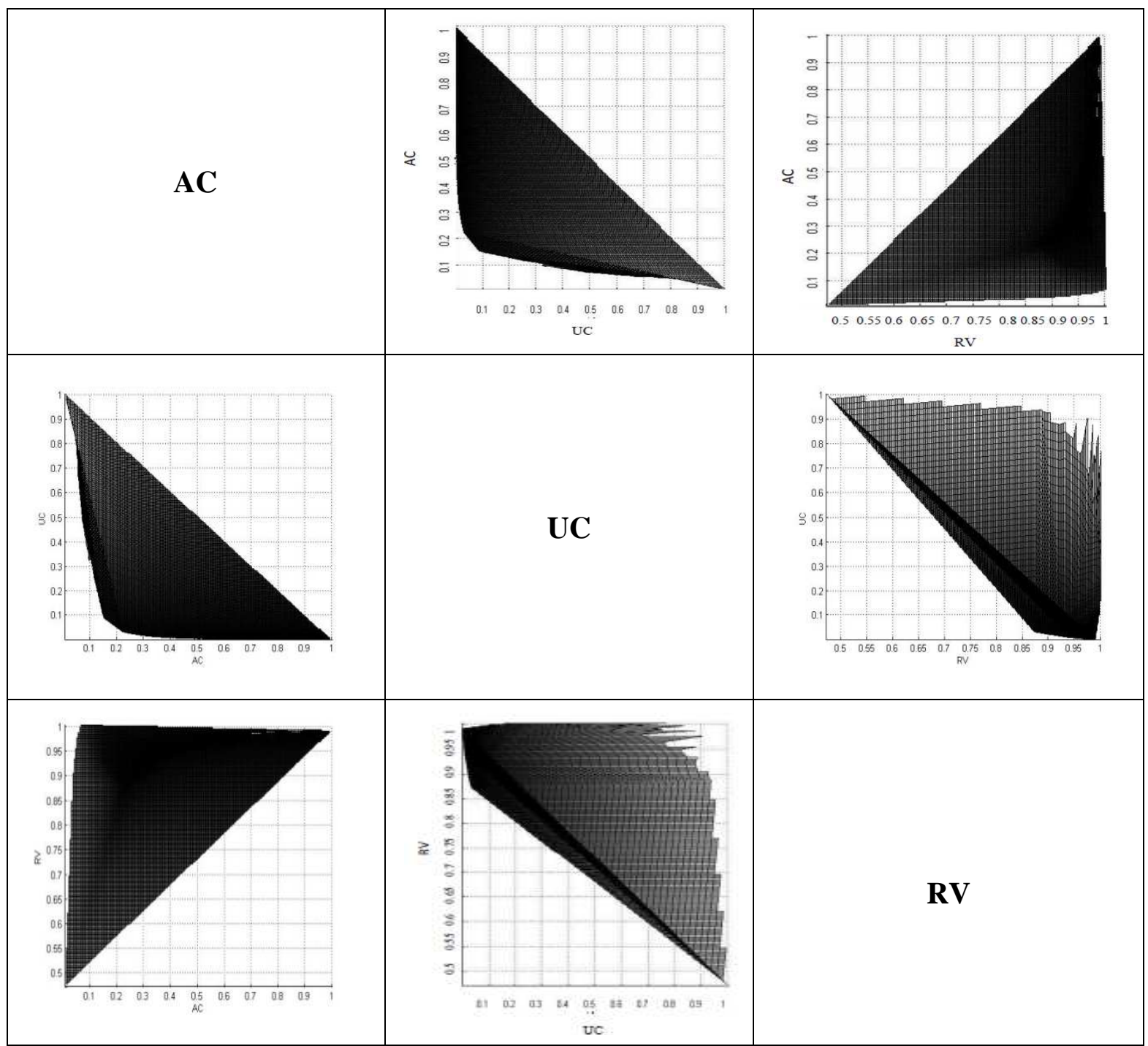

Figure 5-4 - Solutions in a three-objective representation using a scatter-plot matrix

The costs and normalized costs during the entire planning time-span for these five Pareto optimal solutions are summarized in Figures 5.5 and 5.6, respectively. Figure 5.5 shows that, as expected, solution I ("Knee point") is the Pareto optimal solution with the lowest total costs (M\&R costs, plus user costs, minus residual value of pavements), which was the objective considered in the multi-objective optimization model. Solution III, considering the weights $\left(w_{A C}=0.00, w_{U C}=1.00, w_{R V}=0.00\right)$, is the second best 
solution, which corresponds to the minimization of user costs. It is interesting that solution II, which corresponds to the minimization of agency costs, is the worst solution in terms of total costs. Solution $\mathrm{V}$, considering equal weights for the three objectives, is an interesting solution for the road administration because it has the lowest value of $M \& R$ costs minus residual value of pavements.

Figure 5.7 presents the predicted PSI average value over the years of the planning timespan for all the road network pavements and for each solution. One can conclude that solution III, i.e. the solution of the multi-objective optimization approach considering the weights $\left(w_{A C}=0.00, w_{U C}=1.00, w_{R V}=0.00\right)$, corresponds to the highest average PSI values, as expected, because this solution corresponds to the minimization of the user costs. Solution I ("Knee point") is the second best solution in terms of average PSI values, also as expected, because this solution corresponds to a high weight value for user costs and small weight values for the other two objectives $\left(w_{A C}=0.04, w_{U C}=\right.$ $\left.0.95, w_{R V}=0.01\right)$. As expected, solution II, which corresponds to the minimization of agency costs, is the worst solution in terms of average PSI values. 


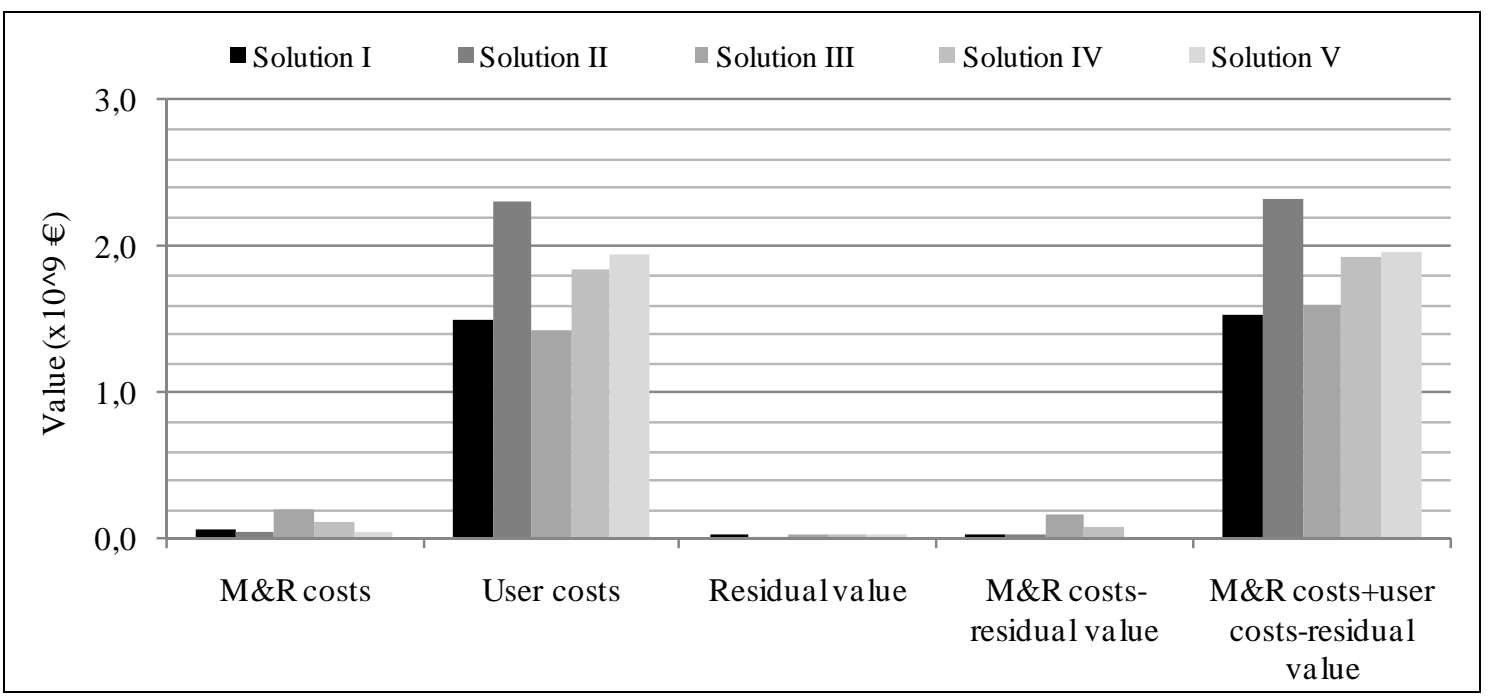

Figure 5-5 - Costs throughout the planning time-span of 20 years

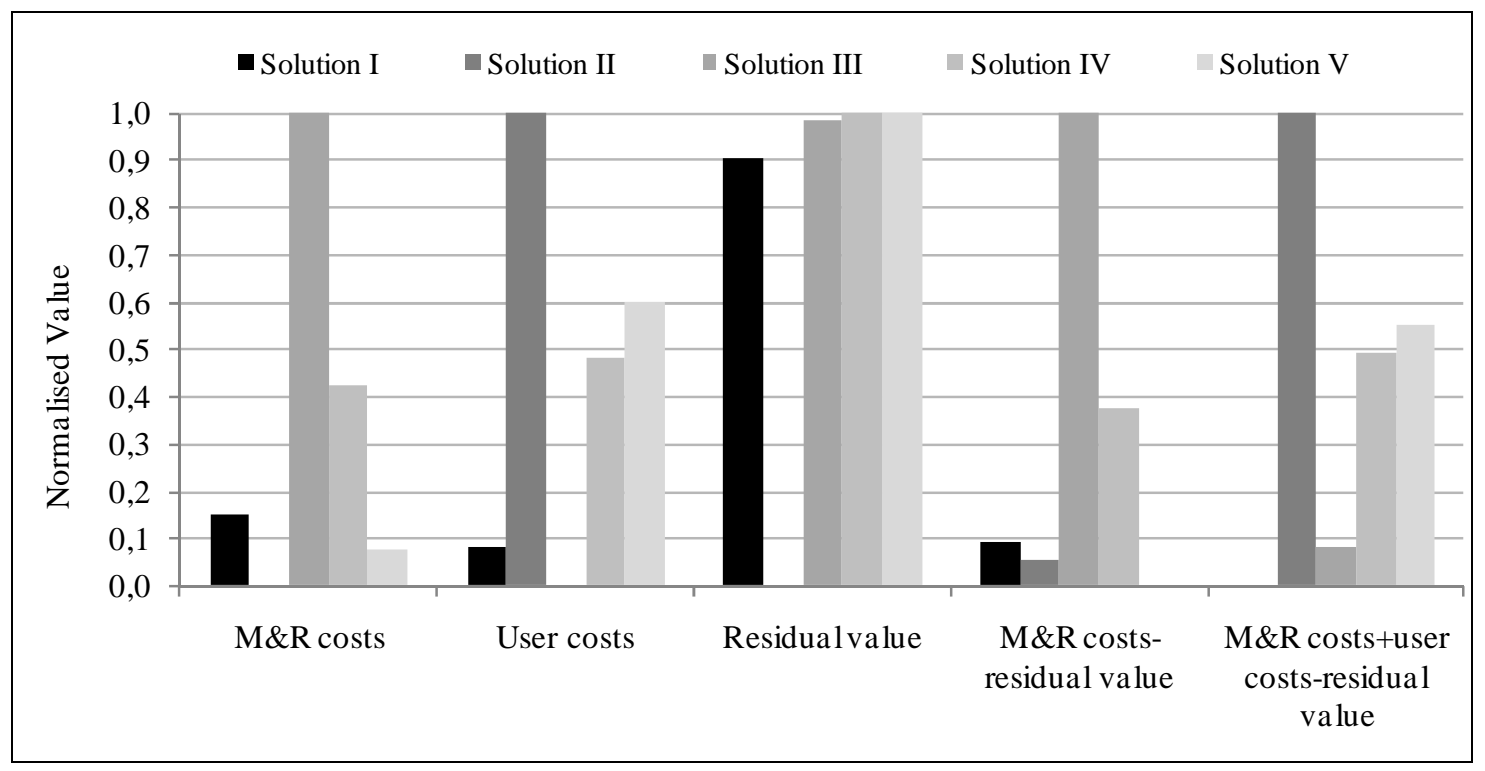

Figure 5-6 - Normalised costs throughout the planning time-span of 20 years 


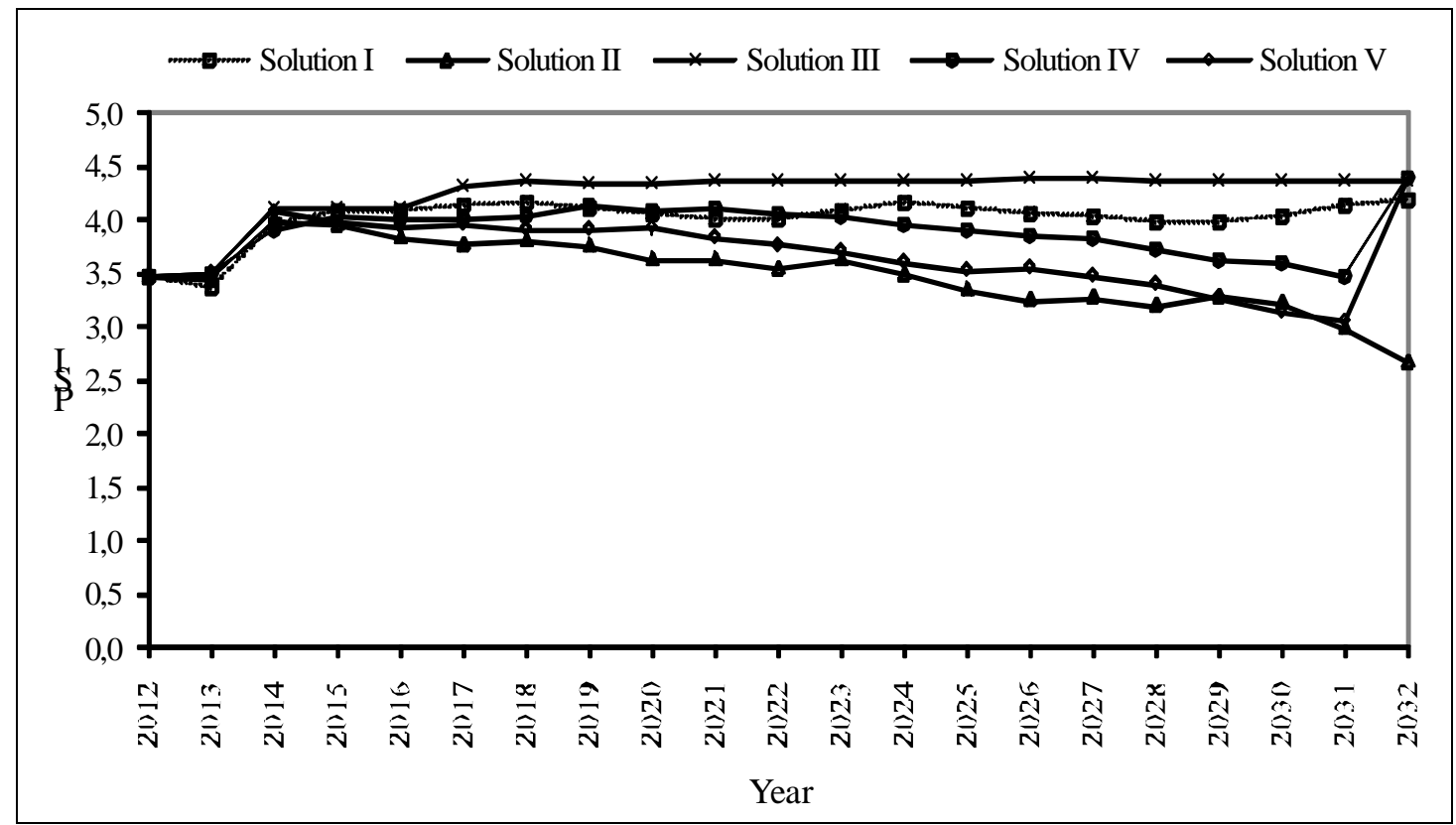

Figure 5-7 - PSI average value for all the road network pavements

The results presented above were defined at network-level. At project-level, the MODAT provides extensive information about the M\&R strategy to be implemented for each road section. To analyze these road section-linked results, four road sections were chosen with different attributes in the present year. Table 5.5 shows the attributes of these four road sections including their present PSI value. Table 5.6 presents the M\&R operations to be applied in the four road sections, considering the five M\&R solutions of the Pareto frontier.

Figure 5.8 shows the predicted evolution of the PSI value over the years for pavement section 05012 of a national road as a consequence of the execution of the M\&R plan. For this pavement section, which is under the minimum quality level (PSI value of 1.79 $<2.0$ ), which means that it needs urgent rehabilitation, if solution I ("Knee Point") or solution V (using equal weight values for each objective) is adopted, two M\&R operations are recommended for application to the pavement section, $\mathrm{M} \& \mathrm{R}$ operation 5 
(major rehabilitation) in year 2012 and M\&R operation 2 (non-structural maintenance) in year 2031. If solution II of MODAT is adopted only one M\&R operation will be needed during all the planning time-span, i.e. M\&R operation 5 in year 2012. Considering solution III, the MODAT recommends the application of M\&R operation 5 in years 2012, 2016, 2020 and 2024. The recommended M\&R operations are heavier in this solution because it corresponds to the minimization of user costs which means that the pavement quality must be always high. Adopting solution IV, the MODAT recommends the application of $M \& R$ operation 5 in year 2012, M\&R operation 3 in year 2016, and M\&R operation 2 in year 2031.

Table 5-5 - Attributes of road sections

\begin{tabular}{|c|c|c|c|c|}
\hline \multirow{2}{*}{$\begin{array}{l}\text { Attributes } \\
\text { Section_ID }\end{array}$} & \multicolumn{4}{|c|}{ Road section } \\
\hline & 05012 & 05004 & 05001 & 05003 \\
\hline Road_class & EN & IC & IP & IC \\
\hline Pavement_type & Flexible & Flexible & Flexible & Flexible \\
\hline District & Castelo Branco & Castelo Branco & Castelo Branco & Castelo Branco \\
\hline Length (m) & 21,455 & 19,439 & 1931 & 14,635 \\
\hline Width (m) & 5.9 & 8.8 & 9.4 & 8.6 \\
\hline Sub-grade_CBR $(\%)$ & 5 & 10 & 6 & 4 \\
\hline Structural_number & 2.47 & 3.51 & 5.20 & 4.80 \\
\hline Age_of_pavements (years) & 16 & 14 & 8 & 3 \\
\hline Annual_average_daily_traffic & 744 & 6,212 & 4316 & 5,828 \\
\hline Annual_average_daily_heavy_traffic & 100 & 1000 & 300 & 1000 \\
\hline Annual_growth_average_tax & 3.0 & 4.0 & 3.0 & 4.0 \\
\hline Truck_factor & 2.0 & 4.0 & 3.0 & 4.0 \\
\hline $\mathrm{PSI}_{0}$ & 1.79 & 2.75 & 3.81 & 3.90 \\
\hline
\end{tabular}


Table 5-6 - M\&R operations to be applied in road sections

\begin{tabular}{|c|c|c|c|c|c|c|c|c|c|c|c|c|c|c|c|c|c|c|c|c|c|}
\hline Section & $\mathrm{PSI}_{0}$ & \multicolumn{20}{|c|}{ Year } \\
\hline \multicolumn{22}{|c|}{ Solution I - Knee point ( $\left.w_{A C}=0.04, w_{U C}=0.95, w_{R V}=0.01\right)$} \\
\hline 05012 & 1.79 & 5 & 1 & 1 & 1 & 1 & 1 & 1 & 1 & 1 & 1 & 1 & 1 & 1 & 1 & 1 & 1 & 1 & 1 & 1 & 2 \\
\hline 05004 & 2.75 & 4 & 1 & 1 & 1 & 1 & 1 & 1 & 1 & 2 & 1 & 1 & 1 & 1 & 1 & 1 & 2 & 1 & 1 & 1 & 1 \\
\hline \multicolumn{22}{|c|}{ Solution II $\left(w_{A C}=1.00, w_{U C}=0.00, w_{R V}=0.00\right)$} \\
\hline 05012 & 1.79 & 5 & 1 & 1 & 1 & 1 & 1 & 1 & 1 & 1 & 1 & 1 & 1 & 1 & 1 & 1 & 1 & 1 & 1 & 1 & 1 \\
\hline 05004 & 2.75 & 3 & 1 & 1 & 1 & 1 & 1 & 1 & 1 & 1 & 1 & 1 & 1 & 1 & 1 & 1 & 1 & 1 & 1 & 1 & 1 \\
\hline 05001 & 3.81 & 1 & 1 & 1 & 1 & 1 & 1 & 1 & 1 & 1 & 1 & 1 & 1 & 1 & 1 & 1 & 1 & 1 & 1 & 1 & 1 \\
\hline 05003 & 3.90 & 1 & 1 & 1 & 1 & 1 & 2 & 1 & 1 & 1 & 1 & 3 & 1 & 1 & 1 & 1 & 1 & 1 & 1 & 1 & 1 \\
\hline 05001 & 3.81 & 1 & 1 & 1 & 1 & 5 & 1 & 1 & 1 & 5 & 1 & 1 & 1 & 5 & 1 & 1 & 1 & 5 & 1 & 1 & 1 \\
\hline 05003 & 3.90 & 1 & 1 & 5 & 1 & 1 & 1 & 5 & 1 & 1 & 1 & 5 & 1 & 1 & 1 & 5 & 1 & 1 & 1 & 1 & 1 \\
\hline \multicolumn{22}{|c|}{ Solution IV $\left(w_{A C}=0.00, w_{U C}=0.00, w_{R V}=1.00\right)$} \\
\hline 05012 & 1.79 & 5 & 1 & 1 & 1 & 3 & 1 & 1 & 1 & 1 & 1 & 1 & 1 & 1 & 1 & 1 & 1 & 1 & 1 & 1 & 2 \\
\hline 05004 & 2.75 & 5 & 1 & 1 & 1 & 3 & 1 & 1 & 1 & 1 & 4 & 1 & 1 & 1 & 1 & 1 & 1 & 1 & 1 & 1 & 3 \\
\hline 05001 & 3.81 & 1 & 1 & 1 & 1 & 1 & 1 & 4 & 1 & 1 & 1 & 3 & 1 & 1 & 1 & 1 & 1 & 1 & 1 & 1 & 3 \\
\hline 05003 & 3.90 & 1 & 1 & 1 & 1 & 1 & 1 & 5 & 1 & 1 & 1 & 1 & 1 & 1 & 5 & 1 & 1 & 1 & 1 & 1 & 3 \\
\hline \multicolumn{22}{|c|}{ Solution V $\left(w_{A C}=1 / 3, w_{U C}=1 / 3, w_{R V}=1 / 3\right)$} \\
\hline 05012 & 1.79 & 5 & 1 & 1 & 1 & 1 & 1 & 1 & 1 & 1 & 1 & 1 & 1 & 1 & 1 & 1 & 1 & 1 & 1 & 1 & 2 \\
\hline 05004 & 2.75 & 3 & 1 & 1 & 1 & 1 & 1 & 1 & 1 & 1 & 1 & 1 & 1 & 1 & 1 & 1 & 1 & 1 & 1 & 1 & 2 \\
\hline
\end{tabular}

KEY (M\&R operations):

1 - Do nothing; 2 - Non-structural maintenance; 3 - Minor rehabilitation; 4 - Medium rehabilitation; 5 Major rehabilitation

An identical analysis could be made for any other pavement section. For example, for pavement section 05001 of another national road (see Table 5.6 and Figure 5.9), which is in good condition (PSI value of 3.81), if solution I ("Knee Point") of MODAT is adopted, only two M\&R operations 2 (non-structural maintenance) will be applied to the pavement section, one in year 2016 and another in year 2026. If solution II of MODAT is adopted, no $M \& R$ operation will be needed during all the planning time- 
span. If solution III of MODAT is adopted the recommended M\&R operations are very different.The MODAT recommends the application of $M \& R$ operation 5 (major rehabilitation) in years 2016, 2020, 2024 and 2028. For solution IV, the MODAT recommends one $M \& R$ operation 4 (Medium rehabilitation) in year 2018 and the application of two M\&R operation 3 (minor rehabilitation) in years 2022 and 2031. If solution $\mathrm{V}$ of MODAT is adopted only one M\&R operation will be needed during all the planning time-span, i.e. M\&R operation 2 in year 2031.

An analogous analysis could be made for any other pavement section. Figures 5.10 and 5.11 present the predicted evolution of the PSI value over the years for pavement section 05003 and pavement section 05004, respectively.

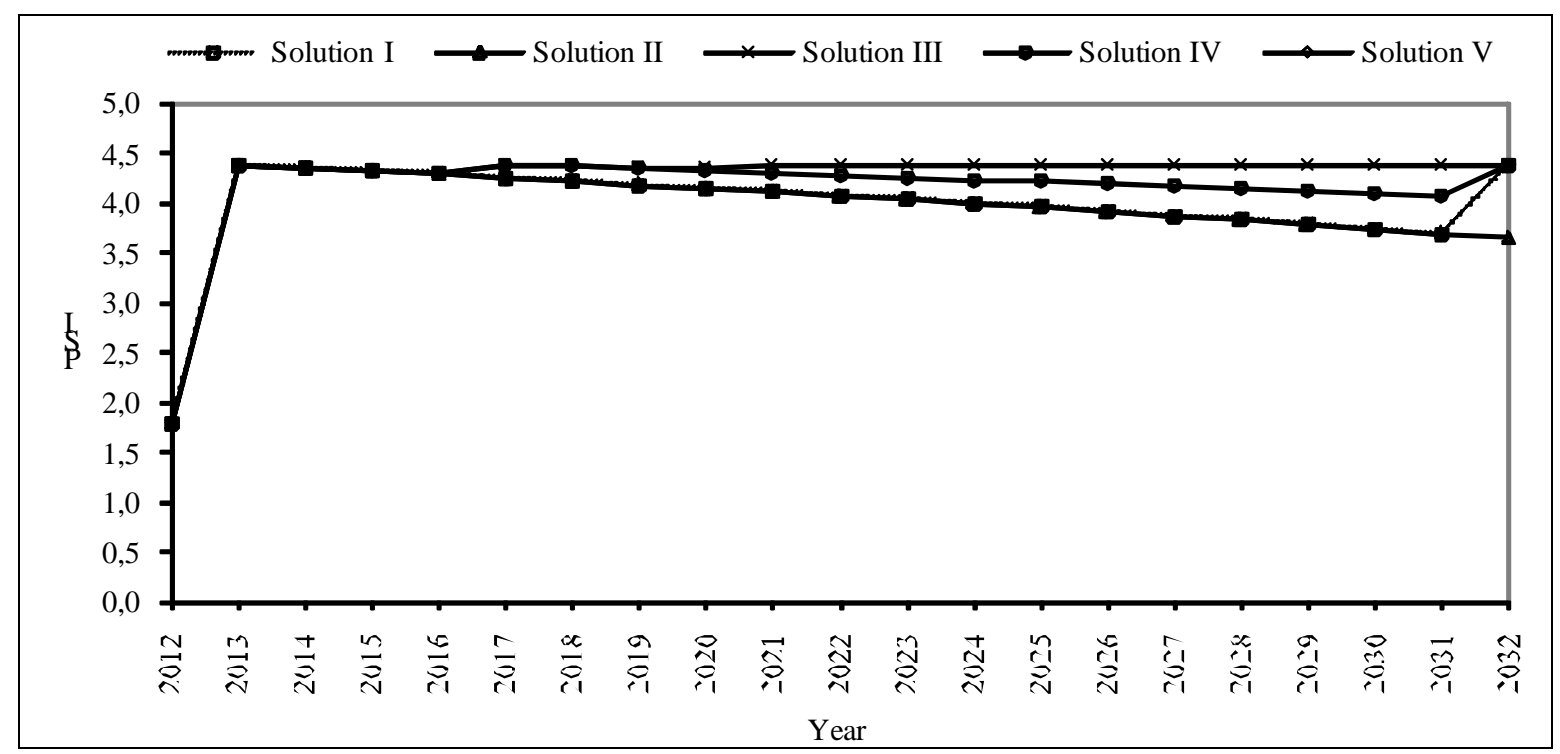

Figure 5-8 - Evolution of PSI for pavement 05012 of a national road 


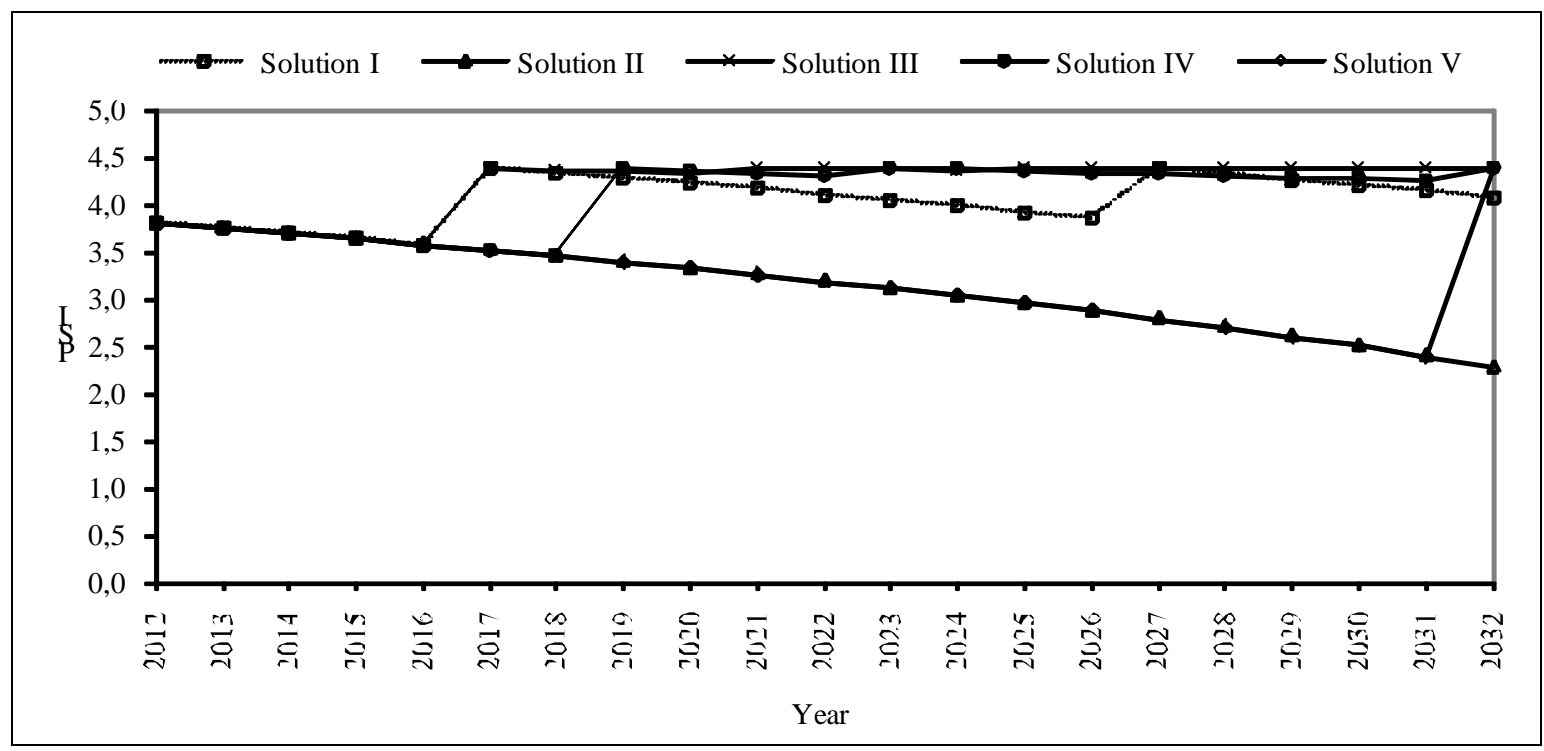

Figure 5-9 - Evolution of PSI for pavement 05001 of a national road

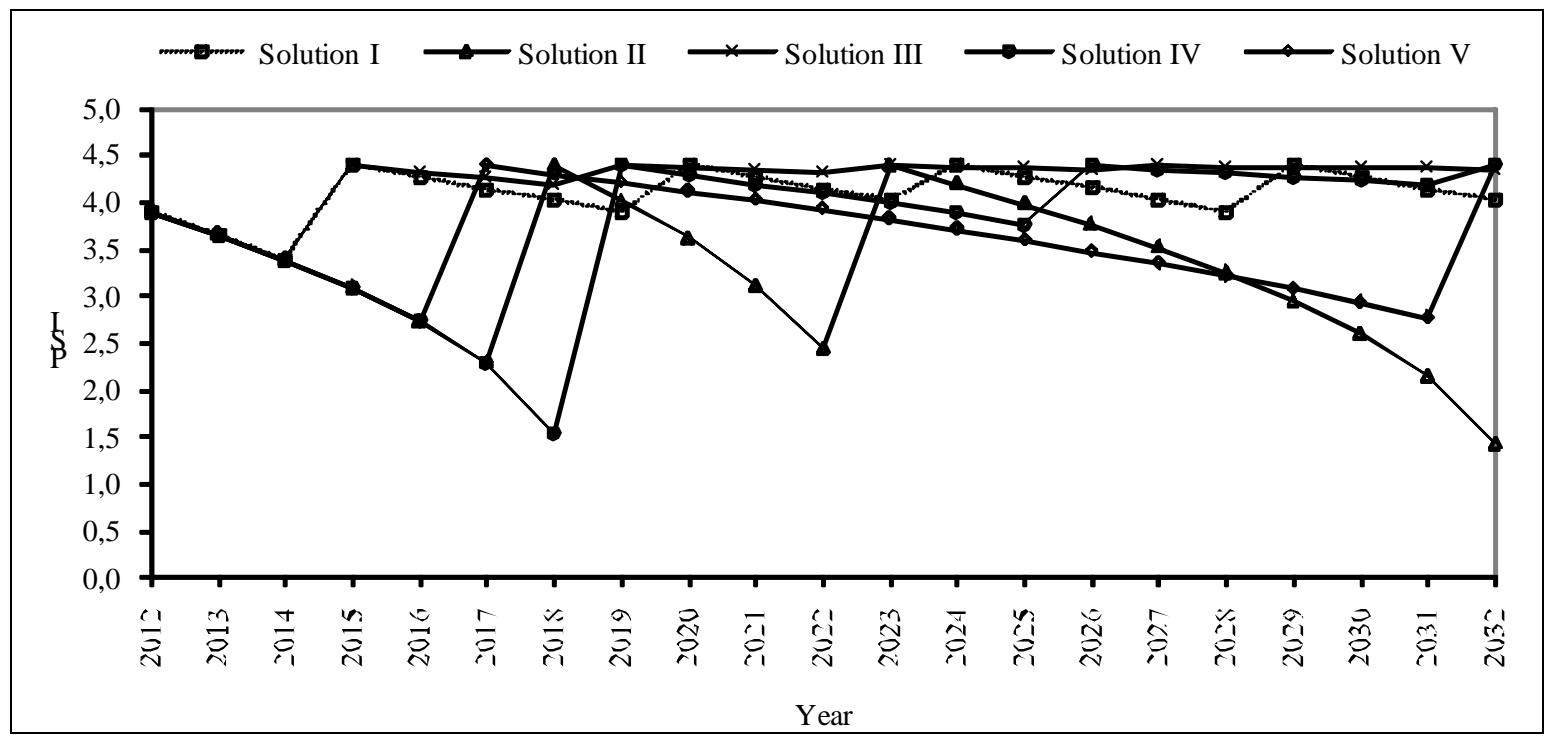

Figure 5-10 - Evolution of PSI for pavement 05003 of a national road 


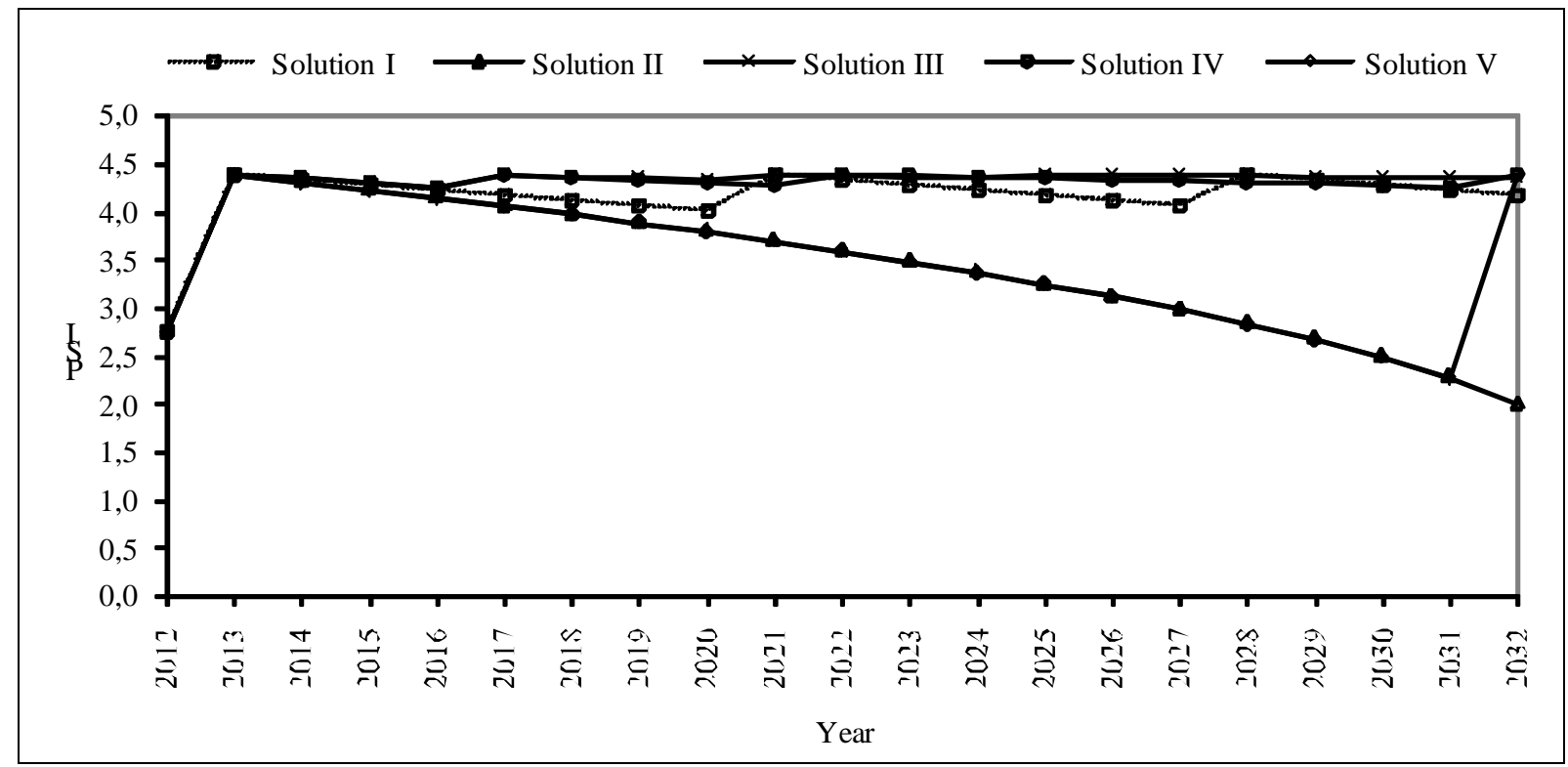

Figure 5-11 - Evolution of PSI for pavement 05004 of a national road

\subsection{Conclusions}

The Multi-objective Decision-Aid Tool (MODAT) presented in this chapter, incorporating several objectives into the same optimization model, can solve the pavement management problem for the case involving major rehabilitation interventions. The MODAT, as well as the decision-aid tool currently in use in the Estradas de Portugal's PMS, aims to minimize costs over a selected planning time-span, closing the gap between project and network management. This is made possible by using a macroscopic approach that uses models for predicting the future condition of the pavement based on measured condition data (i.e. cracking, raveling, potholes, patching, rutting, longitudinal roughness, skid resistance, traffic, climate, etc.). This macroscopic approach requires that each road section is homogeneous in terms of quality, pavement structure, pavement foundation, traffic and climate. It is assumed that each road section possesses one performance curve with any estimated future performance value 
representing the overall average pavement condition. The MODAT considers the pavement performance model used in the AASHTO flexible pavement design method, nevertheless any other preferred model can be used as well.

The MODAT is a useful new tool to help the road engineers in their task of maintenance and rehabilitation of pavements. In this MODAT application, the Knee point, which represents the most interesting solution of the Pareto frontier, corresponds to an agency costs weight value of $4 \%$, a user costs weight value of $95 \%$ and a weight value of $1 \%$ for the residual value of pavements, demonstrating that user costs, which are generally much greater than agency costs and the residual value of pavements, dominate the decision-making process. While the case study of this chapter focuses on a national road network, the approach proposed is applicable to any transportation infrastructure network, e.g., municipal road network, bridge network, where the decision-making process often involves multiple objective considerations. Because the MODAT is an open system, some modifications could be made to better serve the needs of road engineers. In the near future, our research in the pavement management field will follow in three main directions. First, the MODAT will include other objectives, beyond the three existing ones, such as, for example, the maximization of the road network performance. Second, a sensitivity analysis will be made of some input parameters considered in the application of the MODAT system, such as the discount rate. Third, pavement performance models will be developed using pavement performance data available in some road network databases and will be incorporated into MODAT for future applications to road networks. 


\section{APPENDIX 1: NOTATION}

$A C_{r s t}$ is the agency cost for applying operation $r$ to road section $s$ in year $t$;

$B_{t}$ is the budget for year $t$;

$C_{0}$ is the total cracked pavement area in year $0\left(\mathrm{~m}^{2} / 100 \mathrm{~m}^{2}\right)$;

$C_{n}^{e}$ is the structural coefficient of layer $n$;

$C_{n}^{d}$ is the drainage coefficient of layer $n$;

$C_{s, \text { const }}$ is the cost of construction or the cost of the last rehabilitation of pavement section $s$;

$d$ is the discount rate;

$D_{0}$ is the total disintegrated area (with potholes and raveling) in year $0\left(\mathrm{~m}^{2} / 100 \mathrm{~m}^{2}\right)$;

$H_{n}$ is the thickness of layer $n(\mathrm{~mm})$;

$I R I_{0}$ is the pavement longitudinal roughness in year $0(\mathrm{~mm} / \mathrm{km})$;

$M_{R}$ is the subgrade resilient modulus (pounds per square inch);

$N_{\max _{s}}$ is the maximum number of M\&R operations that may occur in road section $s$ over the planning time-span;

$W_{80}$ is the number of $80 \mathrm{kN}$ equivalent single axle load applications estimated for a selected design period and design lane;

$P a_{0}$ is the pavement patching in year $0\left(\mathrm{~m}^{2} / 100 \mathrm{~m}^{2}\right)$;

$P S I_{t}$ is the Present Serviceability Index in year $t$;

$P S I_{s, \text { rehab }}$ is the $P S I$ value after the application of a rehabilitation action in pavement section $s$;

$R$ is the number of alternative M\&R operations; 
Pavement maintenance programming considering three objectives: minimization of maintenance and rehabilitation costs, minimization of user costs and maximization of the residual value of pavements

$R_{0}$ is the mean rut in year $0(\mathrm{~mm})$;

$R V_{s, T+1}$ is the residual value for the pavement of section $s$;

$S$ is the number of road sections;

$S_{0}$ is the combined standard error of the traffic prediction and performance prediction;

$S N_{t}$ is the structural number of a road pavement in year $t$;

$T$ is the number of years in the planning time-span;

$t c$ is the annual average growth rate of heavy traffic;

$T M D A_{p}$ is the annual average daily heavy traffic in the year of construction or the last rehabilitation, in one direction and per lane;

$U C_{s t}$ is the user cost for road section $s$ in year $t$;

$V O C_{t}$ are the vehicle operation costs in year $t(€ / \mathrm{km} / \mathrm{vehicle})$;

$X_{r s t}$ is equal to one if operation $r$ is applied to section $s$ in year $t$, and is equal to zero otherwise;

$Y_{t}$ is the time since the pavement's construction or its last rehabilitation (years);

$Z_{R}$ is the standard normal deviate;

$P S I_{s t}$ are the pavement condition for section $s$ in year $t$;

$\overline{P S I}$ is the warning level for the pavement condition;

$\alpha$ is the average heavy traffic damage factor or simply truck factor;

$\triangle P S I_{t}$ is the difference between the initial value of the present serviceability index $\left(P S I_{0}\right)$ and the value of the present serviceability index in year $t\left(P S I_{t}\right)$;

$\Psi a$ are the agency cost functions;

$\Psi p$ are the pavement condition functions;

$\Psi r$ are the residual value functions; 
$\Psi u$ are the user cost functions;

$\Omega$ are the feasible operations sets.

\section{APPENDIX 2: DECISION-AID TOOL MODEL}

For explanation of notation, refer to the Appendix 1.

\section{A.2.1 Objective functions}

Minimise agency costs (maintenance and rehabilitation costs)

Minimise $A C=\sum_{r=1}^{R} \sum_{s=1}^{S} \sum_{t=1}^{T} \frac{1}{(1+d)^{t}} \cdot A C_{r s t} \cdot X_{r s t}$

Minimize user costs

Minimise $U C=\sum_{s=1}^{S} \sum_{t=1}^{T} \frac{1}{(1+d)^{t}} \cdot U C_{s t}$

Maximize the residual value of pavements at the end of the planning time-span

Maximise $R V=\sum_{s=1}^{S} \frac{1}{(1+d)^{T+1}} \cdot R V_{s, T+1}$

\section{A.2.2 Constraints}

Pavement condition functions

$\boldsymbol{P S I _ { s t }}=\Psi p\left(\boldsymbol{P S I}_{s 0}, X_{1 s 1}, \ldots, X_{1 s t}, \ldots, X_{R s 1}, \ldots, X_{R s t}\right), s=1, \ldots, S ; t=1, \ldots, T$

Warning level constraints

$\boldsymbol{P S I}_{s t} \geq \overline{P S I}_{s}, s=1, \ldots, S ; t=1, \ldots, T$ 
Feasible operation sets

$X_{r s t} \in \Omega\left(P S I_{s t}\right), r=1, \ldots, R ; s=1, \ldots, S ; t=1, \ldots, T$

\section{Annual operations constraints}

$\sum_{r=1}^{R} X_{r s t}=1, s=1, \ldots, S ; t=1, \ldots, T$

Agency cost functions

$A C_{r s t}=\Psi a\left(P S I_{s t}, X_{r s t}\right), r=1, \ldots, R ; s=1, \ldots, S ; t=1, \ldots, T$

User cost functions

$U C_{s t}=\Psi u\left(\boldsymbol{P S I} \boldsymbol{I}_{s t}\right), s=1, \ldots, S ; t=1, \ldots, T$

Residual value functions

$R V_{s, T+1}=\Psi r\left(\boldsymbol{P S} \boldsymbol{I}_{s, T+1}\right), s=1, \ldots, S$

Annual budget constraints

$\sum_{r=1}^{R} \sum_{s=1}^{S} A C_{r s t} \cdot X_{r s t} \leq B_{t}, t=1, \ldots, T$

Planning time-span operations constraints

$\sum_{r=2}^{R} \sum_{t=1}^{T} X_{r s t} \leq N \max _{s}, \forall s=1, \ldots, S$ 
APPENDIX 3: PAVEMENT CONDITION AND OTHER FUNCTIONS USED IN THE MODEL

\section{A.3.1 Pavement condition functions}

$P S I_{0}=5 \cdot e^{-0.000065 \cdot I R I_{0}}-0.000535 \cdot R_{0}{ }^{2}-0.21 \cdot\left(C_{0}+D_{0}+P a_{0}\right)^{0.5}$

$P S I_{t}=P S I_{0}-(4.2-1.5) \cdot 10^{\left[\left(\log _{10}\left(W_{18}\right)-Z_{R} \cdot S_{0}-9.36 \log _{10}(S N+1)+0.2-2.32 \log _{10}\left(M_{R}\right)+8.07\right) \cdot\left(0.4+\frac{1094}{\left.(S N+1)^{5.19}\right)}\right)\right]}$

$S N_{t}=\sum_{n=1}^{N} H_{n} \times C_{n}^{e} \times C_{n}^{d}$

$W_{80_{t}}=365 \times T M D A_{p} \times \frac{(1+t c)^{Y_{t}}-1}{t c} \times \alpha$

\section{A.3.2 User cost function}

$\operatorname{VOC}_{t}=1.20487-0.49116 \times P S I_{t}+0.05458 \times P S I_{t}^{2}$

\section{A.3.3 Residual value of pavements function}

$$
R V_{s, T+1}=C_{s, \text { const }} \cdot \frac{P S I_{s, T+1}-1.5}{P S I_{s, \text { rehab }}-1.5}
$$




\section{References}

AASHTO (1993). Guide for design of pavement structures. American Association of State Highway and Transportation Officials, Washington, D.C., USA, 4th ed., 1-640. AIPCR (2000). Highway development and management, volume one - overview of HDM-4. World Road Association, Paris, France, I, 1-53.

Andersson, P. (2007). Multi-year maintenance optimization for paved public roads segment based modelling and price-directive decomposition. $\mathrm{PhD}$ Thesis, Linköping University, Linköping, Sweden, 1-214.

Cleveland, W. (1994). The elements of graphing data. Murray Hill, New Jersey: AT\&T Bell Laboratories, pp. 1-285.

C-SHRP (2002). Pavement structural design practices across Canada. C-SHRP Technical Brief No. 23, Canadian Strategic Highway Research Program, Ottawa. Ontario, Canada, 1-10.

Das, I. (1999). On characterizing the "knee" of the Pareto curve based on normal boundary intersection. Structural and Multidisciplinary Optimization, 18, 107-115.

David, J., Loton, T., Gunvaldson, E., Bowen, C., Coad, N. and Jefford, D. (2006). Professional Visual Studio 2005 Team System. Wiley Publishing, Inc., Indiana, USA, $1-660$.

Deb, K. (2008). Multi-objective optimization using evolutionary algorithms, Wiley, West Sussex: John Wiley \& Sons, United Kingdom. 1-515. 
Ferreira, A. (2001). Pavement maintenance optimization of road networks. $\mathrm{PhD}$ Thesis, Coimbra University, Coimbra, Portugal, 1-383 (in Portuguese).

Ferreira, A. and Santos, J. (2012). Life-cycle cost analysis system for pavement management at project level: sensitivity analysis to the discount rate. International Journal of Pavement Engineering, 1-19, Published online: 03 September 2012, DOI: 10.1080/10298436.2012.719618.

Ferreira, A., Picado-Santos, L. and Antunes, A. (2002). A segment-linked optimization model for deterministic pavement management systems. The International Journal of Pavement Engineering, 3 (2), 95-105.

Ferreira, A., Meneses, S. and Vicente, F. (2009). Pavement management system for Oliveira do Hospital, Portugal. Proceedings of the Institution of Civil EngineersTransport, 162 (3), 157-169.

Ferreira, A., Picado-Santos, L., Wu, Z. and Flintsch, G. (2008). Analysis of Pavement Performance Models for use in Pavement Management Systems. Proceedings of the Third European Pavement and Asset Management Conference, CD Ed., chapter 1136.pdf, pp. 1-10, Coimbra, Portugal.

Ferreira, A., Picado-Santos, L., Wu, Z. and Flintsch, G. (2011). Selection of pavement performance models for use in the Portuguese PMS. International Journal of Pavement Engineering, 12 (1), 87-97.

Fwa, T., Chan, W., and Hoque, K. (2000). Multiobjective optimization for pavement maintenance programming. Journal of Transportation Engineering, 126 (5), 367374. 
Pavement maintenance programming considering three objectives: minimization of maintenance and rehabilitation costs, minimization of user costs and maximization of the residual value of pavements

Gendreau, M. and Potvin, J. (2005). Metaheuristics in combinatorial optimization. Annals of Operations Research, 140 (1), 189-213.

Haas, R. (2012). Reinventing the (pavement management) wheel. Distinguished Lecture, Fifth International Conference on Managing Pavements (available for download at http://www.asphalt.org/Pubs/PubsO.html).

Holland, J. (1975). Adaptation in natural and artificial systems. University of Michigan Press, Ann Arbor, MI, USA.

Horta, C., Pereira, F., Lopes, S. and Morgado, J. (2013). The EP's Pavement Management System - balance of a consolidated implementation. Proceedings of the $7^{\text {th }}$ Portuguese Road Conference, Laboratório Nacional de Engenharia Civil, CD Edition, Lisboa, Portugal, chapter 149_Art_T5_7CRP_2013.pdf, 1-10.

Hwang, C. and Masud, A. (1979). Multiple objective decision making - methods and applications: a state-of-the-art survey, Springer-Verlag, Berlin, Germany.

Ihs, A. and Sjögren, L. (2003). An overview of HDM-4 and the Swedish pavement management system. VTI - Infrastructure Maintenance, Linköping, Sweden, 1-31.

Iniestra, J. and Gutiérrez, J. (2009). Multi-criteria decisions on interdependent infrastructure transportation projects using an evolutionary-based framework. Applied Soft Computing, 9 (2), 512-526.

Lang, J. and Dahlgren, J. (2001). Prediction model in the Swedish PMS. Proceedings of the Fifth International Conference on Managing Pavements, CD Ed., Seattle, Washington, USA, chapter 100.pdf, 1-10. 
Lang, J. and Potucek, J. (2001). Pavement management systems in Sweden. Proceedings of the Fifth International Conference on Managing Pavements, CD Ed., Seattle, Washington, USA, chapter 097.pdf, 1-12.

Marler, R., and Arora, J. (2004). Survey of multi-objective optimization methods for engineering. Structural and Multidisciplinary Optimization, 26, 369-395.

MathWorks (3013). MATLAB - The language ot Technical computing. http://www.mathworks.com/products/matlab/

Meneses, S. and Ferreira, A. (2013). Pavement maintenance programming considering two objectives: maintenance costs and user costs, International Journal of Pavement Engineering, 14 (2), 206-221.

Meneses, S., Ferreira, A. and Collop, A. (2013). Multi-objective decision-aid tool for pavement management, Proceedings of the Institution of Civil Engineers-Transport, 166 (2), 79-94.

Michalewicz, Z. and Fogel, D. (2004). How to solve it: modern heuristics. SpringerVerlag, Berlin, Germany.

Miettinen, K. (1999). Nonlinear multi-objective optimization, Kluwer Academic Publishers, Boston, USA, 1-324.

Picado-Santos, L., Ferreira, A., Costa Pereira, F. and Conceição Azevedo, M. (2006). The evaluation of maintenance and rehabilitation strategies in the pavement management system of the Portuguese road administration. Proceedings of the $4^{\text {th }}$ Portuguese Road Congress, Lisbon, Portugal, 1-10 (in Portuguese).

Picado-Santos, L., and Ferreira, A. (2007). Development and implementation of a new pavement management system. Proceedings of the Fifth International Symposium on 
Pavement maintenance programming considering three objectives: minimization of maintenance and rehabilitation costs, minimization of user costs and maximization of the residual value of pavements

Maintenance and Rehabilitation of Pavements and Technological Control, CD Ed., 433-438, Utah, USA.

Picado-Santos, L., and Ferreira, A. (2008). Contributions to the development of the Portuguese road administration's pavement management system. Proceedings of the Third European Pavement and Asset Management Conference, CD Ed., chapter 1138.pdf, 1-10, Coimbra, Portugal.

Randolph, N. and Gardner, D. (2008). Professional Visual Studio 2008. Wiley Publishing, Inc., Indiana, USA, 1-946.

Santos, J. and Ferreira, A. (2013). Life-cycle cost analysis for pavement management at project level. International Journal of Pavement Engineering, 14 (1), 71-84.

Santos, J. and Ferreira, A. (2012). Pavement design optimization considering costs and preventive interventions. Journal of Transportation Engineering, 138 (7), 911-923.

Stephenson, M., Epps, R. and Kennedy, C. (2004). Development of deterioration models for local authority roads. Proceedings of the Institution of Civil EngineersMunicipal Engineer 157 (3), 167-172.

Trindade, M. and Horta, C. (2009). Pavement management system of Estradas de Portugal, S.A. Proceedings of the $15^{\text {th }}$ Congreso Ibero-Latinoamericano del Asfalto, CD Ed., 1351-1360, Lisboa, Portugal (in Portuguese).

Wang, F., Zhang, Z., and Machemehl, R. (2003). Decision making problem for managing pavement maintenance and rehabilitation projects. Transportation Research Record, 1853, 21-28, Washington DC, USA. 
Wu, Z., Flintsch, G. (2009). Pavement preservation optimization considering multiple objectives and budget variability. Journal of Transportation Engineering, 135 (5), $305-315$.

Wu, Z., Flintsch, G., Ferreira, A. and Picado-Santos, L. (2012). Framework for multi-objective optimization of physical highway assets investments. Journal of Transportation Engineering, 138 (12), 1411-1421. 


\section{Chapter 6}

\section{Multi-objective decision-aid tool for pavement management: sensitivity analysis to the discount rate}

\subsection{Introduction}

Multi-objective optimization has received increasing attention as a tool to assist transportation agencies in order to be able to make more economical investment decisions. When analyzing long-term public investments, we must compare costs and benefits that occur in different time periods. As time has a money value, a dollar spent in the future is worth less than the present dollar (Jawad and Ozbay 2006). Therefore, the optimization process needs to consider an economic technique known as "discounting" to convert different costs and benefits occurred at different times at a common point in time (FHWA 2002). This technique applies a financial variable called discount rate $(r)$ to represent the time value of the money. 
The discount rate used in a multi-objective application can have quite a large impact on the analysis and in the conclusions that can be reached. Therefore, it is important to apply the correct discount rate for each particular decision problem. However, the question of which discount rate to actually use in a given situation does not have a simple answer.

The choice of the discount rate is one of the most debatable topics in public project evaluation and has been analyzed by many researchers, but there still is uncertainty about which discount rate is most appropriate to evaluate public projects. Therefore, several authors have written about theories and practices in the choice of the social discount rate (e.g. Kula 1985, Kula 1987, Pearce and Ulph 1995, Pearce and Ulph 1999, Evans and Sezer 2002, Young, 2002, Evans 2004, Evans and Sezer 2004, Spackman 2004, Evans and Sezer 2005, Evans 2006, Rambaud and Terrecillas 2006, Spackman 2006, Jenkins and Kuo 2007, Azar 2007, Zhuang et al. 2007, Lally 2008, Percoco 2008, Harrison 2010). Despite the lack of consensus between authors, four alternatives of theoretical basis approaches have been considered for the choice of a social discount rate: social rate of time preference (SRTP); marginal social opportunity cost of capital (SOC); weight average (WA); and shadow price of capital (SPC).

Since there is no consensus about which approach is the most appropriate for the choice of the discount rate used for the evaluation of public projects, many governments and agencies, across countries and within countries, over time, have specified the discount rate to be employed in their public projects. Table 6.1 presents the social discount rates values adopted in several countries (Ferreira and Santos 2013). The analysis of this table permits us to conclude that the tendency is to adopt low social discount rates 
values. For example, the European Commission recommends 5.5\% for cohesion countries and for convergence regions elsewhere with high growth outlook, and 3.5\% for competitive regions.

Table 6-1 - Social discount rate values

\begin{tabular}{|c|c|c|c|}
\hline Country/Region & Values & $\begin{array}{l}\text { Theoretical basis } \\
\text { approach }\end{array}$ & References \\
\hline USA & $10 \%$ (until 1992); 7\% (after 1992) & SOC/SRTP & $\begin{array}{l}\text { Zhuang et al. (2007) } \\
\text { OMB (1992) }\end{array}$ \\
\hline Canada & $10 \%$ (until 2007); 8\% (after 2007) & SOC & $\begin{array}{c}\text { TBCS (2007) } \\
\text { Zhuang et al. (2007) } \\
\text { Spackman (2006) }\end{array}$ \\
\hline Australia & $8 \%$ (until 2010); $7 \%$ (after 2010) & $\mathrm{SOC}$ & $\begin{array}{c}\text { AG (2010) } \\
\text { Zhuang et al. (2007) } \\
\text { IA (2008) }\end{array}$ \\
\hline New Zealand & $10 \%$ (until 2008); 8.0\% (after 2008) & $\mathrm{SOC}$ & $\begin{array}{c}\text { NZT (2008) } \\
\text { Zhuang et al. (2007) }\end{array}$ \\
\hline $\begin{array}{c}\text { European } \\
\text { Commission }\end{array}$ & $\begin{array}{c}5.5 \% \text { - countries and convergence regions } \\
3.5 \% \text { - competitiveness regions }\end{array}$ & SRTP & $\mathrm{EC}(2008)$ \\
\hline $\begin{array}{c}\text { United } \\
\text { Kingdom }\end{array}$ & $6 \%$ (until 2003); 3.5\% (after 2003) & SRTP & $\begin{array}{c}\text { Zhuang et al. (2007) } \\
\text { HMT (2003) }\end{array}$ \\
\hline Germany & $4 \%$ (until 2004); $3.0 \%$ (after 2004) & $\begin{array}{l}\text { Based on federal } \\
\text { refinancing rate }\end{array}$ & $\begin{array}{l}\text { Zhuang et al. (2007) } \\
\text { Spackman (2006) }\end{array}$ \\
\hline France & $8 \%$ (until 2005); $4.0 \%$ (after 2005) & SRTP & $\begin{array}{c}\text { Zhuang et al. (2007) } \\
\text { Spackman (2006) } \\
\text { GCP (2005) }\end{array}$ \\
\hline Italy & $5 \%$ & SRTP & Zhuang et al. (2007) \\
\hline Spain & $6 \%$ & SRTP & Zhuang et al. (2007) \\
\hline Portugal & $4.0 \%$ (after 2003) & $\begin{array}{l}\text { Based on government } \\
\text { refinancing rate }\end{array}$ & MF (2003) \\
\hline Norway & $7 \%$ (until 1998); 3.5\% (after 1998) & $\begin{array}{l}\text { Government } \\
\text { borrowing rate }\end{array}$ & $\begin{array}{c}\text { Zhuang et al. (2007) } \\
\text { Spackman (2006) } \\
\text { Odeck (2005) }\end{array}$ \\
\hline China & $8 \%$ & WA & Zhuang et al. (2007) \\
\hline India & $12 \%$ & SOC & Zhuang et al. (2007) \\
\hline
\end{tabular}

Note: SRTP - social rate of time preference; SOC - marginal social opportunity cost of capital; WA weight average; SPC - shadow price of capital. 
Over the years, highway agencies, influenced by trends suggested by some authors or by government imposition, have changed the discount rate applied in the evaluation of their public projects. Wall and Smith (1998), on life cycle costs analysis (LCCA) in pavement design, specified that the discount rate needs to be consistent with the opportunity cost for the public at large and should reflect the historical trends over long periods of time. Ozbay et al. (2004) carried out a study to examine how LCCA was practiced by State Highway Agencies (SHA) in the United States. The results showed that in 1984 the discount rate ranged between 0.0 and $10.0 \%$ with a mean of $4.3 \%$, whereas in 2001 the applied discount rate ranged between 3.0 and $5.0 \%$ with a mean of 3.9\%. The next step of the study conducted by Ozbay et al. (2004) was performed by Rangaraju et al. (2008). The results showed that in 2005 nineteen SHA used discrete values ranging between $3.0 \%$ and $5.3 \%$; four SHA used the discount rate defined by the USA Office of Management and Budget; and another four used a variable discount rate value depending on available current data. Thoft-Christensen (2009), considering LCCA of bridges, stated that discount rates ranging from 2.0 to $3.0 \%$ are more reasonable than an unrealistically high discount rate, e.g. $6.0 \%$ commonly used in many countries.

Wall and Smith (1998) stated that all LCCA should be subject to a sensitivity analysis in order to determine the impact of the variability of the major LCCA input assumptions, projections and estimates on overall LCCA results. Christensen et al. (2005) affirmed that through this process, decision-makers can identify the inputs of the model that have most influence on model results and/or determine break-even points that alter the ranking of considered alternatives. According to Hall et al. (2003), the 
inputs of the model that most influence the relative cost-effectiveness of different alternatives are: the project life; the predicted traffic over the project life; the initial investment; the discount rate; the timing of follow-up maintenance and rehabilitation $(\mathrm{M} \& \mathrm{R})$ activities; and the quantities associated with initial and follow-up maintenance and rehabilitation activities. Thus, it is fundamental to do a sensitivity analysis in order to determine the impact of the variability of the major input parameters in the results of a multi-objective decision-aid tool application. This chapter presents a sensitivity analysis to the discount rate that was carried out on the application of the MultiObjective Decision-Aid Tool (MODAT). The chapter is divided into three sections. The first section consists of a brief description of the state-of-art in terms of discount rates that have been applied over the years in the assessment of public investment projects. The second section presents the results obtained by the sensitivity analysis to the discount rate considered in the application of the MODAT system to the main road network of Castelo Branco. The final section consists of a synthesis of the conclusions reached so far and a statement of prospects for future research.

\subsection{Sensitivity analysis to the discount rate}

\subsubsection{Introduction}

Chapter 3 presented the development and implementation of a Multi-Objective Decision-Aid Tool (MODAT) tested with data from the Estradas de Portugal's Pavement Management System (Meneses and Ferreira 2013). The MODAT used a multi-objective deterministic section-linked optimization model with two goals: 
minimization of agency costs; and minimization of user costs. The MODAT also used the deterministic pavement performance model used in the AASHTO flexible pavement design method. The application of MODAT was illustrated with a case study involving the main road network of Castelo Branco, a district of Portugal. This application was carried out using a discount rate equal to $2,5 \%$. The next section of this chapter will present the results of the application of MODAT with different discount rates.

\subsubsection{Results}

Figure 6.1 shows the evolution of the discount factor - $\mathrm{f}(r, t)$ - represented by Equation (17) throughout the project analysis period considering different discount rate values. This Figure shows that as the discount rate value increases, the present value of any cost or benefit decreases over time. This Figure also shows that as the discount rate value increases the curvature also increases over time.

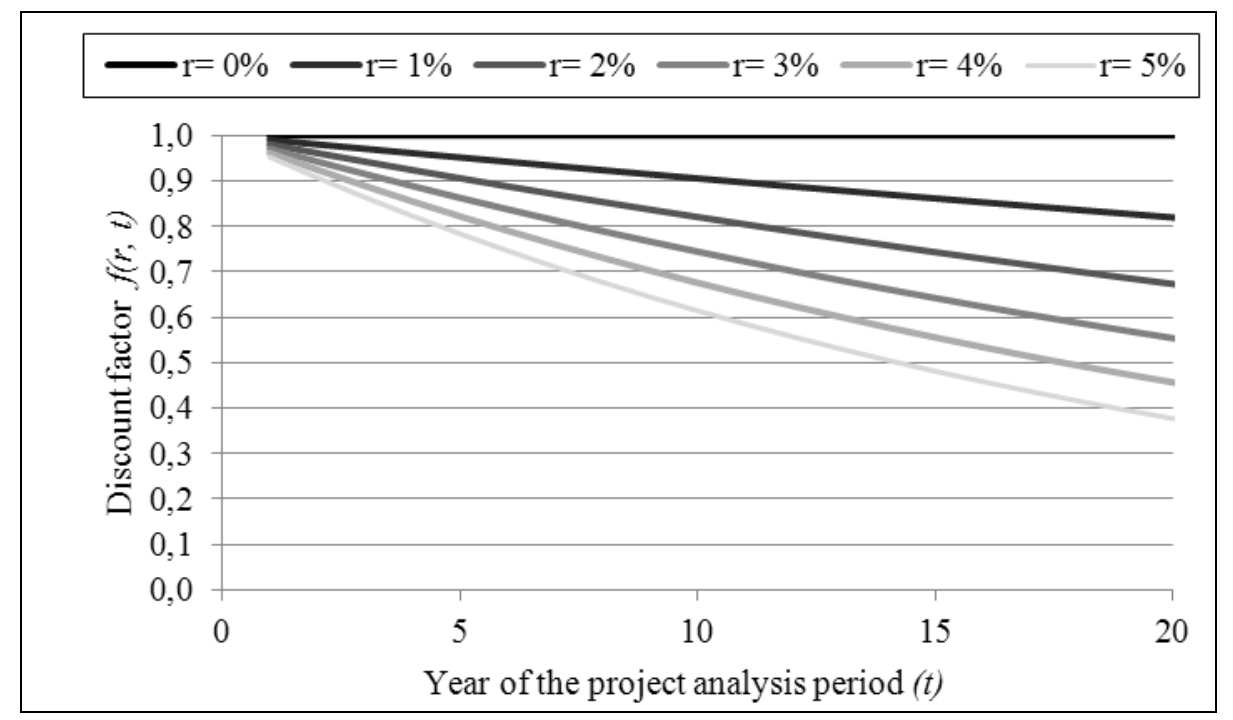

Figure 6-1 - Evolution of the discount factor throughout planning period of 20 years 
$f(r, t)=\frac{1}{(1+r)^{t}}$

Where: $f(r, t)$ is the discount factor; $r$ is the discount rate value; $t$ is any year of the planning period.

In this sensitivity analysis, the discount rate value varied between $1 \%$ and $5 \%$, incremented by $1 \%$, while keeping all the other input values. Using this methodology, the decision-maker can understand the variability of the results associated with the choice of the discount rate value. Figure 6.2 represents the Pareto optimal set of solutions in the objective space by varying the weight values while Figure 6.3 represents the optimal set of normalised solutions.

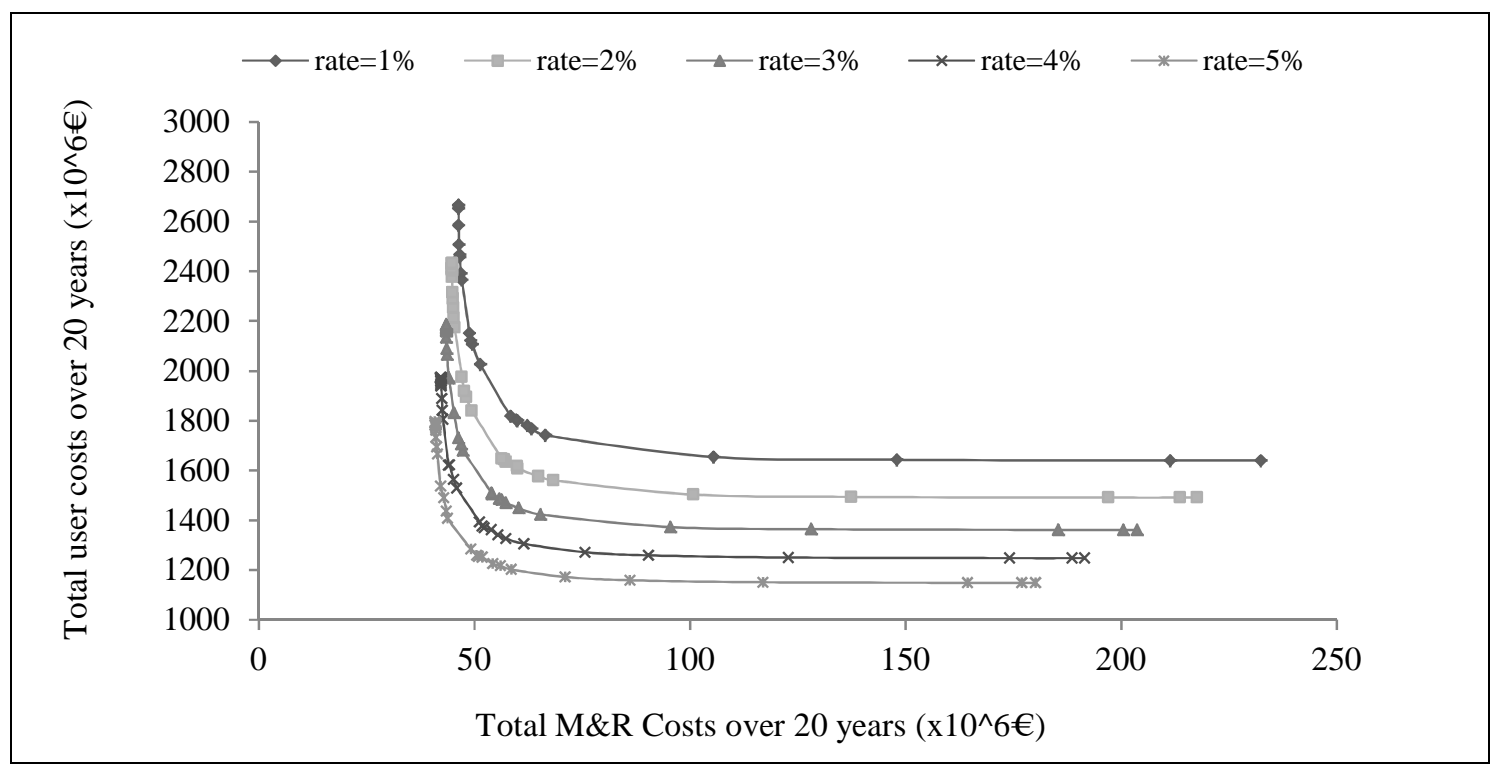

Figure 6-2 - Pareto optimal set of solutions for all considered rates 


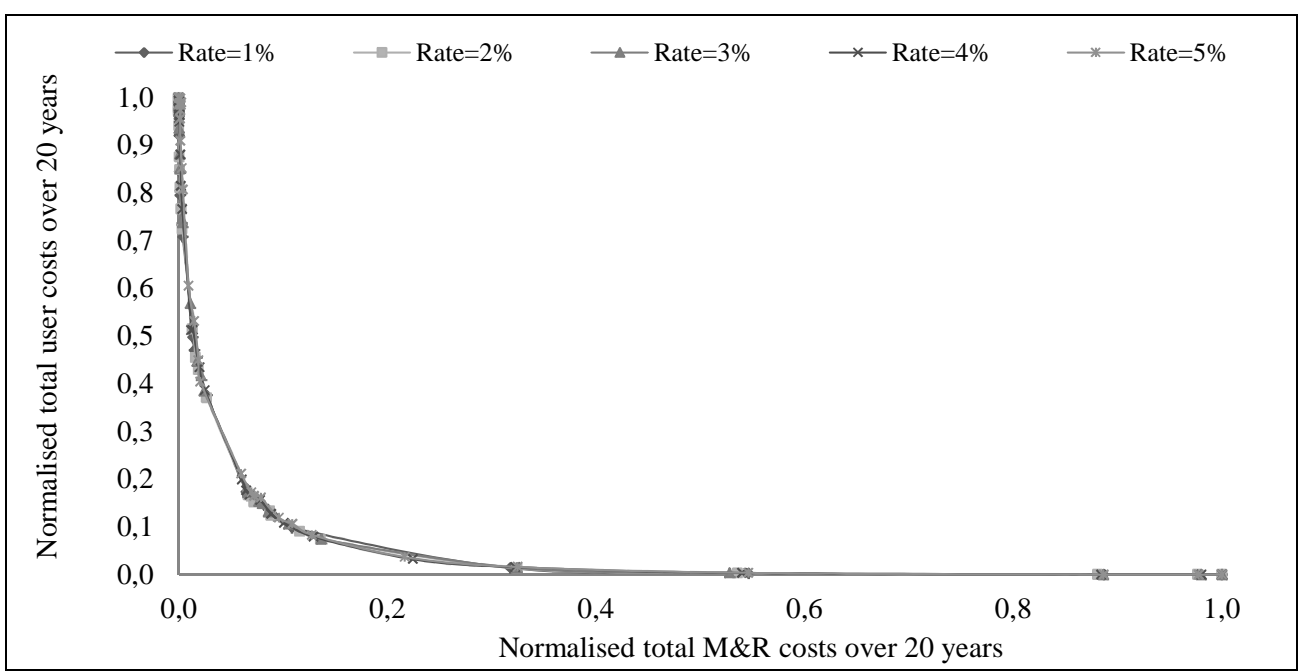

Figure 6-3 - Pareto optimal set of normalised solutions for all considered rates

The "Knee point" for the discount rates of $1 \%, 2 \%, 3 \%$ and $4 \%$ was obtained considering the following weight values: $\left(w_{A C}, w_{U C}\right)=(0.04,0.96)$. For discount rate of $5 \%$, the "Knee point" was obtained considering the following weight values: $\left(w_{A C}, w_{U C}\right)$ $=(0.03,0.97)$. From these Figures it can be concluded that, when the decision-maker considers different discount rate values between $1 \%$ and $5 \%$, the weight values remain the same or almost the same.

In multi-objective problems there is no perfect method to select one "optimal" solution from the Pareto optimal set of solutions. The final best-compromise solution is always up to the decision-maker. For that purpose, four different M\&R solutions of the Pareto frontier were considered for comparison.

a) Solution I: Multi-objective optimization approach (corrective-preventive) considering the "Knee point" ( $\left.w_{A C}=0.04, w_{U C}=0.96\right)$ for discount rates of $1 \%$, $2 \%, 3 \%$ and $4 \%$; and considering the "Knee point $\left(w_{A C}=0.03, w_{U C}=0.97\right)$ for discount rate of $5 \%$; 
b) Solution II: Multi-objective optimization approach (corrective-preventive) considering the following weights $\left(w_{A C}=1.00, w_{U C}=0.00\right)$;

c) Solution III: Multi-objective optimization approach (corrective-preventive) considering the following weights $\left(w_{A C}=0.00, w_{U C}=1.00\right)$;

d) Solution IV: Multi-objective optimization approach (corrective-preventive) considering the following weights $\left(w_{A C}=0.50, w_{U C}=0.50\right)$.

The M\&R costs throughout the planning time-span of 20 years for these four Pareto optimal solutions are summarised in Figure 6.4. This Figure shows that, as expected, the $M \& R$ costs decrease when the discount rate value increases. The same happens for the user costs (Figure 6.5), the residual value of pavements (Figure 6.6), and the total costs (Figure 6.7).

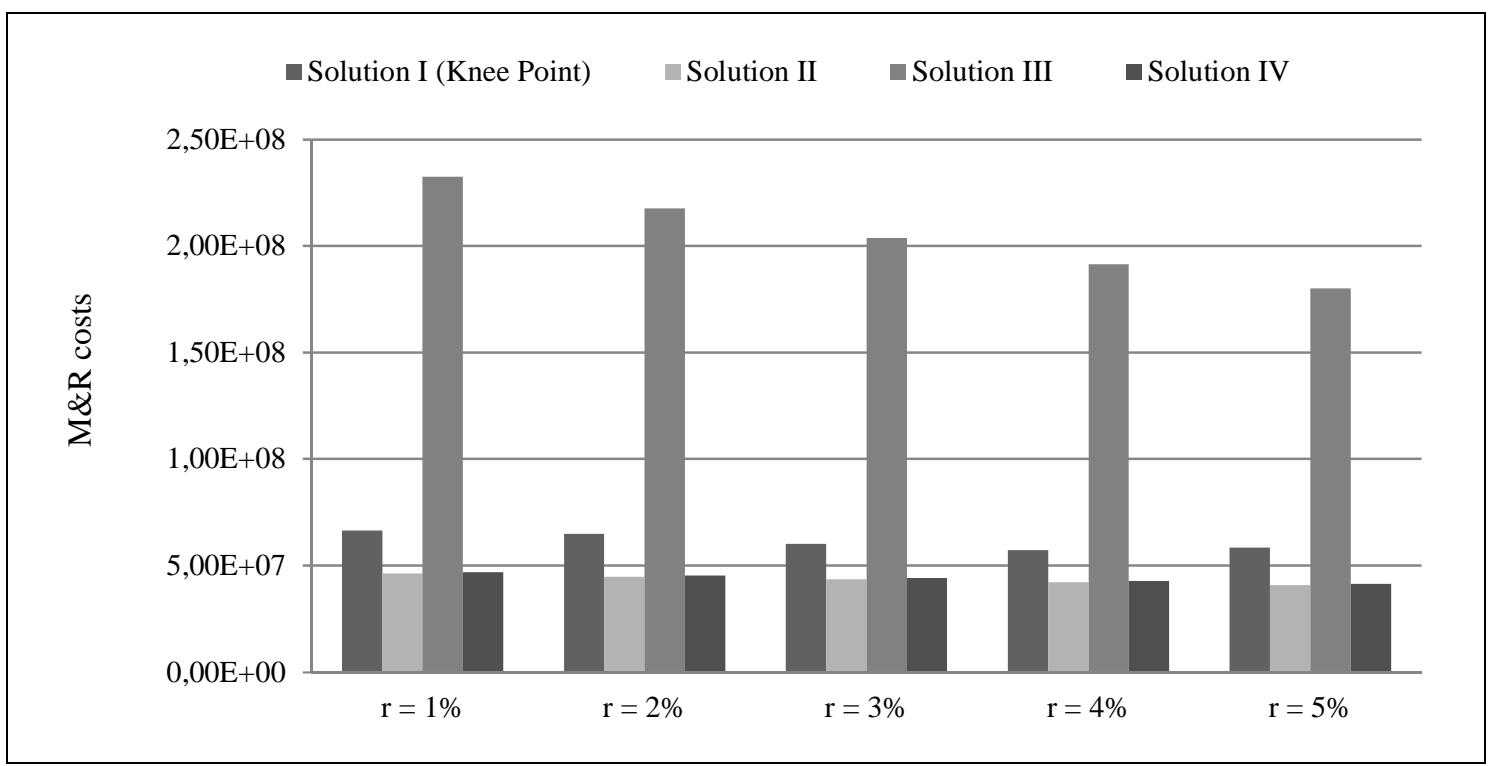

Figure 6-4 - M\&R Costs throughout the planning time-span of 20 years for all considered rates 


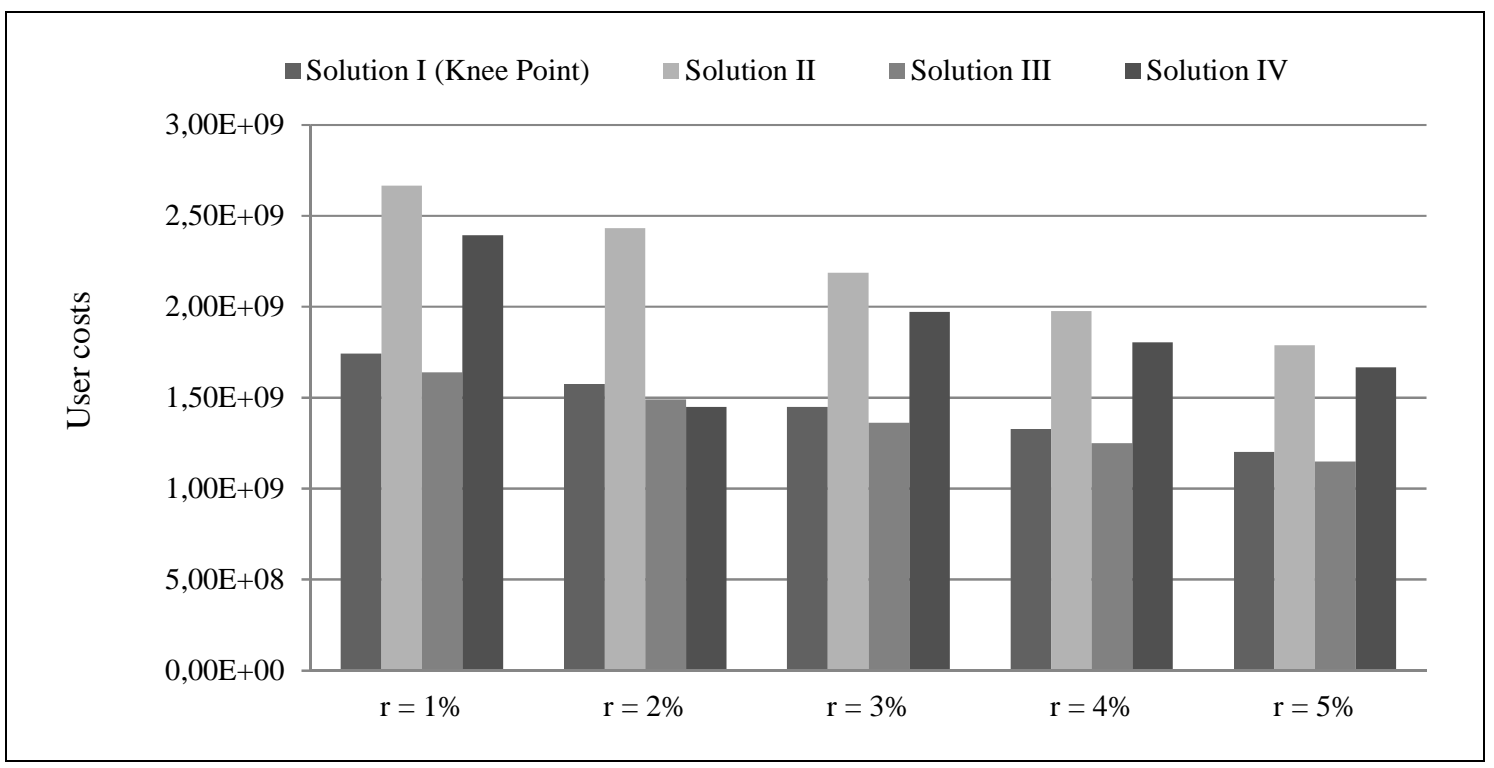

Figure 6-5- User Costs throughout the planning time-span of 20 years for all considered rates

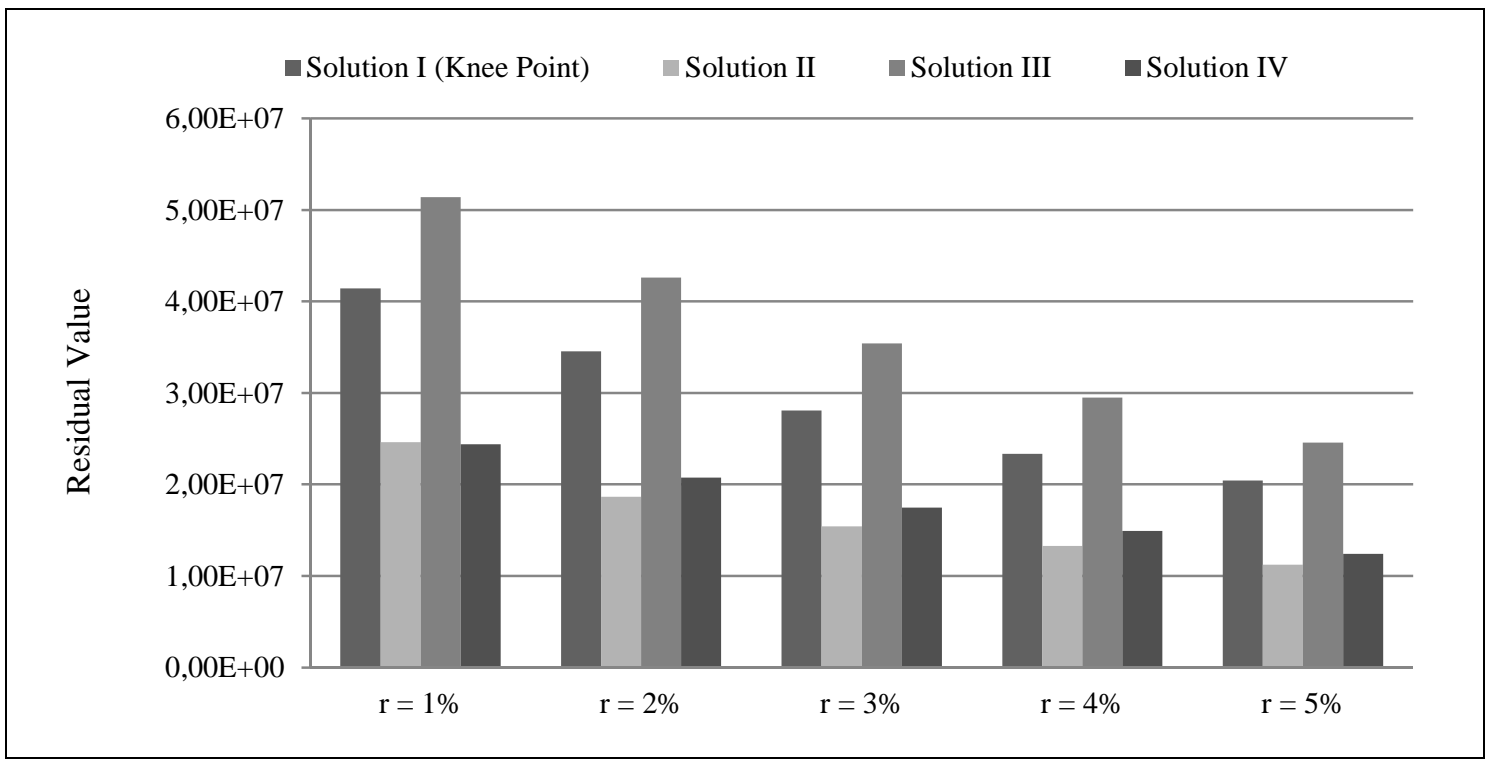

Figure 6-6 - Residual Value throughout the planning time-span of 20 years for all considered rates 


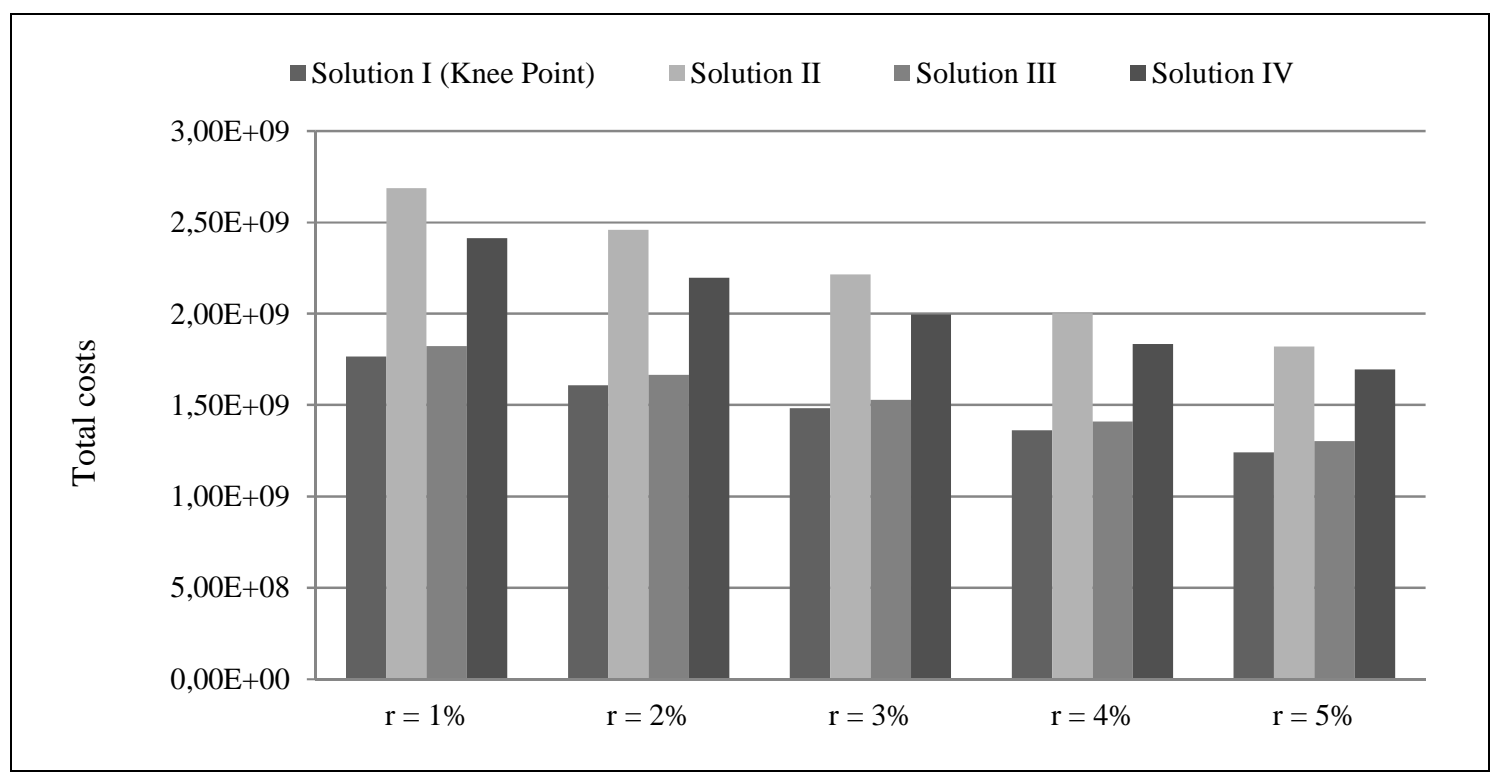

Figure 6-7 - Total Costs throughout the planning time-span of 20 years for all considered rates

In addition to these summarised results, the MODAT provides extensive information about the M\&R strategy to be implemented for each road section. To analyse these road section-linked results, four road sections were chosen. Table 6.2 illustrates the attributes of these road sections including their present PSI value. Table 6.3 presents the M\&R operations to be applied in road section 05012 considering the four M\&R solutions of the Pareto frontier. Figure 6.8 represents the predicted evolution of the PSI value over the years for pavement section 050012 of a national road as a consequence of the execution of the M\&R plan. The results obtained for this pavement section show that the $M \& R$ actions are not independent of the discount rate value. If solution III of MODAT is adopted, different M\&R operations would be applied in function of the discount rate value adopted. A similar analysis could be made for any other pavement section. Tables $6.4,6.5$ and 6.6 present the M\&R operations to be applied in road sections 05004, 05001 and 05003, respectively. Figures 6.9, 6.10 and 6.11 present the 
predicted evolution of the PSI value over the years for pavement sections 05004, 05001 and 05003 , respectively.

Table 6-1 - Attributes of road sections

\begin{tabular}{|c|c|c|c|c|}
\hline \multirow{2}{*}{$\begin{array}{l}\text { Attributes } \\
\text { Section_ID }\end{array}$} & \multicolumn{4}{|c|}{ Road section } \\
\hline & 05012 & 05004 & 05001 & 05003 \\
\hline Road_class & EN & $\mathrm{IC}$ & IP & IC \\
\hline Pavement_type & Flexible & Flexible & Flexible & Flexible \\
\hline District & Castelo Branco & Castelo Branco & Castelo Branco & Castelo Branco \\
\hline \multicolumn{4}{|l|}{ Length (m) } & 14,635 \\
\hline \multicolumn{5}{|l|}{ Width (m) } \\
\hline \multicolumn{5}{|l|}{ Sub-grade_CBR $(\%)$} \\
\hline Structural_number & 2.47 & 3.51 & 5.20 & 4.80 \\
\hline Age_of_pavements (years) & 16 & 14 & 8 & 3 \\
\hline Annual_average_daily_traffi & 744 & 6,212 & 4316 & 5,828 \\
\hline Annual_average_daily_heavy_tr & 100 & 1000 & 300 & 1000 \\
\hline Annual_growth_average_tax & 3.0 & 4.0 & 3.0 & 4.0 \\
\hline Truck_factor & 2.0 & 4.0 & 3.0 & 4.0 \\
\hline $\mathrm{PSI}_{0}$ & 1.79 & 2.75 & 3.81 & 3.90 \\
\hline
\end{tabular}


Table 6-2 - M\&R operations to be applied in road section 05012

\begin{tabular}{|c|c|c|c|c|c|c|c|c|c|c|c|c|c|c|c|c|c|c|c|c|}
\hline \multicolumn{21}{|c|}{ Section 05012; PSI0 = 1.79} \\
\hline \multirow[b]{2}{*}{$r(\%)$} & \multicolumn{20}{|c|}{ Year } \\
\hline & $\underset{N}{\stackrel{N}{N}}$ & $\underset{\omega}{\stackrel{\sim}{\sigma}}$ & $\stackrel{N}{\stackrel{N}{\perp}}$ & $\begin{array}{l}\stackrel{N}{\circ} \\
\stackrel{u}{r}\end{array}$ & $\begin{array}{l}\text { O } \\
\text { a }\end{array}$ & $\stackrel{N}{\ominus}$ & $\underset{\infty}{\stackrel{N}{\infty}}$ & $\begin{array}{l}\stackrel{N}{0} \\
\underset{\sigma}{0}\end{array}$ & $\begin{array}{l}\text { N } \\
\text { N }\end{array}$ & 옹 & $\begin{array}{l}\text { N } \\
\text { N }\end{array}$ & $\begin{array}{l}\text { N } \\
\text { N్ }\end{array}$ & $\begin{array}{l}\text { N } \\
\mathbb{N}\end{array}$ & $\begin{array}{l}\text { No } \\
\text { Un }\end{array}$ & $\begin{array}{l}\text { No } \\
\text { N }\end{array}$ & $\begin{array}{l}\text { O } \\
\text { N }\end{array}$ & $\begin{array}{l}\text { N } \\
\text { N }\end{array}$ & $\begin{array}{l}\text { N } \\
\text { N్ర }\end{array}$ & $\begin{array}{l}\text { No } \\
\text { W }\end{array}$ & $\underset{ٍ}{\stackrel{\omega}{\omega}}$ \\
\hline \multicolumn{21}{|c|}{ Solution I - Knee point } \\
\hline $1 \%$ & 5 & 1 & 1 & 1 & 1 & 1 & 1 & 1 & 1 & 1 & 1 & 1 & 1 & 1 & 1 & 1 & 1 & 1 & 1 & 1 \\
\hline $2 \%$ & 5 & 1 & 1 & 1 & 1 & 1 & 1 & 1 & 1 & 1 & 1 & 1 & 1 & 1 & 1 & 1 & 1 & 1 & 1 & 1 \\
\hline $3 \%$ & 5 & 1 & 1 & 1 & 1 & 1 & 1 & 1 & 1 & 1 & 1 & 1 & 1 & 1 & 1 & 1 & 1 & 1 & 1 & 1 \\
\hline $4 \%$ & 5 & 1 & 1 & 1 & 1 & 1 & 1 & 1 & 1 & 1 & 1 & 1 & 1 & 1 & 1 & 1 & 1 & 1 & 1 & 1 \\
\hline $5 \%$ & 5 & 1 & 1 & 1 & 1 & 1 & 1 & 1 & 1 & 1 & 1 & 1 & 1 & 1 & 1 & 1 & 1 & 1 & 1 & 1 \\
\hline \multicolumn{21}{|c|}{ Solution II $\left(w_{A C}=1.00, w_{U C}=0.00\right)$} \\
\hline $1 \%$ & 5 & 1 & 1 & 1 & 1 & 1 & 1 & 1 & 1 & 1 & 1 & 1 & 1 & 1 & 1 & 1 & 1 & 1 & 1 & 1 \\
\hline $2 \%$ & 5 & 1 & 1 & 1 & 1 & 1 & 1 & 1 & 1 & 1 & 1 & 1 & 1 & 1 & 1 & 1 & 1 & 1 & 1 & 1 \\
\hline $3 \%$ & 5 & 1 & 1 & 1 & 1 & 1 & 1 & 1 & 1 & 1 & 1 & 1 & 1 & 1 & 1 & 1 & 1 & 1 & 1 & 1 \\
\hline $4 \%$ & 5 & 1 & 1 & 1 & 1 & 1 & 1 & 1 & 1 & 1 & 1 & 1 & 1 & 1 & 1 & 1 & 1 & 1 & 1 & 1 \\
\hline $5 \%$ & 5 & 1 & 1 & 1 & 1 & 1 & 1 & 1 & 1 & 1 & 1 & 1 & 1 & 1 & 1 & 1 & 1 & 1 & 1 & 1 \\
\hline \multicolumn{21}{|c|}{ Solution III $\left(w_{A C}=0.00, w_{U C}=1.00\right)$} \\
\hline $1 \%$ & 5 & 1 & 1 & 1 & 5 & 1 & 1 & 1 & 5 & 1 & 1 & 1 & 1 & 5 & 1 & 1 & 1 & 1 & 1 & 1 \\
\hline $2 \%$ & 5 & 1 & 1 & 1 & 5 & 1 & 1 & 1 & 5 & 1 & 1 & 1 & 1 & 5 & 1 & 1 & 1 & 1 & 1 & 1 \\
\hline $3 \%$ & 5 & 1 & 1 & 1 & 5 & 1 & 1 & 1 & 5 & 1 & 1 & 1 & 4 & 1 & 1 & 1 & 1 & 1 & 1 & 1 \\
\hline $4 \%$ & 5 & 1 & 1 & 1 & 5 & 1 & 1 & 1 & 5 & 1 & 1 & 1 & 5 & 1 & 1 & 1 & 1 & 1 & 1 & 1 \\
\hline $5 \%$ & 5 & 1 & 1 & 1 & 5 & 1 & 1 & 1 & 5 & 1 & 1 & 1 & 4 & 1 & 1 & 1 & 1 & 1 & 1 & 1 \\
\hline \multicolumn{21}{|c|}{ Solution IV $\left(w_{A C}=0.50, w_{U C}=0.50\right)$} \\
\hline $1 \%$ & 5 & 1 & 1 & 1 & 1 & 1 & 1 & 1 & 1 & 1 & 1 & 1 & 1 & 1 & 1 & 1 & 1 & 1 & 1 & 1 \\
\hline $2 \%$ & 5 & 1 & 1 & 1 & 1 & 1 & 1 & 1 & 1 & 1 & 1 & 1 & 1 & 1 & 1 & 1 & 1 & 1 & 1 & 1 \\
\hline $3 \%$ & 5 & 1 & 1 & 1 & 1 & 1 & 1 & 1 & 1 & 1 & 1 & 1 & 1 & 1 & 1 & 1 & 1 & 1 & 1 & 1 \\
\hline $4 \%$ & 5 & 1 & 1 & 1 & 1 & 1 & 1 & 1 & 1 & 1 & 1 & 1 & 1 & 1 & 1 & 1 & 1 & 1 & 1 & 1 \\
\hline $5 \%$ & 5 & 1 & 1 & 1 & 1 & 1 & 1 & 1 & 1 & 1 & 1 & 1 & 1 & 1 & 1 & 1 & 1 & 1 & 1 & 1 \\
\hline
\end{tabular}

KEY (M\&R actions):

1 - Do nothing; 2 - Non structural maintenance; 3 - Minor rehabilitation; 4 - Medium rehabilitation; 5 - Major rehabilitation

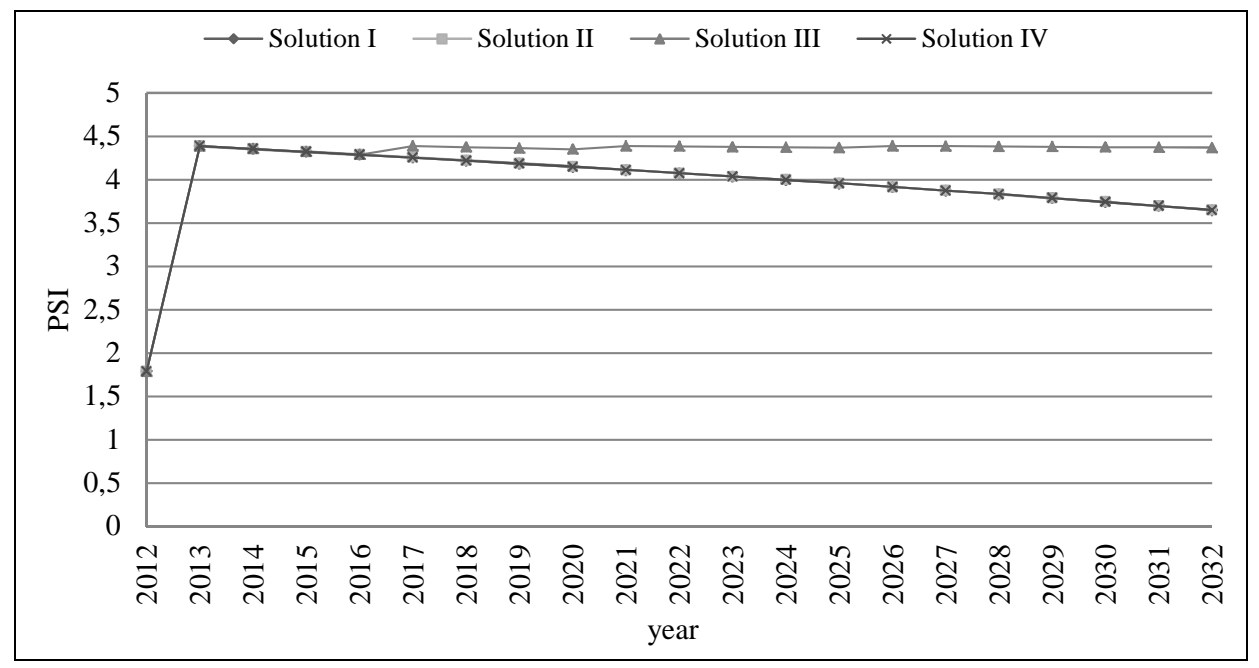

Figure 6-8 - Evolution of PSI for pavement section 05012 of a national road 
Table 6-3 - M\&R operations to be applied in road section 05004

\begin{tabular}{|c|c|c|c|c|c|c|c|c|c|c|c|c|c|c|c|c|c|c|c|c|}
\hline \multirow[b]{3}{*}{$\mathrm{R}(\%)$} & \multicolumn{20}{|c|}{ Section 05004; $\mathrm{PSI}_{0}=2,75$} \\
\hline & \multicolumn{20}{|c|}{ Year } \\
\hline & $\frac{N}{\stackrel{N}{N}}$ & 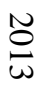 & $\stackrel{N}{\stackrel{N}{\perp}}$ & $\begin{array}{l}N \\
\stackrel{0}{\cup}\end{array}$ & $\stackrel{N}{\circ}$ & $\stackrel{N}{\ominus}$ & $\underset{\infty}{\stackrel{N}{\infty}}$ & $\frac{N}{0}$ & 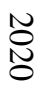 & $\begin{array}{l}\text { N } \\
\text { N } \\
\end{array}$ & $\begin{array}{l}\text { N } \\
\text { N }\end{array}$ & $\begin{array}{c}\text { N } \\
\text { N } \\
\end{array}$ & $\begin{array}{l}N \\
\stackrel{N}{D} \\
\perp\end{array}$ & $\begin{array}{l}\text { No } \\
\text { N } \\
\text { un }\end{array}$ & $\begin{array}{l}\text { No } \\
\text { N }\end{array}$ & $\begin{array}{l}N \\
\text { N } \\
\text { V }\end{array}$ & $\underset{N}{\stackrel{N}{\infty}}$ & $\begin{array}{l}\text { N } \\
\text { N్ర }\end{array}$ & 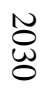 & $\stackrel{N}{\stackrel{\omega}{\omega}}$ \\
\hline \multicolumn{21}{|c|}{ Solution I - Knee point } \\
\hline $1 \%$ & 4 & 1 & 1 & 1 & 1 & 1 & 1 & 2 & 1 & 1 & 1 & 1 & 1 & 1 & 2 & 1 & 1 & 1 & 1 & 1 \\
\hline $2 \%$ & 4 & 1 & 1 & 1 & 1 & 1 & 1 & 2 & 1 & 1 & 1 & 1 & 1 & 1 & 2 & 1 & 1 & 1 & 1 & 1 \\
\hline $3 \%$ & 3 & 1 & 1 & 1 & 1 & 1 & 2 & 1 & 1 & 1 & 1 & 1 & 1 & 2 & 1 & 1 & 1 & 1 & 1 & 1 \\
\hline $4 \%$ & 3 & 1 & 1 & 1 & 1 & 1 & 1 & 2 & 1 & 1 & 1 & 1 & 1 & 2 & 1 & 1 & 1 & 1 & 1 & 1 \\
\hline $5 \%$ & 3 & 1 & 1 & 1 & 1 & 1 & 2 & 1 & 1 & 1 & 1 & 2 & 1 & 1 & 1 & 1 & 2 & 1 & 1 & 1 \\
\hline \multicolumn{21}{|c|}{ Solution II $\left(w_{A C}=1.00, w_{U C}=0.00\right)$} \\
\hline $1 \%$ & 3 & 1 & 1 & 1 & 1 & 1 & 1 & 1 & 1 & 1 & 1 & 1 & 1 & 1 & 1 & 1 & 1 & 1 & 1 & 1 \\
\hline $2 \%$ & 3 & 1 & 1 & 1 & 1 & 1 & 1 & 1 & 1 & 1 & 1 & 1 & 1 & 1 & 1 & 1 & 1 & 1 & 1 & 1 \\
\hline $3 \%$ & 3 & 1 & 1 & 1 & 1 & 1 & 1 & 1 & 1 & 1 & 1 & 1 & 1 & 1 & 1 & 1 & 1 & 1 & 1 & 1 \\
\hline $4 \%$ & 3 & 1 & 1 & 1 & 1 & 1 & 1 & 1 & 1 & 1 & 1 & 1 & 1 & 1 & 1 & 1 & 1 & 1 & 1 & 1 \\
\hline $5 \%$ & 3 & 1 & 1 & 1 & 1 & 1 & 1 & 1 & 1 & 1 & 1 & 1 & 1 & 1 & 1 & 1 & 1 & 1 & 1 & 1 \\
\hline \multicolumn{21}{|c|}{ Solution III $\left(w_{A C}=0.00, w_{U C}=1.00\right)$} \\
\hline $1 \%$ & 5 & 1 & 1 & 1 & 5 & 1 & 1 & 1 & 5 & 1 & 1 & 1 & 1 & 5 & 1 & 1 & 1 & 1 & 1 & 1 \\
\hline $2 \%$ & 5 & 1 & 1 & 1 & 5 & 1 & 1 & 1 & 5 & 1 & 1 & 1 & 1 & 5 & 1 & 1 & 1 & 1 & 1 & 1 \\
\hline $3 \%$ & 5 & 1 & 1 & 1 & 5 & 1 & 1 & 1 & 5 & 1 & 1 & 1 & 5 & 1 & 1 & 1 & 1 & 1 & 1 & 1 \\
\hline $4 \%$ & 5 & 1 & 1 & 1 & 5 & 1 & 1 & 1 & 5 & 1 & 1 & 1 & 5 & 1 & 1 & 1 & 1 & 1 & 1 & 1 \\
\hline $5 \%$ & 5 & 1 & 1 & 1 & 5 & 1 & 1 & 1 & 5 & 1 & 1 & 1 & 5 & 1 & 1 & 1 & 1 & 1 & 1 & 1 \\
\hline
\end{tabular}

Solution IV $\left(w_{A C}=0.50, w_{U C}=0.50\right)$

\begin{tabular}{lllllllllllllllllllll}
\hline $1 \%$ & 3 & 1 & 1 & 1 & 1 & 1 & 1 & 1 & 1 & 1 & 1 & 1 & 1 & 1 & 1 & 1 & 1 & 1 & 1 & 1 \\
$2 \%$ & 3 & 1 & 1 & 1 & 1 & 1 & 1 & 1 & 1 & 1 & 1 & 1 & 1 & 1 & 1 & 1 & 1 & 1 & 1 & 1 \\
$3 \%$ & 3 & 1 & 1 & 1 & 1 & 1 & 1 & 1 & 1 & 1 & 1 & 1 & 1 & 1 & 1 & 1 & 1 & 1 & 1 & 1 \\
$4 \%$ & 3 & 1 & 1 & 1 & 1 & 1 & 1 & 1 & 1 & 1 & 1 & 1 & 1 & 1 & 1 & 1 & 1 & 1 & 1 & 1 \\
$5 \%$ & 3 & 1 & 1 & 1 & 1 & 1 & 1 & 1 & 1 & 1 & 1 & 1 & 1 & 1 & 1 & 1 & 1 & 1 & 1 & 1 \\
\hline
\end{tabular}

KEY (M\&R actions):

1 - Do nothing; 2 - Non structural maintenance; 3 - Minor rehabilitation; 4 - Medium rehabilitation; 5

- Major rehabilitation

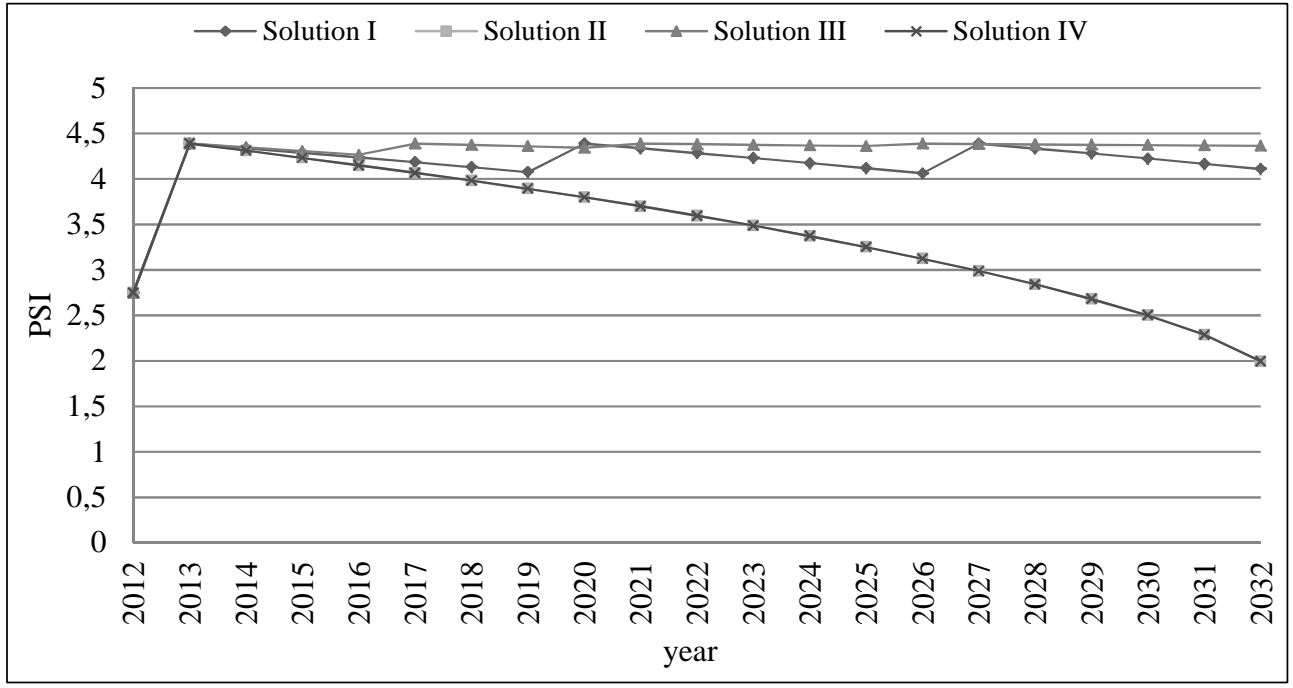

Figure 6-9 - Evolution of PSI for pavement section 05004 of a national road 
Table 6-4 - M\&R operations to be applied in road section 05001

\begin{tabular}{|c|c|c|c|c|c|c|c|c|c|c|c|c|c|c|c|c|c|c|c|c|}
\hline \multirow[b]{3}{*}{$r(\%)$} & \multicolumn{20}{|c|}{ Section $05001 ; \mathrm{PSI}_{0}=3.81$} \\
\hline & \multicolumn{20}{|c|}{ Year } \\
\hline & $\frac{N}{\stackrel{N}{N}}$ & $\stackrel{N}{\varrho}$ & $\stackrel{N}{\mathscr{C}}$ & $\stackrel{\text { O }}{\stackrel{\theta}{u}}$ & $\frac{\sqrt[N]{0}}{\sigma}$ & $\stackrel{N}{\stackrel{\Xi}{\Xi}}$ & $\frac{\stackrel{N}{\circ}}{\infty}$ & $\frac{\mathfrak{0}}{6}$ & N & $\hat{s}$ & $\begin{array}{c}\text { N } \\
\text { N } \\
\text { N }\end{array}$ & 芯 & 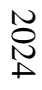 & 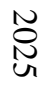 & N & $\begin{array}{l}\text { N } \\
\text { N }\end{array}$ & $\begin{array}{l}\text { N } \\
\text { N }\end{array}$ & 芯 & $\stackrel{N}{\mathscr{W}}$ & 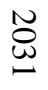 \\
\hline \multicolumn{21}{|c|}{ Solution I - Knee point } \\
\hline $1 \%$ & 1 & 1 & 1 & 1 & 2 & 1 & 1 & 1 & 1 & 1 & 1 & 1 & 2 & 1 & 1 & 1 & 1 & 1 & 1 & 1 \\
\hline $2 \%$ & 1 & 1 & 1 & 1 & 2 & 1 & 1 & 1 & 1 & 1 & 1 & 1 & 2 & 1 & 1 & 1 & 1 & 1 & 1 & 1 \\
\hline $3 \%$ & 1 & 1 & 1 & 1 & 2 & 1 & 1 & 1 & 1 & 1 & 1 & 1 & 2 & 1 & 1 & 1 & 1 & 1 & 1 & 1 \\
\hline $4 \%$ & 1 & 1 & 1 & 1 & 2 & 1 & 1 & 1 & 1 & 1 & 1 & 1 & 2 & 1 & 1 & 1 & 1 & 1 & 1 & 1 \\
\hline $5 \%$ & 1 & 1 & 1 & 1 & 2 & 1 & 1 & 1 & 1 & 1 & 1 & 1 & 2 & 1 & 1 & 1 & 1 & 1 & 1 & 1 \\
\hline \multicolumn{21}{|c|}{ Solution II $\left(w_{A C}=1.00, w_{U C}=0.00\right)$} \\
\hline $1 \%$ & 1 & 1 & 1 & 1 & 1 & 1 & 1 & 1 & 1 & 1 & 1 & 1 & 1 & 1 & 1 & 1 & 1 & 1 & 1 & 1 \\
\hline $2 \%$ & 1 & 1 & 1 & 1 & 1 & 1 & 1 & 1 & 1 & 1 & 1 & 1 & 1 & 1 & 1 & 1 & 1 & 1 & 1 & 1 \\
\hline $3 \%$ & 1 & 1 & 1 & 1 & 1 & 1 & 1 & 1 & 1 & 1 & 1 & 1 & 1 & 1 & 1 & 1 & 1 & 1 & 1 & 1 \\
\hline $4 \%$ & 1 & 1 & 1 & 1 & 1 & 1 & 1 & 1 & 1 & 1 & 1 & 1 & 1 & 1 & 1 & 1 & 1 & 1 & 1 & 1 \\
\hline $5 \%$ & 1 & 1 & 1 & 1 & 1 & 1 & 1 & 1 & 1 & 1 & 1 & 1 & 1 & 1 & 1 & 1 & 1 & 1 & 1 & 1 \\
\hline \multicolumn{21}{|c|}{ Solution III $\left(w_{A C}=0.00, w_{U C}=1.00\right)$} \\
\hline $1 \%$ & 1 & 1 & 1 & 1 & 5 & 1 & 1 & 1 & 5 & 1 & 1 & 1 & 5 & 1 & 1 & 1 & 5 & 1 & 1 & 1 \\
\hline $2 \%$ & 1 & 1 & 1 & 1 & 5 & 1 & 1 & 1 & 5 & 1 & 1 & 1 & 5 & 1 & 1 & 1 & 5 & 1 & 1 & 1 \\
\hline $3 \%$ & 1 & 1 & 1 & 1 & 5 & 1 & 1 & 1 & 5 & 1 & 1 & 1 & 5 & 1 & 1 & 1 & 5 & 1 & 1 & 1 \\
\hline $4 \%$ & 1 & 1 & 1 & 1 & 5 & 1 & 1 & 1 & 5 & 1 & 1 & 1 & 5 & 1 & 1 & 1 & 5 & 1 & 1 & 1 \\
\hline $5 \%$ & 1 & 1 & 1 & 1 & 5 & 1 & 1 & 1 & 5 & 1 & 1 & 1 & 5 & 1 & 1 & 1 & 5 & 1 & 1 & 1 \\
\hline \multicolumn{21}{|c|}{ Solution IV $\left(w_{A C}=0.50, w_{U C}=0.50\right)$} \\
\hline $1 \%$ & 1 & 1 & 1 & 1 & 1 & 1 & 1 & 1 & 1 & 1 & 1 & 1 & 1 & 1 & 1 & 1 & 1 & 1 & 1 & 1 \\
\hline $2 \%$ & 1 & 1 & 1 & 1 & 1 & 1 & 1 & 1 & 1 & 1 & 1 & 1 & 1 & 1 & 1 & 1 & 1 & 1 & 1 & 1 \\
\hline $3 \%$ & 1 & 1 & 1 & 1 & 1 & 1 & 1 & 1 & 1 & 1 & 1 & 1 & 1 & 1 & 1 & 1 & 1 & 1 & 1 & 1 \\
\hline $4 \%$ & 1 & 1 & 1 & 1 & 1 & 1 & 1 & 1 & 1 & 1 & 1 & 1 & 1 & 1 & 1 & 1 & 1 & 1 & 1 & 1 \\
\hline $5 \%$ & 1 & 1 & 1 & 1 & 1 & 1 & 1 & 1 & 1 & 1 & 1 & 1 & 1 & 1 & 1 & 1 & 1 & 1 & 1 & 1 \\
\hline
\end{tabular}

KEY (M\&R actions):

$\mathbf{1}$ - Do nothing; 2 - Non structural maintenance; 3 - Minor rehabilitation; 4 - Medium rehabilitation; 5 - Major rehabilitation

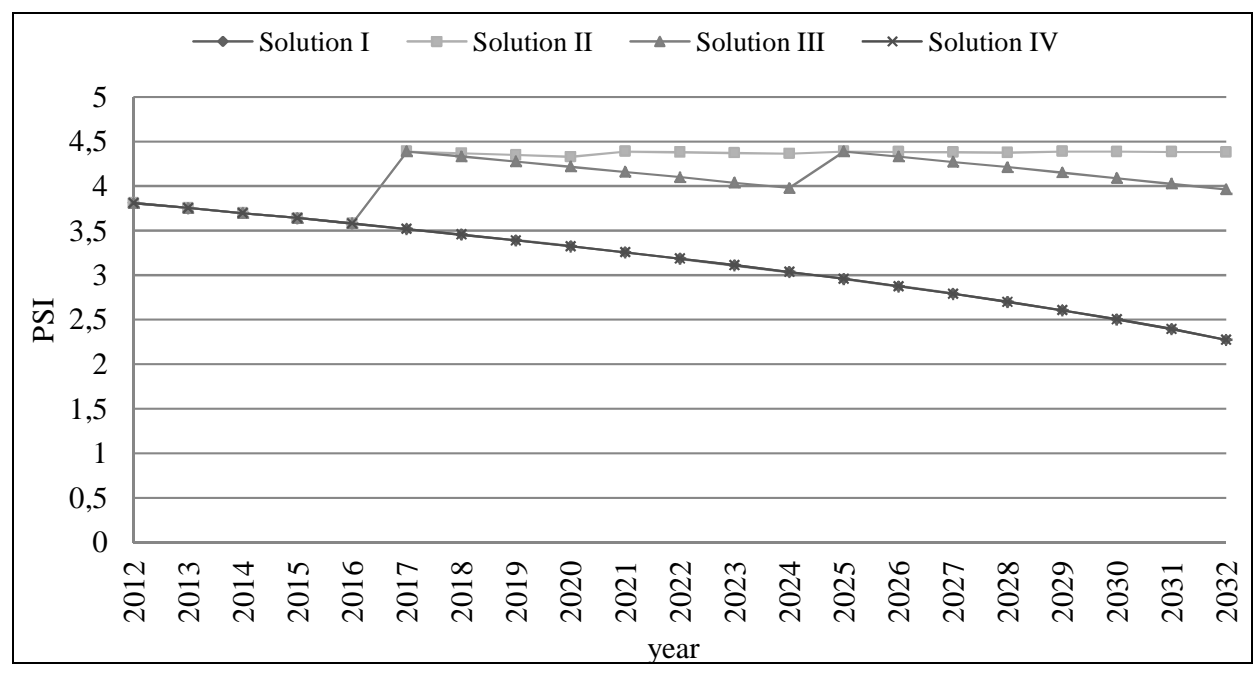

Figure 6-10 - Evolution of PSI for pavement section 05001 of a national road 
Table 6-5 - M\&R operations to be applied in road section 05003

\begin{tabular}{|c|c|c|c|c|c|c|c|c|c|c|c|c|c|c|c|c|c|c|c|c|}
\hline \multirow[b]{3}{*}{$\mathrm{R}(\%)$} & \multicolumn{20}{|c|}{ Section 05003; $\mathrm{PSI}_{0}=3,90$} \\
\hline & \multicolumn{20}{|c|}{ Year } \\
\hline & 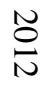 & $\underset{\omega}{\stackrel{N}{\varrho}}$ & $\stackrel{N}{\stackrel{D}{A}}$ & $\begin{array}{l}\stackrel{N}{\ominus} \\
\text { ur }\end{array}$ & 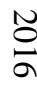 & $\stackrel{N}{\ominus}$ & $\underset{\infty}{\stackrel{N}{\infty}}$ & $\frac{\mathfrak{c}}{\sigma}$ & \begin{tabular}{l}
$N$ \\
\multirow{N}{0}{}
\end{tabular} & $\begin{array}{l}\text { N } \\
\text { N }\end{array}$ & $\begin{array}{l}\text { N } \\
\text { N }\end{array}$ & $\begin{array}{l}\text { N } \\
\text { W }\end{array}$ & $\begin{array}{l}\text { ON } \\
\mathbb{N}\end{array}$ & $\begin{array}{l}\text { No } \\
\text { Nu }\end{array}$ & $\begin{array}{l}\text { No } \\
\text { Na }\end{array}$ & $\begin{array}{l}\text { ON } \\
\text { N }\end{array}$ & $\begin{array}{l}\text { N } \\
\text { N }\end{array}$ & $\begin{array}{l}\text { N్ర } \\
\text { N్}\end{array}$ & $\underset{ٍ ్}{\stackrel{్}{0}}$ & $\stackrel{\sim}{\stackrel{\omega}{\sigma}}$ \\
\hline \multicolumn{21}{|c|}{ Solution I - Knee point } \\
\hline $1 \%$ & 1 & 1 & 4 & 1 & 1 & 1 & 1 & 1 & 2 & 1 & 1 & 1 & 1 & 1 & 2 & 1 & 1 & 1 & 1 & 1 \\
\hline $2 \%$ & 1 & 1 & 5 & 1 & 1 & 1 & 1 & 1 & 1 & 2 & 1 & 1 & 1 & 1 & 1 & 2 & 1 & 1 & 1 & 1 \\
\hline $3 \%$ & 1 & 1 & 5 & 1 & 1 & 1 & 1 & 1 & 1 & 2 & 1 & 1 & 1 & 1 & 1 & 2 & 1 & 1 & 1 & 1 \\
\hline $4 \%$ & 1 & 1 & 3 & 1 & 1 & 1 & 1 & 2 & 1 & 1 & 1 & 2 & 1 & 1 & 1 & 2 & 1 & 1 & 1 & 1 \\
\hline $5 \%$ & 1 & 1 & 4 & 1 & 1 & 1 & 1 & 1 & 2 & 1 & 1 & 1 & 1 & 1 & 2 & 1 & 1 & 1 & 1 & 1 \\
\hline \multicolumn{21}{|c|}{ Solution II $\left(w_{A C}=1.00, w_{U C}=0.00\right)$} \\
\hline $1 \%$ & 1 & 1 & 1 & 1 & 2 & 1 & 1 & 1 & 1 & 1 & 3 & 1 & 1 & 1 & 1 & 1 & 1 & 1 & 1 & 1 \\
\hline $2 \%$ & 1 & 1 & 1 & 1 & 1 & 2 & 1 & 1 & 1 & 1 & 3 & 1 & 1 & 1 & 1 & 1 & 1 & 1 & 1 & 1 \\
\hline $3 \%$ & 1 & 1 & 1 & 1 & 1 & 2 & 1 & 1 & 1 & 1 & 3 & 1 & 1 & 1 & 1 & 1 & 1 & 1 & 1 & 1 \\
\hline $4 \%$ & 1 & 1 & 1 & 1 & 1 & 2 & 1 & 1 & 1 & 1 & 3 & 1 & 1 & 1 & 1 & 1 & 1 & 1 & 1 & 1 \\
\hline $5 \%$ & 1 & 1 & 1 & 1 & 1 & 2 & 1 & 1 & 1 & 1 & 3 & 1 & 1 & 1 & 1 & 1 & 1 & 1 & 1 & 1 \\
\hline \multicolumn{21}{|c|}{ Solution III $\left(w_{A C}=0.00, w_{U C}=1.00\right)$} \\
\hline $1 \%$ & 1 & 1 & 5 & 1 & 1 & 1 & 5 & 1 & 1 & 1 & 5 & 1 & 1 & 1 & 5 & 1 & 1 & 1 & 1 & 1 \\
\hline $2 \%$ & 1 & 1 & 5 & 1 & 1 & 1 & 5 & 1 & 1 & 1 & 5 & 1 & 1 & 1 & 5 & 1 & 1 & 1 & 1 & 1 \\
\hline $3 \%$ & 1 & 1 & 5 & 1 & 1 & 1 & 5 & 1 & 1 & 1 & 5 & 1 & 1 & 1 & 5 & 1 & 1 & 1 & 1 & 1 \\
\hline $4 \%$ & 1 & 1 & 5 & 1 & 1 & 1 & 5 & 1 & 1 & 1 & 5 & 1 & 1 & 1 & 5 & 1 & 1 & 1 & 1 & 1 \\
\hline $5 \%$ & 1 & 1 & 5 & 1 & 1 & 1 & 5 & 1 & 1 & 1 & 5 & 1 & 1 & 1 & 5 & 1 & 1 & 1 & 1 & 1 \\
\hline \multicolumn{21}{|c|}{ Solution IV $\left(w_{A C}=0.50, w_{U C}=0.50\right)$} \\
\hline $1 \%$ & 1 & 1 & 1 & 3 & 1 & 1 & 1 & 1 & 1 & 1 & 1 & 1 & 2 & 1 & 1 & 1 & 1 & 1 & 1 & 1 \\
\hline $2 \%$ & 1 & 1 & 1 & 1 & 3 & 1 & 1 & 1 & 1 & 1 & 1 & 1 & 1 & 2 & 1 & 1 & 1 & 1 & 1 & 1 \\
\hline $3 \%$ & 1 & 1 & 1 & 1 & 3 & 1 & 1 & 1 & 1 & 1 & 1 & 1 & 1 & 2 & 1 & 1 & 1 & 1 & 1 & 1 \\
\hline $4 \%$ & 1 & 1 & 1 & 1 & 3 & 1 & 1 & 1 & 1 & 1 & 1 & 1 & 1 & 2 & 1 & 1 & 1 & 1 & 1 & 1 \\
\hline $5 \%$ & 1 & 1 & 1 & 1 & 3 & 1 & 1 & 1 & 1 & 1 & 1 & 1 & 1 & 2 & 1 & 1 & 1 & 1 & 1 & 1 \\
\hline
\end{tabular}

KEY (M\&R actions):

1 - Do nothing; 2 - Non structural maintenance; 3 - Minor rehabilitation; 4 - Medium rehabilitation; 5

- Major rehabilitation

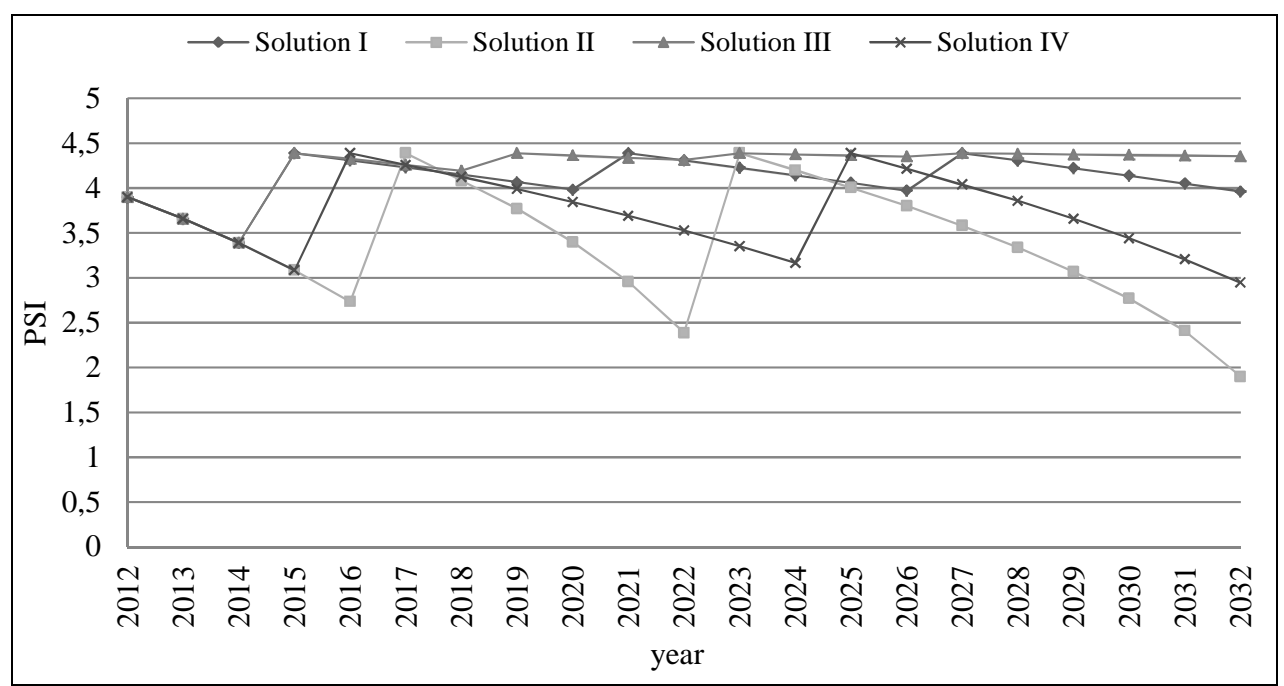

Figure 6-11 - Evolution of PSI for pavement section 05003 of a national road 


\subsection{Conclusions}

The outcomes obtained with the sensitivity analysis to the discount rate value, when applying the MODAT system to a case study, permit us to draw the following conclusions: (1) the M\&R costs, the user costs, and the residual value of pavements always decrease with the increase of the discount rate value; (2) the total costs (the sum of the M\&R costs and the user costs, deducting the residual value of pavements) always decrease with the increase of the discount rate value; (3) the $M \& R$ actions are not independent of the discount rate value. In the near future, in terms of sensitivity analysis, our research will follow with the consideration of other input parameters, such as, for example, the planning period. 


\section{References}

AG (2010). Best practice regulation handbook. Australian Government, Canberra, Australia, 1-89.

Azar, S. (2007). Measuring the US social discount rate. Applied Financial Economics Letters, 3 (1), 63-66.

Christensen, P., Sparks, G., and Kostuk, K. (2005). A method-based survey of life cycle costing literature pertinent to infrastructure design and renewal. Canadian Journal of Civil Engineering, 32 (1), 250-259.

EC (2008). Guide to cost-benefit analysis of investments projects. Structural funds, cohesion fund and instruments for pre-accession. European Commission, Directorate General Regional Policy, Brussels, Belgium, 1-23.

Evans, D. (2004). A social discount rate for France. Applied Economics Letters, 11 (13), 803-808.

Evans, D. (2006). Social discount rates for the European Union. University of Milan, Department of Economics, Business and Statistics, CD Edition, 2006-20.pdf, 1-20.

Evans, D. and Sezer, H. (2002). A time preference measure of the social discount rate for the UK. Applied Economics, 34 (15), 1925-1934.

Evans, D. and Sezer, H. (2004). Social discount rate for six major countries. Applied Economics Letters, 11 (9), 557- 560. 
Evans, D. and Sezer, H. (2005). Social discount rates for member countries of the European Union. Journal of Economic Studies, 32 (1), 47-59.

Ferreira, A. and Santos, J. (2012), Life-cycle cost analysis system for pavement management at project level: sensitivity analysis to the discount rate, International Journal of Pavement Engineering, 1-19, Published online: 03 September 2012, DOI: $10.1080 / 10298436.2012 .719618$.

FHWA (2002). Life-cycle cost analysis primer. Federal Highway Administration, Office of Asset Management, Washington, DC, USA, 1-25.

GCP (2005). Revision of discount rates for public investments. General Commission of the Plan, France, 1-112 (in French).

Hall, K., Correa, C., Carpenter, S. and Elliott, R. (2003). Guidelines for life-cycle cost analysis of pavement rehabilitation strategies. Proceeding of $82^{\text {st }}$ Transportation Research Board Annual Conference. CD Edition, 03-4524.pdf, Washington, DC, 119.

HMT (2003). The green book: appraisal and evaluation in central government. Her Majesty’s Treasury, London, United Kingdom, 1-118.

Harrison, M. (2010). Valuing the future: the social discount rate in cost-benefit analysis. Visiting Researcher Paper, Productivity Commission, Canberra, 1-192.

IA (2008). National PPP guidelines volume 5: discount rate methodology guidance. Infrastructure Australia, Canberra, Australia, 1- 75. 
Jawad, D. and Ozbay, K. (2006). The discount rate in life cycle-cost analysis of transportation projects. Proceedings of the 85th Annual TRB Meeting, Washington, DC, CD Edition, 06-2662.pdf, 1-19.

Jenkins, G. and Kuo, C. (2007). The economic opportunity cost of capital for Canada an empirical update. Department of Economics, Queen's University, Kingston, Canada, working paper 1133.pdf, 1-26.

Kula, E. (1985). An empirical investigation on the social time preference rate for the UK. Environment and Planning, 17 (2), 199-217.

Kula, E. (1987). Social interest rate for public sector project appraisal in the UK, USA and Canada. Project Appraisal, 2 (2), 169-174.

Lally, M. (2008). Measuring the US social discount rate: reply to Azar. Applied Financial Economics Letters, 4 (4), 283-285.

NZT (2008). Public sector discount rates for cost benefit analysis. New Zealand Treasury, The Treasury, Wellington, New Zealand, 1-7.

Odeck, J. (2005). Norwegian road projects are now profitable - the government reduces the discount Rate. Nordic Road and Transport Research, No. 2/3 2005, 34-35.

OMB (1992). Circular A-94: guidelines and discount rates for benefit-cost analysis of federal program. Office of Management and Budget, Washington, DC, USA, 1-22.

Ozbay, K., Jawad, D., Parker, N. and Hussain, S. (2004). Life-cycle cost analysis: state of the practice versus state of the art. Transportation Research Record, 1864, 68-75. 
Pearce, D. and Ulph, D. (1995). A social discount rate for the UK. University of East Anglia, School of Environmental Studies, Norwich, CSERGE working paper 95-01, $1-25$.

Pearce, D. and Ulph, D. (1999). A social discount rate for the UK. Economics and the Environment: Essays on Ecological Economics and Sustainable Development, Edward Elgar, Cheltenham, United Kingdom, 268-285.

Percoco, M. (2008). A social discount rate for Italy. Applied Economics Letters, 15 (1), 73-77.

Picado-Santos, L. and Ferreira, A. (2008). Contributions to the development of the Portuguese road administration's pavement management system. Proceedings of the $3^{\text {rd }}$ European pavement and asset management conference, Coimbra, Portugal, CD Ed., paper 1138.pdf, 1-10.

MF (2003). Dispatch No. 13208/2003. Portuguese Ministry of Finance, Daily of the Republic, 2nd Series, No. 154, 10136 (in Portuguese).

Rambaud, S. and Torrecillas, M. (2006). Social discount rate: a revision. Anales de estudios económicos y empresariales, University of Valladolid, 16, 75-98.

Rangaraju, P., Amirkhanian, S. and Guven, Z. (2008). Life cycle cost analysis for pavement type selection. Clemson University for the South Carolina, Department of Transportation, Columbia, USA, 1-141.

Spackman, M. (2004). Time discounting and of the cost of capital in government. Fiscal Studies, 25 (4), 467-518. 
Spackman, M. (2006). Social discount rates for the European Union: an overview. University of Milan, Department of Economics, Business and Statistics, CD Edition, 2006-33.pdf, 1-36.

TBCS (2007). Canadian cost-benefit analysis guide for regulatory proposals. Treasury Board of Canada Secretariat, Ottawa, Canada, Interim version, 1-51.

Thoft-Christensen, P. (2009). Life-cycle cost-benefit (LCCB) analysis of bridges from a user and social point of view. Structure and Infrastructure Engineering, 5 (1), 49-57.

Young, L. (2002). Determining the discount rate for government projects. New Zealand Treasury, The Treasury, Wellington, New Zealand, working paper 02/21, 1-27.

Walls, J. and Smith, M. (1998). Life-cycle cost analysis in pavement design - in search of better investment decisions. Federal Highway Administration, Washington, USA, $1-107$.

Zhuang, J., Liang, Z., Lin, T. and De Guzman, F. (2007). Theory and practice in the choice of social discount rate for cost-benefit analysis: a survey. Asia Development Bank, Economics and Research Department, 94.pdf, 1-50. 


\section{Chapter 7}

\section{Conclusions}

This PhD thesis presented a Multi-Objective Decision-Aid Tool, called MODAT, which can solve the pavement management problem for the case involving major rehabilitation interventions. The MODAT, which has the objective of minimising costs over a selected planning time-span, allows closing of the gap between project and network management. This is made possible by replacing the traditional microscopic approach, which uses models that include independent variables explaining the pavement deterioration process (i.e. layer thickness, resilient modulus, asphalt characteristics, traffic, climate, etc.), with a macroscopic approach that uses models for predicting the future condition of the pavement based on measured condition data (i.e. cracking, ravelling, potholes, patching, rutting, longitudinal roughness, skid resistance, traffic, climate, etc.). The macroscopic approach requires that each road section is homogeneous in terms of quality, pavement structure, traffic and climate. It is assumed that each road section possesses one performance curve with any estimated future performance value representing the overall average pavement condition. The MODAT 
considers the pavement performance model used in the AASHTO flexible pavement design method but any other preferred model can be used as well. In the implementation of an optimum solution recommended by the MODAT, a field review must be conducted to identify continuous road sections with the same or identical M\&R interventions with the goal of aggregating them into the same road project. It is recommended that whenever actual pavement performance data becomes available, it should replace the predicted PSI values from the AASHTO pavement performance model. Any other appropriate pavement condition indicator can easily be used as an alternative in this methodology. It is further recommended that the MODAT is applied as often as necessary (annually or bi-annually) to obtain revised optimum M\&R plans that would incorporate the impact of any recent changes that might have taken place in the pavement network. The MODAT constitutes a new useful tool to help the road engineers in their task of maintenance and rehabilitation of pavements. This new approach allows PMS to become interactive decision-aid tools, capable of providing road administrations with answers to "what-if" questions in short periods of time.

Chapter 2 presented the results of the application of MODAT to a municipal road network, the road network of the municipality of Oliveira do Hospital. In this application two objectives were considered: minimisation of agency costs (maintenance and rehabilitation costs); and minimisation of user costs. In this MODAT application, the Knee point, that represents the most interesting solution of the Pareto frontier, corresponds to an agency costs weight value of $5 \%$ and an user costs weight value of $95 \%$, demonstrating that user costs, which are generally much greater than agency costs, dominate the decision process. 
Chapter 3 presented the results of the application of MODAT to a national road network, the main road network of Castelo Branco, a district of Portugal. In this application the same two objectives were considered: minimization of maintenance and rehabilitation costs; and minimisation of user costs. In this MODAT application, the Knee point corresponds to an agency costs weight value of $4 \%$ and an user costs weight value of $96 \%$, demonstrating again that user costs dominate the decision process.

Chapter 4 presented the results of the application of MODAT also to a national road network, the main road network of Castelo Branco, but considering other objectives: minimization of maintenance and rehabilitation costs; and maximization of the residual value of pavements. In this MODAT application, the Knee point corresponds to an agency cost weight value of $81 \%$ and a weight value of $19 \%$ for the residual value of pavements, demonstrating that agency costs, because they are generally much greater than residual value of pavements, dominate the decision process.

Chapter 5 presented the results of the application of MODAT also to the main road network of Castelo Branco, but considering three objectives: minimization of maintenance and rehabilitation costs; minimization of user costs; and maximization of the residual value of pavements. In this MODAT application, the Knee point corresponds to an agency costs weight value of $4 \%$, a user costs weight value of $95 \%$ and a weight value of $1 \%$ for the residual value of pavements, demonstrating that user costs, which are generally much greater than agency costs and the residual value of pavements, dominate the decision-making process.

Chapter 6 presented the results of a sensitivity analysis to the discount rate considering the optimization problem presented in chapter 2 . The outcomes obtained with the 


\section{Chapter 7}

sensitivity analysis to the discount rate value, permit us to draw the following conclusions: (1) the M\&R costs, the user costs, and the residual value of pavements always decrease with the increase of the discount rate value; (2) the total costs (the sum of the $M \& R$ costs and the user costs, deducting the residual value of pavements) always decrease with the increase of the discount rate value; (3) the $M \& R$ actions are dependent of the discount rate value.

Because the MODAT is an open system, some modifications could be made to better serve the needs of road engineers. In the near future, our research in the pavement management field will follow in three main directions. First, the MODAT will include other objectives, beyond the three existing ones, such as, for example, the maximization of the road network performance. Second, a sensitivity analysis will be made of some input parameters considered in the application of the MODAT system, such as the planning period. Third, pavement performance models will be developed using pavement performance data available in some road network databases and will be incorporated into MODAT for future applications to road networks. 
